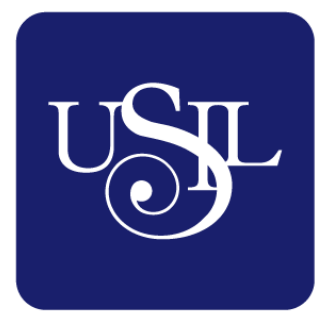

UNIVERSIDAD

SAN IGNACIO

DE LOYOLA

ESCUELA DE POSTGRADO

Maestría en Educación con mención en Docencia en Educación Superior

\title{
ESTRATEGIA METODOLÓGICA PARA DESARROLLAR LA COMPETENCIA DE RESOLUCIÓN DE PROBLEMAS MATEMÁTICOS EN LOS ESTUDIANTES DE SECUNDARIA DE UNA INSTITUCIÓN EDUCATIVA PRIVADA DE LIMA
}

Tesis para optar el grado de Maestro en Educación con mención en Docencia en Educación Superior

\section{JOSEPH HATSON MENDOZA GONZALES}

Asesor:

Míriam Encarnación Velázquez Tejeda

Lima - Perú 
Dedicatoria

Primero a Dios, a mi familia y en especial a mi novia por apoyarme de manera incondicional y brindarme el apoyo necesario para terminar mi trabajo de investigación. 
Agradezco a Dios por la salud y la oportunidad de permitir alanzar este objetivo. Así también agradezco a los docentes de la Unidad de Postgrado de la Universidad San Ignacio de Loyola en particular a mi asesora, Dra. Miriam Encarnación Velázquez Tejeda por su paciencia, por sus enseñanzas y pasión por fomentar el desarrollo profesional de la investigación formando seres humanos de calidad que contribuyan al bienestar intelectual individual y social. 


\section{Aspectos iniciales}

Carátula

Dedicatoria

Agradecimiento

Índice

Resumen

Abstract

\section{Introducción}

Planteamiento del problema de la investigación

Preguntas científicas

Objetivo general

Objetivos específicos o tareas de la investigación 3

Categorías y subcategorías apriorísticas 3

Justificación teórica, metodológica y práctica 4

\section{Metodología de la investigación}

Tipo y diseño de investigación

Población, muestra, muestreo: unidad de análisis $\quad 6$

$\begin{array}{ll}\text { Métodos del nivel teórico } & 6\end{array}$

$\begin{array}{ll}\text { Técnicas e instrumentos aplicados } & 7\end{array}$

\section{Fundamentación teórica}

\section{Capítulo I Marco teórico}

$\begin{array}{ll}\text { Antecedentes de las investigaciones } & 11\end{array}$

Antecedentes históricos de la enseñanza Matemática en el Perú 14

$\begin{array}{ll}\text { Fundamentos teóricos sobre el aprendizaje por competencia } & 18\end{array}$

$\begin{array}{ll}\text { Reflexiones teóricas sobre la resolución de problemas matemáticos } & 25\end{array}$

El enfoque socio formativo y el tratamiento del aprendizaje por competencias 27

Reflexiones teóricas sobre el proceso de enseñanza - aprendizaje 34

Métodos orientados al desarrollo de la resolución de problemas 36

La estrategia metodológica y la resolución de problema matemático 40 


\section{Capítulo II Diagnóstico o trabajo de campo}

Análisis, interpretación y discusión de los resultados

Análisis e interpretación de las categorías emergentes

Relaciones analíticas e interpretativas entre datos y categorías emergentes 59

Conclusiones aproximativas de la investigación

Capítulo III Modelación, validación y aplicación de la propuesta

Propósito de la investigación

$\begin{array}{ll}\text { Diseño gráfico funcional de la propuesta } & 73\end{array}$

$\begin{array}{ll}\text { Desarrollo e implementación de la propuesta } & 74\end{array}$

Valoración de las potencialidades de la estrategia por criterio de expertos $\quad 90$

\section{Aspectos finales}

Conclusiones

Recomendaciones

Referencias

Anexos 


\section{Índice de Tablas y Figuras}

\section{Tablas}

\section{Índice de Tablas}

Tabla 1: Categorías y subcategorías

$\begin{array}{ll}\text { Tabla 2: Dosificación de una unidad didáctica } & 70\end{array}$

Tabla 3: Diseño de talleres de capacitación docente $\quad 87$

Tabla 4: Selección de Especialistas 90

$\begin{array}{ll}\text { Tabla 5: Escala valorativa de la tabla } & 91\end{array}$

Tabla 6: Promedio parcial de la valoración interna de la propuesta 91

Tabla 7: Promedio parcial de la valoración interna de la propuesta 92

Tabla 8: Valoración interna y externa de la propuesta 92

Tabla 9: Consolidado y validación final de la propuesta 93

\section{Figuras}

\section{Índice de figuras}

Figura 1: Resultado de la prueba pedagógica 52

Figura 2: ¿Motiva resolver un problema matemático? 56

Figura 3: ¿El docente reconoce los logros del aula sobre la resolución de problemas? 57

Figura 4: Presentación de las categorías emergentes $\quad 57$

Figura 5: Categorías apriorísticas y emergentes incidentes en el problema 58

Figura 6: Esquema teórico funcional 73

Figura 7: Etapas que conforman la estrategia metodológica diseñada 77 


\section{Resumen}

La investigación se orientó a diseñar una estrategia metodológica para desarrollar la competencia de resolución de problemas matemáticos en los estudiantes de $\mathrm{V}$ de Secundaria de institución educativa privada de Lima. La investigación es de tipo educacional aplicada y se ubica en el paradigma socio - crítico interpretativo con enfoque cualitativo debido a que el docente investigador trata de comprender el problema educativo desde el aula. La muestra estuvo conformada por tres docentes y doce estudiantes, seleccionados por muestreo no probabilístico. Como parte del estudio se emplearon diversas técnicas e instrumentos como: entrevista a los docentes, observación a clases a los docentes, cuestionario a los estudiantes y prueba pedagógica a los estudiantes que hizo posible constatar la objetividad del problema; además el criterio de expertos permitió valorar la efectividad de la propuesta. La investigación se fundamenta en las diferentes teorías, enfoques y modelos relacionados con la enseñanza problémica, el aprendizaje socioformativo y la relación de ambas durante la dirección del proceso pedagógico en la resolución de problemas matemáticos. El resultado obtenido del diagnóstico de campo, al ser contrastado con las categorías apriorísticas permitió identificar las categorías que influyen sobre el problema estudiado. Se cumplió con el objetivo general y las tareas del proceso científico programadas facilitando la modelación de una estrategia metodológica basada en los fundamentos científicos, principios didácticos y otros argumentos pedagógicos que contribuyen al desarrollo de la competencia de resolución de problemas matemático en los estudiantes de Secundaria.

Palabras clave: estrategia metodológica, resolución de problemas, enseñanza problémica, enfoque socioformativo. 


\begin{abstract}
The research aims to design a methodological strategy to develop the competence to solve mathematical problems in students of V Secondary School of private educational institution of Lima. The research is applied educational and is located in the socio-critical interpretive paradigm with a qualitative approach because the research teacher tries to understand the educational problem from the classroom. The sample consisted of three teachers and twelve students, selected by non-probabilistic sampling. As part of the study, various techniques and instruments were used, such as: teacher interview, teacher class observation, student questionnaire and pedagogical test for students that made it possible to verify the objectivity of the problem; In addition, the expert criteria evaluated the evaluation of the proposal. The research is based on the different theories, approaches and models in relation to problem teaching, socio formative learning and the relationship of pregnancies during the direction of the pedagogical process in solving mathematical problems. The result obtained from the field diagnosis, when contrasted with the aprioristic categories identifying the categories that influence the problem studied. The general objective and the programmed scientific process tasks were fulfilled, facilitating the modeling of a methodological strategy based on the scientific foundations, didactic principles and other pedagogical arguments that are developed to develop the competence to solve mathematical problems in Secondary students.
\end{abstract}

Keywords: methodological strategy, problem solving, problem teaching, socio formative approach. 


\section{Introducción}

El siglo XXI tiene sumergido a la humanidad en una nueva era en la que los cambios tecnológicos evolucionan exponencialmente generándose nuevas necesidades en las personas y en la sociedad en general (Guaña, Quinatoa y Pérez, 2017). La explosión tecnológica ha incido en el desarrollo de la ciencia de todas ramas trayendo consigo un volumen de información exponencial que influyen en la cultura de las personas y la sociedad en su conjunto.

Para enfrentar ese reto, de comprender la cantidad de información que se recibe por diversos medios es necesario que la educación contribuya al desarrollo del pensamiento crítico, valorativo y las habilidades en los estudiantes para afrontar cada vez situaciones de mayor exigencia a fin de que puedan analizar, procesar la información, interpretarla, proponer posibles soluciones y tomar decisiones para asumir una práctica, valorativa, reflexiva y sostenible(Organización para la Cooperación y Desarrollo Económico (OCDE, 2013).

Congruente con esa posición, la Organización de las Naciones Unidas para la Educación, la Ciencia y la Cultura (Unesco, 2015), indica que los sistemas educativos y la sociedad en general, debían proyectarse por alcanzar la cultura que encierra el desarrollo sostenible. Enfrentar ese reto requiere que los sistemas educativos, desarrollen el proceso de enseñanza- aprendizaje desde posiciones analíticas y problematizadoras, de manera que los educandos analicen la información, la interpretarla, asuman posiciones críticas y apliquen el conocimiento en la solución de problemas de su contexto de actuación, como refieren Vygotsky (1987), Castellanos, Reinoso y García (2007), Ortiz (2012), Flores (2013) y Fernández y Aguado (2016).

En América Latina, no solo en las universidades se implementan esfuerzos para lograr una enseñanza más cualitativa y científica, sino también en los institutos como centros formadores de técnicos y profesionales están llamados a transformar las práctica docente donde el profesor asuma un rol de facilitador y comunicador con el propósito de estimular en los estudiantes las capacidades, el pensamiento, compromiso ético, social, sostenible y asuma una actitud que ayude a resolver los problemas de la sociedad y de su contexto (Parra-Sandoval, Bozo and Inciarte, 2010 y la Unesco, 2015 ).

En el Perú se llevó a cabo una evaluación integral por el Programme for International Student Assessment (PISA, 2012) en el área curricular de Matemática del Nivel de Secundaria, cuyos resultados evidenciaron un $47 \%$ de desaprobados. Entre las causas principales se reseñan: incomprensión de los enunciados, falta de habilidades en la 
aplicación de fórmulas, identificar y resolver un problema cuyos datos son indirectos o deducibles.

Ese resultado refleja la falta de aplicación en el proceso de enseñanza- aprendizaje de la didáctica polémica, de métodos y procedimientos interactivos, dialógicos, heurísticos, reflexivos que le permita a los educandos problematizar el contenido de la clase a partir de sus saberes previos y experiencias de su contexto de actuación para estimular el desarrollo de las capacidades, destrezas, habilidades y competencias matemáticas para aplicarlas en diversas situaciones y contextos (Gramvemijer, Teruel y Freudental, 2000; Pimienta, 2012 y Tobón, 2013).

En ese sentido, el Ministerio de Educación de Perú ( 2015), indica en el Diseño Curricular para el V grado de Educación Secundaria que los estudiantes deben desarrollar la competencia de resolución de problemas matemáticos; deberán reconocer, formular y resolver los problemas de manera eficiente demostrando al realizar las actividades un rol protagónico al interactuar en la sociedad mediante la toma de decisiones responsable y consciente, por ello la necesidad de utilizar estrategias, métodos y actividades problematizad oras, contextualizadas, con diferentes niveles de complejidad y de interacción social.

Sin embargo, en la práctica pedagógica de esa materia se observan deficiencias en la dirección del proceso de enseñanza-aprendizaje que conlleva a que los estudiantes manifiesten un bajo nivel en los conocimientos y las habilidades en la observación, análisis, asimilación, procesamientos y comprensión del problema matemático; interactúan en grupo, no problematizan ni relacionan los saberes previos con el objeto de estudio y en general evidencian desinterés por el aprendizaje.

\section{Planteamiento del problema de la investigación}

¿Cómo desarrollar la competencia de resolución de problemas matemáticos en los estudiantes del $\mathrm{V}$ grado de Secundaria de una institución educativa privada de Lima?

\section{Preguntas científicas}

¿Cuál es el estado actual del desarrollo de la competencia de resolución de problemas matemáticos en los estudiantes del V grado de Secundaria de una institución educativa privada de Lima?

¿Cuáles son los fundamentos teóricos y metodológicos del desarrollo de la competencia de la resolución de problemas matemáticos en los estudiantes del $\mathrm{V}$ grado de Secundaria de una institución educativa privada de Lima?

¿Qué criterios teóricos y didácticos sustentan (sirven de base) a la modelación de la estrategia metodológica para contribuir al desarrollo de la competencia de resolución de 
problemas matemáticos en los estudiantes del V grado de Secundaria de una institución educativa privada de Lima?

¿Cómo validar la efectividad de la estructura metodológica modelada, para contribuir al aprendizaje en el desarrollo de la competencia de resolución de problemas matemáticos en los estudiantes del V grado de Secundaria de una institución educativa privada de Lima?

\section{Objetivo general}

Diseñar una estrategia metodológica para contribuir al desarrollo de la competencia de resolución de problemas matemáticos en los estudiantes de $\mathrm{V}$ grado de Secundaria de una institución educativa privada de Lima.

\section{Objetivos específicos o tareas de la investigación}

Diagnosticar, el estado real del desarrollo de la competencia de resolución de problemas en el área de Matemática en los estudiantes de $\vee$ grado de Secundaria en una institución educativa de Lima.

Sistematizar los fundamentos teóricos y metodológicos del desarrollo de la competencia de resolución de problemas en el área de Matemática en los estudiantes de $\checkmark$ grado de Secundaria en una institución educativa privada de Lima.

Determinar los criterios teóricos y metodológicos que sirven de base a la modelación de la estrategia metodológica para estimular el desarrollo de la competencia de resolución de problemas en el área de Matemática en los estudiantes de $\mathrm{V}$ grado de Secundaria en una institución educativa privada de Lima.

Evaluar por expertos la viabilidad y efectividad de la estrategia metodológica contemplada, para estimular el desarrollo de la competencia de resolución de problemas en el área de Matemática en los estudiantes de $\mathrm{V}$ grado de Secundaria en una institución educativa privada de Lima.

\section{Categorías y subcategorías apriorísticas}

En relación con las categorías apriorísticas Cisterna (2007), resalta que las categorías apriorísticas son constructos conceptuales que permiten teorizar y debatir desde distintas posiciones un campo teórico. 
Las categorías apriorísticas son aquellas que se sistematizan antes de realizar el proceso de recojo de información, y las emergentes se identifican a partir del procesamiento de los instrumentos.

Tabla 1

Categorías y subcategorías

\begin{tabular}{|c|c|}
\hline Categorías apriorísticas & Subcategorías apriorísticas \\
\hline \multirow{3}{*}{$\begin{array}{l}\text { Competencia de resolución de problema: } \\
\text { Es un proceso complejo que incluye una interacción de conocimientos y } \\
\text { procesos con el objetivo de guiar la enseñanza - aprendizaje, permitiendo } \\
\text { al estudiante crear relaciones entre experiencias, conceptos, } \\
\text { procedimientos e interpretaciones matemáticas frente a las situaciones de } \\
\text { contextos diferentes que estimulen el desarrollo del aprendizaje } \\
\text { interpersonal y social (Minedu, 2015). }\end{array}$} & Base conceptual \\
\hline & Base procedimental \\
\hline & Base actitudinal \\
\hline \multirow{4}{*}{$\begin{array}{l}\text { Estrategia metodológica: } \\
\text { Es el grupo de procedimientos o métodos aplicados al proceso enseñanza } \\
\text { - aprendizaje, que se entrelazan para desarrollar un aprendizaje significativo } \\
\text { en el estudiante, tomando en cuenta el qué, el cómo y el porqué de lo que } \\
\text { hacen (Díaz y Hernández,2010). }\end{array}$} & $\begin{array}{c}\text { Exigencia del proceso } \\
\text { Enseñanza - Aprendizaje. }\end{array}$ \\
\hline & Método problémico \\
\hline & Rol del docente \\
\hline & Rol del estudiante \\
\hline
\end{tabular}

Elaboración propia (2019).

\section{Justificación teórica, metodológica y práctica}

\section{Teórica.}

La investigación, busca innovar el enfoque tradicional o conductista, por uno que permita a la labor pedagógica docente guiar, dirigir y motivar a través de su proceso didáctico a los estudiantes y que además este centrado en el desarrollo del ser humano. Al respecto, el aporte más relevante en el presente trabajo de investigación está en la propuesta de una estrategia metodológica que permita estimular el desarrollo de la competencia de resolución de problemas matemáticos en los estudiantes, orientándola desde un enfoque integral, es decir que el estudiante vaya más allá de solo visualizar operaciones numéricas o cálculos matemáticos, sino también tomando en consideración los aportes del enfoque cognitivista, constructivista y de los paradigmas existentes, con el objetivo de solucionar problemas de la realidad y del contexto ( Minedu, 2015), a través de la resolución de problemas, el estudiante puede construir significados, organizar y generar nuevos aprendizajes basados en su contexto.

\section{Práctica.}

La propuesta metodológica modelada aportada por la investigación además, de presentar una nueva forma de mejorar la práctica pedagógica de los docentes del área de matemática, viene a ser una alternativa que atiende a las necesidades de un desarrollo óptimo de la competencia de resolución de problemas matemáticos, en los estudiantes del 
V grado de Educación Secundaria de una institución educativa de Lima, así como también en su formación integral, orientándolos a desarrollar en la práctica su capacidad crítica, creativa, analítica, de toma de decisiones y de resolución de problemas. Dándole de esta manera un valor agregado a los saberes primarios y desarrollando una mejor calidad de vida.

\section{Metodológica.}

El proceso de la investigación permitió modelar una estrategia metodológica como producto científico, de carácter teórico practico para aportarla a la práctica pedagógica. Ello facilitará al docente tener una guía para orientarse y profundizar en la enseñanza problémica al desarrollar el proceso enseñanza- aprendizaje en la competencia de resolución de problemas matemáticos del $\mathrm{V}$ grado de manera que los estudiantes generen un propio conocimiento autónomo y lo apliquen en la solución de problemas. La propuesta metodológica, incluye actividades de aprendizaje colaborativas e instrumentos de evaluación como una forma de constatar el desarrollo de los conocimientos y habilidades que irán adquiriendo los estudiantes. Así, la presente investigación aporta a la mejora de la práctica pedagógica, por medio de la estrategia metodológica.

\section{Metodología de la investigación}

\section{Tipo y diseño de investigación}

El tipo y diseño de investigación se ubica en el paradigma socio - crítico interpretativo con enfoque cualitativo, pues el objetivo es establecer patrones, modelos o reglas que se deben seguir para realizar la búsqueda el conocimiento e interpretarlo y aplicarlo en la práctica como precisa Martínez (2004). En tal sentido, se considera que la realidad se encuentra en constante cambio y necesita conocer los fundamentos teóricos y analizar las causas que inciden en el comportamiento del determinado hecho pedagógico para identificar, comparar y relacionar los elementos que inciden en él, en un espacio de tiempo determinado para guiar las acciones de manera objetiva (Cisterna, (2005). En ese sentido, el estudio se concreta en una investigación educacional de tipo aplicada. En ella el docente investigador trata de comprender el problema educativo desde el aula y accede al conocimiento científico para aplicarlo en la solución del problema objeto de estudio para mejorar, modificar, cambiar o corregir una situación pedagogía específica como es la resolución de problemas matemáticos a partir del cual se propone una estrategia metodológica que orienta al profesor al dirigir el proceso de enseñanza- aprendizaje para contribuir al desarrollo de esa competencia en los estudiantes del $V$ grado de Secundaria. 


\section{Población, muestra, muestreo: unidad de análisis}

La población objeto de estudio está integrada por 20 estudiantes que reciben la asignatura de Matemática y tres docentes especialistas del área curricular de Matemática, quienes ejercen la docencia en los grupos de estudiantes del $\mathrm{V}$ grado de Secundaria de una institución educativa de Lima.

La muestra seleccionada mediante el muestro no probabilístico por conveniencia, la forman 12 estudiantes que reciben la asignatura Matemática tres docentes especialistas del área curricular de Matemática, quienes ejercen la docencia en los grupos de estudiantes del V grado de Secundaria de una institución educativa de Lima.

\section{Unidades de análisis.}

Las unidades de análisis la conforman los estudiantes, los docentes de la especialidad, las fuentes teóricas especializadas, los documentos normativos del Ministerio de Educación y de la institución educativa privada de Lima.

\section{Métodos del nivel teórico.}

En el proceso investigativo se emplearon los siguientes métodos del nivel teórico

Histórico - lógico.

Según Rodríguez y Pérez (2017), lo histórico está relacionado al análisis de la trayectoria social, política y económica a lo largo del tiempo del objeto de investigación. Lo lógico se encarga de interpretar los hechos históricos y conllevar a una conclusión. La combinación de estas dos perspectivas, trae como resultado dar propuestas lógicas de los hechos, relacionadas coherentemente y no puras especulaciones. Se utilizó para analizar, indagar y establecer las distintas etapas cronológicas acerca de cómo las diferentes estrategias metodológicas relacionadas al proceso enseñanza - aprendizaje, contribuyen el desarrollo de la competencia de resolución de problemas en el área de Matemática.

\section{Análisis - síntesis.}

Según Cerezal y Fiallo (2005), el análisis es aquel procedimiento que permite subdividir un todo en fragmentos los cuales se mantienen relacionados entre sí, preservando sus propiedades y componentes. Y la síntesis permite establecer de manera abstracta relaciones de unidad entre los fragmentos previamente analizados para así poder comprender aún más las características entre dichos elementos. Fue aplicado para realizar un estudio más concienzudo acerca de los fundamentos teóricos y a su vez, permitirá obtener un mejor panorama acerca de los resultados obtenidos de las estrategias metodológicas relacionadas al proceso enseñanza - aprendizaje y su desarrollo de la competencia de resolución de problemas en el área de Matemática. 


\section{Inductivo - deductivo.}

Lanuez, y Fernández, (2003), sostienen que la inducción puede ser definida como un razonamiento, a través del cual se puede generalizar un conocimiento, partiendo del análisis de casos particulares. Y la deducción es el proceso mediante el cual, se particulariza un conocimiento general basado en principios, leyes o axiomas, que establecen relaciones fundamentales entre dichos objetivos y situaciones diversas de la realidad. Se usó para realizar el análisis y las deducciones requeridas al argumentar las formulaciones teóricas orientadas a mejorar la base metodológica de la presente investigación y a construir los fundamentos teóricos de las categorías y subcategorías de la estrategia metodológica asociada a la competencia de resolución de problemas en el área de Matemática.

\section{Análisis documental.}

Para López (2002), el investigador debe tener como actividad inicial, el recopilar los documentos relacionados al problema a investigar, como libros, artículos, revistas científicas, ponencias, documentos normativos entre otros. Al haber tanta diversidad, es necesario que el investigador tenga criterio a la hora de su selección ya sea comparando con otros documentos de la misma línea de investigación, sus fuentes, o citas para su mayor fiabilidad y veracidad. Se aplicó durante el proceso de observación, consultas y revisiones correspondientes a los documentos normativos, artículos científicos y libros que brindan el soporte teórico científico a la investigación y a la elaboración de la propuesta metodológica para el desarrollo de la competencia de resolución de problemas matemáticos.

\section{Modelación.}

Para Reyes y Bringas (2006), toda investigación debe sugerir constructos teóricos los cuales representen la propuesta de solución ante el problema investigado. Estos constructos teóricos son diseños abstractos los cuales sistematizan las formas y cualidades en las que están relacionado los componentes y pre-supuestos teóricos. Para ello el investigador, debe ser un amplio conocedor del marco teórico, para poder dar el soporte teórico a la construcción teórica propuesta. Se aplicó durante el proceso de diseño y modelación de la propuesta metodológica con el objetivo de estimular el desarrollo de la competencia de resolución de problemas matemáticos.

\section{Técnicas e instrumentos aplicados}

Para el presente trabajo, se considerará entre los métodos de nivel empírico, llamados también técnicas a los siguientes: 


\section{Observación a clases a docentes.}

Para Hernández, Fernández y Baptista (2014), dentro de la investigación cualitativa, se trata de percibir algo al detalle considerando el contexto social, cultural, religioso, económico y político aplicado a los actores sobre los cuales se investiga, mediante un análisis continuo de cada aspecto mencionado. Se utilizó, con el objetivo de verificar el grado de conocimientos teórico metodológico, que posee el docente y el cual aplica al realizar el proceso de enseñanza - aprendizaje correspondiente al área de Matemática. Como instrumento se aplicó una guía de observación.

\section{Entrevista semiestructurada a los docentes.}

Para Martínez (1998), en la investigación cualitativa, la entrevista es una de las técnicas de recolección de datos más provechosas y fiables, porque permite obtener información de manera más completa y directa con relación a un tema específico, debido a que el entrevistador partiendo de preguntas planificadas, puede ir personalizando según sea el entrevistado. Se usó con el objetivo de conocer el nivel de conocimientos y habilidades que poseen los docentes sobre el tratamiento a la resolución de problemas matemáticos en el nivel de Secundaria. Como instrumento se aplicó una guía de entrevistas.

\section{Encuesta a los estudiantes.}

Según Mayntz; Holm y Hubner (1975), la encuesta en el enfoque cualitativo es el medio por el cual se recolecta información respecto de una cantidad significativa de individuos que pueden ser todos (censo) o aplicado a la muestra, seleccionados por tener vínculos importantes con el caso de estudio y mediante un análisis cualitativo o cuantitativo se podrá llegar a conclusiones que verifiquen o cuestionen la investigación. Se aplicó, con el objetivo de diagnosticar el grado de satisfacción de los estudiantes por la enseñanza- aprendizaje de la competencia de resolución de problemas en el área de matemática por los docentes. Como instrumento se usó un cuestionario con varios ítems en una guía de entrevistas.

\section{Prueba pedagógica a los estudiantes.}

Cerezal y Fiallo (2002) postulan, que las pruebas pedagógicas se emplean para determinar el estado de los conocimientos, procedimientos y capacidades de los sujetos a ser evaluados en un tiempo específico. Esto permite poder recoger información y a su vez tomar control del proceso enseñanza- aprendizaje por parte del docente y del estudiante. Esta prueba se aplica a una disciplina en particular a los estudiantes. Se empleó para constatar el nivel de conocimientos y habilidades de los estudiantes en la competencia de resolución de problemas en el área de Matemática. El instrumento aplicado es un 
cuestionario de cinco ítems.

\section{Criterio de expertos.}

Según Escobar y Cuervo (2008), el juicio o criterios de expertos, se entiende como la opinión exclusiva, de personas consideradas con amplia carrera en un determinado tema y que a su vez son reconocidos por los demás como expertos calificados para constatar, dar juicio y valoraciones acerca del tema en estudio. Se empleó para validar la efectividad de la estrategia metodológica para contribuir al desarrollo de la competencia de resolución de problemas matemáticos en los estudiantes. Se usó como instrumentos dos rúbricas para validar la efectividad de la propuesta.

\section{Métodos matemáticos.}

Cerezal y Fiallo (2005) afirman que, la estadística va ser utilizada para dar soporte a la confiabilidad sobre la investigación realizada. Esto va permitir determinar numéricamente el nivel de veracidad o incertidumbre de las posibles conclusiones a obtener y visualizar así la distribución de los datos respecto de algún indicador estadístico. Para esto, se debe considerar los estadígrafos más acordes a la investigación a tratar. Se utilizó para determinar porcentualmente los datos obtenidos durante la prueba pedagógica aplicada a los estudiantes.

\section{Novedad científica.}

Consiste en la sistematización de los referentes teóricos de las categorías y subcategorías apriorísticas que sustentan la modelación de la estrategia metodológica como resultado de la investigación, que se erige como una herramienta metodológica para guiar la acción del proceso enseñanza-aprendizaje a fin de contribuir al desarrollo de la competencia de resolución de problemas matemáticos.

\section{Estructura de la tesis}

Capítulo I. En este capítulo se evidencian los referentes teóricos y metodológicos del área de Matemática en educación básica regular, como trabajos de investigación, artículos científicos, tesis de maestría y doctoral a nivel nacional e internacional que sustentan el estudio de las categorías de investigación: Competencia de resolución de problemas y la estrategia metodológica mediante una sistematización de manera holística comenzando por un análisis crítico, reflexivo. 
Capítulo II. El presente capítulo está enfocado a corroborar el nivel de desarrollo de la competencia de resolución de problemas alcanzado por los estudiantes del $\mathrm{V}$ grado de Secundaria. Se utilizaron métodos empíricos utilizados durante el proceso de indagación para el recojo, procesamiento y triangulación de los datos orientados a determinar las categorías sustantivas, las incidentes en el problema y las conclusiones aproximativas. Cada instrumento después de ser diseñado, fue sometido a la evaluación de efectividad mediante el criterio de expertos, pudiendo acotar sugerencias según sea el caso, y que al final resolvieron su conveniencia para su aplicación en el diseño de la modelación de la propuesta metodológica.

Capítulo III. Este capítulo comprende el diseño de la estrategia metodología propuesta la cual se modeló a partir de las categorías emergentes incidentes en el problema investigado. El objetivo de la propuesta, es capacitar al docente en la dirección del proceso de enseñanza- aprendizaje del área de Matemática sobre el tratamiento a la competencia de resolución de problemas a fin de contribuir al desarrollo al de la competencia de resolución de problemas matemáticos en los estudiantes del V grado de Secundaria de una institución educativa privada de Lima. 


\section{Capítulo I \\ Marco teórico}

\section{Antecedentes de las investigaciones}

Hay una diversidad de investigadores que han realizado estudios sobre la resolución de problemas en el proceso enseñanza - aprendizaje.

\section{En el ámbito internacional}

Ozturk y Guven (2015), realizaron una investigación en Karadeniz Technical University de Turquía, con el fin de conocer la implicancia de las creencias en la resolución de problemas de los estudiantes de noveno grado de Secundaria de un High School de Turquía. El enfoque aplicado es cualitativo, la muestra la conforman todos los estudiantes y docentes de Secundaria, en la cual se empleó como métodos: el estudio de caso, entrevistas los participantes, una prueba pedagógica y consulta de experto en resolución de problemas, quienes hicieron posible conocer el estado real del problema investigado. Arribó a la conclusión que es necesario afianzar los conocimientos de los estudiantes para resolver problemas matemáticos.

Por su parte, Wismath y Orr (2015), desarrollaron una investigación en la Universidad de Lethbridge en los estudiantes de las facultades de Arte, Ciencia, Administración y Educación de Canadá; su objetivo es identificar la relación entre el trabajo colaborativo y el estímulo que genera en la resolución de problemas. La metodología se orientó bajo el enfoque de tipo cuantitativo y cualitativo, la muestra estuvo integrada por 133 participantes, a los que le aplicó varios instrumentos como: fichas de datos personales, inventario de estilos de aprendizaje, encuesta de actitudes y entrevistas, que facilitaron una objetiva información. Se concluye que la propuesta metodológica a desarrollar partirá del trabajo colaborativo para contribuir al desarrollo de su habilidad de resolución de problemas matemáticos.

Así mismo, otro estudio fue realizado por Wiggins, Harding y Engelbretch (2017), en la Universidad de Pretoria de Sud África. La metodología aplicada es mixta, basada en realizar un curso de enriquecimiento de las matemáticas, utilizando el enfoque de aprendizaje basado en la investigación en los estudiantes de I Ciclo de la carrera de Matemática de una universidad de Sud África, con el objetivo de estimular el desarrollo de la competencia de resolución de problemas en el área de Matemática. En este caso, la muestra seleccionada fue de 19 estudiantes. Los instrumentos utilizados fueron: encuestas, entrevistas a estudiantes y fichas de observación de clases a los estudiantes. 
De este estudio, se arribó a la conclusión que una propuesta metodológica debe contener también de manera transversal un aprendizaje basado en investigación, pues esto estimula en el estudiante que pueda profundizar mucho más sus conocimientos y habilidades a la hora de resolver problemas matemáticos.

Tambychic y Mohd (2010), en la Universidad Kebangsaan de Malasia junto con el Ministerio de Educación de ese país en los alumnos del III Grado de Secundaria con el fin de identificar el porqué de la falta de desarrollo de las habilidades matemáticas durante el proceso de resolución de problemas. La metodología es mixta y la muestra seleccionada por muestreo intencionado es 107 estudiantes de 14 años de edad, a la cual le aplicó varios instrumentos: pruebas pedagógicas, cuestionarios, entrevistas grupales e individuales que aportaron una información objetiva del estado actual del problema. Concluyó que la estrategia metodológica contribuye a las habilidades en la resolución de problemas.

Álvarez, Grau y Tortosa (2016), realizaron un trabajo de investigación en la Universidad de Alicante- España, cuyo objetivo se orientó a proponer una metodología que considere tres aspectos: el aprendizaje cooperativo, el significativo y la situación problémica matemática. La investigación responde al método cuantitativo, la muestra la formaron dos estudiantes que conforman parte del grupo piloto docente, una sicóloga y 171 estudiantes de primer año de la Facultad de Química y Geología. Los instrumentos aplicados: cuestionarios de tipo Likert de 14 ítems, prácticas calificadas, exámenes parciales y prácticas digitales con el fin de hacer un seguimiento al desarrollo del aprendizaje de los estudiantes de la competencia de resolución de problemas matemáticos. Concluye que la estrategia metodológica propuesta, basada en el aprendizaje cooperativo, el aprendizaje significativo y la situación problémica, permitió el desarrollo de las habilidades de resolución de problemas.

\section{En el ámbito nacional.}

Bustamante (2016), realizó una tesis de Maestría en la Universidad San Ignacio de Loyola USIL, de tipo descriptivo correlacional, en 248 estudiantes del V Grado de secundaria de una Institución Educativa en el asentamiento humano Villa Los Reyes del distrito de Ventanilla, donde se plantea determinar la relación entre la estrategia de aprendizaje y la resolución de problemas matemáticos. Esta investigación fue aplicada a 180 estudiantes entre 78 hombres y 102 mujeres del quinto año de Secundaria, los instrumentos utilizados fueron: el Test ACRA para calcular la utilización de estrategias de aprendizaje y una prueba escrita de opciones múltiples para determinar los conocimientos acerca de la capacidad de resolución de problemas, siendo registrado los datos recogidos en una base de datos Excel 
y con apoyo de un software estadístico SPSS versión 15. De esta tesis, se puede fundamentar el hecho por el cual una adecuada manera de seleccionar las estrategias contribuye a un eficiente desarrollo de la competencia de resolución de problemas del área de Matemática en los estudiantes.

En este mismo hilo, Mejía (2016), realizó una tesis de maestría en la Universidad San Martín de Porres, bajo el enfoque cuantitativo de tipo descriptiva - correlacional, no experimental en estudiantes del I ciclo de estudios generales de la universidad de San Martín de Porres en el año 2014. Aquí se buscó medir el grado de relación entre las estrategias didácticas involucradas en el proceso enseñanza - aprendizaje de las matemáticas. La muestra fue conformada por 274 estudiantes quienes fueron divididos en tres turnos: mañana, tarde y noche, en cantidades de 229, 635 y 88 estudiantes respectivamente. Estos, fueron encuestados en una escala tipo Likert, que validó la fiabilidad por el valor alfa de Cronbach y evaluados mediante dos exámenes pedagógicos. Concluye que, para optimizar el desarrollo de la competencia de resolución de problemas matemáticos, es necesario hacer una selección de la estrategia a utilizar por el docente en la clase, para el aprovechamiento de la información y el procesamiento de contenidos.

Apaza (2018), llevó a cabo una tesis de Maestría, en la Universidad Nacional de educación Enrique Guzmán y Valle, con el objetivo de identificar la influencia dela estrategia aplicada en el desarrollo de las capacidades de resolución de problemas. La metodología responde al enfoque cuantitativo de tipo descriptivo, con un diseño cuasi experimental. La población y muestra la conformaron 41 estudiantes de IV grado de Secundaria de dos secciones de la institución educativa de San Juan de Miraflores, consideró un grupo de control y a otro experimental. Mediante el uso de instrumentos como: encuestas, registros de observación, diario de campo, mapas, cuaderno de notas y siendo validados por el coeficiente Alfa de Cronbach, y procesados por el software estadístico SPSS versión 20. Concluye que la propuesta metodológica basada en el método orientado a la resolución de problemas influye significativamente en la mejora del aprendizaje conceptual, procedimental y latitudinal de los estudiantes.

Cáceres (2018), realizó una tesis de Maestría en la Universidad Nacional de Educación Enrique Guzmán y Valle. El enfoque es cuantitativo debido a la hipótesis planteada y el cuasi - experimental en 72 estudiantes del IV Grado de Secundaria. EI objetivo es identificar la influencia entre los proyectos formativos y el desarrollo de resolución de problemas en el área de Matemática. Con dicho fin, la muestra estuvo conformada por 64 estudiantes, quienes a su vez fueron ordenados en dos grupos equitativamente, el primer grupo fue llamado experimental y el segundo grupo denominado 
control, los instrumentos utilizados fueron: fichas de evaluación de clase por competencia, lista de cotejo, prueba pedagógica de entrada, salida y encuestas. Se concluye que el desarrollo de una estrategia metodológica mediante proyectos formativos en el cual tenga como base a problemas matemáticos contextualizados, contribuye a que el estudiante pueda sentirse estimulado e identificado plenamente con el tema y así poder desarrollar con mayor eficiencia su capacidad de resolución de problemas matemáticos.

Romero, Gamarra y Miranda (2017), realizaron un trabajo de investigación en la Universidad Nacional Intercultural de la Amazonia de Pucallpa, la metodología aplicada fue cuantitativa, con diseño cuasi experimental e inductivo - deductivo con el objetivo principal de determinar el grado de influencia de la etnomatemática en la resolución de problemas del área de Matemática en los estudiantes de una Institución Educativa del distrito de Yarinacocha en Ucayali. Para ello se escogió como muestra a 52 estudiantes. Los instrumentos utilizados en esta investigación fueron cuestionarios pre - test y post - test siendo validado por el coeficiente de Cronbach, así como también su procesamiento mediante el software SPSS v19. Se concluye, que una estrategia metodológica como la etnomatemática, permite desarrollar la competencia de resolución de problemas, y logra que el estudiante: identifique, comprenda y represente de manera adecuada un problema matemático, según su contexto.

Al concluir la revisión de las investigaciones relacionadas con el tema de estudio, se ha enriquecido el campo de conocimientos teóricos y metodológicos del autor acerca de la resolución de problemas matemáticos. Se observan diversos estudios sobre el desarrollo de la competencia de resolución de problemas, las estrategias aplicadas, y su influencia en el aprendizaje y el desarrollo de las habilidades en la resolución de problemas matemáticos por los educandos.

\section{Antecedentes históricos de la enseñanza Matemática en el Perú}

El inicio de la Matemática se comienza a desarrollar profesionalmente en el siglo XVII, por Francisco Ruiz Lozano y posteriormente oficializado en el año 1857 en la Universidad Nacional Mayor de San Marcos, como afirma (Carranza, 2007).

Para entender los cambios, reformas y enfoques que han ocurrido en el contexto peruano, a continuación, se presenta un breve resumen acerca de la enseñanza sobre la resolución de problemas matemáticos, sus enfoques y su problematización comprendidas entre 1970 y el 2015.

\section{Primera etapa de 1970 a 1989.}

En esta etapa el Perú, después del golpe militar del tres de octubre del 1968, se instaura el gobierno del presidente Juan Velasco, quien buscó establecer un hito en la educación 
peruana. Por ello el 21 de marzo de 1972, mediante un Decreto Ley inició la Reforma de la Educación, en la cual se pretendió dar solución a los problemas de la época, como: analfabetismo, falta de atención a los niños marginados, carencia de un programa de recuperación, educación para las minorías, abstracción total de la realidad, falta de patriotismo, tecnicismo, memorismo, intelectualismo, inadecuada formación de docentes, tendencia academizaste.

Para ello, se planteó como objetivo promover mayor igualdad social y económica, centrándose en desarrollar una formación más humanista, investigativa, bilingüe y tecnológica. En el caso de la Aritmética tradicional, se insertó la Matemática moderna en todos los programas educativos. Sus enseñanzas ahora debían ser impartidas de manera más concreta, lúdica, participativa, con el objetivo de erradicar la enseñanza tradicional expositiva, por un aprendizaje más significativo para el estudiante.

Esta reforma fracasó debido a la falta de recursos tanto materiales como de disposición y compromiso por parte de los entes directivos a cargo del sistema educativo, para llevar a cabo un cambio en la educación. Y en 1982 con el regreso al gobierno, de Belaunde Terry se tomó la decisión de regresar al sistema educativo anterior, aplicando para tal fin, una contrarreforma que continuó con la enseñanza tradicional en todas las áreas curriculares y en especial en las Matemáticas (Churchill 1980).

De lo anterior, se concluye que la problemática actual respecto de la educación escolar y la enseñanza- aprendizaje de las Matemáticas, tiene mucho que ver con las decisiones inadecuadas tomadas en los cambios de gobierno, las cuales han tratado de mantener una educación tradicional y conductista.

\section{Segunda etapa de 1990 a 1999.}

En el año 1990, con el golpe de estado de Fujimori, el Ministerio de Educación realiza un diagnóstico del aprendizaje que dio como resultados la identificación de la falta de materiales adecuados para la enseñanza, ineficientes metodologías, poca remuneración al docente y falta de liderazgo.

En 1997, se inicia la aplicación del diseño curricular como parte de la reforma neoliberal, promoviendo el enfoque pedagógico constructivista, el sentido mercantil y de capital humano, la privatización empresarial de la educación, calidad e igualdad educativa, revalorización de los docentes y personal administrativo. Este tipo de educación se centró solamente en el hacer, más que en el tratamiento del ser, practicándose un sistema que veía a la educación como una empresa, la cual se regía por la ley de la oferta y la demanda (Morillo, 2000). 
En esta misma línea, en 1990 se da la declaración mundial de Educación para Todos en Jomtien - Tailandia. Se sostiene que para promover un eficiente desarrollo humano, debemos buscar satisfacer las necesidades básicas del aprendizaje, como: lectura, escritura, expresión oral, escrita, aritmética y resolución de problemas los cuales son los contenidos fundamentales para el desarrollo de conocimientos, habilidades, valores y actitudes que necesitan los seres humanos para vivir, convivir, mejorar la calidad de vida, tomar decisiones consientes y estar dispuestos a seguir aprendiendo. El Informe de Educación de Delors (1996), el cual enfatiza en los principios de la educación.

En el año 1994, se decreta que el problema principal consistía en que el diseño curricular se orientaba de manera cerrada y centrada solo en el contenido, lo que implicaba una nueva reforma en la educación. Pero esto trajo consigo otros problemas. En las orientaciones del Minedu donde se apreciaban una confusión en la calificación de la evaluación cualitativa que se hacía a través del uso de letras.

En general se constató que los docentes no conocían a profundidad la definición de competencias ni los métodos y metodologías activas por la falta de capacitación en cómo orientar el aprendizaje y el trabajo por proyectos. Ello encasillando nuevamente al docente al tratamiento de tareas de comunicación y Lógico Matemático, pero con la exigencia del diseño curricular por competencia (Robles, 2005).

En resumen, si bien se aprecia una adecuada intención para mejorar la calidad educativa en esta etapa, se tomaron decisiones apresuradas para implementar una nueva reforma educativa sin haber antes evaluado los requerimientos necesarios para su puesta en marcha, generando un mayor rechazo por parte de la plana docente.

\section{Tercera etapa de 2000 a 2015.}

En el año 2000, se buscó erradicar la enseñanza memorística, mecánica y tradicional e implantar un nuevo sistema escolar que estimule el aprendizaje por competencias y en donde el estudiante contraste lo aprendido con su realidad, mediante el uso de la reflexión y la creatividad de los conocimientos adquiridos, dando mayor tiempo para el tratamiento a las competencias e impulsar la evaluación cualitativa por competencias.

En el año 2005, se logró promulgar el Diseño Curricular Nacional, el cual representa la esencia de los cambios en la enseñanza de la Matemática. Esto a su vez, fracaso por tener demasiadas exigencias para el docente y en el cual el desarrollo progresivo no estaba bien planteado. Ello desembocó en una profunda brecha entre lo que se demanda y lo que el docente realiza en el aula. En respuesta a esta problemática, en el año 2007, se realiza una reforma para establecer un marco curricular más viable, objetivo y contextualizado a las disciplinas por los docentes y los estudiantes (Minedu, 2014). 
Así se enfatizó en ocho aprendizajes entre los cuales está el de construir y usar la Matemática para la vida cotidiana, el trabajo, la ciencia y la tecnología. Para ello promueve el enfoque basado en la resolución de problemas, el cual se orienta a las formas de cómo el ser estudiante enfréntalos problemas matemáticos, en diversos contextos, esto a su vez genera que haya una interacción dinámica entre lo cognoscitivo, procedimental y actitudinal, la cual debe involucrar plantar y resolver problemas de complejidad progresiva y creciente, que permitan la retroalimentaciones el estudiante, con el fin de construir y desarrollar un aprendizaje significativo.

Para llevar a cabo estas actividades, es necesario que el docente empleé diferentes métodos, procedimientos y estrategias para potenciar el desarrollo de las capacidades, los conocimientos y las habilidades en los estudiantes frente a una situación polémica cotidiana, laboral o científica, permitiéndoles plantear, criticar, reflexionar, argumentar, valorar y tomar decisiones de manera consciente y solucionar los problemas.

En tal sentido, Flores y Gaita (2014), plantea que los docentes tienen arraigadas prácticas conductistas donde prevalece la exposición, los materiales educativos por sí solos no llevan al educando hacia ruta progresiva, sino que deben usarse en el momento idóneo para reforzar el contenido, de lo contrario se muestra una discontinuidad entre los diversos contenidos, enfocados únicamente a la aplicación del saber aprendido, desarrollados bajo una posición tecnicista en referencia a la Matemática.

Se concluye que en esta última etapa, el sistema educativo peruano ha mejorado, se ha ampliado el sistema de contenido del área de Matemática, mejores prácticas docentes y un acceso a la información de forma ilimitada que permite realizar un proyecto de continua retroalimentación tanto de la parte operativa y ejecutora por parte del docente.

Sin embargo, las evaluaciones y seguimiento a la enseñanza- aprendizaje a nivel nacional y en el área de las investigaciones se refleja que existen aún docentes que rehúsan a los nuevos paradigmas de la educación, así como hay un sector que percibe a la educación como un negocio más, en detrimento del proceso formativo que potencia el proceso educacional en cualquier país.

Para enfrentar esas deficiencias resulta esencial la superación permanentemente del magisterio e investigar su propio desempeño profesional para poner en práctica os métodos, tecnologías y estrategias metodológicas que oriente al docente en cómo dirigir la enseñanza- aprendizaje para contribuir al desarrollo del pensamiento crítico y reflexivo de los estudiantes y aprendan a solucionar los problemas académicos y de su contexto de actuación. 


\section{Fundamentos teóricos sobre el aprendizaje por competencia}

El aprendizaje es un proceso psicológica complejo y contradictorio abordado por varios psicólogos de tendencias muy diversas. Para una mejor comprensión se realiza una sistematización teórica de algunas posiciones asumidas por los estudios científicos.

Al respecto, Piaget (1978), afirma que el aprendizaje es un proceso interno donde el sujeto va construyendo los conocimientos a medida que va interactuando con el objeto de manera activa. Es decir, viene a ser los cambios en las estructuras mentales que el sujeto realiza, para poder enfrentar una situación problémica y así adaptarse a su medio.

Una posición teórica que da cuenta no solo de la esfera cognitiva, sino de la afectiva motivacional aporta Ausubel (1983) con su aprendizaje significativo, definido como un proceso mediante el cual el estudiante interioriza el nuevo conocimiento, asociándolo al conocimiento que ya se posee. En otras palabras, el aprendizaje es un proceso donde se crean redes conceptuales entre la nueva información y la ya existente generando un cambio significativo en la persona, haciendo mayor hincapié en la forma de cómo integrar estos conceptos en el estudiante para lograr un aprendizaje consciente.

Una concepción integradora aporta Vygotsky (1987), al definir el aprendizaje como un proceso interpersonal e intrapersonal, mediante el cual el sujeto produce los conocimientos interactuando con el objeto, con otros y su entorno sociocultural, convirtiéndose este último en un factor clave para que el sujeto de forma activa y consciente potencie el desarrollo de las capacidades, los conocimientos, las habilidades y las actitudes de una manera integral.

Desde esas perspectivas, sus seguidores Castellanos (2001), Zilberstein y Silvestre (2002), González (2003) y Rico et al. (2013), han enriquecido la práctica pedagógica adecuando su concepción teórica a la enseñanza- aprendizaje. Consideran el aprendizaje como un proceso individual y social, que produce el conocimiento al trabajar en grupo donde no solo atienden el qué sino el cómo aprenden de forma activa y consciente y dialógica que incide en su formación de manera integral.

Esta concepción teórica sostiene que la zona de desarrollo actual está compuesta por aquellos logros, adquisiciones, conocimientos y habilidades que al sujeto le permiten interrelacionarse con su entorno, resolviendo problemas de manera independiente, mientras que la Zona de Desarrollo Próximo (ZDP), está definida por el trecho entre lo que puede realizar de manera individual el niño y lo que puede realizar con ayuda.

En la práctica en el aula, se muestran casos de estudiantes que poseen una gran cantidad de conocimiento adquirido, pero cuando se enfrentan a nuevas situaciones problémicas no pueden relacionar lo ya aprendido para llegar a una solución al problema planteado. Mientras que por el contrario hay estudiantes con un pequeño número de 
conocimientos adquiridos pero que si son capaces de afrontar una nueva situación problema con un poco de ayuda del docente.

De ese modo se hace necesario en el proceso de enseñanza - aprendizaje se considere el tratamiento a la esfera afectiva y al nivel de logros alcanzado en lo cognitivo, del educando, sino los que aún no puede enfrentar solo, además de los conocimientos, habilidades y destrezas evaluándolo de manera dinámica entre profesor - alumno, con el objetivo de potenciar el desarrollo del estudiante de manera integral y pueda así integrarse e interactuar de manera eficiente con su entorno.

Por su parte, Bronckart (2008), Venet y Correa (2014), el aprendizaje antecede al desarrollo, por ello la necesidad de estimular los espacios de intersubjetividad donde se produzca una interacción en la que el estudiante asimile, procese y se apropie de los nuevos conocimientos convirtiéndolos en parte de su ZDA permitiéndole actuar de manera independiente. El docente como sujeto a cargo de guiar el proceso enseñanza aprendizaje debe planificar, seleccionar y establecer la dirección del desarrollo del estudiante tomando en cuenta sus saberes previos y el contexto en el cual se desarrollará (Sesento, 2017).

Sobre el aprendizaje, Bruner (1987), aporta otra concepción teórica que enriquece este campo, al expresar que, para un aprendizaje óptimo en el estudiante de educación escolar, el docente debe proporcionar un apoyo temporal, denominan andamiaje, con el objetivo de llevar a cabo tarea específica hasta el momento que lo pueda ejecutar por sí solo, garantizando así un aprendizaje en el que se estimule el pensamiento lógico y la curiosidad del estudiante por relacionar información en búsqueda de una solución permitiendo el desarrollo de diversas competencias y capacidades frente a una situación problémica.

Congruente con ello, Crispín y Esquivel (2011), afirman que el aprendizaje ocurre en cada persona de manera particular, como resultado de las interacciones entre sus agentes internos y externos y siendo evidenciados mediante su actitud frente a lo que le exige el contexto. Bajo esta definición el aprendizaje se considera como un proceso complejo y multifactorial, en los cuales se consideran cuatro factores que influencian el aprendizaje académico: Cognitivo, socio afectivo, fisiológico y ambiental como refiere también (Vargas 2013).

Cognitivo: Son aquellos procesos en los que se busca comprobar los conocimientos adquiridos por los estudiantes en relación con conceptos, gráficos, símbolos, demostraciones y resolución de problemas.

Socio afectivo: Son aquellos procesos relacionados al desarrollo de los intereses, motivaciones y actitudes los cuales son puestos a prueba de manera interna en el sujeto 
al momento de realizar una determinada actividad con el fin de adquirir nuevos conocimientos.

Fisiológico: Son aquellos procesos relacionados al funcionamiento del cuerpo humano y su influencia al adquirir nuevos conocimientos. En algunos casos estos factores logran una significancia como resultado de fracasos o desencajes en ambientes educativos entorpeciendo el desarrollo del aprendizaje en el niño.

Ambientales o Sociales: Son aquellos procesos referidos a la interacción del sujeto con su contexto los cuales son regidos por la cultura y factores ambientales (espacio, tiempo) del lugar de actuación y bajo los cuales el estudiante aprende a desenvolver en diversas situaciones.

Desde estas perspectivas, Gamboa (2014), resalta que el modelo educativo que considera el desarrollo cognitivo, procedimental y conductual como eje fundamental para guiar el proceso de enseñanza- aprendizaje prepara al estudiante a enfrentar diversas situaciones ya que los conocimientos son asimilados y comprendidos de manera consciente; sumado a las experiencias, expresiones verbales y aptitudinales establecen un aprendizaje duradero.

En ese sentido la escuela debe orientar el proceso de aprendizaje a través de métodos activos que estimulen el pensamiento y se concretó en acto pedagógico en un ambiente asertivo, donde se potencien e integren los conocimientos, habilidades y actitudes en la formación de los estudiantes para ser útil a la sociedad. Al respecto, Delors (1996), sostiene que los procesos educacionales deben ser eficientes e integradores de forma tal que el educando asimile los conocimientos desde el plano teórico, técnico y actitudinal para incidir en su formación para la vida. En esa línea de acción propuso los cuatro pilares de la educación base del proceso del aprendizaje por competencia:

Aprender a conocer: Es el aprendizaje relacionado al entorno del niño, en donde se busca que el sujeto aprenda a partir de la comprensión su mundo.

Aprender a hacer: Es el aprendizaje relacionado a la manera como el estudiante puede aplicar los conocimientos adquiridos frente a un mercado laboral cambiante e imprevisible.

Aprender a vivir: Es el aprendizaje relacionado a la cultura en la cual se encuentra inmerso el sujeto, y bajo la cual reconoce las reglas de interacción entre los individuos y se las apropia modificándola según la situación a enfrentar.

Aprender a ser: Es el aprendizaje relacionado al desarrollo de la personalidad como un proceso personal interior, resultado de una interacción social. En otras palabras, la persona debe desarrollar un pensamiento crítico, propio y en donde pueda establecer juicios consientes, frente a una situación determinada. 
Otro aspecto a tener en cuenta en la enseñanza, son los aportes de la Neuroeducación, al sostener que el aprendizaje requiere del activismo efectivo -emocional del sujeto para estimular las conexiones y nexo emocionales del cerebro, ya que estas permiten la integración de diversos aspectos como el cognitivo y afectivo produciendo un disfrute y mayor capacidad de retención en el estudiante.

A su vez es una evidencia que el docente guía, controla y toma las acciones necesarias para potenciar el desarrollo personal basado en su cultura mediante la observación, el análisis, la comprensión y la asimilación consciente del conocimiento como resultado de la interacción social y emocional del individuo (Ortiz, 2015; Mora, 2017 y Bueno, 2017).

En tal sentido, el autor de la tesis asume el aprendizaje como un proceso complejo de funciones psíquicas superiores del ser humano, las cuales implican dos procesos psicológicos fundamentales, el interindividual y el intraindividual, los cuales van a ser modificados en el paso de un proceso a otro, obteniendo como resultado una transformación de sus estructuras sociales y psicológicas. Estos cambios, no solo se dan en el sujeto sino también en el objeto el cual es regido por su contexto sociocultural en un momento histórico determinado, esta influencia puede provenir de otros compañeros o individuos o de las herramientas que este utiliza, por ello la importancia de considerar los factores ambientales, cognitivos, afectivos y físicos para un desarrollo óptimo del aprendizaje ( Vygotsky, 1987; González, 2003; Crispín y Esquivel, 2011; Vargas, 2013; Venet y Correa, 2014; Ortiz, 2015; Mora, 2017 y Sesento, 2017).

\section{Reflexiones sobre el aprendizaje por competencia}

Es preciso analizar en qué consiste el término de competencia por ser un vocablo polisémico que tiende a distintas interpretaciones. La RAE (2014), considera a la competencia, como aquella aptitud para realizar algo o poder participar en algún contexto determinado.

Para Argudín (2005), el término competencias proviene del griego agón y agonistes en referencia al acto de ganar en las diversas competencias olímpicas saliendo airoso de las mismas. Mientras que la competencia en el latín competere significa ser responsable de realizar algo. Por su parte el término competencia en latín, está muy ligado a la palabra Ikanótis, que significa ser capaz de poder obtener algo (Mulder, Weigel y Collins, 2008).

Acorde a esta perspectiva, Norris (1991), sostiene que las competencias vienen a ser las habilidades genéricas de un grupo de personas, que dan significancia a los diferentes comportamientos relacionados a la eficiencia al realizar una actividad laboral. 
Estos desempeños comunes, deben ser adecuados para su aplicación en un escenario en particular, como agrega (Hager, 1998).

Congruente con esta posición, Weinert (2001), sostiene que, las competencias están relacionadas a los procesos mentales, necesarios para realizar actividades que comprometen la adquisición de nuevos conocimientos y poder obtener así un mejor desempeño. Aquí se hace una clara distinción entre competencia y desempeño, a diferencia de lo propuesto por (Chomsky, 1970), quien consideraba que, la competencia es la habilidad innata del ser humano para realizar algo.

Desde esa mirada, Gonczi y Athanasou (1996 - 2008), Vasco (2003) y Villa y Poblete (2004), consideran que, la competencia es una estructura compleja que posee características necesarias para que el individuo pueda desenvolverse en situaciones determinadas, integrando diversos aspectos como: actitudinales, valorativos y cognoscitivos.

En esa misma postura, García (2010), define la competencia como un constructo complejo donde interactúan los aspectos actitudinales, sociales, técnicos y procedimentales para alcanzar un eficiente aprendizaje donde el estudiante sea un ser analítico, reflexivo y cuestionador.

Una posición más actual expresa Zavalza (2011), al considerar la competencia como aquella habilidad que posee un individuo para poder enfrentar las demandas complejas que exige un contexto en particular. El desarrollo de estas competencias implica el desplazamiento de conocimientos, habilidades cognitivas y procedimentales, actitudinales, emocionales, motivacionales y valorativas. Estas competencias deben desarrollarse en torno a 3 ejes fundamentales: la demanda laboral, empresarial y profesional, las necesidades de la sociedad actual y el desarrollo de la persona como un proyecto ético de vida como agrega (Tobón, 2013).

Acorde con esta definición, el Minedu (2016), define a la competencia, como la aptitud que posee un individuo para poder entrelazar diversas capacidades con el objeto de alcanzar una meta determinada, considerando la magnitud de la situación y evaluando las posibles soluciones dentro de un plano moral y ético. También sostienen que el desarrollo de estas competencias debe ser de manera constructiva y permanente que permita un aprendizaje progresivo, acorde a sus experiencias de vida.

Se concluye que la competencia es el resultado de la interacción de un conjunto organizado de conocimientos, capacidades, destrezas, actitudes, habilidades y valores axiológicos que las personas debe demostrar en sus modos de actuación al desempeñarse en diferentes contextos específicos, combinando los componentes de la personalidad: 
cognoscitivas, afectivas, emocionales y procedimentales (Pimienta y García, 2010; Zavalza, 2011; Álvarez, 2013; Tobón, 2013 y el Minedu, 2016).

Una forma de concebir la competencia de manera integral es propuesta por Tobón (2013), que argumenta que el proceso de enseñanza- aprendizaje implica toda acción del estudiante al realizar las diferentes actividades problémicas de su contexto considerando el compromiso ético.

El aprendizaje por competencia, según Argudín (2005), es un proceso de indagación, sintonización y valoración que el estudiante debe dar a la información que recibe del contexto para formar personas que tomen decisiones consientes y responsables. Por tanto, en las escuelas es necesario que se enseñe al estudiante a aprender a aprender para hacer frente a una sociedad de constantes cambios y mantener su integridad psicológica, emocional y social.

En ese sentido, se busca que el estudiante identifique los procedimientos que son llevados a cabo para alcanzar ciertos objetivos y así permitirle desarrollar mayor autocontrol al momento de realizar las actividades que conllevan a la meta. Estos objetivos a alcanzar en el aprendizaje por competencia están ligados estrechamente a las demandas laborales de la sociedad actual y en la que se busca que el estudiante pueda alcanzar un lugar, pero con la certeza de tener personas con una formación integral tanto en valores morales, actitudinales, cognitivos y procedimentales.

Por su parte, Araya (2011), sostiene que el aprendizaje basado en competencias mediante el proceso de enseñanza aprendizaje plantea desarrollar en la persona las competencias y capacidades necesarias para su formación profesional de manera eficiente y que a su vez no se limiten al tiempo y espacio. El objetivo es formar personas de manera integral con pensamiento crítico de la realidad, capaces de indagar, sintetizar información y proponer soluciones para que puedan disfrutar de la vida a nivel personal, familiar, laboral y social.

En el Real Decreto 1105 (2014), documento normativo de la educación de España, se sostiene que el aprendizaje por competencias contribuye al desarrollo de los procesos de aprendizaje de manera dinámica e integral generando que el estudiante se sienta motivado a aprender. Para alcanzar este objetivo el docente tiene que estar capacitado para diseñar situaciones problémicas en donde el estudiante aplique los conocimientos adquiridos y desarrolle actividades integradoras que favorezcan la resolución de problemas.

Los estudios afirman que, en la concepción del aprendizaje por competencias la teoría y la práctica están ligadas como un principio del proceso de enseñanza - aprendizaje y por tanto, contribuye al desarrollo progresivo del estudiante en los diferentes aspectos 
de la personalidad. De ahí que el docente debe prepararse para planificar e implementar las actividades en el diseño curricular de la asignatura el aprendizaje por competencias basado en el pensamiento complejo e integrador para lo cual necesita aplicar los diferentes enfoques teóricos y didácticos existentes como argumenta (Tobón 2005 - 2013).

En ese aspecto, Aguaded (2014) sostiene que la formación por competencia es la forma cómo la escuela intenta integrar de manera sistemática las herramientas de información y comunicación actuales para su aplicación en la educación bajo un entorno que responda a las exigencias y desafíos de la era de la información incrementando el rendimiento de la tarea educacional.

Por su parte Carrión (2015), sugiere que la educación por competencias debe aplicarse en el desarrollo del proceso pedagógico ya que favorece el desarrollo del área cognitiva tomando de manera transversal el área ético-social del estudiante. Así como también puede potenciarse aún más esta práctica, si el docente presenta un mayor dominio metodológico de estrategias y técnicas de la asignatura a tratar, permitiendo formar sujetos reflexivos, empáticos, críticos y observadores a partir del saber hacer.

Una conceptualización más integradora ofrece el Tuning Europa (2003 - 2007), Pimienta y García (2010), García, López y Valdés (2011), Tobón (2013) y Álvarez (2013), Álvarez (2018), quienes reestructuraron el aprendizaje propuestos por Delors, al considerar que las competencias involucran la combinación de distintas habilidades en relación con los cuatro pilares, organizándolo en tres dimensiones e interrelacionándolas dentro de un proyecto ético de vida, con el objetivo de desarrollar una formación integral en el ser humano. Estas dimensiones asociadas a las competencias son:

Dimensión cognoscitiva: Son las competencias relacionadas al procesamiento de conocimientos factuales, teorías, conceptos y habilidades cognitivas de una manera significativa, en la que el estudiante utiliza herramientas para indagar, sistematizar, analizar, discriminar, reconstruir y aplicar la información de manera consciente.

Dimensión socio afectiva - motivacional: Son las competencias relacionadas a las actitudes y valores que el individuo posee a la hora de interrelacionarse con su medio. El desarrollo de estas competencias, contribuyen a la construcción de la personalidad y al control de las actitudes y emociones frente a la resolución de un problema.

Dimensión actuaciones o procedimental: Son las competencias relacionadas a las habilidades procedimentales y técnicas que la persona desempeña a la hora de resolver un problema, de manera consciente y planificada.

La sistematización teórico práctica realizada sobre el aprendizaje por competencias, el autor de la investigación concluye que este tipo de aprendizaje es una nueva forma de desarrollar el proceso de enseñanza aprendizaje que contribuye a la 
formación integral del estudiante para la vida, en el cual el docente direcciona el aprendizaje con el objetivo de que el alumno haga uso de la información, el conocimiento, el razonamiento lógico, emocional, moral y reflexivo en la práctica para el beneficio del ser y su comunidad (García, Loredo, Luna y Rueda, 2008; Araya, 2011;Álvarez, 2013; Tobón, 2013; Aguaded, 2014; Carrión, 2015 y Álvarez, 2018).

\section{Reflexiones teóricas sobre la resolución de problemas matemáticos}

Distintos especialistas y pedagogos, consideran que para poder resolver problemas se requiere de una operación compleja y sistemática en el que la estructura psicológica está presente de manera transversal tanto en la identificación de los datos y en el establecimiento de relaciones entre datos e incógnitas que posteriormente serán eliminadas según el objetivo trazado (Vygotsky,1987).

La Real Academia de la lengua Española RAE (2015), define a la resolución de problemas como aquel proceso mediante el cual se busca aclarar algo. Situación que dificulta el logro de un fin específico y en el que se debe obtener una solución mediante métodos científicos.

Para Polya (1981), la resolución de problemas se basa en procesos cognitivos cuyo objetivo es encontrar una nueva salida ante una dificultad, es decir encontrar un camino alrededor de una dificultad y salir airoso pues para obtener la solución se tiene que aplicar muchos de sus conocimientos y recursos. Por tanto, la resolución de problemas matemáticos, viene a ser una habilidad que permite al estudiante plantear, explorar y encontrar soluciones con un poco de exigencia ante situaciones que proyecta la vida y la ciencia seleccionando para ello la acción más apropiada según la concepción del sujeto (De Guzmán, 1993).

Posteriormente, Polya (1984) plantea como resultado de sus aportes teóricos un marco conceptual sobre el proceso de resolución de problemas, y lo clasifica en cuatro fases.

Primera fase. Comprensión del problema: En esta fase el docente guía al estudiante para que se plantee una serie de preguntas con el objetivo de que pueda analizar los datos del problema.

Segunda fase. Concepción de un plan: Esta fase busca que el estudiante pueda expresar la relación existente entre los datos y las incógnitas ya sea de una ecuación o una fórmula.

Tercera fase. Ejecución de un plan: En esta el estudiante identifica las constantes y variables, evalúa y selecciona la fórmula a utilizar y resuelve la operación planificada. 
Cuarta fase. Verificación de la solución: En esta fase, el estudiante comprueba si el resultado obtenido en base a su razonamiento es correcto y acorde con el problema planteado.

En ese sentido, Schoenfeld (1992) añade que el proceso de resolución de problemas es complejo, por involucrar además de lo cognitivo el aspecto afectivo, emocional, psicológico, sociocultural, a diferencia de Polya, que resalta la importancia de las estrategias a utilizar para resolver un ejercicio de ese tipo. Para Schoenfeld al resolver un problema, se necesita planificar, establecer metas y retroalimentar constantemente el proceder. En este sentido los conceptos matemáticos que el estudiante posee al enfrentarse a resolver un problema, así como integrar el aspecto social, cultural e individual va influenciar de manera transversal a lo largo de los diferentes subprocesos del aprendizaje. Para ello se enmarcan cuatro subcategorías que son:

Recursos: En referencia a los conocimientos que el estudiante posee a la hora de resolver un ejercicio matemático.

Heurística: En referencia a las técnicas y estrategias que utilizan los estudiantes al resolver un problema matemático.

Control: En referencia a la forma como se utiliza la información obtenida o desarrollada ante un problema matemático.

Creencias: En referencia al contexto sobre el cual, el estudiante va a utilizar recursos, aplicar la heurística y definir un determinado comportamiento frente a un problema matemático.

Para Villalobos (2008), un problema matemático viene a ser una situación donde están integrados dos objetos esenciales; las características de estos objetos y las relaciones entre los mismos y bajo las cuales el individuo si es motivado por las condiciones y exigencias que plantea la situación procederá a ejecutar las acciones con disposición al responder a las interrogantes propuestas basándose en sus conocimientos y experiencias previas.

El Ministerio de Educación de Singapur (2013), considera la resolución de los problemas como un área esencial para la enseñanza- aprendizaje del área de Matemática. Para esto es necesario incluir en las clases actividades que promuevan la atención y el constructivismo social al trabajar en grupo, ya que mediante a la socialización e intercambio de experiencias frente a una situación problémica generada a partir de su propio contexto se puede enriquecer el análisis, la reflexión y las propuestas de solución en colaboración con sus compañeros (Chirinda y Barmby, 2017).

Otro aspecto aporta García y Pérez (2014), al sostener que la resolución de problemas no solo abarca el hecho de conseguir una respuesta ante la situación polémica 
planteada, sino que se debe valorar también su importancia, el conjunto de procedimientos, acciones y operaciones que condujeron a la solución y la propuesta para transformar la realidad (Tobón, 2009).

Según el Minedu (2015), un problema es una situación significativa de contenido matemático que conlleva al individuo a reflexionar, buscar estrategias y tomar decisiones con el objetivo de obtener una solución. Para esto, es necesario hacer una diferencia entre problema y ejercicio, pues a diferencia del primero, en este último ya se posee el procedimiento a ejecutar y se utiliza para que el estudiante practique y afiance el uso del mismo. En otras palabras, con el ejercicio se busca el dominio de una técnica en particular, pero con el problema se busca desarrollar la capacidad y habilidad para que el estudiante por sí mismo pueda enfrentar una situación desconocida y así diseñar una forma de solución, como agrega Villarroel (2008).

Para Norabuena (2015), la resolución de problemas matemáticos se da de manera transversal a cualquier asignatura ya que es aplicable y permite contrastar su funcionalidad con la vida real. Aquí se va desde lo conocido a lo desconocido de forma gradual y sistemática, aplicando los procedimientos y métodos para la obtención de una solución. Esto se convierte en una oportunidad de desarrollo de las habilidades y destrezas si se direcciona apropiadamente tanto en contenidos, tipos de problemas y métodos de solución.

A partir del análisis realizado se llega a la conclusión que la resolución de problemas matemáticos es el proceso que requiere estimular en el estudiante la motivación para pensar, reflexionar, buscar soluciones y tomar decisiones con el fin de poder encontrar un camino que responda a resolver una dificultad cognitiva, procedimental y actitudinal. Para ello debe activar los saberes y experiencias previos y aplicar lo aprendido en la solución de problema de la práctica cotidiana (Polya, 1984; Schoenfeld, 1992; Villaroel, 2008; Villalobos, 2008; Ministerio de Educación de Singapur, 2013; Minedu, 2015; Norabuena, 2015 y Chirinda y Barmby, 2017).

\section{El enfoque socio formativo y el tratamiento del aprendizaje por competencias}

En esta última década se puede ser consciente de los cambios que se dan a un ritmo acelerado. Pasando de una era industrializada a una era del conocimiento en donde el objetivo en la educación es que el individuo este apto para interactuar con gran cantidad de información de una manera eficiente considerando las reglas de su contexto y buscando preservar su ecosistema para las futuras generaciones. De ahí la importancia de aportar una nueva propuesta basada en un enfoque problémico e integrador desde una sistematización teórica, metodológica y práctica de este. 
Para Kilpatrick (1918), el proyecto formativo es el proceso dinámico con el cual se busca que la enseñanza sea significativa para el estudiante realizando diversas actividades aplicadas al contexto real y generando motivación para un eficiente desarrollo pedagógico. Es por esta razón que debe considerarse a la educación como un sistema complejo y formativo, pues relaciona diversas áreas al interrelacionarse con su medio, permitiéndole aprender, evolucionar, responder y auto realizarse de mañerea dinámica y variada, como afirman (Michel, 1996 y Morín, 2011).

En este mismo argumento, Hernández (1998) sostiene que los proyectos formativos son un conjunto de estrategias utilizados en el proceso enseñanza aprendizaje, que guíen al estudiante a resolver situaciones problémicas contribuyendo al desarrollo de diversas competencias, capacidades, habilidades, y actitudes de manera integral, consiente y autónoma.

Así mismo, Morín (2000a), considera que el ser humano al ser un ente biológico, físico, social, cultural e histórico debe tener una educación formativa integral que busque desarrollar sus diversas áreas, considerándolo como una unidad compleja en la que el estudiante sea consciente del desarrollo de su identidad de manera intrapersonal e interpersonal para con su entorno social.

Por otro lado, Gómez y Alzate (2010) considera que la enseñanza por competencias es la consecuencia de factores educativos y sociales que demandan mayor estudio de algunos conocimientos, mayor desarrollo de habilidades personales, sociales y mayor integración de los saberes para promover una educación integral que busca el equilibrio entre lo formativo y el mundo profesional.

Acorde con esta definición, Mendoza (2013) afirma que la educación por competencia es aquella que busca desarrollar las capacidades, habilidades, conocimientos y valores de una forma holística combinando el área personal, social y laboral.

Por su parte Valdés (2017), asevera que la socioformación no solo se limita a estructurar lo teórico y lo práctico, sino que también analiza e identifica los componentes necesarios para su aplicación y fomenta una evaluación integral tanto en tiempo, perspectiva y aplicabilidad a su contexto.

Complementando este argumento, Guzmán y García (2017), añade que el enfoque socioformativo tiene sus bases en el constructivismo, la escuela histórico cultural de Vygotsky y la epistemología de lo complejo orientando la enseñanza- aprendizaje de lo individual a lo social, de lo conocido a lo desconocido mediante actividades socializadoras y cooperativas que contribuyen a la identificación, asimilación y resolución de los problemas culturales, económicos, sociales y ambientales. En ese sentido, el aprendizaje se orienta a través de la zona de desarrollo real planteada por Vygotsky y de manera 
gradual va transitado a la zona próxima por lo que se potencia las capacidades y el educando alcanza los objetivos propuestos de manera individual y colectiva en espacios de colaboración y diálogo con la mediación del docente (Castellanos et al. 2007, Tobón, 2009; Rico et al. 2013 y Hernández, 2014).

Una postura más actual sostiene Vázquez (2018), al afirmar que la socioformación en un mundo donde el acceso a la información está al alcance de todos, es más que necesaria ya que no solo se da en el salón de clases y el docente como orientador o guía del proceso, sino que también involucra aspectos sociales mediante las comunidades de aprendizaje y en donde se busca una enseñanza crítica, integradora, reflexiva, equitativa, respetuosa del medio ambiente, con ética y valores.

De ese modo, el enfoque socioformativo contribuye al desarrollo de las competencias de aprendizaje integral en los educandos porque centra el quehacer pedagógico en la estimulación de las capacidades y destrezas del pensamiento complejo, que debe tomarse cuenta en cualquier contexto educativo. La escuela debe estar consciente que para poder formar estudiantes competentes, integras y de compromiso ético debe enfocar el tratamiento didáctico del contenido al estudio de las partes del objeto y luego integrarlo en un todo (Tobón, 2013).

Este enfoque se centra en el aspecto formativo de los estudiantes considerando lo cultural, lo social y el contexto que lo rodea, para ello busca promover un cambio en la educación, tomando como punto de partida el cambio de pensamiento de las personas que son responsables de la misma, mediante la investigación - acción. El enfoque socioformativo, posee las siguientes características:

Aquí las competencias son una dimensión más de la persona humana, la cual puede ser entendida si se percibe al sujeto como la integración de diversos factores: psicológico, social y espiritual.

La competencia no es el objetivo a alcanzar en la educación.

La formación es resultado de la interacción de la persona y su entorno económico, cultural, social y ambiental de forma sistémica y dinámica en la cual el sujeto actúa de manera creativa modificando su contexto y produciendo a su vez que este genere nuevas situaciones.

El enfoque socio formativo basado en competencias, busca desarrollar una formación ética de manera transversal a todo espacio formativo, pues considera que la ética es el eje principal de toda competencia.

Este enfoque busca estructurar de manera sistémica las competencias dentro del currículo, con el fin de hacerlo más comprensible y posible de llevar a cabo. 
El mismo autor (2017-2018) agrega que la socioformación posee elementos definidos que permiten obtener cambios significativos en la educación, comenzando por enfrentar al estudiante ante problemas basados en su contexto social y terminando el proceso pedagógico con la construcción de un proyecto de vida que sea emprendedor, creativo e innovador en cualquier área.

El autor de la investigación concluye que el enfoque socioformativo es un marco de reflexión - acción en el plano educativo que se alimenta de la pedagogía crítica y la escuela Sociocultural de Vygotsky (1987), cuyo objetivo es propiciar mediante la aplicación de métodos y estrategias activas, problémicas y dinámicas; el protagonismo del estudiantes en la formación y desarrollo de la competencia de resolución de problemas en sus diversos campos como son: social, político, económico, personal, religioso, artístico y deportivo bajo el cual se encuentra inmerso como argumentan (Michel, 1996; Morín ,2011; Tobón, 2013; Hernández,2014; Addine et al; 2015; Valdés, 2017; Guzmán y García, 2017 y Vázquez, 2018).

\section{Fundamentos de la competencia de resolución de problemas.}

Dentro de la educación tradicional se consideraba a la resolución de problemas como una actividad aislada dentro del proceso didáctico en el aula, encasillando en la práctica a ejercicios de rutina, dejando de lado el pensamiento crítico, indagatorio, sintético y analítico como refiere Gumercinda (2013), y como se puede ver reflejado en el bajo índice de estudiantes con capacidad para resolver problemas de contexto (PISA 2002). Para un mejor entendimiento acerca de la resolución de problemas en el área de Matemática se realiza una sistematización teórica y práctica del mismo.

En este mismo hilo, Dijkstra (1991), sostiene que la resolución de problemas es un proceso didáctico donde el aprendizaje involucra estructuras cognitivas, estrategias y técnicas de resolución que están almacenadas en la memoria de corto y largo plazo. Por tanto, resolver un problema implica procesos complejos en la cual el docente no puede basarse a desarrollar ejercicios de repetición, sino también plantear problemas donde el estudiante se sienta retado a razonar, interpretar y apropiar dichos conocimientos.

En congruencia con lo expresado Ausubel, Novak y Hanesian (1997), plantearon que la resolución de problemas a diferencia del aprendizaje de ensayo y error es una nueva forma de aprender basado en el descubrimiento y se orienta a la adquisición de un conocimiento consciente por el sujeto a partir de sus saberes previos, experiencias y vivencia significativa y su relación contexto - objetivo.

El proceso de enseñanza aprendizaje de la Matemática, desde un punto de vista social, cultural, histórico y científico afronta nuevos retos y desafíos en donde se busca que 
el estudiante sea el constructor de su propio conocimiento, por tanto, esto involucra una redefinición en el proceso de formación, a fin de promover el desarrollo de competencias matemáticas, como sostiene (Coronado y García 2011).

Para Tobón (2013), Sáez (2014) y De Corte (2015), la enseñanza en el área de la Matemática debe comprender el área cognoscitiva, afectiva y emocional como un todo y direccionarla con el objetivo de motivar y concientizar a los estudiantes en la importancia del tema a tratar y de las formas de aplicación a su realidad.

En tal sentido, Tobón (2013), asevera que el tratamiento a la resolución de problemas cómo competencia es preciso realizar cinco pasos metodológicos, a saber:

Comprender el problema en su contexto personal, social, ambiental, económico y disciplinar.

Proponer diversas estrategias de solución tomando en cuenta lo incierto y lo imprevisto.

Analizar y evaluar el impacto del problema y las consecuencias de la solución en el sistema

Aprender del problema para enfrentar y dar solución a problemas similares.

En esta misma línea, Felmer (2014), resalta la importancia de desarrollar diversas habilidades mediante la resolución problemas, así como también los aprendizajes que pueden llegar a desarrollarse a partir de estas, en los estudiantes. Algunas de estas competencias o aprendizajes son: autonomía, creatividad, comunicación y argumentación de ideas, capacidad para trabajar en equipo y la capacidad de sobreponerse al fracaso.

Complementa esta posición Artigue y Blomhog (2013), al considerar la resolución de problemas matemáticos desde el enfoque socioformativo como aquel proceso que no se limita a los procedimientos y busca crear un ambiente donde docentes y estudiantes puedan interactuar de manera vivencial entre lo abstracto y lo real permitiendo un aprendizaje significativo y consciente que compromete al estudiante a resolver los problemas de manera voluntaria. De esta forma se contribuirá al desarrollo de la habilidad de resolución de problemas en el estudiante, aplicable en cualquier ámbito de su vida personal o social; y posibilitará la valoración de la resolución de problemas como una herramienta que enriquece su formación integral de vida (Pinzón y Téllez, 2016, Valdés y Tobón 2018).

Al respecto, el Minedu (2016), en el Programa Curricular Nacional conceptualiza la resolución de problemas basado en competencias, como un proceso complejo que incluye una interacción de conocimientos previos y técnicas de resolución permitiendo al estudiante crear relaciones entre experiencias, conceptos, procedimientos e 
interpretaciones matemáticas cada vez más elaboradas, desarrolladas en un contexto real, que estimulen el desarrollo del aprendizaje interpersonal y social. Por ello, es una condición necesaria, que los problemas objeto de estudio deban responder a intereses y necesidades tanto de los estudiantes como de su contexto para provocar la problematización en la solución de estos.

Desde este punto de vista Delgado, Mayta y Alfaro (2018) expresan que la resolución de problemas no solo se basa en aplicar un procedimiento de forma mecánica o memorística, si no que involucra al conjunto de operaciones cognitivas, capacidades, habilidades y dominio de la asignatura que posea la persona.

Un aporte más actual del proceso de resolución de problemas visto de forma integral afirma que aquello, es útil dentro y fuera de la escuela para el estudiante; y en caso del docente facilita el uso de diversos procedimientos genéricos, cognitivos, heurísticos y metacognitivos que promueven un desarrollo matemático y complejo (Tobón 2018).

En el sistema educativo peruano se promueve el enfoque de resolución de problemas en el área de Matemática, de manera que permita al estudiante enfrentarse a diferentes contextos con el objetivo de crear, indagar, investigar y resolver problemas que requieren de la experimentación, análisis de estrategias, sistematización, representación y comunicación de los nuevos conocimientos adquiridos aplicados al contexto (Minedu, 2015).

En esa línea de argumentos, el Minedu(2015), en su concepción teórica sobre las habilidades de resolución de problemas en el área de Matemática, las clasifica en cuatro invariante, a saber.

Resolución de problemas de cantidad: Esta competencia está relacionada a que el estudiante plantee, construya y comprenda los sistemas numéricos y las estrategias asociadas a esta.

Resolución de problemas regularidad y equivalencia al cambio: Esta competencia está en relación con que el estudiante pueda diferenciar y establecer equivalencias entre magnitudes, así como también plantear ecuaciones, inecuaciones y estrategias para resolverlas.

Resolución de problemas de gestión de datos e incertidumbre: Esta competencia está asociada a que el estudiante analice los datos de un tema específico y pueda establecer afirmaciones comprobadas por una sistematización, gestión y representación de datos de forma probabilística.

Resolución de problemas de forma, movimiento y localización: Esta competencia está en relación con que el estudiante identifique el desplazamiento de objetos, interprete, construya representaciones y utilice diversos instrumentos para la medición de las mismas. 
Esta estructuración de la competencia de resolución de problemas, responde a la necesidad de poder desarrollar en el estudiante un pensamiento crítico, una comprensión integral de la Matemática y una actitud transformadora y asertiva, frente a las diversas situaciones según contexto.

Por todo ello, el autor concluye que la educación desde un enfoque por competencias es el más adecuado para contribuir en el desarrollo de la personalidad del educando ya que considera las áreas del saber de manera interactiva, interrelacionada, consiente y las orienta a un desarrollo equilibrado que responda a las necesidades y problemática actuales.

La sistematización realizada en relación a la categoría apriorística resolución de problemas, desarrollada desde diferentes puntos de vista teóricos, prácticos y metodológicos y dado los objetivos que sostienen la presente investigación el autor considera por conveniencia como autor base al (Minedu, 2015) pues se adecua al problema de estudio en la investigación, donde se busca promover el desarrollo integral del estudiante en el área de matemática mediante una adecuada selección y aplicación de estrategias didácticas orientadas a la resolución de problemas y en donde el estudiante sea el generador de su propio conocimiento ( Coronado y García 2011; Artigue, y Blomhog 2013; Gumercinda2013; Tobón 2013; Felmer, 2014; Sáez 2014; De Corte, 2015; Minedu, 2016;Pinzón y Téllez, 2016; Delgado, Mayta y Alfaro, 2018; Valdés y Tobón 2018).

Desde esa perspectiva teórica se reconocen las subcategorías apriorísticas propuestas por (Tobón, 2013-2018) y los indicadores que se exponen en la matriz de categorización (Anexo N. 1).

\section{Subcategorías.}

Base conceptual. Son los conocimientos teóricos, principios o leyes que el estudiante posee en relación con una actividad determinada y mediante la cual el estudiante analiza, sistematiza, argumenta, plantea, discrimina e interioriza la nueva información.

Indicadores. Conoce los principios, teorías, leyes y postulados sobre la resolución de problemas matemáticos. Maneja argumentos matemáticos para realizar demostraciones. Identifica y discrimina la información relevante para la resolución del problema.

Base procedimental. Es la forma en la que el estudiante relaciona los nuevos conocimientos con la experiencia que ya posee, es decir, es el desarrollo de las habilidades, estrategias y técnicas que el estudiante utiliza al representar el lenguaje verbal 
en lenguaje matemático, al seleccionar y construir gráficos estadísticos según necesidades del contexto, y al diseñar estrategias para afrontar una situación problémica.

Indicadores. Realiza representaciones de ideas matemáticas. Elabora gráficos estadísticos usando terminologías y reglas matemáticas. Diseña una estrategia para afrontar una situación problémica, empleando un amplio repertorio de recursos o procedimientos.

Base actitudinal. Son las competencias que permiten relacionar de manera satisfactoria al estudiante con su entorno, es decir es la aplicación de la nueva información adquirida frente a las diversas situaciones problémicas que el sujeto pueda afrontar en la vida y que se reflejan en su personalidad, en su manejo de actitudes y emociones.

Indicadores. Muestra motivación al momento de resolver una situación problémica. Valora la actividad realizada, contrastándola con su realidad. Respeta las opiniones de los demás al momento de trabajar en equipo con el objetivo de resolver una situación problémica

\section{Reflexiones teóricas sobre el proceso de enseñanza - aprendizaje}

El principal objetivo de la educación es contribuir a la formación constante en el estudiante con el fin de desarrollar los conocimientos, las habilidades y las actitudes de manera integral. Para lograrlo, el docente deberá ser consciente y estar claro en qué consiste el proceso de enseñanza- aprendizaje que se concreta en un proceso comunicativo a través de una relación bilateral entre profesor y alumno, con objetivos precisos a corto, mediano y largo plazo.

Para Freire (1997), Álvarez (1999), González (2003), Peñaloza (2004) y Addine (2013), el proceso de enseñanza- aprendizaje es un proceso planificado, controlado y tiene como objetivo la formación integral de la personalidad del estudiante mediante la interacción dialógica basada en la comprensión, el respeto y comunicación asertiva.

Es este mismo pensamiento, Díaz (2002), sostiene que la función del docente no es solo el transmitir conocimientos, sino también el de ayudar a que el propio estudiante construya los conocimientos mediante la interacción de profesor - alumno y alumno alumno.

Complementando esta posición, Castellano et al. (2007), refiere que el proceso de enseñanza- aprendizaje se asocia o responde a la forma en la que interactúa el docente con los estudiantes de su clase, con el propósito de estimular y potenciar el pensamiento reflexivo, afectivo y procedimental mediante el uso de diversos procedimientos, métodos y estrategias y medios didácticos para lograr la motivación del estudiantado por el aprendizaje. 
Una postura más actual sostiene Yáñez (2016), al considerar que el proceso pedagógico demanda el cumplimiento progresivo de diversas etapas que se encuentran interrelacionadas entre sí; así mismo cada etapa debe ir de menor a mayor dificultad y esfuerzo en la planificación para los estudiantes y docentes ya sea en el aula o fuera de ella. El resultado obtenido de este proceso complejo dependerá entre otros factores de la motivación y el interés que el docente genere en el estudiante para que se involucre en la construcción de su aprendizaje, asumiendo un rol protagónico que le permita asimilar de manera consciente los nuevos conocimientos de forma integradora a partir del análisis de situaciones problémicas reales las cuales se deben resolver y culminando con una evaluación cualitativa y cuantitativa.

Una visión más integradora expresan Álvarez (1999), Peñaloza (2004), Castellanos, et al. (2007), Pimienta (2012) y Addine (2013), al definir a la didáctica como la rama de la Pedagogía, que tiene como objetivo el estudio del proceso enseñanza aprendizaje, el cual es un proceso pedagógico consciente, planificado, organizado, evaluado y orientado por el docente al desarrollo de la formación integral del estudiante tomando como base las leyes, dimensiones, principios y componentes del proceso de enseñanza aprendizaje.

Las leyes: Para Álvarez (1999) y Addine (2013), las leyes de la didáctica involucradas en el proceso enseñanza aprendizaje, son aquellas que responden a las exigencias que la sociedad demanda a la escuela. Estas leyes son: La relación entre escuela y sociedad y la relación entre instrucción, educación y desarrollo.

Las dimensiones: son consideradas como las dimensiones del proceso- enseñanza aprendizaje son tres: instructiva, educativa y desarrolladora, con el fin de poder fomentar una educación integral en los estudiantes a través de las actividades de aprendizaje, orientadas a la adquisición de conocimientos y al desarrollo de diversas competencias, habilidades y destrezas (Álvarez, 1999 y Addine, 2004).

Los principios didácticos: Según Díaz (1999), los principios didácticos conforman un sistema que permite dar un carácter científico y lógico al proceso de enseñanza aprendizaje mediante la sistematización del contenido, la unión entre lo concreto y lo abstracto y la vinculación entre lo teórico y lo práctico, para fomentar un aprendizaje significativo en el estudiante, que le permita contrastar la realidad y generar conocimientos y habilidades que le sirvan para enfrentar situaciones problémicas en cualquier contexto.

Las categorías didácticas o componentes: Las categorías didácticas del proceso enseñanza- aprendizaje, son diversas: problema, objetivos, contenido, métodos, medios materiales, la evaluación y las formas organizativas de la clase. Estos al desarrollar la clase 
le dan la lógica y aunque cada uno tiene su especificidad, su integración le proporciona activismo a la clase e incide en las formas de pensar, sentir y hacer de los estudiantes (González, 2003, Peñaloza, 2004; Castellanos, et al. 2007; Addine, 2013 y Freire, 2017).

De lo anterior, el autor llega a concluir que el proceso enseñanza - aprendizaje debe involucrar principios didácticos que den rigor científico, lógico y rítmica, para una asimilación consiente del contenido por parte del estudiante y este a su vez pueda interiorizar y procesar la información, contrastarla con la realidad y transformarla en conocimientos propios, los cuales le ayuden a resolver problemas en cualquier contexto donde se encuentre, como sostienen (Freire, 1997;Álvarez, 1999; González, 2003; Addine, 2013;Yáñez 2016 y Velázquez 2018).

\section{Métodos orientados al desarrollo de la resolución de problemas}

Durante el proceso pedagógico el rol del docente como facilitador y guía es fundamental para una formación integral donde se valore lo conceptual, procedimental y aptitudinal. Esto exige a que los docentes tengan un mayor demonio pedagógico teórico y práctico para que el estudiante asuma un rol protagónico: se motivándose por el aprendizaje, demuestran do interés en la actividad a realizar y siendo el constructor de su propio aprendizaje, es por ello que a continuación se revisará algunos métodos como los problémicos, heurísticos, investigativos, dialógicos, lúdicos y por proyectos:

Los métodos según la RAE (2014), define al método como la forma de ejecutar un procedimiento con el fin de cumplir con un objetivo propuesto. Esto muestra la entrañable relación que hay entre los métodos y procedimientos.

Para Álvarez (1997), el método es el elemento que sistematiza y organiza la enseñanza - aprendizaje basado en la exposición y construcción del conocimiento e incluyendo la revisión, valoración, evaluación y retroalimentación de los resultados.

Así mismo, Álvarez de Zayas (2012), sostiene que estos métodos se concretan a través de las diversas técnicas empleadas por los estudiantes. Por ello la importancia del dominio teórico y metodológico que debe poseer el docente para enriquecer aún más estas técnicas y modificarlas a su conveniencia, según el tipo de metodología, conocimiento y características del grupo de estudiantes al cual va dirigido, durante el proceso de enseñanza aprendizaje yendo de lo conocido a lo desconocido como añade Montes y Machado (2011) y Sáenz (2014).

En caso de los métodos de la enseñanza problémica, Álvarez (1999), Pérez (2012), Hernández (2014), Arizaga (2015); Fernández y Aguado, (2017) y Quijandría (2019), afirman que estos están estructurados por una variedad de procedimientos con los cuales 
se busca modelar el pensamiento, a partir del análisis, la reflexión, la búsqueda de investigación y la aplicación del conocimiento adquirido en una situación real.

Dentro de la enseñanza problémica, se plantean en general cuatro métodos que serán implementados como herramientas de la estrategia metodológica propuesta:

\section{Método de la exposición problémica.}

Relacionado al método de la exposición problémica, el docente presenta situaciones en las cuales se revela parte de la información y que, mediante preguntas, se busca generar un ambiente de contradicción donde el docente ayuda a construir la lógica de resolución de problemas, fundamentando cada operación a realizar hasta el momento que el desarrollo se dé por sí mismo (Arizaga, 2015).

Al presentar la situación problémica de esta forma se fomenta el análisis, el debate, el razonamiento científico, la construcción de un entorno de seguridad y confianza; incrementa el interés del educando; se demuestra el dominio teórico metodológico del docente considerando el nivel de dificultad y efectividad del tema a tratar y el estudiante es coparticipe de esta actividad en todo momento de forma consciente (Arandia, Alonso y Martínez, 2010). Aquí se utilizan varias técnicas como: la exposición, la conferencia, el dialogo entre otros.

La conversación heurística se emplea cuando el docente presenta una situación problémica y reta a los estudiantes a través de un sistema de preguntas a proponer alternativas de solución, basado en sus saberes y experiencias previos. A partir de ahí se produce un debate y cuestionamiento desde las respuestas de los estudiantes. Se parte primero de lo empírico y gradualmente ascienden a lo teórico. En esa actividad se fortalece la interacción docente -educando sobre un contenido específico valiéndose de la mayéutica y tomando como herramientas de apoyo a la inducción, la contradicción, la ironía y la crítica para despejar las dudas y promover el interés, la motivación por el nuevo conocimiento; el libre pensamiento, el razonamiento lógico y las actitudes positivas al dialogar y socializar sus ideas en grupo potenciándose así la formación de la personalidad (Arizaga, 2015; Campi, Campi y De Lucas, 2015).

\section{Método de la búsqueda parcial.}

El método de la búsqueda parcial o heurística para Arizaga (2015), se orienta que los estudiantes propongan alternativas de solución ante un problema específico de su contexto o realidad escolar. En ello el docente como moderador y guía elabora un sistema de preguntas o cuestionamientos heurísticos provoca que surja un clima de dudas e incertidumbre que pone a los estudiantes en tensión intelectual. Permite por momentos la 
consulta y la interacción grupal, lo que estimula y activa el diálogo, el razonamiento lógico, analítico y la propuesta de opiniones y puntos de vistas. Se crea una situación pedagógica donde los estudiantes analizan la teoría, aportan ideas, formulan de hipótesis y ofrecen propuestas de solución basados en la investigación, observación y experimentación identificándose con ciertas etapas del proceso de conocimiento científico y luego el docente orienta diferentes ejercicios para ejercitar el nuevo conocimiento y desarrollar habilidades (Guanche, 2011).

\section{Método investigativo.}

Álvarez de Zayas (2012), sostiene que el método investigativo proporciona un conjunto de procedimientos, técnicas y actividades creativas que busca ampliar y consolidar los conocimientos adquiridos por los estudiantes mediante la integración de forma sistémica de las experiencias cognoscitivas individuales. Ese proceder requiere de la orientación completa del docente sobre el quehacer, estimulándose en el estudiantado el desarrollo de la capacidad de indagación, curiosidad, descubrimiento y la búsqueda de la información para aplicarla en la solución de problemas (Bunge,1981).

Esa manera de organizar el aprendizaje genera en el sujeto satisfacción y disfrute porque sabe qué y cómo hacer y por tanto es exitoso el proceso y el resultado de su aprendizaje porque integra los aspectos procedimentales, conceptuales y actitudinales científicas. Esta metodología requiere de un conjunto de métodos con el objetivo de lograr la dinámica, interés y consolidar el desarrollo integral de las capacidades, conocimientos, habilidades, destrezas, valores individuales y sociales (Addine, 2013 y Arizaga, 2015).

\section{Método de aprendizaje social.}

Crispín et al., (2011), en relación con el método de aprendizaje social el objetivo es establecer una conexión estrecha entre las capacidades, habilidades e interés de los educandos para gestionar y realizar una actividad grupal en donde todos participan de forma colectiva siendo debidamente guiado por el docente. Para esto se distribuye las responsabilidades de forma que cada integrante tenga un rol específico y que a su vez esta tarea sea parte de una estructura consensuada y aprobada por ellos mismos. Aquí el docente evalúa de manera secuencial y sumativa mediante la exposición oral y el uso de rúbricas para la autoevaluación, evaluación y coevaluación (Castellanos et al. 2007; Ortiz, 2012; Tobón, 2013 y Addine, 2013). 


\section{Método de proyecto.}

En el método de proyecto consiste en sistematizar y estructurar un conjunto de métodos, procedimientos, técnicas y actividades seleccionadas según el contenido tratado durante un periodo determinado y la diversidad del aula. El objetivo es que los estudiantes mediante las relaciones interpersonales y la participación activa, reflexiva, dialógica y respetuosa de la discusión que se genera en el estudio lleguen a un consenso y propongan una alternativa de solución ante un problema presentado de su realidad.

Al organizar el aprendizaje a través del método de proyecto se potencia a la formación integral del educando porque además de fomentar los valores morales y las relaciones interpersonales de la convivencia democrática con su participación activa, dialógica, de interacción con sus compañeros, consensuar, reflexionar y buscar alternativas de solución a los problemas que son objeto de estudio que en la generalidad emergen de su propia experiencia y contextos social (Pimienta 2012, y Rímac, Hernández y Velázquez 2017).

\section{Método creativo.}

Refiere Álvarez (1999), que el método creativo tiene como objetivo fomentar el desarrollo de la creatividad y la innovación con actividades para el desarrollo del pensamiento a partir de formular una respuesta a una situación problémica que el docente propone a los estudiantes. Esta metodología tiende a generar un ambiente de motivación e interés por asumir riesgos, descubrir nuevas alternativas de solución y generar cambios que transformen en su contexto. Al realizar actividades creativas los estudiantes se sitúan o ponen en contacto con la realidad; lo interesante es que no reproducen la información o el conocimiento adquirido, sino que lo aplican a partir del objetivo trazado con originalidad, buscan alternativas o innovan que les estimula la ejercitación de las habilidades para descubrir nuevos conocimientos, inventar o proponer la metodología a seguir ante una tarea (Addine, 2013; Gallardo, 2014; Saavedra, 2009 y Gallardo, 2014) .

\section{Método de la didáctica crítica.}

Este método busca orientar la enseñanza con el fin de desarrollar en los estudiantes el pensamiento crítico y reflexivo que les permita enfrentar diversas situaciones problémicas de la realidad. El método crítico tiene como función potenciar el juicio propio, la valoración, el cuestionamiento y la flexibilidad para recepcionar nuevos conceptos (Vygotsky; 1987; Álvarez, 1999; Álvarez de Zayas (2012); Tobón, 2013 y Ortiz, 2015).

La aplicación de este método dentro del proceso pedagógico exige al docente planificación y dominio teórico y práctico de los conceptos a tratar para poder generar un 
ambiente que estimule la formulación de ideas, la creación de juicios veraces y la comprensión de la información.

En ese orden de pensamiento, Muñoz y Páges (1991), Garza (2013), Vargas (2013), Tobón (2013) y Moreno y Velázquez (2017) sintetizan el conjunto de acciones a tomar, de la siguiente manera:

Decidir para elegir el tema a tratar

Identificar y definir las categorías y variables a tomar en cuenta

Investigar e informarse sobre dichas variables.

Evaluar la validez, la lógica y el proceso de la información

Identificar las diferencias entre los hechos objetivos y las opiniones

Tomar en consideración las evidencias de forma integral y valorar las ventajas y

desventajas

Llegar a conclusiones concretas.

Resolver los problemas

\section{La estrategia metodológica y la resolución de problema matemático}

En la práctica pedagógica, los docentes son conscientes que la educación actual exige cambios en el proceso de enseñanza aprendizaje con el objetivo de involucrar al docente, al estudiante, a los conocimientos y a los valores, con la sociedad de manera integral, haciendo nuevas propuestas frente a la desmotivación y desinterés de los estudiantes, en especial en el área de Matemática. Por ello la importancia de desarrollar una propuesta metodológica que tome en consideración los puntos mencionados anteriormente.

Al hacer una revisión etimológica del término estrategia, se encontró que deriva de la palabra griega stratos, que significa ejército y de la palabra agein como guía. Entonces un primer significado asociado a la estrategia es el arte de conducir con destreza eficiencia las tropas militares hasta llegar a su aplicación en el campo de la educación posterior a la Segunda Guerra Mundial asociándolo a la planificación para alcanzar un objetivo específico dentro del proceso enseñanza aprendizaje (Velázquez 2018).

Según la RAE (2018), la estrategia es el arte que permite dirigir las operaciones militares, o aquel arte que permite formar una traza para dirigir un asunto. En el área de matemática, el término estrategia es un proceso controlable, es decir es un proceso que posee un conjunto de reglas que permiten asegurar una toma de decisión de manera óptima en cada momento.

En relación a lo pedagógico, Latorre y Seco (2013) precisa que la estrategia de enseñanza es la forma en la que se toman decisiones frente a un contexto o situación 
determinada. Por tanto, es importante que la persona sea consciente de su intención hacia un objetivo específico en el proceso de enseñanza aprendizaje. La estrategia se estructura en dos dimensiones: cognitivas y procedimentales las cuales se desarrollan a través de las diversas actividades con el objetivo de dar solución a una situación problémica.

Por su parte Sierra (2015), sostiene que la estrategia es un proceso mediante el cual se construyen las bases para lograr alcanzar las metas a pesar de la incertidumbre del comportamiento frente al accionar de la fuerza externa.

De lo anterior, se puede concluir que la estrategia es un proceso que está planificado, organizado y orientado al cumplimiento de un objetivo utilizando técnicas y procedimientos efectivos, los cuales son seleccionados para plantear propuestas de solución frente a una situación determinada.

El término metodología deriva del vocablo griego metá, que traducido sería ir más allá, del vocablo griego odós que significa el camino y el vocablo griego logos, que significa estudio. Se puede concluir que la metodología es el estudio de los procedimientos racionales que permiten llevar a cabo un objetivo específico, como refiere (Velázquez 2014)

El método es definido por Labarrere y Valdivia (1998), Vargas (2009), Díaz Barriga (2010), Tobón (2013), y Addine (2015), como la manera de conducir y controlar la actividad de la clase por el docente y de los estudiantes, con el fin de cumplir los objetivos. Su construcción, sistematización y ejecución son producto de la interacción entre estudiante, docente y grupo colectivo garantizando de esa manera que el objeto de estudio haya sido cumplido.

Acorde a este argumento, Sánchez (2002), considera que la metodología viene a ser considerada como una categoría global que estudia los métodos desde el enfoque sistémico, a través del cual desarrollaran las diferentes formas del saber. Y el método es considerado como la ruta que sigue el maestro y los estudiantes para poder conseguir de una manera más estructurada y secuencial un fin específico, teniendo en cuenta las reglas ya establecidas.

En esa misma idea, Zabalza (2011), define la metodología como el punto de concurrencia entre lo teórico y lo práctica en relación con las normas, tradiciones y paradigmas individuales e institucionales. La metodología es la herramienta más importante para el docente y que a su vez está sujeta a factores externos y normativos de la institución en particular.

Al respecto, Torres (2017) expresa que, la metodología es entendida como un concepto global referido al estudio del método (o de los métodos) desde un proceso sistemático en el cual se adquieren modos y formas de conocimiento. En consecuencia, el método es más restringido, es el camino, la guía, las orientaciones interactivas que se 
aplican al analizar un fenómeno con el fin de alcanzar los objetivos de manera planificada y controlada. Como se aprecia la metodología es considerada como un proceso con valor inductor, con acciones y procedimientos organizados e inducidos al logro de una meta trazada por el docente en la enseñanza- aprendizaje como precisa (Álvarez de Zayas y González, 1998 y Cruz y Velázquez, 2017).

De lo anterior, se concluye por el autor de la investigación, que la metodología es el conjunto de métodos aplicado de manera sistemática e integradora por el docente a fin de busca desarrollar e interrelacionar los diversos saberes para generar un aprendizaje significativo y meta cognitivo en los estudiantes estimulando el pensamiento crítico y valorativo como sostienen (Castellanos et al. 2007; Tobón, 2009; Barriga y Hernández, 2010; Zabalza, 2011 y De Corte, 2015).

En la práctica pedagógica actual se requiere que el docente aplique en su clase una estrategia metodológica que se adapte a las características de la diversidad de sus alumnos a fin de influir en su formación integral desde el proceso enseñanza- aprendizaje.

Al respecto, Gordillo (2007), refiere que la metodología es entendida como un concepto global referido al estudio del método (o de los métodos) desde un proceso sistemático en el cual se adquieren modos y formas de conocimiento; el método es considerado como el camino para obtener un fin de manera ordenada, desde un conjunto de reglas.

El autor refiere que la estrategia metodológica es el conjunto de métodos y procedimientos que se llevan a cabo en el proceso de enseñanza- aprendizaje de manera óptima. En ese orden de ideas, Pimienta (2012) asevera que, las estrategias metodológicas de enseñanza - aprendizaje son herramientas con los que el maestro promueve el desarrollo de las competencias de los estudiantes, para alcanzar un objetivo específico.

Una conceptualización más integral expresa Barrera, Hernández y Reynoso (2013), al considerarla estrategia metodológica como una proyección sistematizada de acciones tanto a corto, mediano o largo plazo con el objetivo de transformar la dirección del proceso de enseñanza - aprendizaje, teniendo como base los diferentes métodos y procedimientos para alcanzar los objetivos determinados en un tiempo específico.

En este sentido, Velázquez (2014) argumenta que la estrategia metodológica se orienta al proceso de enseñanza - aprendizaje, partiendo del profesionalismo del maestro para orientar el aprendizaje desde un sistema basado en métodos, con el objetivo de problematizar, reflexionar, discutir y valorar el contenido de la enseñanza en donde se busca que el estudiante sea el personaje principal y asimile de manera consciente los cambios que logra en la forma de pensar, sentir y hacer.

En línea con esa perspectiva, el Ministerio de Educación de Bolivia (2015), define las estrategias metodológicas como el uso de procedimientos didácticos correlativos que el 
maestro utiliza de forma reflexiva y flexible, para poder estimular y promover los aprendizajes productivos en los estudiantes, basados en las necesidades específicas según el contexto. También están inmersos todo material o recurso que coadyuve a alcanzar el objetivo holístico, con el fin de garantizar que estos procesos sean integradores, creativos y críticos respecto de su contexto, naturaleza y bajo la perspectiva de poder construir una sociedad intra e intercultural, comunitaria, productiva, digna y sostenible.

Como se ha referido, la estrategia metodológica es una concepción que incluye métodos, procedimientos y procesos que utiliza el profesor en el proceso de enseñanza con el objetivo de que el estudiante desarrolle de manera eficiente el aprendizaje, integrando los conocimientos teóricos y prácticos en el estudio de situaciones problémicas basado en su contexto desde un enfoque colaborativo (Díaz y Hernández, 2010; Tobón, 2013; Velázquez, 2014 y el Minedu, 2015).

Por su parte Díaz y Hernández (2010), sostienen que la estrategia metodológica, está formada por un conjunto de procedimientos que ayudan a dirigir la sesión de clase, con el objetivo de fomentar conciencia entre los estudiantes mediante la aplicación de diversos procedimientos, aplicando el autoaprendizaje y la autoevaluación respecto a la tarea que realiza, cómo y porqué lo realiza contribuyendo al desarrollo de las habilidades y de la independencia cognoscitiva integral.

Al concluir la sistematización teórica de la categoría apriorística, estrategia metodológica, se asume como autor de base a Díaz y Hernández (2010), por considerar que su posición teórica se ajusta a los objetivos de la investigación. Desde esta concepción teórica se identificaron las subcategorías apriorísticas y los indicadores:

Subcategorías.

Exigencia del proceso enseñanza - aprendizaje. Para realizar un proceso de aprendizaje óptimo, se debe seleccionar una estrategia que tenga como objetivo final que el estudiante se desarrolle de mañerea integral con pensamiento crítico y toma decisiones consientes mientras plantea las posibles soluciones a un problema determinado en su contexto.

Esto involucra que el docente profundice aún más en sus conocimientos relacionados a los contenidos a enseñar, para poder realizar una eficiente sesión de clase, donde se planifique, se aplique estrategias idóneas y se lleve un control constante durante toda la clase (Monereo 2000 y Velázquez, 2018). En este mismo hilo se sugiere construir currículos donde se considere el perfil del egresado para poder distribuir los diferentes contenidos a desarrollar acordes con los objetivos establecidos, (Castellano et al, 2007).

Indicadores: Diagnostica la situación real para reconocer las fortalezas y debilidades sobre la resolución de Problemas. Aplica las leyes, principios y teorías en la Enseñanza Aprendizaje de resolución de problemas. 
Sistematización del método problémico. La sistematización del método problémico viene hacer un proceso que busca que el estudiante como protagonista desarrolle una autogestión del conocimiento y en donde pueda generarse nuevos conocimientos partiendo de la reflexión de sus propias experiencias y en la que la nueva información impartida, potencie, confronte y modifique al conocimiento anterior para toda la vida (Bunge,1981; Álvarez, 1998; Addine, 2006; Castellanos et al, 2007, Díaz y Hernández, 2010; Ortiz, 2012 y Bravo, 2014).

Indicadores: Aplica diferentes sistemas de métodos problémicos, heurísticos, investigativos y argumentativos para el tratamiento de contenidos. Presenta contenido a partir de situaciones problematizadoras, reflexivas y dialógicas.

Rol del docente. Para Díaz, Hernández (2010) y Velázquez (2018), el docente tiene la responsabilidad y el deber de utilizar métodos que motiven al estudiante a desarrollar un pensamiento lógico, un proceso de información, una construcción de conocimiento y aplicación al contexto real, al momento de resolver un problema. Esto se debe reflejar en la secuencia metodológica al desarrollar la clase, donde la relación entre categorías didácticas debe ser armónica y dialéctica de manera integral a fin de desarrollar en el estudiante las habilidades, destrezas y conocimientos tanto aptitudinales como procedimentales para la vida.

Indicadores: Evidencia ser un mediador asertivo y competente, que atiende la diversidad del grupo. Promueve una buena actitud de aprendizaje a través del trabajo en grupo.

Rol del estudiante. Según Ausubel (1978), Rugeles, Mora y Metaute (2015), el estudiante adquiere un rol protagónico, autónomo, cooperativo e inter relacional, al buscar organizar y sistematizar la información de manera integral con el objetivo de resolver problemas aplicados a su contexto real, mediante un análisis crítico - reflexivo, interpretativo y argumentativo, en donde el estudiante es consiente que ocupa un lugar fundamental para el desarrollo de su propio aprendizaje, por lo que participa activa y colaborativamente durante las diversas actividades, considerando el ritmo y estilo de aprendizaje propio y de los demás.

Para tal fin, es necesario que asuma mayores responsabilidades de manera progresiva, comenzando desde tareas individuales hasta llegar al trabajo colaborativo, las cuales son acompañadas y evaluadas constantemente, como añade (De Zubiría, 2004).

Indicadores: Demuestra dominio del saber hacer y es responsable de su propio aprendizaje. Establece relaciones interpersonales asertivas con sus compañeros. 


\section{Capítulo II \\ Diagnóstico o trabajo de campo}

El diagnóstico de campo se realizó en una institución educativa privada de Lima, ubicada en el distrito de San Martín de Porres de la ciudad de Lima. El propósito de dicho proceso es corroborar el nivel de desarrollo de la competencia de resolución de problemas matemáticos alcanzado por los estudiantes del V grado de Secundaria.

Para tal fin, se utilizaron diversos métodos y técnicas de recojo, procesamiento y triangulación de la información recogida. Durante dicho proceso, las técnicas e instrumentos empleados son: la entrevista y la observación a clases a los docentes y prueba pedagógica y un cuestionario a los estudiantes (Anexo Nro. 3 - 6).

La información recabada responde a dos tipos de datos: los cuantitativos y los cualitativos; los cuantitativos fueron analizados por tablas de frecuencias, permitiendo establecer algunas tendencias y regularidades, mientras que los datos cualitativos, fueron procesados por medio de tablas de reducción de datos, posibilitando así la identificación de las categorías emergentes de manera general y contribuyen al reconocimiento de las categorías emergentes influyentes en el problema de la investigación.

\section{Análisis, interpretación y discusión de los resultados obtenidos mediante la aplicación de los instrumentos}

\section{Análisis de la entrevista aplicada a los docentes.}

La entrevista aplicada, fue semiestructurada y se realizó a tres docentes del área de Matemática en Educación Secundaria y cuyo proceso de codificación respectivo, figura en el Anexo Nro. 3 de los cuales, se obtuvieron los siguientes resultados interpretativos:

De los tres docentes que fueron entrevistados, dos evidenciaron pobreza en conocimientos teóricos acerca de la resolución de problemas como competencia; mientras que uno de ellos, manifestó que las competencias de resolución de problemas son las habilidades y destrezas para resolver una situación problémica, aunque no se refirió a situaciones cotidianas, sino a lo teórico y ninguno argumentó sobre el desarrollo de este

tipo de competencias en el aula. Ello demuestra desconocimiento teórico y metodológico acerca de las estrategias para desarrollar la competencia de resolución de problemas matemáticos que conlleven a un aprendizaje significativo en el estudiante.

En relación con el recojo de saberes previos al inicio, dos docentes manifestaron que utilizan distintas preguntas del tema visto en la clase anterior, pero sin ningún objetivo de conectarlo con el tema a tratar, no dieron la debida importancia a la nueva materia, sino 
con el objeto solo de saber si los estudiantes están repasando los temas tratados anteriormente, y uno refirió que presenta situaciones de la vida cotidiana y realiza preguntas para conocer sus ideas sobre el tema a tratar.

Con respecto a la planificación de estrategias didácticas, los tres docentes se limitaron a estudiar el contenido del libro, a consultar otro libro teórico, y a resolver los problemas propuestos en pizarra, en los que dieron mayor énfasis a la formula a utilizar en la parte aplicativa y su réplica en los estudiantes y desarrollaron practicas escritas y exámenes centrados en la operatividad de la resolución de los problemas y dejaron de lado otro medio que permita evaluar de manera integral la de resolución de problemas.

Acerca de las estrategias didácticas utilizadas para la resolución de problemas, un docente argumentó que utiliza la formación de grupos en el aula, otro, situaciones problémicas, y el tercero se limita a resolver el libro, pero realiza preguntas para que los estudiantes sigan la secuencia del proceso de resolución. Esto significa que, en sus experiencias han ido desarrollando algunas estrategias que si bien se complementan habría que profundizar más en la manera como la están aplicando, en que momentos, y en qué condiciones se están realizando, como explicaremos en la guía de observación de clase.

La situación problémica es utilizada apropiadamente al inicio de la clase por un docente, pero luego no lo vuelve a proponer a los estudiantes mientras que los otros dos docentes, solo realizaron preguntas acerca del tema anterior.

En relación con la motivación dos de los docentes realizaron preguntas directas a los estudiantes, comenzando por los que están distraídos y el tercer docente realizó una lluvia de ideas acerca del tema a tratar y reflexionó sobre la relación con la vida diaria. Esto muestra que aún hay docentes, que mantienen la enseñanza tradicional, tratando de obligar al estudiante a concentrarse en la clase a la fuerza, sin considerar sus intereses o concientizarlos de la importancia del tema con su vida diaria.

Respecto de la manera como logran que el estudiante reconozca, discrimine la información necesaria para la resolución de problemas, los tres docentes evidencian que la forma en que ellos puedan lograr estas capacidades es de explicarles nuevamente el proceso de resolución de un problema y darles a ellos otro problema similar para su réplica exacta. Esto muestra el desarrollo de una educación tradicional bajo la cual son mecanizados, centrándose solo en el desarrollo de un problema abstracto y descontextualizado, dejando de lado el razonamiento y análisis del problema.

Acerca del manejo de argumentos matemáticos para realizar demostraciones, solo un docente lo desarrolló en su clase, y bajo la cual percibió que la gran mayoría de estudiantes presenta dificultades al expresar sus argumentaciones. Por su parte los otros 
dos docentes evidenciaron que solo realizan las demostraciones cuando algún estudiante lo exige por considerarlo innecesario. Esto evidencia un desconocimiento teórico y metodológico de la pedagogía aplicada por el docente al realizar demostraciones, a pesar de que reconocen la importancia que estos tienen en la resolución de problemas y limitándose al desarrollo de los problemas propuestos en el libro.

Acerca de los métodos problémicos que proponen a los estudiantes, con el objetivo de que analicen y relacionen las incógnitas y las variables, los tres docentes manifestaron que realizan preguntas mientras desarrollan los problemas en la pizarra. Nuevamente se puede evidenciar una enseñanza tradicional, orientada a la repetición de procedimientos los cuales los estudiantes se deben aprender de forma mecánica.

En relación con el uso de recursos pedagógicos o educativos, los tres docentes manifestaron serias deficiencias de orden teórico al definir los tipos de recursos, así como también el uso que le dan, limitándose a desarrollar el contenido del libro y prácticas escritas. Esto refleja la carencia en el uso de estrategias donde los estudiantes puedan desarrollar de manera integral la competencia de resolución de problemas.

Respecto al uso de proyectos interdisciplinarios los tres docentes manifestaron no realizar este tipo de actividades, por el tiempo que implica este y por la sobre carga de documentación que exige la institución. Lo que, si realizan de manera obligatoria, es el día del logro o feria de Matemáticas, una vez al año, limitándose a dejar trabajos expositivos sin ninguna relevancia para la vida de los estudiantes, al no pertenecer a su contexto social, y en donde se le da parámetros establecidos que el estudiante debe seguir. Esto demuestra la falta de compromiso profesional de los docentes y la ausencia de proyectos interdisciplinarias.

Las actividades que realizan los docentes para promover una buena actitud entre los estudiantes fueron las de realizar trabajos grupales, orientados a resolver una lista de ejercicios y problemas del libro o algún material adicional similar a los desarrollados por el docente en la pizarra. Así mismo, uno de los docentes sostuvo que tiene muchos problemas porque no todos trabajan en el grupo y que le toma mucho tiempo el hacer este tipo de actividades, por lo que no lo realiza si no ha terminado de desarrollar todo el contenido del libro. De esto podemos observar que se presenta una carencia de autoridad para manejar diferentes situaciones grupales, manteniendo el respeto y el compromiso con su aprendizaje personal y social.

En relación con el desarrollo de actividades donde el estudiante demuestre lo aprendido en clase, tres de los docentes manifestaron que utilizan la pizarra para tomar paso oral, o las prácticas escritas de manera permanente, para medir su grado de 
aprendizaje del tema tratado, colocando una nota aprobatoria al que llegara a la respuesta correcta. Esto manifiesta que la enseñanza está más centrada en replicar los pasos para la resolución de un determinado problema, que en la forma de cómo asimilan y aprenden los estudiantes.

En referencia a la diferencia actitudinal que los docentes observan en los estudiantes al momento de realizar trabajos colaborativos, dos de ellos afirman que son situaciones más bien complicadas porque muchos no trabajan y esperan a que los más aplicados lo resuelvan para solo copiar, mientras que el tercer docente manifestó que es una situación enriquecedoras para sus estudiantes pues le permite manejar la capacidad de liderazgo así como también fomenta el aprendizaje entre compañeros y que muchas veces ayuda a que los alumnos puedan comprender mucho mejor el tema propuesto. Esto nos muestra que los docentes tienen deficiencia teórico-metodológica acerca de los trabajos colaborativos y no se encuentran capacitados para llevarlo a cabo de manera que sea una experiencia favorable para la clase.

Al concluir el análisis, se observan deficiencias teóricas y didácticas en cada uno de los docentes, al momento de realizar el proceso de enseñanza - aprendizaje, aplicando una metodología tradicionalista que solo se enfoca en la transmisión de conocimientos, pero que no conlleva al desarrollo del pensamiento crítico, reflexivo, aprendizaje significativo y expresión libre en los estudiantes. Así mismo, hay un desconocimiento acerca de la motivación como proceso fundamental del aprendizaje.

\section{Análisis de la observación a clase a docentes.}

Se realizó una observación de clase a tres docentes del área de Matemática de educación secundaria, a fin de conocer el nivel de dominio teórico, metodológico que poseen. El proceso de codificación se muestra en el Anexo Nro. 4, del cual se obtuvo el siguiente resultado:

En relación con la presentación de una situación problémica para estimular la motivación e interés del estudiante, los tres docentes revelaron deficiencias al iniciar su clase. Sin embargo, realizaron preguntas acerca del tema anterior y al tratar el nuevo tema, constantemente mantenían la atención de los estudiantes haciéndole preguntas, respecto de las propiedades que se iban presentando. $Y$ lo iban registrando con una nota vigesimal en el registro diario.

Se puede decir que los docentes no acondicionan de manera óptima la motivación para generar el interés de los estudiantes durante la clase de Matemática, en tal sentido 
se muestran desganados a aprender y presionados a participar por ser de carácter obligatorio en el cumplimiento de su rendimiento académico.

Acerca del uso del uso del lenguaje, los tres docentes evidenciaron un buen manejo de palabras sencillas, comprensibles por los estudiantes y en muchos casos se generaba un ambiente alegre, mediante el cual podía hacer la clase un poco más amena y motivadora, al momento de presentar las propiedades y desarrollar algunos ejercicios y problemas en la pizarra. $S$ e podría generalizar que el uso de un lenguaje asertivo y contextualizado de un profesor genera motivación en los estudiantes, a la hora de resolver problemas matemáticos.

En cuanto al dominio teórico del tema a desarrollar, los tres docentes mostraron seguridad, empatía y disposición para resolver dudas en los estudiantes. También, proponían ejemplos que reforzaban la aplicación de las propiedades y fórmulas vistas en clase, aquí hubo participación de los estudiantes y llegaron a resolver todos los problemas propuestos en el libro para dichas clases. Nótese, que el contenido propuesto en el libro presentado por los docentes no responde a las necesidades e intereses de los alumnos, se centra en repetir la estrategia y algunos problemas, de corte tradicional.

El dominio metodológico que mostraron los tres docentes al momento de resolver los problemas del libro fue deficiente, pues todo el desarrollo de la clase lo realizaron en la pizarra; Cabe resaltar que dos de los docentes se limitaron a presentar las fórmulas y mecanismos necesarios para desarrollar los problemas tipo examen de admisión, mientras que uno de ellos constantemente realizaba preguntas, para que el estudiante vaya construyendo la secuencialidad de pasos para la resolución de dichos problemas.

El uso de estrategias grupales fue deficiente, debido a que dos de los docentes a veces forman grupos de cinco estudiantes con el objetivo de que puedan aplicar por repetición lo aprendido en clase, en algunos problemas propuestos en su libro. Mientras que un docente no realiza nunca trabajo grupal, por falta de tiempo y por la indisposición y falta de compromiso que los estudiantes muestran en su clase; Esto indica a modo general, que hay falta de motivación por el aprendizaje en los estudiantes y una carencia en los docentes por elaborar mayor variedad de problemas matemáticos, pues estos no solo deben ser repetitivos, sino también contextualizados y reales.

En las tres clases observadas se identificó que el uso de argumentos matemáticos es de uso limitado; Dos docentes esperan a que algún estudiante consulte sobre alguna demostración para poder explicarlo en pizarra, mientras que un docente al final de su clase propone una demostración como pregunta reto para los estudiantes y al cabo de un tiempo, de no haberlo podido resolver, el docente mismo, expone en la pizarra la resolución. 
Respecto de la etapa final del desarrollo de la clase, los tres docentes consultan a los estudiantes sobre alguna duda sobre el tema visto en clase para su respectivo refuerzo sea de manera individual o grupal. Esto genera un buen clima donde el estudiante se siente escuchado y muestra a los docentes predispuestos a apoyar a todos los estudiantes de manera homogénea y asertiva.

En cuanto a las evaluaciones aplicadas por los tres docentes son deficientes, pues se dan de forma tradicional, cuantitativa y obligatoria pues la institución educativa tiene reglamentado la evaluación diaria mediante el uso de una prueba escrita con 5 preguntas iguales a las vistas en clase. Dichas pruebas, no son equitativas para todos los estudiantes, pues solo se toma en cuenta a los más destacados en conocimientos, pero no de los progresos que van mostrando los menos destacados.

En relación con la realización de proyectos interdisciplinarios y trabajos de campo donde los estudiantes puedan realizar un estudio real y aplicado de los temas vistos en clase, hay un desconocimiento teórico y metodológico acerca de los beneficios que estos generan en el estudiante, ya que los tres docentes se centran sólo en el desarrollo de los contenidos del libro; Por otro lado, manifiestan su incomodidad con la presentación de un proyecto de área una vez al año, pues sienten que no es tan provechoso como practicar en pizarra la resolución de problemas.

Al concluir el análisis, se evidenció una contradicción en cuanto a lo expresado por los docentes en la entrevista, sobre el uso de estrategias didácticas para que los estudiantes sean más conscientes de su aprendizaje, pero en las clases observadas ninguno las empleó; no presentan situaciones problémicas, reales y contextualizadas, ni el trabajo con proyectos interdisciplinarios y colaborativos que estimulan la motivación e interés por el aprendizaje y se continúa usando la evaluación tradicional, enfocada en lo cuantitativo, y dejando de lado a la evaluación formativa que conlleva a un aprendizaje más consciente y a la formación integral de los educandos para la vida diaria.

\section{Resultados de la prueba pedagógica aplicadas a los estudiantes.}

La prueba pedagógica se aplicó a 12 estudiantes del $\mathrm{V}$ grado de Secundaria, el análisis cuantitativo figura en el anexo 6 y su valoración cualitativa se presenta a continuación:

Se constató, que el 10 (83.33\%) de los estudiantes, manifiestan que no conocen los principios, teorías, leyes y postulados necesarios para la resolución de problemas y dos (16.67\%) expresaron que si los conocen. Esto implica que las estrategias didácticas empleadas por el docente al dirigir el proceso de enseñanza aprendizaje, no son las adecuadas y en consecuencia ese es el resultado. 
En cuanto a identificar el argumento matemático utilizado para realizar la demostración del teorema de Pitágoras, 10 (83.33\%) reflejaron que no son capaces de manejar argumentos matemáticos para ello y dos (16.67\%) evidencian que si son capaces de manejar argumentos matemáticos. Ello revela la necesidad de demostrarles los argumentos matemáticos en la clase para que los estudiantes lo interioricen y puedan resolver los ejercicios.

Respecto de la identificación y discriminación de la información relevante para poder resolver un problema, 10 (83.33\%) no identifican la información y dos (16.67\%) sí pudieron hacerlo bien. Por tanto, se aprecia que la mayoría no pudo resolver la actividad ya que no logran desarrollar un aprendizaje integral, consciente y significativo en el que les permita aplicar los saberes en diferentes contextos.

Al realizar la representación de un enunciado textual a una gráfica bidimensional, $10(83.33 \%)$ de los estudiantes evidencian que no realizan representaciones matemáticas al momento de resolver problemas matemáticos y dos (16.67\%) de los mismos sí; Esto muestra el perfil de la institución, por reproducir una enseñanza tradicional en donde se busca el desarrollo mecánico e intuitivo de problemas de corte teórico.

Acerca del uso de terminologías apropiadas al realizar gráficas estadísticas, se visualiza que dos (16.67\%) de los individuos pertenecientes a la muestra, cuando realizan gráficas estadísticas no usan las terminologías y reglas matemáticas apropiadas y 10 (83.33\%) sí; Esto manifiesta que los estudiantes tienen claro los conceptos y formas de analizar, procesar y obtener información por lo que no debería ser ningún problema el realizar trabajos de campo, pero que no se lleva a cabo porque los docentes solo se enfocan en realizar los problemas del libro.

En cuanto a los métodos de resolución de problemas se evidencia que el 10 (83.33\%) de los estudiantes no consideran diversos métodos de resolución de problemas y dos $(16.67 \%)$ de los mismos si considera diversos métodos de resolución de problemas, esto es un indicador que corrobora que el tipo de enseñanza es meramente repetitiva y tradicional los cuales no le permiten al estudiante, diseñar sus propias formas de resolución.

Sobre la sensación, que produce el resolver problemas se observa que seis $(50.00 \%)$ de las personas se sienten motivadas al momento de resolver una situación problémica, y así mismo el otro seis (50.00\%) de los individuos, no; Esto permite seleccionar eficientemente las estrategias motivacionales y crear un ambiente más agradable que genere mayor interés por el aprendizaje de resolución de problemas en los estudiantes. 
Sobre los beneficios que produce una actividad colaborativa en clase, se visualiza que uno $(8.33 \%)$ de los sujetos son indiferentes ante las actividades que impliquen interacción, colaboración y aprendizaje social, mientras que el $11(91.67 \%)$ muestra su preferencia por realizar actividades donde los mismos puedan construir su propio aprendizaje. Esto es fundamental al momento de plantear actividades o proyectos colaborativos para que el estudiante se sienta motivado para aprender, pero que el docente no realiza por considerarlo innecesario para el aprendizaje.

En referencia a los valores que se deben tener al realizar una actividad grupal, se muestra que tres (15\%) de los estudiantes no respetan las opiniones de los demás al momento de trabajar en equipo y el 9 (75\%) de los mismos si, lo cual indica que el docente podría aplicar de manera asertiva las actividades grupales dando las indicaciones necesarias y monitoreando el desarrollo de los mismos, permitiéndoles enfrentar situaciones problémicas reales, en las que tengan que respetar las opiniones de cada uno.

Como conclusión general se aprecia disposición en los estudiantes y cierto dominio en el área curricular de Matemática, de los cuales dos (16.67\%) se encuentran en un nivel bajo de desarrollo de la competencia de resolución de problemas matemáticos, 7 (58.33\%) de los mismos se ubica en un nivel medio y tres (25\%) están en un nivel alto de desarrollo;

De los 12 estudiantes solo tres resolvieron los problemas de forma cuantitativa, en los problemas de razonamiento, a pesar de que 7 (58.33\%) están en el nivel medio, el desarrollo de la habilidad en la resolución de problemas es inferior al programa de la asignatura. Se constata que los docentes presentan deficiencias teóricas y metodológicas al dirigir el proceso de enseñanza -aprendizaje que le impide a los estudiantes desarrollar los conocimientos y las habilidades en la resolución de problemas del área de Matemática. Como se aprecia en la figura Nro. 1.

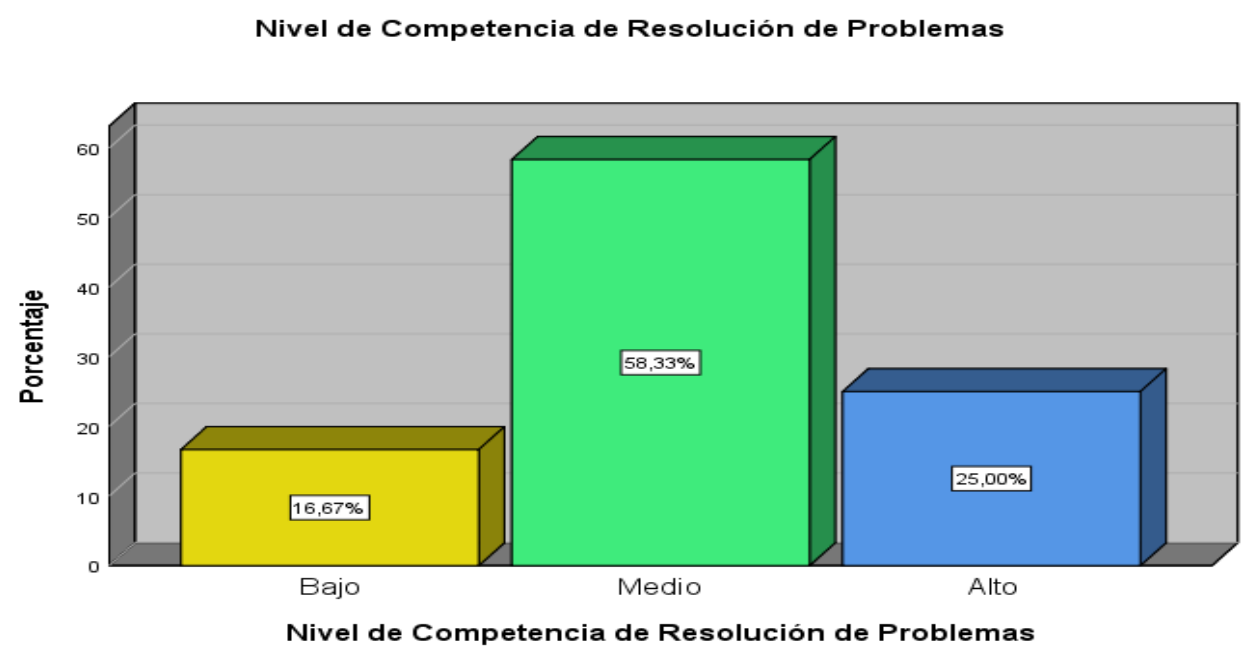

Figura 1. Resultado de la prueba pedagógica. Elaboración propia (2019). 


\section{Resultados de la encuesta aplicadas a los estudiantes.}

Se aplicó una encuesta a 12 estudiantes del V grado de Secundaria; sus resultados cuantitativos aparecen en el anexo 5 y en análisis de los resultados son los siguientes:

En cuanto a la satisfacción de los conocimientos adquiridos en la clase de Matemática, se evidenció que el uno (8.33\%) de los sujetos encuestados nunca se sienten lo suficientemente satisfechos, cinco (41.67\%) opinan que a veces y 6 (50\%) opinan que siempre. Este resultado, muestra que el docente no aplica una metodología activa, donde el estudiante aplique el contenido al contexto, permitiéndole concientizar con la asignatura.

Acerca de la capacidad que posee el estudiante para realizar demostraciones matemáticas se observó que 11 (91.67\%) expresan que a veces son capaces de realizar estos ejercicios y uno (8.33\%) de los mismos opina que siempre es capaz de realizarlo. Esto revela que el docente no está realizando de manera óptima las demostraciones en clase permitiendo un aprendizaje más reflexivo y analítico al estudiante.

En relación con la capacidad de discriminar información, se puede visualizar que 9 (75\%) de los encuestados a veces logran reconocer en un problema matemático cual es la información relevante para su solución, mientras que 3 (25\%) siempre lo reconocen. Esto demuestra, que los docentes poseen dominio teórico de la asignatura y son mediadores asertivos, esto habría que contrastarse con actividades vivenciales para poder hacer más real este proceso de resolución de problemas.

Por su parte, dos (16.67\%) de los encuestados nunca utiliza alguna representación gráfica al resolver problemas matemáticos, el 7 (58.33\%) a veces y el 3 (25\%) siempre revelando que la mayoría de estudiantes no se encuentra seguro al utilizar estos métodos, por ende se encuentran en proceso de desarrollo de esta estrategia de resolución de problemas, y que el docente debería tomar en cuenta para afianzar la seguridad en el estudiante, al momento de diseñar su estrategia para resolver problemas.

Acerca del uso de los términos apropiados al utilizar gráficas estadísticas se observa que uno $(8.33 \%)$ de los sujetos nunca considera la terminología, ni las reglas cuando utiliza gráficos estadísticos, el 7 (58.33\%) a veces y el cuatro (33.33\%) siempre utiliza de manera óptima la terminología evidenciando que existe una inseguridad en los estudiantes por utilizar los términos apropiados en referencia a procesos estadísticos. Esto se da como consecuencia de que el docente no realiza trabajos de campo, donde el mismo estudiante recoja los datos, procese la información y exponga sus resultados obtenidos mediante gráficos estadísticos.

Cuando se les consultó, sobre la consideración de diversos métodos o formas de resolver problemas, se pudo identificar que uno (8.33\%) de los estudiantes nunca lo 
considera, cuatro (33.33\%) a veces y 7 (58.33\%) siempre lo hace. Esto refleja que la mayoría de las estudiantes reflexiona y analiza la situación del problema para poder seleccionar la mejor estrategia, sin embargo, en la prueba pedagógica esto tuvo una contradicción pues los estudiantes aplican bien los algoritmos de los ejercicios similares a los vistos en clase, pero frente a ejercicios de razonamiento la mayoría no pudo contestarlo. Se aprecia que los alumnos solo resuelven problemas de un determinado tipo de resolución, más no son analíticos, ni reflexivos como producto de una enseñanza tradicionalista.

En cuanto a la motivación que tienen al resolver un problema matemático dos (16.67\%) de los encuestados sostienen que nunca se sienten motivados, cinco (41.67\%) a veces y 5 (41.67\%) siempre; A simple análisis, esto pudiera significar que hay un alto índice de motivación por el aprendizaje de la Matemática en el aula, pero si se contrasta con los resultados obtenidos de las guías de observación de clase, se podrá constatar que esta motivación es debida a que los docentes, padres de familia y alumnos que perteneces a la institución en análisis, tienen por objetivo el ingreso a la universidad mediante un examen tradicional de conocimientos en donde los docentes presionan al estudiante a que pueda memorizar las propiedades y fórmulas para la resolución de cierto tipo de preguntas.

Respecto a la práctica pedagógica realizada por el docente se puede observar que dos $(16.67 \%)$ de las personas encuestados expresan que el docente nunca promueve la reflexión del tema desarrollado en clase de Matemática con su aplicación a la vida diaria, mientras que el $8(66.67 \%)$ expresa que a veces lo realiza y dos (16.67\%) siempre. Esto manifiesta que la gran mayoría considera que el docente contextualiza los problemas, pero si se contrasta con la guía de observación, se puede percibir que la mayoría de los docentes no lo hace.

En lo referido a la promoción de la participación equitativa de los estudiantes al momento de realizar trabajos grupales, se identificó que tres (25\%) de los encuestados consideran que el docente nunca promueve la participación de todos, dos (16,67\%) opinan que a veces y 7 (58.33\%) que siempre; Aquí se puede observar que el docente tiene una buena práctica didáctica pero al contrastarlo con la guía de observación de clase y las entrevistas, se evidencia que el docente solo utiliza las preguntas respuestas como único medio de participación del estudiante, mostrando una carencia en la aplicación de métodos que fomenten una participación más activa en el estudiante, sin descuidar la equitativita.

Acerca de las actividades realizadas por el docente con el fin de reconocer las fortalezas y debilidades del aula sobre la resolución de problemas, se visualiza que cuatro (33.33\%) de los sujetos encuestados perciben que nunca se realiza este tipo de 
actividades, 7 (58.33\%) perciben que a veces y uno (8.33\%) siempre. Este resultado indica que a veces o nunca el docente muestra interés en conocer las fortalezas y debilidades del estudiante en el área de Matemática, y como también se puede visualizar en las guías de observación de clases y las entrevistas a los docentes, ellos están más centrados en que el estudiante memorice las fórmulas y la manera de resolución de ciertos tipos de ejercicios y problemas.

Sobre las actividades que se desarrollan en clase de Matemática, se identifica que uno (8.33\%) de los encuestados siente que estas actividades nunca son adecuadas para la resolución de problemas, dos (16.67\%) sienten que a veces son adecuadas y 9 (75\%) perciben que siempre son apropiadas. Asimismo, dos (16.67\%) manifiestan que los métodos presentados nunca contribuyen en su aprendizaje personal, tres (25\%) a veces y $7(58.33 \%)$ siempre. A pesar de que los docentes tienen un gran porcentaje de respaldo se constató con la observación de clase que solo realizan preguntas respuestas y que los estudiantes quienes han sido formados en su mayoría por una educación tradicional consideran como óptimo.

En cuanto al uso de situaciones problémicas, uno (8.33\%) de los encuestados expresa que el profesor nunca lo propone, 8 (66.67\%) expresa que a veces y tres (25\%) siempre. Esto revela que los docentes en su mayoría a veces presentan situaciones problémicas sin embargo al contrastarse con la guía de observación de clase y la entrevista a los docentes, se muestra que la concepción de situación problémica es referida a un problema complejo y no a un problema contextualizado ni necesariamente real en la mayoría de los casos.

Los resultados revelan que, cuatro (33.33\%) de los estudiantes manifiestan que el docente a veces muestra una conducta agradable y dinámica que permite interactuar en la clase de matemática con mayor facilidad y el 8 (66.67\%) manifiesta que siempre lo hace; Este resultado manifiesta, que el docente es muy asertivo y empático al realizar el proceso de enseñanza aprendizaje, debido a su amplia experiencia en la labor pedagógica.

En cuanto a la realización de trabajos grupales, uno (8.33\%) de los sujetos encuestados expresa que el profesor nunca realiza este tipo de actividades, seis $(50 \%)$ expresan que a veces y cinco (41.67\%) siempre. Este resultado muestra algo totalmente contradictorio a lo recogido en la entrevista a los docentes y a la guía de observación de clases, pues los docentes reconocen y evidencian no fomentar mucho este tipo de actividades por la falta de tiempo y por la complejidad que amerita el control y seguimiento a los estudiantes en este proceso.

Respecto a las actividades que el docente realiza donde se exige que aplique to aprendido en la clase, se identifica que uno (8.33\%) de los encuestados afirma que nunca 
se realiza, uno (8.33\%) a veces y 10 (83.33\%) afirman que siempre. Este resultado, debe entenderse con cuidado, pues los estudiantes entienden como actividades de aplicación a las pruebas escritas, practicas calificadas y exámenes diarios. Aquí se refleja una falta de manejo de otro tipo de evaluaciones, donde se valore lo formativo y cognitivo de manera armónica contribuyendo a una educación integral.

Los resultados revelan que, uno (8.33\%) de los estudiantes considera que el docente nunca reconoce los logros y procesos alcanzados en las diferentes actividades grupales desarrolladas en clase de matemática, el seis (50\%) manifiesta que a veces se reconoce los logros y cinco (41.67\%) siempre. Esto evidencia, que el docente reconoce los logros destacados por los estudiantes en el proceso de enseñanza aprendizaje, pero si se analiza con el respaldo de la guía de observación a clases y entrevistas, referencia a la nota vigesimal obtenida mediante una prueba escrita o en una exposición.

El análisis concluye con la afirmación de que se pudo comprobar que los estudiantes que asisten a esta institución educativa se sienten motivados únicamente por el afán de prepararse para un examen de conocimientos tradicional, y bajo el cual los docentes desarrollan una educación de este tipo, carente de métodos que orienten a desarrollar un pensamiento crítico, reflexivo, analítico mediante la resolución de problemas del área de Matemática.

Del mismo modo no se promueve las actividades colaborativas, investigativas, situaciones problémicas o trabajos de campo, que coloquen al estudiante como el protagonista de su propio aprendizaje debido al desconocimiento teórico y metodológico de los docentes, los cuales no reconocen los diferentes logros que pudieran alcanzar los estudiantes en las diferentes áreas, centrándose por el contrario únicamente en lo cuantitativo mediante una prueba escrita, como se aprecia en las figuras Nro. 2 y 3.

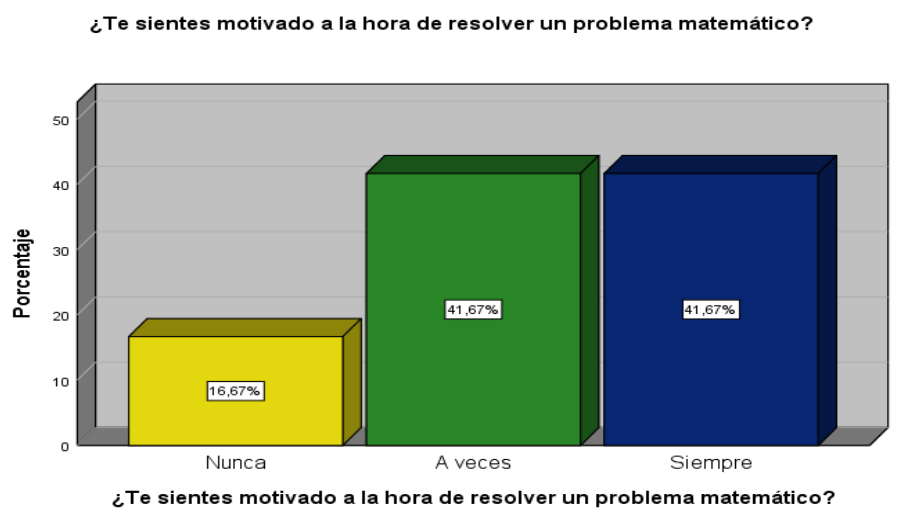

Figura 2. ¿Motiva resolver un problema matemático? Elaboración propia (2019). 


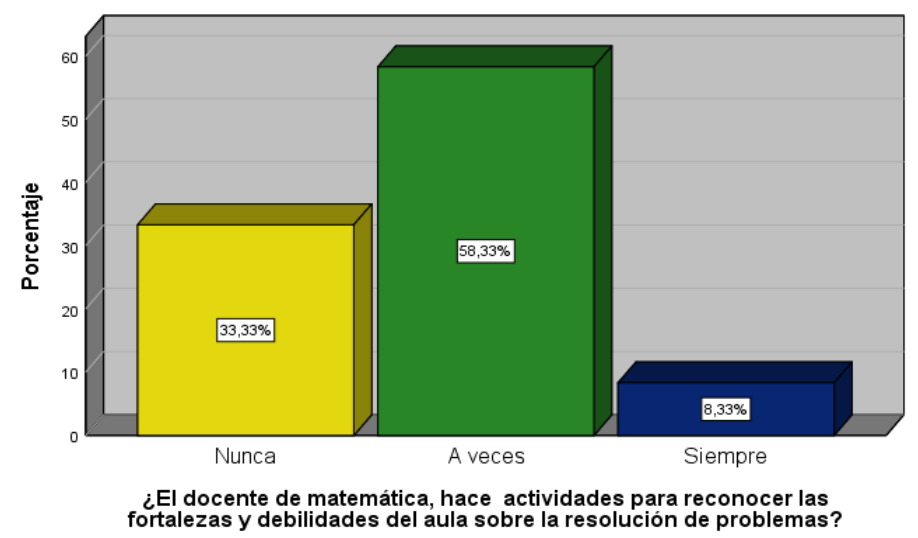

Figura 3. ¿El docente reconoce los logros del aula sobre la resolución de problemas? Elaboración propia (2019).

\section{Análisis e interpretación de las categorías emergentes}

Mediante el proceso de triangulación realizado a partir de la información obtenida de la sistematización teórica y la aplicación y procesamiento de los instrumentos, se pudo analizar los resultados del procedo de diagnóstico de campo, las discrepancias y coincidencias teóricas existentes y de las cuales se identificaron las categorías emergentes sustantivas o generales.

La figura Nro. 4 presenta las categorías emergentes sustantivas, resultantes del diagnóstico de campo.

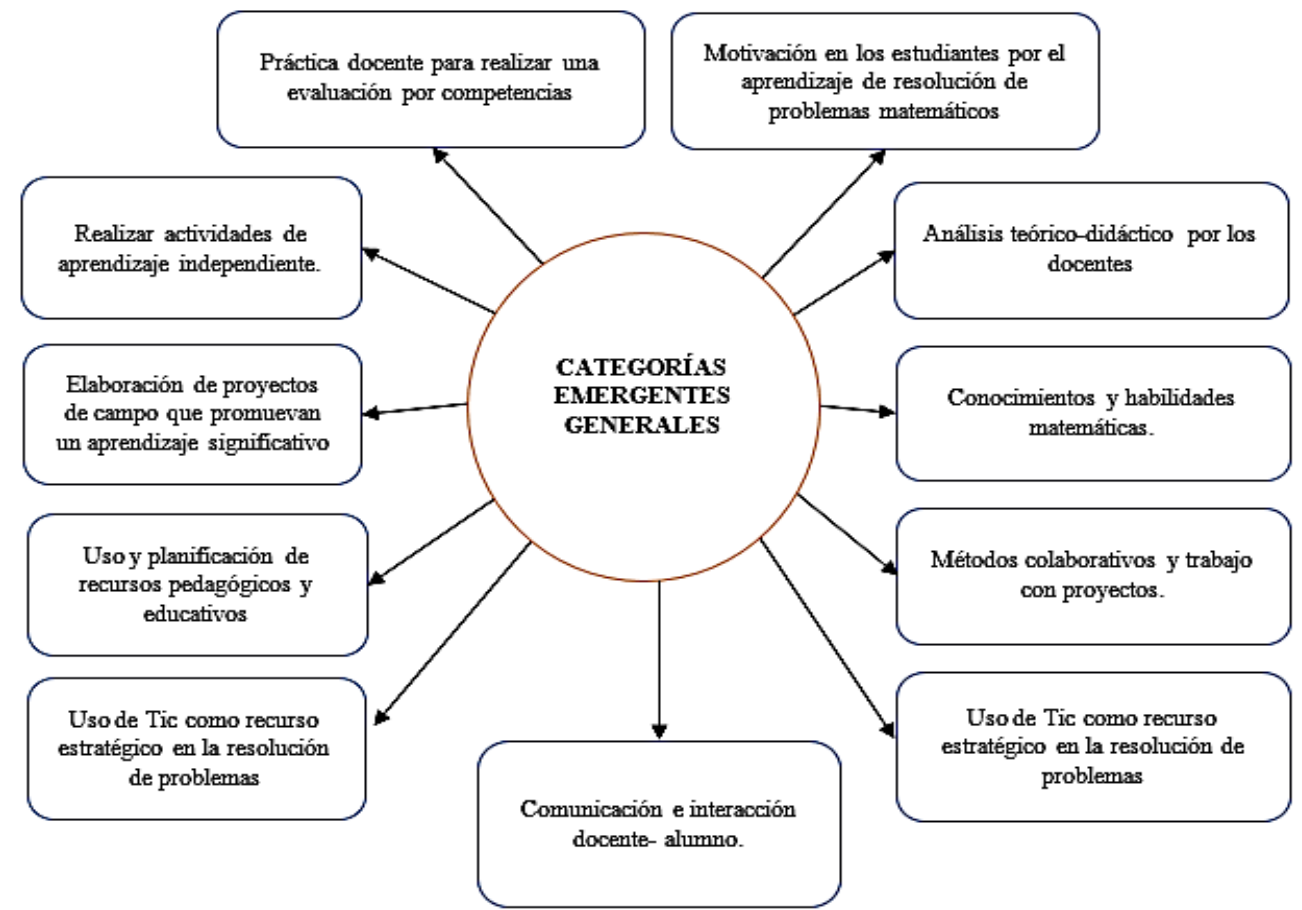

Figura 4. Presentación de las categorías emergentes. Elaboración propia (2019). 
A partir del análisis holístico realizado de las categorías emergentes generales encontradas durante el proceso de diagnóstico, se identificaron también las categorías emergentes que influyen en el problema de investigación: El desarrollo de la competencia de resolución de problemas de los alumnos es inferior a las exigencias curriculares del grado; Desmotivación en los estudiantes por el aprendizaje de resolución de problemas matemáticos y Deficiencias teórico didácticas en los docentes para dirigir la enseñanzaaprendizaje de la competencia, resolución de problemas.

A continuación, se presenta a modo de conclusión las categorías y subcategorías apriorísticas, y las categorías emergentes que influyen de manera negativa al problema objeto de la presente investigación.

Figura 5. Categorías apriorísticas y emergentes incidentes en el problema.

\section{Diagnóstico de campo}

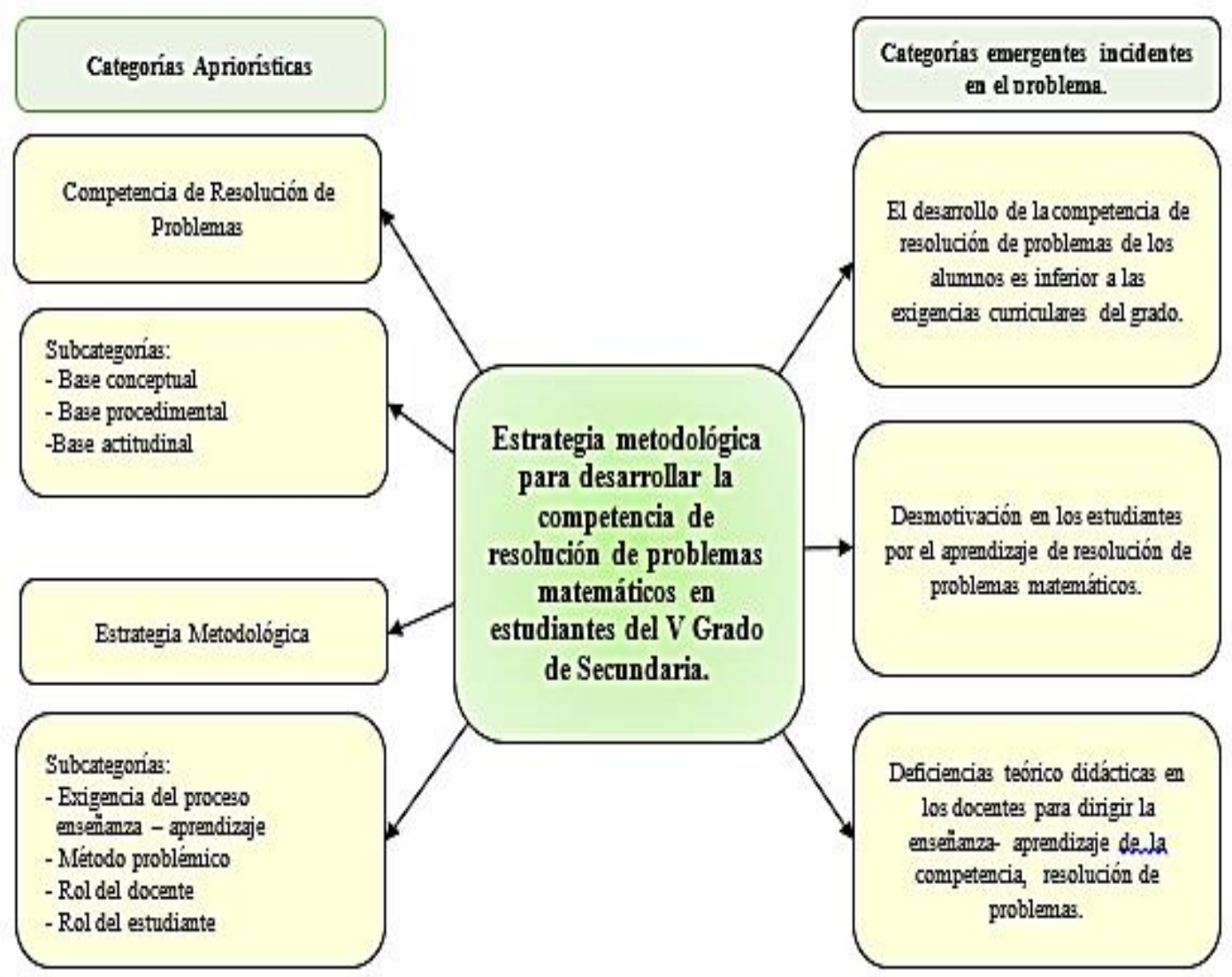

Elaboración propia (2019). 


\section{Relaciones analíticas e interpretativas entre datos y categorías emergentes}

A continuación, se realiza la Contrastación teórica de las categorías emergentes incidentes en el problema objeto de la investigación con sus referentes teóricos.

\section{El desarrollo de la competencia de resolución de problemas de los alumnos es inferior a las exigencias curriculares del grado.}

En el perfil de egreso del Currículo Nacional de educación Básica Regular (2016), se indica que los estudiantes deben demostrar capacidad para interpretar la realidad y proponer soluciones que beneficien a la sociedad en un ambiente de respeto mutuo, a partir de conocimientos matemáticos. Para ello, hacen uso de diversos métodos o estrategias de resolución de problemas aplicándolos a situaciones reales (económica, política y social), a partir de los cuales diseñan argumentos y expresan sus propuestas de solución usando el lenguaje matemático.

Como sostiene Cantoral (2013), el pensar de manera matemática, es un proceso complejo y dinámico de interacción de los factores cognitivos, afectivos, sociales y volitivos mediante los cuales se fomenta una conducta en los estudiantes para actuar y elaborar ideas que respondan a problemas de sus contextos. Por ello, en el proceso de enseñanza aprendizaje de la matemática los conocimientos del área son un medio más no el fin, como agregan Gravemeijer y Teruel (2000).

En contraste a esto, en la prueba pedagógica se demostró que el nivel de competencias, habilidades, conocimientos y actitudes están por debajo de las exigencias curriculares del área de matemática en el V Grado de Educación Básica Regular. A pesar de haber respondido bien, la mayoría de preguntas de cálculo matemático directo, en las preguntas contextualizadas que implicaban razonamiento y análisis, no lograron realizarlo, este análisis permite afirmar que el problema es la consecuencia de una enseñanza tradicional, que no utiliza metodologías activas, donde se promueva el análisis, la reflexión, el pensamiento crítico, la observación y el procesamiento del contenido, de forma que motive a construir un aprendizaje significativo, consiente e integral en los estudiantes.

\section{Desmotivación en los estudiantes por el aprendizaje de resolución de problemas matemáticos.}

Para Ausubel (1983), Bisquerra (2000), Castellanos et al. (2012), Díaz y Hernández (2002), Ortiz (2012), De Corte (2015), y Velázquez (2018), sostiene que la motivación es fundamental para poder realizar actividades que permitan a la persona adquirir nuevos conocimientos de manera más consiente y significativa, relacionando elementos de aprendizajes cognitivo, sociales y afectivos. Así mismo, cuando la motivación es reforzada 
de manera intrínseca y extrínseca, el individuo muestra mayor disposición para el desarrollo de actividades que implican perseverancia, sintiendo satisfacción al lograr alcanzar el objetivo propuesto.

Es por ello por lo que el docente debe estar capacitado teórico y metodológicamente para poder dirigir el proceso de enseñanza aprendizaje para fomentar un ambiente donde el estudiante participe de trabajos grupales, talleres y trabajos de campo sintiéndose valorado en cada logro alcanzado, siendo consciente de su aprendizaje de forma integral (saber ser, hacer y convivir).

En ese sentido, los instrumentos aplicados demostraron que los docentes carecen de referentes teóricos acerca de la motivación por el aprendizaje, lo cual fue evidenciado mediante las observaciones de clase y entrevistas realizadas a los docentes donde se condiciona al estudiante a aprender y mostrar disposición por la asignatura si desea obtener una calificación aprobatoria e ingresar a la universidad mediante un examen de admisión. Así mismo en la encuesta los estudiantes revelaron su preferencia por el desarrollo de trabajos grupales, pero que solo un docente realiza y de forma mínima, debido a la práctica de una enseñanza tradicional y la falta de una metodología que promueva y estimule el pensamiento reflexivo, analítico y crítico mediante trabajos colaborativos.

\section{Deficiencias teórico- didáctica en los docentes para dirigir la enseñanza - aprendizaje de la competencia, resolución de problemas.}

En la educación de hoy, es necesario desarrollar actividades que permitan trabajar juntos a estudiantes y alumnos en la construcción de los saberes a diferencia de los trabajos cooperativos, donde los estudiantes solo forman grupos con el objetivo de alcanzar un objetivo pedagógico propuesto por el docente, así mismo se debe proyectar estos trabajos de manera interdisciplinaria, que conlleve al estudiante a enfrentar distintas situaciones con el fin de que aplique lo aprendido de manera integral y transversal, para una mayor comprensión de la realidad.

En este punto, la didáctica para Álvarez (1997), Silvestre y Zilbertein (2002), Díaz y Hernández (2010), Pimienta (2012), Tobón (2013) y Addine et al. (2015), es un acto pedagógico que es direccionado por el docente, y cuyo objetivo es la formación integral del estudiante, el cual debe ser organizado, planificado, y evaluado durante todo el proceso de enseñanza aprendizaje, realizando actividades que permitan el análisis, la problematización e investigación del contenido, a partir de los saberes previos y la interacción de sus iguales, llevándolos a asumir un rol protagónico en la construcción de su aprendizaje. 
No obstante, en los resultados obtenidos de las entrevistas y observaciones de clase se identificó la utilización de una enseñanza tradicional donde se promueve el aprendizaje por repetición, el docente es el expositor y los estudiantes son los receptores, asumiendo un rol estrictamente pasivo.

Así mismo, se identificó la falta de preparación teórico y metodológica por parte de los docentes, para desarrollar otro tipo de actividades, alejándolos de la valoración de las áreas afectivas, volitivas y psicológicas mediante las prácticas sociales e interdisciplinarias, que conlleven al desarrollo de un pensamiento más reflexivo, crítico y analítico.

En este punto NCTM (2000) sostiene que una enseñanza eficaz implica conocer los saberes previos de los estudiantes y lo que necesitan aprender, para poder motivarlos a realizar un buen proceso de aprendizaje más significativo y real. Para tal fin el trabajo colaborativo es una actividad que permite maximizar el aprendizaje pero que implica mayor preparación del docente, como agrega Oropeza (2015).

\section{Conclusiones aproximativas de la investigación}

A partir del análisis realizado durante el proceso de investigación, se pudo constatar la desmotivación de los estudiantes hacia las clases de Matemática, debido a que el docente presenta deficiencias teórico didácticas al aplicar un aprendizaje por competencias, limitándose a realizar clases expositivas centradas solo en el desarrollo del contenido, generando un proceso de enseñanza aprendizaje pasivo para el estudiante y en donde no es el protagonista de la construcción de su aprendizaje, sino solo un repetidor de conocimiento y tomando como meta el examen tradicional de conocimientos para el ingreso a la universidad.

La carencia metodológica de los docentes para dirigir el proceso de enseñanza aprendizaje de manera integral, donde se potencia el área cognitiva, procedimental y actitudinal, se evidencia también en el nivel de razonamiento que poseen los estudiantes respecto de la resolución de problemas, pues es inferior a las exigencias curriculares en el área de matemática, al enfrentar problemas de reflexión y análisis de manera individual o grupal.

Los estudiantes consideran que la resolución de problemas es importante solo para el ingreso a una universidad, mediante el examen de admisión y nada más, mostrando el desconocimiento acerca de los beneficios de poder desarrollar la resolución de problemas como competencia y la aplicación a su vida diaria. Esto es debido a que hay una ausencia de elaboración de proyectos colaborativos e interdisciplinarios, que fomenten un análisis más crítico y reflexivo, en donde los estudiantes tengan que diseñar propuestas de solución 
ante problemas de su contexto, generando así mayor motivación por el aprendizaje en la resolución de problemas.

Por tanto, se concluye que a partir del análisis de los resultados obtenidos, se pudo identificar la dimensión del problema científico, las categorías emergentes sustantivas y las influyentes en el problema mediante el proceso de diagnóstico y la triangulación holística, a partir de las cuales se modela la estrategia metodológica propuesta para contribuir al desarrollo de la competencia de resolución de problemas matemáticos en los estudiantes del $V$ grado de Secundaria de una institución educativa de Lima. 


\section{Capítulo III}

\section{Modelación, validación y aplicación de la propuesta}

Como resultado del proceso de diagnóstico se realizó la triangulación de la información obtenida que permitió identificar las categorías emergentes que inciden en el problema investigado: El desarrollo de la competencia de resolución de problemas de los alumnos es inferior a las exigencias curriculares del grado; Desmotivación en los estudiantes por el aprendizaje de resolución de problemas matemáticos y Deficiencias teórico didácticas en los docentes para dirigir la enseñanza- aprendizaje de la competencia, resolución de problemas.

Tras analizarlas de manera integral se procedió a realizar la modelación de la estrategia didáctica, dirigida a transformar la problemática objeto de estudio.

\section{Propósito de la investigación}

El propósito de la estrategia metodológica propuesta se orienta a contribuir al desarrollo de la competencia de resolución de problemas del área de Matemática en los estudiantes del V grado de Educación Secundaria de una Institución educativa de Lima, mediante la elaboración de una guía de actividades a aplicar en el proceso de enseñanza- aprendizaje de Matemática.

\section{Fundamento socioeducativo.}

La estrategia metodológica está dirigida a los estudiantes del V grado de Secundaria del área curricular de Matemática de una institución educativa de Lima, ubicada en el distrito de San Martín de Porres. La institución es una empresa privada conformada por un inmueble de tres niveles y por 20 aulas docentes con un soporte material adecuado para el servicio educacional. La población estudiantil de Secundaria asciende a 60 alumnos, los cuales 12 ingresaron en el año 2019 y que reciben las asignaturas del área de Matemática como parte de la investigación.

Los estudiantes proceden de los distritos de Comas y San Martín de Porres; y en su mayoría de hogares en condiciones económicamente media baja, por lo que los padres de familia en su mayoría tienen que trabajar todo el día, desatendiendo muchas veces sus obligaciones para con la institución educativa y justificando a su hijo en el incumplimiento de sus responsabilidades por la desatención de los padres. También esto genera un cuadro de desorden alimenticio pues los estudiantes vienen a la institución sin desayunar y esperan al primer receso para poder comprar sus alimentos. Esto podría provocar la desatención las primeras horas de la mañana generando bajo rendimiento académico. 
La comunidad educativa la conforman cuatro directivos, el claustro está conformado por tres docentes especialistas del área y un coordinador general, encargado de velar por el control, la supervisión y el cumplimento de los objetivos previstos, aunque todos ellos revelan ausencia de preparación psicopedagógica al ser ingenieros que se dedicaron a la docencia, motivo por el cual no hay un eficiente desarrollo del proceso de enseñanzaaprendizaje de Matemática.

\section{Fundamentos sociológicos.}

La institución en una zona geográfica con alto índice de problemas sociales, como delincuencia, acumulación de basura en zona peatonal, difícil acceso a la institución y a su alrededor existen grandes empresas de manufactura que no permiten un buen desarrollo de sus pobladores.

Frente a este contexto social se hace necesario que los estudiantes sean adecuadamente orientados en la esfera cognitiva, volitiva y afectiva para desarrollar la competencia en la inteligencia emocional, la convivencia democrática y de resolución de problemas, para poder afrontar los problemas escolares, de su vida diaria a partir de un diagnóstico psicopedagógico para conocer las fortalezas y necesidades de los educandos interacción con las familias y otras personas la comunidad educativa.

Los docentes presentan deficiencias en la esfera pedagógica y las teorías de aprendizaje que les limita el desempeño eficiente del proceso de enseñanza- aprendizaje en cuanto a la aplicación de los métodos problematizadores y dialógicos que incidan en la asimilación, procesamiento y atención personalizada a los educandos para potenciar su formación integral.

\section{Fundamento psicológico.}

La edad de los estudiantes está entre los catorce a dieciséis años, los cuales se encuentran en desarrollo de sus facultades tanto físico, psicológico y biológico. Dichas características tienen que ser percibidas y reconocidas por los docentes con el objetivo de comprender y orientar de forma asertiva el proceso de enseñanza aprendizaje en los adolescentes, ya que se encuentran en plena búsqueda y reafirmación de su propia identidad.

Las potencialidades y deficiencias que manifiestan los estudiantes en la esfera psicológica, afectiva y volitiva del proceso biopsicosocial como parte de su desarrollo integral, fueron identificadas por el autor y constatadas mediante el diagnóstico psicopedagógico que evidencia la falta de motivación y predisposición por los estudios en el área de Matemática, de la mayoría de los estudiantes, al afirmar que preferirían realizar 
actividades donde ellos mismos sean los protagonistas y constructores de su aprendizaje y que la mayoría de docentes no realiza.

La propuesta metodológica diseñada considera los fundamentos de la psicopedagogía en relación al desarrollo de la personalidad, la motivación interés por el aprendizaje a partir de situaciones problémicas, mediante el uso de métodos de enseñanza que estimule el pensamiento crítico y la problematización con el fin de fortalecer el aprendizaje consciente y el desarrollo de la competencia de resolución de problemas desde la enseñanza problémica y en enfoque por competencias (Vygotsky, 1987; Martínez, 1999; Tobón, 2013; Arizaga, 2015; Fernández, y Aguado (2017 y Mora, 2017), entre otros investigadores revisados.

\section{Fundamento pedagógico.}

Se asume la Pedagogía como ciencia, que tiene como objeto de estudio, la formación y desarrollo integral de la persona para la vida que se logra a través de un proceso social en la medida que el sujeto transita por la institución educativa formal. Al respecto, afirma Pansza et al. (1987), Álvarez (1999), Peñaloza, 2004, Tobón, 2009 y Addine (2015) que la pedagogía es la ciencia de la educación que contribuye a través de un cuerpo teórico de ciencias afines a conducir la enseñanza- aprendizaje con el fin de potenciar el pensamiento, el lenguaje y la dimensión humana del estudiante de manera integral para su inserción en la sociedad y contribuir a su desarrollo.

La pedagogía se enriquece de diversas disciplinas como la sociología, la neuroeducación, la psicología, la filosofía, la historia de la educación y la antropología, entre otras, por ser una ciencia de carácter psicosocial que se orienta al desarrollo de la personalidad de forma integral del educando, como afirma Álvarez (1999), Peñaloza, (2004), González (2008), Sánchez (2010), Pimienta (2012), Rico et al. 2013 y Durán (2018).

La propuesta concibe el proceso de enseñanza- aprendizaje como el acto pedagógico organizado, planificado evaluado y dirigido por el docente con el fin de alcanzar los objetivos propuestos para la clase, mediante la interacción ente educandos y estudiantes en un ambiente de respeto, de comunicación asertiva y comprensión mutua, contribuyendo al desarrollo de forma integral (cognitivo, afectivo, emocional y volitivo) en los estudiantes, como afirman Álvarez (1999), Peñaloza (2004), Castellanos et al. (2007), Addine (2013) y Velázquez (2018).

Para dirigir, el proceso enseñanza- aprendizaje se asume lo dispuesto por Tobón (2015), en relación con el enfoque socio formativo por competencias, el cual fomenta el desarrollo de lo conceptual, procedimental y actitudinal del alumno al interactuar en la 
actividad. Es una enseñanza reflexiva proyectada mediante situaciones problémicas desde las experiencias y saberes personales a fin de socializarlos para generar un aprendizaje significativo en la se estimula el rol protagónico del estudiante.

Ello permite socializar ideas, colaborar y construir el autoconocimiento, y el docente es un mediador, guía eficiente que orienta a los estudiantes a alcanzar tal fin mediante el uso de diversos métodos de trabajos colaborativos que exijan mayor dificultad, promoviendo una formación integral a partir de la interacción social dentro de un contexto socio histórico (lengua, creencia, habilidades y destrezas).

\section{Fundamento del área de Matemática.}

La matemática es una actividad fundamental y única del ser humano que promueve el desarrollo del conocimiento y de la cultura acorde al contexto en que éstas están involucradas, por tanto, al estar en constante cambio y adecuación demandan más investigaciones en el campo científico y tecnológico, los cuales son fundamentales para el progreso integral del país.

Así también se requiere formar ciudadanos capaces de sistematizar, organizar, buscar y analizar información para un mejor entendimiento de su mundo y en base a ello puedan tomar decisiones que mejoren su entorno y resuelvan problemas de manera eficiente utilizando sus estrategias y conocimientos matemáticos.

En el Programa Curricular Nacional de Educación Básica (Minedu, 2016), se fundamenta la importancia del desarrollo de un enfoque basado en resolución de problemas en el área de Matemática, pues posibilita la comprensión e interacción del entorno natural o social de manera consiente y responsable.

Complementando esta posición Tobón (2018) argumenta cuatro características del proceso de resolución de problema matemáticos:

La modelización matemática: Expresa la estrecha relación que existe entre una didáctica basada en conceptos y otra en técnicas con el fin de analizar situaciones problémicas de la realidad. Así mismo se debe considerar como parte de esta etapa: el formular, el solucionar, el interpretar y el evaluar (Socas y Domínguez, 2016). Si luego de analizar y aplicar los nuevos conocimientos se varían las restricciones de algunas variables, esto conllevaría a comenzar un nuevo ciclo de modelación. Los aportes de esta práctica son: evalúa problemas reales, permite seleccionar las variables a considerar en el caso de estudio, fomenta el diálogo y el cuestionamiento en el proceso de la búsqueda de respuestas de forma simultánea. (López, Molina y Castro, 2017)

Desarrollo de procesos psíquicos superiores: Para hablar de aprendizaje es importante considerar las actividades que realiza el estudiante y las acciones que ésta 
demanda las cuales Desarrollo de procesos psíquicos superiores: Para hablar de aprendizaje es importante considerar las actividades que realiza el estudiante y las acciones que ésta demanda las cuales.

Desarrollo de procesos psíquicos superiores: Para hablar de aprendizaje es importante considerar las actividades que realiza el estudiante y las acciones que ésta debe demandar como: percibir, analizar, memorizar, sintetizar, contrastar, inducir, deducir, razonar lógicamente, abstraer, desarrollar la heurística y la metacognición con el objetivo de activar los procesos psíquicos de orden superior (Cabezas y Mendoza, 2016).

El problema y el contexto: Para poder llevar a cabo un aprendizaje donde el estudiante ponga en juego toda sus habilidades es necesario que enfrente situaciones en las que: identifique las necesidades, se sienta satisfecho al encontrar una respuesta debidamente argumentada, perciba sus logros en el proceso de búsqueda de solución, proponga diferentes alternativas de solución que impacten a su entorno y mediante la meta cognición identifique, discrimine, interprete, argumente y por ende resuelva una situación problemática con el nuevo conocimiento adquirido. Esto orientado con los trabajos colaborativos son una vía de formación integral para alcanzar el éxito y estimular el desarrollo cognitivo, procedimental, afectivo, y social en los educandos.

Los sub problemas auxiliares: Para hacer posible una asimilación consciente, y efectiva en los estudiantes es necesario organizar y presentar los contenidos de manera dinámica. Esto implica que afrontaran dificultades de menor a mayor complejidad con el fin de promover la interacción entre los agentes del proceso de enseñanza aprendizaje en la búsqueda de solución, lo cual exige en el docente el dominio teórico - práctico del tema a presentar (Gómez, Sanjosé y Solaz, 2016). Esto implica que, ante la necesidad de resolver un problema mayor, se debe descomponer en problemas auxiliares que permitan encontrar la solución buscada de manera sistemática y ordenada.

Sistemas de representación: Toda actividad Matemática debe desarrollarse en los aspectos: numéricos, algebraicos y gráficos de forma inseparable ya que propician un mejor ambiente de aprendizaje. Esto a su vez demanda el uso de la tecnología como: tablets, laptops, software educativo de pago o libre pues facilita la interacción entre dichos aspectos (Parada, Conde, y Fiallo, 2016).

\section{La metodología propuesta a aplicar en la resolución de problemas} matemáticos.

Para la resolución de problemas hay una diversidad de formas en el manejo del proceso pedagógico. A continuación, se detalla las fases consideras en la presente propuesta metodológica, las cuales fueron sistematizadas de los aportes de Tobón, González, 
Nambo, y Vázquez, 2015; y Valdez y Tobón 2018.

- Exposición de los problemas y productos a lograr

- Trabajo colaborativo

- Análisis de saberes previos

- Gestión y co-creación del conocimiento

- Contextualización y diagnostico

- Aplicación de la resolución de problemas

- Socialización del proceso de formación y abordaje del problema

\section{Fundamento curricular.}

Para el diseño de la estrategia metodológica propuesta, se toma en cuenta los principios educativos declarados en el DCN (Minedu, 2016) los cuales fueron definidos en la Ley General de Educación 28044 (Art. 8) y del Plan Nacional de Igualdad de Género (20122017), con el fin de orientar la labor docente para lograr alcanzar los objetivos trazados durante el proceso de aprendizaje de los estudiantes. Estos principios a su vez se sustentan en los referentes teóricos de las corrientes socio constructivistas del aprendizaje y estos son: Principio de calidad, de equidad, de ética, de democracia, de conciencia ambiental, de interculturalidad, de inclusión, de creatividad e innovación, de igualdad de género y de desarrollo sostenible.

Asimismo, los fines de la educación peruana son dos: Formar seres humanos que posean la capacidad de expresarse cultural, física, religiosa, espiritual, intelectual, ética, y afectiva, así como su afianzamiento de su integridad como persona y su inserción en la sociedad de manera adecuada en un ambiente de armonía y promoviendo una cultura de paz, respeto, inclusividad, solidaridad, tolerancia, democracia y justicia que consolide su identidad nacional y contribuya a la mejora continua de la calidad de vida impulsando el desarrollo sostenible del país, como plantea el Art. Nro. 9.

Por su parte, en el marco curricular (Minedu, 2016) se establece el perfil de egreso del estudiante del VII Ciclo de Educación Básica Regular, el cual se orienta a satisfacer las necesidades de los estudiantes, las necesidades nacionales y las demandas de un mundo globalizado, proponiendo una educación progresiva, motivadora, creativa e innovadora que permita desarrollar las diferentes habilidades, capacidades y competencias en los estudiantes y que promueva una comunicación afectiva, de respeto mutuo, un clima de seguridad, de confianza, de diálogo y debate; en donde se tomen decisiones como resultado de la interacción con otras personas a través de trabajos cooperativos que contrastan su realidad. Con este objetivo es que el estudiante debe ser considerado el eje principal del proceso educativo (Addine, 2004; Tobón, 2013 y Mora, 2017). 
Los contenidos curriculares a desarrollar en las diversas asignaturas deben potenciar un aprendizaje significativo que relacione el nuevo aprendizaje con el ya adquirido, para esto utiliza diversos métodos como: los problémicos, investigativos y heurísticos, tomando en cuenta tres aspectos fundamentales: el conceptual, procedimental y aptitudinal (Silvestre y Zilbertein, 2002; Díaz-Barriga, 2010 y Tobón, 2013).

Para una mejor comprensión de cómo se integran estos principios y fundamentos curriculares, se definen cuatro factores claves en la práctica pedagógica que se debe tener en cuenta: competencias, capacidades, estándares de aprendizaje y desempeño. Así mismo, para lograr que estos contenidos curriculares, logren desarrollar un aprendizaje significativo

Para una mejor comprensión de cómo estos aspectos curriculares se integran, se representa a continuación, la dosificación de una Unidad Didáctica número I de la asignatura de Matemática para el $\mathrm{V}$ grado de Secundaria, con el objetivo de que sirva como ejemplo del cómo proceder metodológicamente en el uso de las habilidades investigativas y la aplicación de los métodos sugeridos (ver Tabla 2). 
Tabla 2

Dosificación del sistema de clase correspondiente a la unidad I.

\begin{tabular}{|c|c|c|c|c|c|c|}
\hline $\begin{array}{l}\text { Sesión de } \\
\text { aprendizaje }\end{array}$ & Competencias & Capacidades & Método & Conocimientos y contenidos & Indicadores y evaluación & Valores \\
\hline $\begin{array}{l}\text { Sesión 1: } \\
\text { Razonamiento } \\
\text { lógico }\end{array}$ & $\begin{array}{l}\text { Permite al estudiante el } \\
\text { desarrollo de habilidades de } \\
\text { abstracción y organización } \\
\text { de información, para dar } \\
\text { soluciones prácticas en su } \\
\text { vida profesional basado en el } \\
\text { planteamiento y resolución } \\
\text { de ecuaciones. }\end{array}$ & $\begin{array}{l}\text { Organiza datos a } \\
\text { partir de vincular } \\
\text { información } r \text { en } \\
\text { situaciones cotidianas } \\
\text { y lo expresa } \\
\text { matemáticamente. }\end{array}$ & $\begin{array}{l}\text { Método crítico. } \\
\text { Método creativo. } \\
\text { Método de } \\
\text { aprendizaje social. }\end{array}$ & $\begin{array}{l}\text { Interpreta la relación de días de la } \\
\text { semana colocándolos en una recta } \\
\text { numérica y lo matematiza. } \\
\text { Interpreta la relación de } \\
\text { parentesco existente en un } \\
\text { determinado contexto y lo expresa } \\
\text { mediante uso de organizadores } \\
\text { visuales. }\end{array}$ & $\begin{array}{l}\text { Redacta enunciados y otros } \\
\text { problemas matemáticos de } \\
\text { forma clara y con el mínimo } \\
\text { de errores. }\end{array}$ & Responsabilidad \\
\hline $\begin{array}{l}\text { Sesión 2: } \\
\text { Planteo de } \\
\text { ecuaciones }\end{array}$ & & $\begin{array}{l}\text { Diseña y ejecuta un } \\
\text { plan orientado a la } \\
\text { investigación } \\
\text { resolución } \\
\text { problemas }\end{array}$ & $\begin{array}{l}\text { Método crítico Método } \\
\text { búsqueda parcial. } \\
\text { Método de la } \\
\text { exposición } \\
\text { problémica. }\end{array}$ & $\begin{array}{l}\text { Interpreta del lenguaje verbal a } \\
\text { lenguaje matemático, mediante el } \\
\text { uso de diversos métodos de } \\
\text { resolución de problemas }\end{array}$ & $\begin{array}{l}\text { Coopera mediante el trabajo } \\
\text { en grupo para la resolución } \\
\text { de problemas. }\end{array}$ & Cooperación \\
\hline $\begin{array}{l}\text { Sesión 3: } \\
\text { Distribución } \\
\text { numérica }\end{array}$ & $\begin{array}{l}\text { Comprende los diversos } \\
\text { métodos de resolución de } \\
\text { problemas que le ayudarán } \\
\text { en su práctica laboral, } \\
\text { identificando y analizando } \\
\text { para ello las relaciones }\end{array}$ & $\begin{array}{l}\text { Razona y argumenta } \\
\text { sobre operaciones } \\
\text { matemática básicas } \\
\text { generando nuevas } \\
\text { relaciones } \\
\text { matemáticas. }\end{array}$ & $\begin{array}{l}\text { Método crítico } \\
\text { reflexivo de } \\
\text { Método docial. } \\
\text { aprendizaje so } \\
\text { Método creativo. }\end{array}$ & $\begin{array}{l}\text { Identifica las relaciones } \\
\text { matemáticas existentes entre } \\
\text { varios numerales, trabajando en } \\
\text { grupos de } 4 \text { estudiantes. }\end{array}$ & $\begin{array}{l}\text { Justifica y comunica las } \\
\text { relaciones } \\
\text { encontradas. }\end{array}$ & Soli \\
\hline $\begin{array}{l}\text { Sesión 4: } \\
\text { Inducción } \\
\text { deducción }\end{array}$ & $\begin{array}{l}\text { existentes entre los datos y } \\
\text { generando diversas hipótesis } \\
\text { hasta llegar a una conclusión. }\end{array}$ & $\begin{array}{l}\text { Induce } 0 \text { deduce } \\
\text { propiedades } \\
\text { generales del arreglo } \\
\text { de datos y elabora }\end{array}$ & $\begin{array}{l}\text { Método de } \\
\text { exposición. } \\
\text { problémica. } \\
\text { Método crítico. }\end{array}$ & $\begin{array}{l}\text { Interpreta y determina las } \\
\text { relaciones existentes entre un } \\
\text { ordenamiento específico de datos }\end{array}$ & $\begin{array}{l}\text { Reconoce datos y relaciones } \\
\text { no explicitas en situaciones } \\
\text { duales y relativas, al expresar }\end{array}$ & Compromiso \\
\hline
\end{tabular}




\begin{tabular}{|c|c|c|c|c|c|c|}
\hline & & $\begin{array}{l}\text { predicciones basado } \\
\text { en su análisis. }\end{array}$ & Método de proyecto. & $\begin{array}{l}\text { mediante el uso de algoritmos } \\
\text { matemáticos. }\end{array}$ & $\begin{array}{l}\text { un modelo usado números } \\
\text { enteros y sus operaciones }\end{array}$ & \\
\hline $\begin{array}{l}\text { Sesión 5: } \\
\text { Lógica } \\
\text { proposicional }\end{array}$ & $\begin{array}{l}\text { Evalúa la veracidad de la } \\
\text { información recibida, } \\
\text { mediante diversos métodos } \\
\text { de orden de información } \\
\text { como la lógica proposicional } \\
\text { o tablas de doble entrada, los } \\
\text { cuales servirán para }\end{array}$ & $\begin{array}{l}\text { Interpreta } \\
\text { expresiones } \\
\text { simbólicas de los } \\
\text { conectivos lógicos. }\end{array}$ & $\begin{array}{l}\text { Método crítico. } \\
\text { Método de la } \\
\text { exposición } \\
\text { problémica. } \\
\text { Método Investigativo. } \\
\text { Método de } \\
\text { aprendizaje social. }\end{array}$ & $\begin{array}{l}\text { Determina correctamente las } \\
\text { proposiciones moleculares } \\
\text { identificando si es Tautología, } \\
\text { Contradicción o contingencia de } \\
\text { acuerdo a los valores de verdad } \\
\text { obtenidos en las respuestas } \\
\text { cuando trabajan en pares. }\end{array}$ & $\begin{array}{l}\text { Interpreta } \\
\text { simbólicas al elaborar las } \\
\text { tablas de verdad de } \\
\text { proposiciones moleculares } \\
\text { con el menor error posible }\end{array}$ & Tolerancia \\
\hline $\begin{array}{l}\text { Sesión 6: } \\
\text { Ordenamiento } \\
\text { de información }\end{array}$ & $\begin{array}{l}\text { establecer de manera } \\
\text { adecuada la información a } \\
\text { presentar en cualquier } \\
\text { ámbito requerido. }\end{array}$ & $\begin{array}{l}\text { Maneja información, } \\
\text { procesa y elabora una } \\
\text { conclusión }\end{array}$ & $\begin{array}{l}\text { Método de la } \\
\text { exposición } \\
\text { problémica. } \\
\text { Método crítico. } \\
\text { Método de } \\
\text { aprendizaje social. }\end{array}$ & $\begin{array}{l}\text { Aplica las propiedades y métodos } \\
\text { de resolución para el } \\
\text { ordenamiento de información } \\
\text { mediante el uso de tablas de doble } \\
\text { entrada o gráficos circulares. }\end{array}$ & $\begin{array}{l}\text { Organiza y representa la } \\
\text { información de manera lineal } \\
\text { o circular según sea el caso. }\end{array}$ & Perseverancia \\
\hline
\end{tabular}

Elaboración propia (2019). 
El sistema de clases de la unidad analizada se planifica a partir de los sustentos teóricos referidos y en donde se integra dialécticamente los contenidos conceptuales, procedimentales y actitudinales, en el proceso de enseñanza - aprendizaje de la asignatura del área de Matemática.

Para ello deberá aplicar el diagnóstico pedagógico, tener en cuenta las fortalezas y las carencias para proyectar los métodos problémicos, investigativo, heurístico, creativos y dialógicos para estimular el desarrollo del educando a fin de transitar de la dependencia a la independencia cognoscitiva y práctica en la solución de los problemas como se expresa en el esquema teórico funcional que representa las relaciones de coordinación y subordinación lógica e interna que se concretan en la propuesta modelada como producto teórico- práctico del proceso de investigación. 


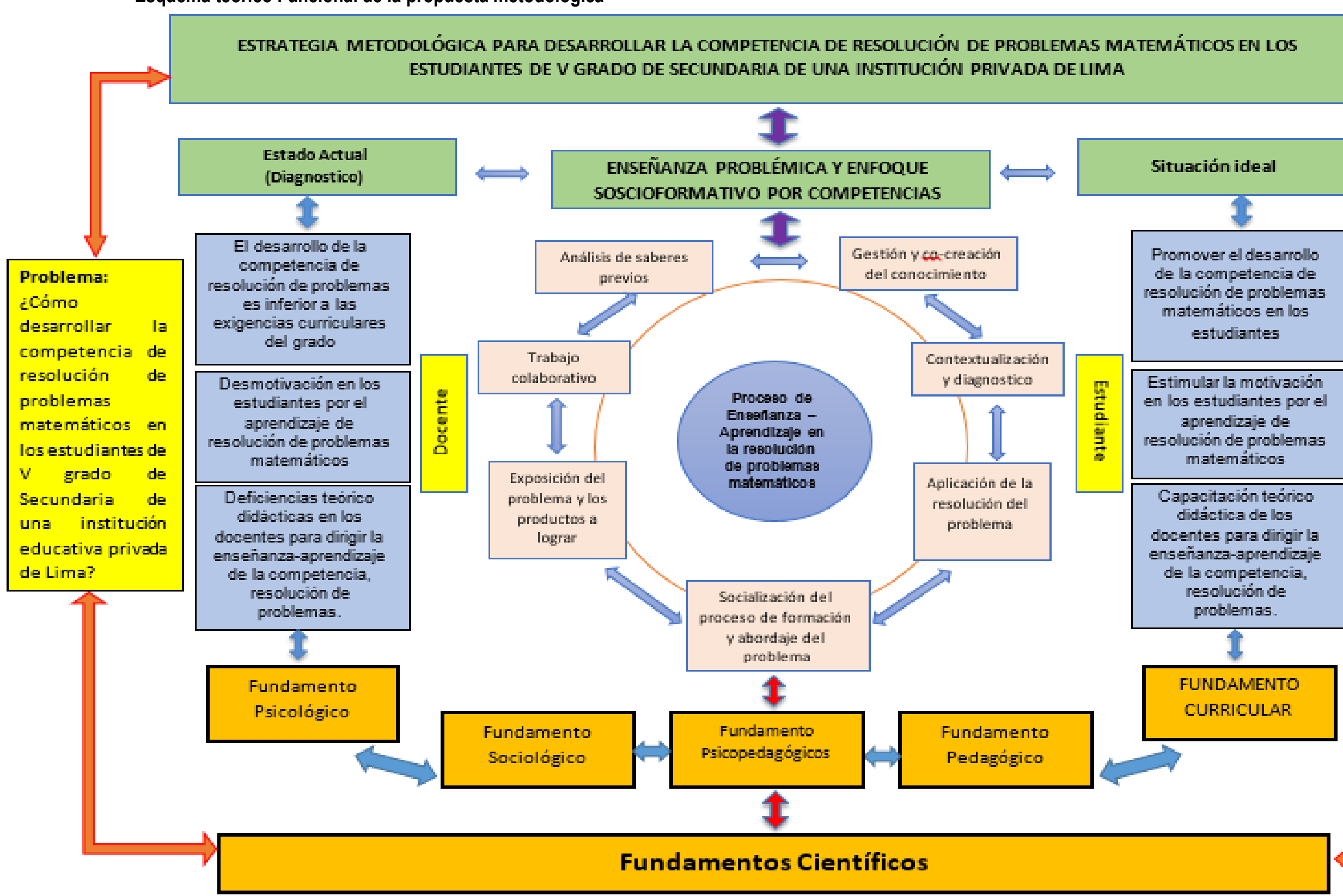

Figura 6. Esquema teórico-funcional de la aplicación de la estrategia metodológica. Elaboración propia (2019). 


\section{Explicación del esquema teórico -funcional que representa la propuesta.}

El esquema teórico - funcional presenta la dinámica interna, de forma abierta y transversal del problema estudiado en la investigación, con el objetivo de orientar a la solución a través de la propuesta metodológica. Para el diseño de la modelación, se partió de la categoría apriorística: competencia de resolución de problemas la cual se desarrollará mediante los contenidos de la asignatura de Matemática y que involucran la participación de los estudiantes y del profesor como guía y mediador del proceso de enseñanza aprendizaje.

Para tal fin, se partió del diagnóstico de campo realizado, donde se pudo constatar dos resultados generales: Desmotivación en los estudiantes por el aprendizaje de resolución de problemas matemáticos, Deficiencias teórico didácticas en los docentes para desarrollar un aprendizaje por competencias en la resolución de problemas matemáticos, de cuyo proceso emergieron las siguientes subcategorías, nivel de análisis y razonamiento inferior a las exigencias curriculares en el área de matemática y ausencia de elaboración de proyectos colaborativos e interdisciplinarios, que serán resueltos a través de la propuesta.

\section{Desarrollo e implementación de la propuesta}

El aporte de propuesta metodológica se sustenta en las bases científicas de la Pedagogía, la cual considera el acto de enseñanza - aprendizaje como un proceso estructurado, ordenado, planificado, organizado, controlado y guiado por principios, categorías y leyes didácticas. En la propuesta diseñada se toma en cuenta los principios didácticos planteados por Martinez (1999), Chávez (2002), Minedu (2009), Díaz y Hernández (2010), De la Herrán (2011), Addine et al. (2015), Tobón (2015) y Arizaga (2015) los cuales fueron contextualizados al objeto de la presente investigación para orientar al docente a lograr sus objetivos propuestos en el aprendizaje, como se muestra a continuación:

\section{Principio del carácter científico.}

El carácter científico se basa en la verdad teórica del contenido de la enseñanza. La estrategia metodológica se fundamenta en la falta de desarrollo de un aprendizaje significativo por parte de los estudiantes, en el área de Matemática, expresada en los resultados de cada instrumento durante la etapa de diagnóstico. Por lo que se propone desarrollar de manera integral las diversas competencias, capacidades, habilidades y destrezas de la persona mediante la implementación de una didáctica que genere el pensamiento reflexivo, analítico, interpretativo, aplicativo y asimilativo de los nuevos conocimientos en un entorno donde el estudiante es el protagonista de la construcción de su propio aprendizaje. 


\section{Principio de sistematización de los contenidos.}

Los contenidos deben ser expuestos de una forma organizada, secuencial y coherente con el objetivo de contrastar el conocimiento actual con el nuevo conocimiento generando un aprendizaje significativo en el estudiante.

\section{Principio de la activación de conocimientos y experiencias previas.}

Este principio debe tomarse en cuenta al momento de iniciar el proceso de enseñanza aprendizaje, ya que para que el nuevo conocimiento sea más productivo y genere mayor interés en los estudiantes, este debe estar asociado a los saber previos del estudiante respecto del tema a desarrollar en el área de Matemática.

\section{Principio del vínculo teórico - práctico.}

Con el objetivo de desarrollar un aprendizaje significativo en los estudiantes, es necesario realizar actividades que impliquen la aplicación de los contenidos a la realidad, para ello el docente crea las condiciones necesarias, para su contextualización en tiempo y espacio juntamente con los estudiantes en referencia al tema de estudio del área de Matemática.

Principio de la asequibilidad. Las estrategias didácticas y los recursos para utilizar durante el proceso de enseñanza- aprendizaje deben ser claros, asequibles y muy bien orientadas las acciones de igual forma para todos los estudiantes comprendan el qué y cómo realizar las actividades desde las más simple a las más complejas.

Principio del carácter audiovisual. Aquí se establece que los contenidos deben ser elaborados y expresados utilizando diversos organizadores visuales como mapas mentales, conceptuales, esquemas gráficos que permitan jerarquizar e interrelacionar la información de una manera más efectiva.

Principio de atención a las diferencias individuales. En el desarrollo del proceso de enseñanza aprendizaje es necesario que el docente esté capacitado y dispuesto a atender a cada una de las dificultades particulares de cada estudiante generando un ambiente ameno donde se presenta una buena relación entre el docente y el estudiante.

Principio de la participación. La enseñanza docente requiere la utilización de métodos en donde se fomente la motivación por el aprendizaje mediante la participación del estudiante en todo momento, desde el recojo de saberes previos y hasta la elaboración de productos aplicativos a su realidad, por ello se plantean el uso de trabajos colaborativos, proyectos interdisciplinarios y trabajos grupales. 
Principio de los contenidos aprendidos significativamente. Para fomentar un aprendizaje más consiente en los estudiantes se requiere que los docentes planifiquen, ejecuten y evalúen una didáctica consistente, orientada a desarrollar un aprendizaje por descubrimiento mediante el uso de diversos métodos donde el estudiante ponga en juego sus competencias, capacidades, habilidades, destrezas y actitudes de forma integral.

Los principios didácticos considerados para la propuesta metodológica contribuyen a la organización, planificación y elaboración del proceso de enseñanza- aprendizaje a partir de la didáctica problémica, a través de la cual busca que los estudiantes asimiles los conocimientos de una manera más consciente, crítica, reflexiva y significativa.

Etapas de la estrategia metodológica. La estrategia metodológica modelada se orienta al proceso pedagógico del área de Matemática la cual es impartida a los estudiantes del $\mathrm{V}$ grado de secundaria, fortaleciendo el desarrollo cognitivo, procedimental y axiológico de manera integral desde la didáctica problémica y el enfoque socioformativo. Para su aplicación en la práctica, se proponen cinco etapas:

Primera etapa. Abarca la definición de la misión de la estrategia, del objetivo y de sus participantes para así establecer sus dos líneas de acción: una orientada al desarrollo de la competencia de resolución de problemas en los estudiantes y la otra para la capacitación de los docentes.

Segunda etapa. Reunión con el colectivo pedagógico para mostrar los resultados del diagnóstico de campo, producto de la investigación realizada, así como también las fortalezas y carencias con el fin de obtener sus propuestas que serán escuchadas y valoradas con el fin de persuadirlos y concientizarlos acerca de la necesidad de una variación en su práctica pedagógica a partir del planteamiento de los objetivos planteados en la estrategia modelada orientada a desarrollar la competencia de resolución de problemas matemáticos de los estudiantes los cuales necesitan recibir una formación acorde a las exigencias actuales que les permita enfrentar y dar solución a los problemas individuales y sociales. Para ello se requiere realizar una reunión con los docentes del área, informar sobre el diagnóstico actual y analizar los documentos normativos vigentes del Ministerio de Educación para Educación Secundaria.

Tercera etapa. Abarca al conjunto de actividades y acciones que harán posible el cambio. Ello exige la realización de talleres teórico-prácticos y comunidades de aprendizaje que fundamenten los enfoques teóricos y los momentos del proceso metodológico de la actividad de aprendizaje para fomentar: el desarrollo del pensamiento creativo, analítico, reflexivo e innovador frente a situaciones problémicas mediante el diseño de 
procedimientos y estrategias de solución obtenidas de la aplicación de sus conocimientos previos y de la interacción con sus compañeros auto valorándose y autorregulando su conducta y sus emociones. Esta etapa involucra: la fundamentación teórico-metodológica de la propuesta, de la unidad didáctica modelada y la capacitación didáctica-metodológica de los docentes.

Cuarta etapa. Instrumentalización del sistema de acciones de orden teórico, práctico, didáctico y metodológico orientadas a mejorar el desempeño docente del área en estudio y el uso de estrategias, métodos, recursos materiales, valores morales, formas de evaluación, tipo de actividad o tarea de aprendizaje a realizar en cada unidad; y la dosificación y distribución del sistema de clases con el fin de contribuir a la formación integral de los estudiantes con relación a la resolución de problemas.

Quinta etapa. Aplicación y validación del impacto originado con la aplicación de la estrategia metodológica en el proceso de enseñanza- aprendizaje para contribuir al desarrollo de la competencia de resolución de problemas matemáticos en los estudiantes del V grado de Secundaria. A continuación, se presenta la lógica expuesta del contenido de las etapas dela aplicación de la estrategia.

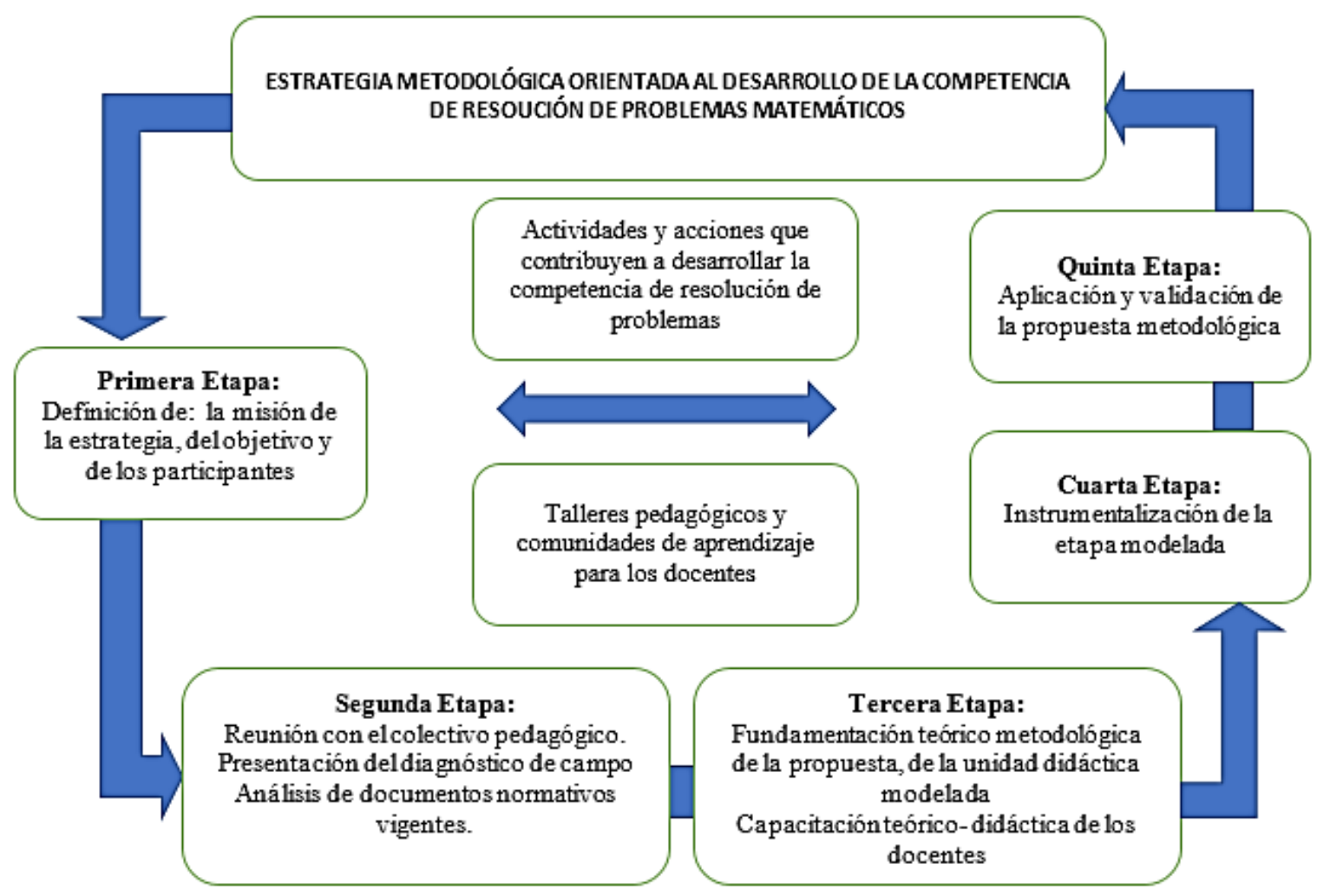

Figura 7. Etapas que conforman la estratega metodológica diseñada. Fuente: Elaboración propia (2019). 


\section{La propuesta ha sido modelada desde la dinámica de la didáctica problémica.}

Se asume la didáctica problémica que valora el enfoque histórico cultural de los agentes participantes del proceso enseñanza aprendizaje con el objetivo de provocar situaciones problemáticas que generen contradicciones en los estudiantes en el plano afectivo, valorativo y volitivo, a fin de desarrollar instrumentos mentales y sistemas operacionales que faciliten la obtención de una solución. Arizaga (2015).

La enseñanza problémica es la base de un sistema didáctico que permite al docente organizar situaciones problémicas, plantearlas al estudiante y construir de forma creativa, colaborativa y significativa caminos de solución de manera sistemática y organizada, como afirman Bravo Salinas (1997), Leyva, Folgueira y Córdova (2005), Hernández (2008).

Desde esta perspectiva el modelo propuesto se sustenta en los aportes de Vygotsky (1987), González (2003), Castellanos et al. (2007), Crispín et al. (2011) y Mora (2017) que han sido sistematizados por Díaz y Hernández (2010), Pimienta (2012), Arizaga (2015) y Norabuena (2015) en cuanto al proceso de enseñanza aprendizaje fomentando una comunicación asertiva, reflexiva y dialógica con carácter investigativo para la resolución de problemas en función de su formación integral de los estudiantes. Este modelo connota las siguientes categorías.

La categoría problema. Es considerado como punto de partida la contradicción que se genera en el estudiante al no poder tener la capacidad de resolver con sus saberes previos una situación desconocida para él, debiendo interactuar con sus compañeros o docentes durante el proceso investigativo para la construcción de la solución. Esto, contribuirá en el desarrollo integral del educando, facilitando un aprendizaje más significativo y controlado de los procedimientos lógicos mentales necesarios para la resolución del problema tratado. Asimismo, el rol del docente en esta categoría será el de guiar las actividades hacia el desarrollo cognitivo, procedimental y aptitudinal de manera consiente en los estudiantes deviniendo en mejoras para su entorno social y ambiental. En la propuesta, el problema es la desmotivación en los estudiantes por el aprendizaje de resolución de problemas matemáticos.

La categoría objetivo. Se establece a partir de la identificación del problema: la desmotivación en los estudiantes por el aprendizaje de resolución de problemas matemáticos y teniendo como meta revertir dicho resultado a través de la modelación de la situación deseada, sin desconocer las acciones a realizar durante el proceso de enseñanza aprendizaje.

Los objetivos considerados como logros a alcanzar deben ser orientados y tratados de manera integral, por ello comprende tres áreas principales: 
El aspecto cognitivo, es todo lo relacionado a los contenidos, competencias y habilidades de la asignatura a desarrollar.

El aspecto procedimental, es lo referido a la aplicación del conocimiento para la obtención de la solución de las situaciones problémicas del área de Matemática de forma integradora, a partir de sus saberes previos y construyendo el vínculo con los nuevos saberes, mediante diversas actividades propuestas por el docente en el acto pedagógico.

El aspecto afectivo - valorativo, contempla los sentimientos, las actitudes, los intereses y los valores necesarios para un desarrollo personal, profesional y social.

Estas áreas interactúan entre si durante el proceso de enseñanza aprendizaje con el fin de lograr en los estudiantes una formación Integral, Tobón (2017).

La categoría contenida. En la propuesta, se considera al contenido como parte de la cultura que se organiza y sistematiza de manera que involucra el pensamiento, las actitudes, los sentimientos y los valores intrínsecos y sociales, los cuales son seleccionados previamente para orientar el proceso pedagógico del área de Matemática hacia una formación integral en el estudiante acorde a los intereses y necesidades de su contexto, Castellanos et al. (2007), Díaz y Hernández (2010), Addine (2013) y Tobón (2017).

La concepción del contenido desde esta perspectiva exige al docente una profunda preparación teórica y metodológica en el área de Matemática para potenciar una formación escolar en donde se promueva la sustentación de la parte conceptual, procedimental y actitudinal del tema revisado en clase, mediante el uso de métodos y procedimientos creativos y socio formativos estimulando el interés y la motivación por el aprendizaje en la resolución de problemas matemáticos. Para ello se debe considerar los pilares de la educación propuestos por Delors (1996).

La categoría método de enseñanza. El método de enseñanza está constituido por las actividades y operaciones que los docentes y estudiantes realizan durante el proceso pedagógico a fin de alcanzar los objetivos propuestos para la clase. Es de carácter sistémico y dinámico, guiado por el docente, por lo que su selección, adaptación y ejecución fomenta un ambiente agradable de interacción entre el estudiante, el docente y el grupo, analizando y aplicando operaciones, procedimientos, técnicas y acciones que contribuyan a encontrar soluciones a situaciones problémicas variadas; garantizando así un aprendizaje más significativo de la resolución de problemas matemáticos de forma individual y grupal,

En la propuesta se consideran métodos diversos, como: el problémico, el investigativo, el heurístico, el creativo y el crítico, los cuales toman como referentes teóricos 
a Vygotsky (1987), Álvarez (2013), Polya (1982), Tobón (2013), Valdés (2015) y Arizaga (2015).

La categoría medios de enseñanza o recursos materiales. Son aquellos que facilitan la interacción del proceso de enseñanza, brindando el soporte material y haciendo posible alcanzar los objetivos trazados en la clase. Así mismo la inserción de estos medios de enseñanza en la organización, planificación y aplicación de la sesión de clase requiere un dominio profundo por parte del docente en relación al recurso seleccionado para contribuir en la asimilación y comprensión de la información, potenciación del pensamiento abstracto, creativo, crítico, investigativo y productivo; y adquisición de procesos mentales superiores que permitan asumir diferentes posturas del tema tratado.

Para la propuesta, los medios utilizados son: libros digitales, audiovisuales, multimedia, fichas didácticas, libros físicos, gráficos estadísticos, entre otros.

La categoría evaluación. Como parte del proceso educativo, permite controlar el grado de progreso de los estudiantes según el objetivo propuesto con el fin de que el docente tome decisiones de reajuste al proceso educativo de ser necesario, según las necesidades presentadas.

Por tal motivo, el autor de la propuesta considera importante realizar una evaluación continua que abarque la evaluación diagnóstica, para poder conocer el nivel con el que están iniciando la clase; la formativa, que permita conocer la forma de aplicación de los diversos procedimientos en los procesos, y la sanativa, como resultado final de un trabajo de seguimiento durante todo el proceso de enseñanza aprendizaje. Estos tipos de evaluaciones requieren de diversos instrumentos como: cuestionarios, fichas de cotejo, fichas de evaluación, autoevaluación y coevaluación, fichas de observación y rúbricas para lo cual se debe aplicar actividades evaluativas individuales, grupales y colaborativas promoviendo un diagnóstico real e integral de sus capacidades procedimentales, operacionales, reflexivas y sociales, como sostiene también (Tobón ,2017 y Valdés 2017).

La categoría rol del docente. Para Castellanos et al. (2002), Díaz y Hernández (2010), Rico et. al (2013), Tobón (2013) y Arizaga (2015) en el proceso pedagógico el docente es el responsable de establecer y garantizar las condiciones para que haya una mediación eficiente entre la cultura y los educandos; y de esta forma contribuir en el desarrollo integral de los estudiantes, tomando en consideración los intereses sociales, los contenidos a tratar y el crecimiento progresivo del educando yendo de niveles inferiores a niveles superiores.

Es en este punto, que el docente como agente mediador debe favorecer la creación de un aula cuyo ambiente permita al estudiante expresar sus diversas capacidades y 
destrezas mediante el intercambio de ideas, la investigación, la indagación, tanto a nivel individual como colectivo.

Las características que debe tener un docente son: Disponibilidad para motivar, ejecutar y orientar las actividades; Comunicador Asertivo; Dominio Teórico y Metodológico del tema a desarrollar; Alto nivel profesional y experiencia; Carácter íntegro y con práctica de valores; y Capaz de evaluar y tomar decisiones sobre su práctica pedagógica; Promotor de un aprendizaje significativo; Brinda ayuda de manera adecuada y oportuna; Fomenta actividades grupales colaborativas; con el objetivo de crear un aula donde los estudiantes valoren la enseñanza tanto en el aspecto cognitivo, procedimental, aptitudinal, social y moral; se apropien de ella y obtengan como resultado del intercambio de ideas entre todos los agentes educativos un concepto propio del tema tratado, capaces de aplicarlo en cualquier contexto de la vida. Como sostienen (Castellanos et al. 2007; Díaz Barriga, 2013), Sáez, 2014; Arizaga 2015 y Mora, 2017).

La categoría rol del estudiante. Para Castellanos et al. (2002, 2007), El educando en el proceso de enseñanza aprendizaje es el responsable directo de su aprendizaje, ejerciendo así un rol protagónico en la educación como agente activo y cuyos intereses, necesidades fortalezas y debilidades permitirán la construcción de su propio aprendizaje mediante la reflexión y el análisis meta cognitivo en las diversas actividades, autorregulando y autoevaluando las acciones a realizar en la interacción con sus compañeros de forma respetuosa, solidaria y colaborativa.

Así mismo el estudiante debe realizar actividades de indagación, predicción y creación de tareas productivas durante todo el proceso pedagógico identificando los pasos a seguir para alcanzar el objetivo propuesto, los objetivos y beneficios de la problematización del saber de forma dialéctica, contribuyendo a la obtención de aprendizajes más significativos.

También debe poseer motivación constante de manera que se sienta comprometido con la actividad a desarrollar de manera consciente aportando sus experiencias y saberes previos, autorregulando y autoevaluando la eficiencia de sus propias decisiones, de sus propios avances y logros a partir de la reflexión y la valoración de la actividad tanto de forma: individual, social, intelectual, afectiva y moral.

La categoría rol de grupo. Según Castellanos et al. $(2002,2007)$ se entiende como aquel conjunto de estudiantes que construyen su propia identidad alcanzando niveles superiores de autonomía funcional producto de la interrelación con sus iguales en un ambiente cuyas condiciones motivan la actuación individual y colectiva mediante trabajos grupales, colaborativos y formativos. 
El grupo está constituido por las relaciones que se forman entre los participantes, así como la comunicación generada en el intercambio de ideas con el fin de obtener una solución a la situación problémica enfrentada. Estas interacciones contribuyen al desarrollo de los interaprendizajes, los cuales además serán los que orienten el proceso educativo. Por ello la importancia por parte del docente al momento de establecer los grupos, ya que se debe considerar la promoción de actividades que estimulen y desarrollen el aspecto cognitivo, procedimental y aptitudinal en la resolución de problemas en un ambiente participativo, colaborativo y de respeto mutuo que permite un intercambio de roles; a partir de la socialización y el nivel de ayuda dado entre los estudiantes (Viale, 2012 y Tobón, 2017).

En la propuesta metodológica se toma en cuenta el trabajo individual, grupal, colaborativo y socio formativo los cuales se irán aplicando según conveniencia durante el proceso pedagógico basado en la enseñanza problémica en el área de Matemática.

Exigencias de la actividad del aprendizaje. Así como es de gran importancia los contenidos, los procedimientos y la práctica de valores en el desarrollo del proceso de enseñanza aprendizaje, también lo son las actividades a través de las cuales se lograrán alcanzar los objetivos propuestos y la metodología a aplicar en clase, la cual permitirá dosificar las sesiones de clase en un sistema que guarde interrelación de manera progresiva y consecuente. (Castellanos et al., 2007 y Rico, et al. 2013).

Para Brito (1987), Alonzo (1999), Arizaga (2015) y Urday (2019), la actividad es un proceso a través del cual el estudiante interpreta su realidad, en respuesta a la búsqueda de alternativas de solución según sus necesidades, motivaciones e intereses.

En línea con esa posición, la actividad es el proceso por el cual un individuo interacciona con los objetos y sujetos del mundo que lo rodea los cuales producen nuevos conocimientos, desarrollan nuevas capacidades y potencian la motivación por el aprendizaje mediante la práctica de forma integral incidiendo en lo conceptual, procedimental y aptitudinal de su formación personal y social. (Vygotsky, 1987; Márquez, 1999; Gonzáles, 2008; y; Ortiz 2008; Sáez y Ruiz, 2012 y Mora, 2017).

En ese mismo orden de ideas, Silvestre y Zilberstein (2002) sostienen que el proceso de enseñanza- aprendizaje demanda en los docentes: planificación previa de los contenidos, acciones, orientaciones de control y evaluaciones que serán ejecutados por los estudiantes, logrando una participación activa, dinámica, acorde a su contexto; asumiendo un rol protagónico y estimulando un aprendizaje más significativo y consiente que permita tomar decisiones ante cualquier situación problemática.

De lo anterior podemos concluir que la actividad de aprendizaje es de gran relevancia por ser una categoría psicológica que favorece el desarrollo de la personalidad 
en los estudiantes y que dentro del proceso pedagógico cumplen un papel fundamental al ser el objeto mediante el cual se interrelacionan los conocimientos, los procedimientos, las actitudes, capacidades, habilidades y destrezas de forma práctica entre el estudiante, sus compañeros y el docente; deviniendo en un cambio en si mismo y en su entorno.

Par la propuesta metodológica se consideró el paso de una educación tradicional o pasiva a una educación donde el estudiante posee un rol activo y protagónico, teniendo como mediador al docente a través de diversas actividades debidamente diseñadas para generar interés y motivación por la búsqueda de soluciones frente a una problemática, que conlleve al análisis, la investigación, el debate, el cuestionamiento y la indagación.

\section{Característica de la secuencia metodológica de la clase.}

Las actividades a realizarse durante la clase deben poseer una secuencia lógica que vaya de lo simple a lo complejo o de lo conocido a lo desconocido y que facilite el desarrollo del conocimiento de manera sistemática, dinámica, fluida y coherente permitiendo en los estudiantes la construcción y asimilación consiente de la información de forma conceptual, procedimental y aptitudinal. Por tanto, las actividades de aprendizaje y evaluación propuestas estarán debidamente articuladas entre ellas para contribuir en la resolución de problemas (Díaz y Hernández, 2010; Tobón y Pimienta, 2010; Addine et. al; 2015 y Arizaga, 2015).

La sesión de clase es la célula principal del proceso pedagógico donde el docente comunica, direcciona y demuestra las acciones correspondientes para alcanzar el aprendizaje propuesto durante los diferentes momentos didácticos según su nivel de complejidad y en donde los estudiantes evidencien y sustenten, sus logros y avances en cada momento: inicio, desarrollo y cierre de la clase; propiciando el desarrollo del pensamiento y su habilidad investigativa en la resolución de problemas matemáticos.

Durante el inicio de la clase: En esta primera etapa el objetivo es ganar la atención del estudiante partiendo de lo conocido y lograr establecer un vínculo permanente entre los saberes previos y el objetivo de la sesión. Para ello se plantea una situación problemática en la que el profesor y los educandos puedan entablar un diálogo analítico, crítico y reflexivo generando interés y expectativa por el nuevo conocimiento, valiéndose para esto de la mayéutica.

Durante el desarrollo de la clase: Luego que se activó el interés y la motivación en el estudiante a partir de su propio conocimiento, el docente establece la necesidad de la búsqueda de información necesaria para resolver problemas matemáticos planteándolos en diversas actividades de aprendizaje sea individual o grupal; que les permita observar, analizar, comparar y asumir diferentes roles mediante el uso de recursos y materiales seleccionados y preparados previamente para facilitar la comprensión y asimilación del 
aprendizaje en los estudiantes, quienes deben ser los protagonistas en este proceso, participando de forma activa. El rol del docente en este tipo de enseñanza es de acompañar durante todo el proceso de construcción del aprendizaje, por ello verifica constantemente los logros que va adquiriendo el estudiante a través del diálogo y la observación.

A continuación, se presentará algunos momentos de aprendizaje que muestran el accionar del docente desde la enseñanza problémica en colaboración con el enfoque socio formativo:

\section{Ejemplo 1: Probabilidad}

Se inicia la sesión realizando una dinámica en la que el docente formará grupos de la misma cantidad de alumnos. Luego se les hace llegar un conjunto de fichas que abordan diferentes posiciones para que puedan apostar por una posición determinada en una ruleta digital que está presentada en una diapositiva dividida y numerada en diez partes equivalentes.

Una vez realizado el ejercicio varias veces, se formulan un sistema de preguntas como: ¿A qué se debe que haya salido de un color en específico? ¿Qué oportunidades tengo de salir ganador en una partida? ¿Habrá alguna forma de predecir el siguiente resultado? ¿Por qué?, ¿Crees que exista alguna forma dentro de lo legal, para que uno pueda ganar en la mayoría de las veces? ¿Cómo? y ¿A qué se debe esto?

Ante este cuestionamiento surge la pregunta en el docente: ¿Cuál será el resultado en el estudiante?

De esta manera, el estudiante se enfrenta a cuestionamientos cada vez más complejos, porque van de lo conocido a lo desconocido, genera en ellos expectativa, curiosidad e incertidumbre por el nuevo contenido a tratar en la clase mientras disfruta la actividad al participar, dialogan, comparten y llegan a conclusiones en el equipo.

De esta manera grupal e individual, al momento de seleccionar una posición en la ruleta y al contestar las preguntas de diagnóstico se potencia no solo la esfera cognitiva al dilucidar la actitud teórica a asumir, sino el valor que tiene y las relaciones interpersonales que se fortalecen con la participación y dinámica en el equipo.

Ejemplo 2: Gráficos Porcentuales.

Se inicia la sesión con una exposición sobre la cantidad de víctimas del feminicidio, para ello se utilizan gráficos porcentuales de datos reales obtenidos del Instituto Nacional de Estadística e Informática (INEI, 2018). Luego mediante el uso de la Mayéutica se establece un diálogo crítico acerca de las posibles causas que pudieron haber generado estos resultados. Para ello se lleva a cabo un sistema de preguntas como: ¿A qué se deberá el alto índice de victimas de feminicidio?, ¿Por qué habrá aumentado de manera exponencial este índice del 2018 al 2019?, ¿Quiénes deben tener mayor responsabilidad 
los hombres o las mujeres en este tema?, ¿Cómo se recabó los datos analizados?, ¿Cómo se procesó estos datos?, ¿Conoces algún método de procesamiento de datos?, ¿Cómo se calculan los porcentajes? Y se reta a que hagan algunos caculos de porcentajes con su respectiva gráfica en la pizarra yendo de lo simple a lo complejo.

De esta forma se logra captar el interés y generar la motivación adecuada por el contenido a tratar, iniciando con una situación problemática real para luego aperturar un debate abierto en las que todos pueden participar y sustentar su posición de manera que permita también al docente diagnosticar el estado inicial de los estudiantes, mientras estos interactúan.

Posterior a ello, se estructuran grupos con el fin de realizar una breve investigación sobre un tema libre en la cual los estudiantes puedan establecer la dimensión de su proyecto, instrumentos de recojo de información y software que permita realizar los gráficos estadísticos porcentuales. Durante todo este proceso el docente guía la actividad para que cumpla los objetivos trazados en la sesión, brindando sugerencias en caso se necesite al estudiante y facilitando los permisos para el recojo de información dentro de la institución educativa. Así mismo se establecerán: las rúbricas de evaluación por parte del jurado en la exposición final incluido el informe escrito y digital de su propuesta de solución; y los indicadores de autoevaluación y coevaluación de los estudiantes durante la presentación.

Como se puede observar en los ejemplos expuestos anteriormente, el rol del docente es importante para planificar las actividades que ayuden a conseguir el objetivo de la sesión, para diagnosticar en todo momento el avance del aprendizaje de los estudiantes, y para desarrollar una formación integral que interrelacione sus conocimientos, capacidades, habilidades, destrezas, valores personales y sociales.

La secuencia metodológica propuesta contribuye a la construcción de un ambiente que posibilita el pensamiento crítico, reflexivo, investigativo, proactivo, creativo en respuesta a una problemática que despierta el interés y la motivación por el aprendizaje en resolución de problemas matemáticos con hechos reales.

Durante el cierre de la sesión: El docente promueve la autoevaluación, autorreflexión y la metacognición tanto a nivel conceptual, como procedimental y aptitudinal de lo aprendido y aplicado en las diversas actividades de aprendizaje, permitiendo al estudiante expresar, sustentar y poner en práctica su nuevo conocimiento adquirido a fin de dar soluciones a diversos problemas reales.

Las actividades para ejecutar en esta etapa pueden ser de carácter personal o grupal, ya sea a través de pruebas escritas, trabajos grupales o proyectos que permitan recoger información real y establecer propuestas de solución a una problemática de su 
entorno, favoreciendo aún más el desarrollo de lo cognitivo, procedimental y axiológico. Arizaga (2015).

La evaluación en este punto debe darse de forma integral, de manera que los estudiantes reconozcan y valoren su progreso alcanzado y el docente tome decisiones para la ayuda y soporte inmediata de los que no lograron alcanzar el objetivo propuesto como precisan Medina y García (1998), Álvarez (1999), Castellano (2007), Addine (2013), Arizaga (2015), Tobón (2017).

La secuencia metodológica en la clase, según Tobón y Pimienta (2010), Addine (2013) y Arizaga (2015) debe promover:

La motivación por el aprendizaje del nuevo conocimiento como eje de partida para generar el interés y captar la atención de los estudiantes.

Diagnóstico de los saberes previos de forma integral considerando lo conceptual, procedimental y aptitudinal.

Selección de diversas estrategias de la enseñanza problémica y del enfoque por competencias de modo que generen curiosidad en los educandos; y métodos que faciliten la participación activa de la clase la mayor parte del tiempo como: problémicos, investigativos, heurísticos, creativos y lúdicos.

Estimular actividades que produzcan en los estudiantes: contradicción, conflicto y desequilibrio cognitivo al enfrentar situaciones problémicas de la cual se tiene información limitada y se busca la solución.

El estudiante debe tener una participación activa y protagónica durante todo momento de la clase siendo el constructor de su propio aprendizaje.

El docente debe proponer actividades que exijan la aplicación de la nueva información adquirida.

El estudiante debe lograr transferir o aplicar lo aprendido al afrontar una nueva situación problémica, como evidencia de un eficiente proceso metodológico de enseñanza aprendizaje.

El docente debe considerar las estrategias y acciones de evaluación, coevaluación y metacognición formativa del progreso de los estudiantes, valorando su área cognitiva, procedimental y aptitudinal de manera individual y grupal.

\section{Propuesta de talleres pedagógicos a los docentes.}

Durante la recolección de información y diagnóstico de campo se evidenció que los docentes poseían deficiencias teórico didácticas y metodológicas para orientar el proceso pedagógico a un aprendizaje por competencias en la resolución de problemas matemáticos 
en los estudiantes del V grado de Educación Secundaria de una Institución educativa Privada de Lima.

Frente a esta problemática y con el fin de contribuir a la preparación teórica y metodológica de los docentes se propone realizar talleres pedagógicos que refuercen el dominio de las estrategias y los métodos de la enseñanza problémica bajo un enfoque socio formativo que permita discutir, debatir y reflexionar acerca de las exigencias teóricas y didácticas actuales que demanda el proceso de enseñanza aprendizaje, los que se realizarán en el periodo de vacaciones entre enero y febrero, para ello es necesario las coordinaciones previas con el departamento de dirección académica.

Para dicho fin, se toma en cuenta la interconectividad y secuencialidad que debe haber para motivar a los docentes a asimilar los nuevos conocimientos tomando como punto de partida una situación problémica en el salón de clases, así como realizar actividades colaborativas en la que los docentes compartan experiencias, analicen la información, comprendan las necesidades del contexto, reflexionen en su práctica diaria y puedan apropiarse de los nuevos conocimientos adquiridos en favor de su desempeño docente.

A continuación, se presenta el diseño de los talleres de capacitación docente.

Tabla 3

Diseño de talleres de capacitación docente

\begin{tabular}{|c|c|c|c|c|}
\hline Tema del taller & $\begin{array}{c}\text { Capacida } \\
\text { d }\end{array}$ & Objetivo & $\begin{array}{c}\text { Campo } \\
\text { temático }\end{array}$ & Actividades \\
\hline $\begin{array}{l}\text { Fundamentos de la } \\
\text { enseñanza problémica } \\
\text { en el área de } \\
\text { Matemática }\end{array}$ & $\begin{array}{l}\text { Analiza } \\
\text { Valora } \\
\text { Sustenta }\end{array}$ & $\begin{array}{l}\text { Analizar, valorar y profundizar los } \\
\text { sustentos teóricos y metodológicos } \\
\text { de la enseñanza problémica en el } \\
\text { área de Matemática y su relevancia } \\
\text { en el proceso de formación integral } \\
\text { de los estudiantes de V Grado de } \\
\text { Secundaria }\end{array}$ & $\begin{array}{l}\text { La } \\
\text { enseñanza } \\
\text { problémica }\end{array}$ & $\begin{array}{l}\text { Situación problémica } \\
\text { Lluvia de Ideas y discusión por } \\
\text { pares } \\
\text { Construcción de una sesión de } \\
\text { clase } \\
\text { Organizador visual }\end{array}$ \\
\hline $\begin{array}{l}\text { Fundamentos } \\
\text { enfoque } \\
\text { competencias }\end{array}$ & $\begin{array}{l}\text { Compren } \\
\text { de } \\
\text { Analiza } \\
\text { Reflexion } \\
\text { a } \\
\text { Explica }\end{array}$ & $\begin{array}{l}\text { Brindar a los docentes los referentes } \\
\text { teóricos que guíen el proceso de } \\
\text { enseñanza aprendizaje por } \\
\text { competencia y establecer la } \\
\text { necesidad de aplicar un aprendizaje } \\
\text { por competencias para contribuir a la } \\
\text { formación integral de los educandos } \\
\text { en el área de Matemática para } \\
\text { estudiantes de V Grado de } \\
\text { Secundaria. }\end{array}$ & $\begin{array}{l}\text { Enfoque por } \\
\text { competenci } \\
\text { as }\end{array}$ & $\begin{array}{l}\text { Emisión de un Video sobre la } \\
\text { problemática actual en } \\
\text { Educación Básica } \\
\text { Lectura de un texto } \\
\text { Diseño de cuadros } \\
\text { comparativos por grupos } \\
\text { Mesa de debate sobre } \\
\text { beneficios del enfoque por } \\
\text { competencias }\end{array}$ \\
\hline
\end{tabular}




\begin{tabular}{|c|c|c|c|c|}
\hline $\begin{array}{l}\text { Métodos de } \\
\text { de resolución } \\
\text { matemáticos basademas } \\
\text { en la enseñanza } \\
\text { problémica y el enfoque } \\
\text { por competencias }\end{array}$ & $\begin{array}{l}\text { Investiga } \\
\text { Aplica } \\
\text { Innova }\end{array}$ & $\begin{array}{l}\text { Orientar a los docentes acerca de los } \\
\text { métodos y estrategias a utilizar en el } \\
\text { proceso de enseñanza aprendizaje } \\
\text { de la resolución de problemas del } \\
\text { área de Matemática }\end{array}$ & $\begin{array}{l}\text { Estrategias } \\
\text { y métodos } \\
\text { de } \\
\text { enseñanza } \\
\text { aprendizaje } \\
\text { para } \\
\text { resolver } \\
\text { problemas } \\
\text { matemático } \\
\text { s }\end{array}$ & $\begin{array}{l}\text { Presentación de casos de } \\
\text { problemas para resolver } \\
\text { problemas } \\
\text { Propuestas de solución por } \\
\text { grupos } \\
\text { Presentación de los diversos } \\
\text { métodos bajo en enfoque por } \\
\text { competencias } \\
\text { Diseño de una sesión de } \\
\text { aprendizaje acoplando nuevos } \\
\text { métodos }\end{array}$ \\
\hline
\end{tabular}

Elaboración propia (2019).

En cada sesión de los talleres, se propone que los docentes elaboren una sesión de aprendizaje según el enfoque a trabajar para que les sirva de reforzamiento de lo aprendido y de concientización acerca de la importancia de estimular, construir, evaluar y retroalimentar los conocimientos adquiridos en los talleres y de esta manera realizar una tarea docente efectiva planificando, organizando, sistematizando y orientando las actividades pedagógicas (Díaz y Hernández, 2010 y Velázquez, 2014).

\section{Propuesta de Comunidades de aprendizaje para los docentes.}

Como se ha podido reflexionar en la investigación, la socialización es un factor importante al momento de desarrollar un proceso de enseñanza aprendizaje integral.

Al respecto. las comunidades de aprendizaje tienen la función de brindar un ambiente donde los individuos se reúnen con un objetivo en común, aprender juntos en relación a un tema específico. En estas comunidades se promueve el aprendizaje colectivo donde todos enseñan y todos aprenden; ya sea de forma verbal o procedimental, que permite el intercambio de pensamientos, conceptos, ideas e interrelaciones sociales de manera respetuosa en un contexto determinado (Délaño, 2015).

Por tal motivo se propone el uso de las comunidades de aprendizaje instituido por el claustro docente como parte de la capacitación teórico metodológico para potenciar el desarrollo de la competencia de resolución de problemas a partir de la exposición e intercambio de experiencias, estrategias, métodos y técnicas aplicadas en el aula de forma crítica, reflexiva, colaborativa y continua.

En la comunidad de aprendizaje se debe considerar el estudio, análisis y reflexión de la información a tratar, la colaboración debe tener un solo propósito, mejorar el aprendizaje en los estudiantes; la búsqueda exhaustiva de prácticas innovadoras de enseñanza aprendizaje en la resolución de problemas, la promoción de la lectura y el 
debate, la elaboración de productos acordes a las exigencias educativas actuales y la retroalimentación de información obtenida para la mejora de la práctica docente.

Algunas exigencias para orientar las comunidades de aprendizaje son: Poseer valores a fines de la visión institución; Liderazgo compartido y equitativo; Aprendizaje individual y social; Compartir experiencias y permitir sugerencias; Mantener la confianza, el respeto y el apoyo mutuo; Establecer redes de aprendizaje; Responsabilidad colectiva y Provisión de recursos y materiales. Esta comunidad de aprendizaje se propone llevarla a cabo luego de los talleres, donde los docentes podrán compartir su problemática inicial en el aula y las experiencias vividas a partir de lo aprendido en las capacitaciones.

\section{Orientaciones para la Implementación de la propuesta modelada.}

Para la implementación de la propuesta metodológica en la práctica pedagógica en educación secundaria debe realizarse de forma secuencial para poder alcanzar y desarrollar los objetivos planteados que a continuación se detallan:

Primero, realizar una reunión con las autoridades educativas, padres de familia y estudiantes para sensibilizar y dar a conocer los lineamientos teóricos, metodológicos y didácticos que integran y fundamentan la propuesta metodológica del proceso pedagógico en la resolución de problemas del área de Matemática dirigida a los estudiantes de $\mathrm{V}$ grado de Educación Secundaria.

Segundo, realizar una reunión con los profesores del área respectiva para examinar y evaluar que la propuesta respete los elementos normativos en la Ley general de Educación, en el Currículo Nacional y en el Programa curricular de educación secundaria en relación al área de Matemática y su aporte al desarrollo de la formación integral del estudiante.

Tercero, se debe sustentar la necesidad de organizar, planificar y dosificar los contenidos en las unidades y sesiones pedagógicas de manera que fortalezcan los diversos contenidos, capacidades, habilidades, destrezas y valores a través de las actividades de aprendizaje, las estrategias, los métodos, las técnicas, los instrumentos y tipos de evaluación que consideren lo conceptual, procedimental y aptitudinal.

Cuarto, se presentará los resultados del diagnóstico de campo recabados en la investigación como: las fortalezas, las debilidades, las causas, las consecuencias del problema y las formas de cómo proceder para cambiar esa realidad con la aplicación de la propuesta metodológica que contribuirá al desarrollo de la competencia de resolución de problemas en Matemática. 
Quinto, se realizará la fundamentación teórica y didáctica basado en los referentes teóricos actuales de la pedagogía, de la enseñanza problémica, del enfoque socio formativo por competencias y de los métodos de enseñanza para la resolución de problemas matemáticos los cuales justifican la propuesta y permiten desarrollar los conocimientos, competencias, habilidades y aptitudes de forma integral en los estudiantes a partir de la orientación y guía del docente durante el proceso de enseñanza aprendizaje y el rol protagónico del educando.

Por último se dará a conocer y justificará la unidad didáctica, diseñada y modelada como parte de la propuesta para ser de guía en las siguientes unidades del año académico y que además comprende dos sesiones de aprendizaje desarrolladas como ejemplo, las cuales se formularon en respuesta a los interés y carencias identificadas en los estudiantes, orientando a la construcción de un proceso pedagógico que estimule el desarrollo de las competencias y habilidades de la resolución de problemas matemáticos en los educandos. Así mismo se adjunta los instrumentos de evaluación formativa y sus respectivos indicadores según la actividad a realizar y producto a entregar dentro del aula de clases.

\section{Valoración de las potencialidades de la estrategia por criterio de expertos}

La propuesta metodológica diseñada fue evaluada por el criterio de expertos para medir su efectividad. Para tal fin se utilizó dos fichas de valoración, una para medir los aspectos internos y otra para los aspectos externos del resultado científico.

Los especialistas fueron seleccionados según los siguientes criterios: poseer el grado de maestro o doctor, ser especialistas en Ciencias de la educación y que trabajen en el área de Educación o áreas a fines y ser docente de una institución educativa. Los especialistas elegidos para participar del proceso de validación se detallan a continuación:

Tabla 4

Selección de especialistas.

\begin{tabular}{lcccc}
\hline $\begin{array}{l}\text { Nombres y } \\
\text { Apellidos }\end{array}$ & $\begin{array}{c}\text { Grado } \\
\text { académico }\end{array}$ & $\begin{array}{c}\text { Especialidad } \\
\text { profesional }\end{array}$ & Ocupación & Años de experiencia \\
\hline $\begin{array}{l}\text { Alejandro Cruzata } \\
\text { Martínez }\end{array}$ & Doctor & $\begin{array}{c}\text { Licenciado en } \\
\text { Lengua y Literatura }\end{array}$ & $\begin{array}{c}\text { Director de Grado } \\
\text { y Sustentación }\end{array}$ & Treinta \\
\hline $\begin{array}{l}\text { Hernán Flores } \\
\text { Valdiviezo }\end{array}$ & Magister & Sociólogo - Investigador & Docente Investigador & Cuarenta \\
\hline $\begin{array}{l}\text { Fernando Goñi } \\
\text { Cruz }\end{array}$ & Doctor & $\begin{array}{c}\text { Licenciado en } \\
\text { Educación - Matemática }\end{array}$ & Docente & Dieciocho \\
\hline
\end{tabular}

Elaboración propia (2019). 


\section{Valoración interna y externa.}

Para la validación interna y externa se elaboró dos fichas de validación conteniendo diez criterios e indicadores cuantitativos y cualitativos según corresponde.

Desde lo cuantitativo, cada especialista expresó su apreciación en cada uno de los diez criterios. La valoración considerada fue la siguiente: Deficiente (puntaje 1); Baja (puntaje 2); Regular (puntaje 3), Buena (puntaje 4) y Muy buena (puntaje 5). De manera que por cada ficha de evaluación se podía obtener como puntaje máximo cincuenta puntos y que en total hacían cien puntos, como se representa en la siguiente tabla:

Tabla 5:

Tabla de valoración

\begin{tabular}{lc}
\hline $0-25$ & DEFICIENTE \\
\hline $26-59$ & BAJA \\
\hline $60-70$ & REGULAR \\
\hline $71-90$ & BUENA \\
\hline $91-100$ & MUY BIEN \\
\hline
\end{tabular}

Elaboración propia (2019).

En relación con lo cualitativo, se tuvo en cuenta la apreciación crítica positiva, negativa; y las sugerencias realizadas por los especialistas.

La primera ficha (Anexo 7) corresponde a la valoración interna, en ella se juzga el contenido de la propuesta bajo diferentes criterios como: la factibilidad de su aplicación, claridad de la propuesta, posibilidad de extensión a otros contextos semejantes; correspondencia con las necesidades sociales; congruencia entre el resultado propuesto y el objetivo fijado, novedad en el uso de conceptos y procedimientos; propósitos basados en los fundamentos educativos, la propuesta es contextualizada a la realidad en estudio, presenta objetivos claros, coherentes y posibles de alcanzar; y contiene un plan de acción.

En la siguiente tabla se representa el promedio parcial obtenido en relación a la valoración interna de los expertos.

Tabla 6

Promedio parcial de la valoración interna de la propuesta.

\begin{tabular}{ccccc}
\hline $\begin{array}{c}\text { Nombres y } \\
\text { Apellidos }\end{array}$ & $\begin{array}{c}\text { Grado } \\
\text { académico }\end{array}$ & $\begin{array}{c}\text { Especialidad } \\
\text { profesional }\end{array}$ & Recomendaciones & Valoración \\
\hline $\begin{array}{c}\text { Alejandro Cruzata } \\
\text { Martínez }\end{array}$ & Doctor & $\begin{array}{c}\text { Licenciado en } \\
\text { Lengua y Literatura }\end{array}$ & Ninguna & 49 \\
\hline $\begin{array}{c}\text { Hernán Flores } \\
\text { Valdiviezo }\end{array}$ & Magister & Sociólogo - Investigador & Ninguna & 50 \\
\hline $\begin{array}{c}\text { Fernando Goñi } \\
\text { Cruz }\end{array}$ & Doctor & $\begin{array}{c}\text { Licenciado en } \\
\text { Educación - Matemática }\end{array}$ & Ninguna & 47 \\
\hline
\end{tabular}

Elaboración propia (2019). 
En caso de la ficha de validación externa (Anexo 8) los criterios a considerar son: la claridad, objetividad, actualidad, organización, suficiencia, intencionalidad, consistencia, coherencia, metodología y pertinencia.

La siguiente tabla presenta a continuación el promedio parcial correspondiente a la valoración externa realizada por los especialistas.

Tabla 7

Promedio parcial de la valoración externa de la propuesta.

\begin{tabular}{ccccc}
\hline $\begin{array}{c}\text { Nombres y } \\
\text { Apellidos }\end{array}$ & $\begin{array}{c}\text { Grado } \\
\text { académico }\end{array}$ & $\begin{array}{c}\text { Especialidad } \\
\text { profesional }\end{array}$ & Recomendaciones & Valoración \\
\hline $\begin{array}{c}\text { Alejandro Cruzata } \\
\text { Martínez }\end{array}$ & Doctor & $\begin{array}{c}\text { Licenciado en } \\
\text { Lengua y Literatura }\end{array}$ & Ninguna & 49 \\
\hline $\begin{array}{c}\text { Hernán Flores } \\
\text { Valdiviezo }\end{array}$ & Magister & Sociólogo - Investigador & Ninguna & 50 \\
\hline $\begin{array}{c}\text { Fernando Goñi } \\
\text { Cruz }\end{array}$ & Doctor & $\begin{array}{c}\text { Licenciado en } \\
\text { Educación - Matemática }\end{array}$ & Ninguna & 46 \\
\hline
\end{tabular}

Elaboración propia (2019).

\section{Valoración integral.}

Los resultados parciales de cada ficha de validación tanto interna y externa se encuentran en el (Anexo 7,8) y las fichas de validación de cada uno de los especialistas (Anexo 9 y10). A continuación, se presenta la tabla resumen de la valoración realizada de forma integral:

Tabla 8

Valoración interna y externa de la propuesta

\begin{tabular}{ccccc}
\hline $\begin{array}{c}\text { Nombres y } \\
\text { Apellidos }\end{array}$ & $\begin{array}{c}\text { Grado } \\
\text { académico }\end{array}$ & $\begin{array}{c}\text { Ficha de validación } \\
\text { interna }\end{array}$ & $\begin{array}{c}\text { Ficha de validación } \\
\text { externa }\end{array}$ & $\begin{array}{c}\text { Sumatoria de } \\
\text { validación }\end{array}$ \\
\hline $\begin{array}{c}\text { Alejandro Cruzata } \\
\text { Martínez }\end{array}$ & Doctor & 49 & 49 & 98 \\
\hline $\begin{array}{c}\text { Hernán Flores } \\
\text { Valdiviezo }\end{array}$ & Magister & 50 & 50 & 100 \\
\hline $\begin{array}{c}\text { Fernando Goñi } \\
\text { Cruz }\end{array}$ & Doctor & 47 & 46 & 93 \\
\hline Total & 291 & & & \\
\hline
\end{tabular}

Elaboración propia (2019). 


\section{Resultado de la valoración de los especialistas y conclusiones.}

Los resultados consolidados de la valoración de expertos son los siguientes.

\section{Tabla 9}

Consolidado y validación final de la propuesta.

\begin{tabular}{ccc}
\hline Sumatoria de valoración total & Promedio de valoración & Valoración \\
\hline 291 & 97 & Muy Bien \\
\hline
\end{tabular}

Elaboración propia (2019).

Al valorar las recomendaciones y luego de subsanar las sugerencias y observaciones propuestas por los especialistas con el fin de enriquecer la efectividad de la propuesta como resultado de la investigación se concluye, que el producto científico diseñado es adecuado para la Educación Secundaria y que podría ser aplicado en otras áreas curriculares, siempre que se considere las cualidades del estudiante, su entorno, su cultura y el área en la que se pretende llevar a cabo. 


\section{Conclusiones}

Al concluir el proceso investigativo a través de la sistematización, diagnóstico de campo y modelación de la estrategia metodológica para contribuir al desarrollo de la competencia de resolución de problemas matemáticos en los estudiantes, se arriba a las siguientes conclusiones:

\section{Primera}

Se cumplió el objetivo general de la investigación al modelar la estrategia metodológica para contribuir a desarrollar la competencia de resolución de problemas matemáticos en los estudiantes de V Grado de Secundaria de una Institución Educativa Privada de Lima.

\section{Segunda}

Se cumplió la tarea científica relacionada con el marco teórico al sistematizarse de forma integral las categorías y subcategorías apriorísticas sobre la competencia de resolución de problemas matemáticos. Luego se sistematizaron las categorías emergentes congruentes al proceso de investigación y se diseñó la matriz de categorización.

\section{Tercera}

El diagnóstico de campo se realizó con éxito, a partir del diseño, validación, aplicación de los instrumentos y mediante distintas técnicas de recojo, procesamiento y triangulación de la información recabada permitieron identificar las categorías emergentes sustantivas y las que inciden en el problema investigado en el proceso de enseñanza del área de Matemática, cumpliéndose así la segunda tarea científica.

\section{Cuarta}

Se cumplió con la tercera tarea científica al determinar los criterios teóricos y metodológicos que permitieron modelar la estrategia metodológica propuesta que se sustenta en los enfoques teóricos actuales del aprendizaje y la enseñanza problémica en la orientación del proceso de enseñanza- aprendizaje para contribuir al desarrollo de la competencia resolución de problemas en los estudiantes de quinto grado de Secundaria. 


\section{Quinta}

La validación de la estrategia metodológica propuesta por el juicio de criterio de expertos permitió cumplir con la cuarta tarea científica. La evaluaron de positivo y destacaron su pertinencia y aplicabilidad en la enseñanza- aprendizaje donde el docente es un mediador eficiente que estimula la motivación, el interés, el pensamiento crítico y la adquisición del aprendizaje significativo de la resolución de problema matemáticos de forma integral en los estudiantes. 


\section{Recomendaciones}

\section{Primera}

Aplicar la estrategia metodológica como resultado de la investigación en el proceso de enseñanza-aprendizaje en el área de Matemática de Educación Básica Regular, como una alternativa innovadora que guía al docente en la dirección de la práctica pedagógica desde posiciones reflexivas, problematizadoras, dialógicas e interactivas que inciden en la apropiación del conocimiento de manera consciente, activa y significativa en los estudiantes.

\section{Segunda}

Validar el impacto de la aplicación de la estrategia metodológica modelada en la práctica con el fin de verificar su efectividad en el desarrollo de la competencia de resolución de problemas matemáticos que alcancen los estudiantes y analizar su posible aplicabilidad a otras áreas curriculares.

\section{Tercera}

Sugerir la realización de las comunidades de aprendizaje y los talleres de capacitación teórico metodológicas orientados a los docentes, con el objetivo de que conozcan y se apropien de los sustentos teóricos y didácticos en relación a los métodos problémicos, investigativos, de proyectos, creativos, dialógicos, críticos, sociales que favorecen el desarrollo de la competencia de resolución de problemas matemáticos. 


\section{Referencias}

Abarca, S. (2006). Psicología de la motivación. San José, Costa Rica: Euned

Addine, F. (2006). Modo de actuación profesional pedagógico: de la teoría a la práctica. La Habana: Institución educativa privada

Addine, F. (2013) La didáctica general y su enseñanza en la Educación Superior Pedagógica. Aportes e impactos. La Habana: Editorial Pueblo y Educación, 9-27.

Addine, F. et. al (2015). Didáctica de la pedagogía y la Psicología: Pueblo y Educación La Habana.

Álvarez, C. (1999). Didáctica. La escuela en la vida, La Habana, Pueblo y Educación.

Álvarez, C.et al (2015). Didáctica de la pedagogía y la psicología. La Habana: Pueblo y educación.

Álvarez de Zayas, C. (1999). La escuela en la vida. Didáctica. La Habana: Pueblo y Educación.

Álvarez de Zayas, R. (1997, 2012). Hacia un curriculum integral y contextualizado. La Habana: Editorial Académica.

Álvarez, I. (2005). Evaluación como situación de aprendizaje o evaluación autentica. Perspectiva Educacional, Vol. 45, p. 45-47. Recuperado de http://www.redalyc.org/pdf/3333/333329100004.pdf

Álvarez T., Grau C., Tortosa Y. (2016). Innovaciones metodológicas en docencia universitaria: resultados de investigación. Alicante: Universidad de Alicante, Vicerrectorado de Estudios, Formación y Calidad, Instituto de Ciencias de la Educación (ICE).

Álvarez, Z. (1997) Hacia un currículo integral y contextualizado. Recuperado de file://C:/Users/crowned/Downloads/Rita\%20Marina\%20Alvarez Curriculum\%20Int egral\%20y20Contextualizado.pdf

Argote, I., Hernández, G., y Martínez, Á. (2016). Matemáticas para la ingeniería de sistemas. Ponencia presentada en Congresos CLABES. Medellín, Colombia. Recuperado de https://goo.gl/CE2FL5

Apaza C. J. (2018) La aplicación de la Estrategia de Miguel de Guzmán en el desarrollo de Capacidades Matemáticas bajo el enfoque de Resolución de Problemas en el 
Cuarto Grado de Secundaria de la Institución Educativa № 7207 Mariscal Ramón Castilla de San Juan de Miraflores. Tesis Para optar al Grado Académico de Maestro en Ciencias de la Educación con mención en Educación Matemática

Araya M. (2011). Competencias en educación: Ideas para el diseño curricular desde la deliberación práctica y crítica, basada en el desarrollo humano y la transformación social Revista Electrónica Educare, vol. XV, núm. 1, enero-junio, 2011, pp. 109-121. Universidad Nacional Heredia, Costa Rica

Argudín, Y., (2005), Educación basada en competencias. Distrito Federal, México: Trillas.

Arias, F. (2012). El proyecto de investigación. Introducción a la metodología científica. (5ª ed.). Caracas, Venezuela: Episteme

Arizaga R. (2015). Módulo de didáctica problémica. Fondo Editorial UCH. Universidad de Ciencias y Humanidades

Ausubel, D. (1992). Teorías de Aprendizaje Constructivista

Ausubel, Novak, Hanesian, h. (1983). Psicología educativa: un punto de vista cognoscitivo. México, Editorial Trillas. Traducción al español, de Mario Sandoval P., de la segunda edición de Educational psychology: a cognitive view.

Ausubel, Novak y Hanesian (1992). Psicología educativa: un punto de vista cognitivo: Trillas: México

Ausubel, D. (2002). Adquisición y retención del conocimiento desde una perspectiva cognitiva. Paidós. España

Bolaños Rodríguez, E. (2012). Muestra y Muestreo. México: Universidad Autónoma del

Estado de Hidalgo. Recuperado de http://www.uaeh.edu.mx/docencia/P_Presentaciones/tizayuca/gestion_tecnologica /muestraMuestreo.pdf

Bruner, Jerome (1987). Importancia de la educación. Editorial Paidos. Barcelona C.f. (1994) bieberach. Psicología.

Bueno D. (2017). Neurociencia para educadores: todo lo que los educadores siempre han querido saber

Bustamante León, M. (2014). Programa de habilidades comunicativas para mejorar el nivel de comprensión lectora en los alumnos de $5^{\circ}$ de secundaria del centro educativo particular “JUAN PABLO II"- Trujillo- 2014. Tesis para optar el grado de maestra en 
educación con mención en problemas de aprendizaje. Universidad Privada Antenor Orrego. Escuela de Postgrado. Trujillo, La Libertad, Perú.

Cabezas C. y Mendoza R. (2016). Manifestaciones Emergentes del Pensamiento Variacional en Estudiantes de Cálculo Inicial. Formación universitaria, 9(6), 13-26. DOI: http://doi.org/b952

Campi, M. I, Campi, M. J. y Coloma, L. (2015). El Método Heurístico como recurso en la resolución de problemas en la Educación. Revista de Ciencia Tecnología e Innovación, 2, 1-6. Recuperado de file://C:/Users/crowned/Downloads/93-549-1PB.pdf

Cantoral, Ricardo. (2013). Teoría socioepistemológica de la matemática educativa. México D. F.: Editorial Gedisa Mexicana.

Carneiro, R. (2007). The big picture: understanding learning and meta-learning challenges. European Journal of Education, Vol. 42, No. 2, págs. 151 a 172.

Castellanos, D. et. al (2002). Aprender y Enseñar en la Escuela: Una concepción desarrolladora. Pueblo y Educación. La Habana.

Castellanos, et al (2007). Para promover un aprendizaje desarrollador. La Habana: Colección de proyectos.

Cerezal, J. y Fiallo, J. (2005). Cómo investigar en pedagogía. La Habana: Pueblo y Educación.

Chomsky, N. (1970). Aspectos de la teoría de la sintaxis. Madrid: Editorial Aguilar

Churchill (1980), El modelo peruano de innovación: la reforma de la educación básica. Unesco.

Cerezal, J. y Fiallo, J. (2002). Los métodos científicos en las investigaciones pedagógicas. Ciudad de La Habana.

Cisterna, F. (2005). Categorización y triangulación como procesos de validación del conocimiento. España: Grau.

Cisterna, F. (2007): Métodos de Investigación Cualitativa en Educación, Libro de Docencia, Chile.

Corbalán, Fernando (1998): Juegos Matemáticos y Bachillerato. España. Editorial Síntesis S.A. 
Coronado, A., \& García, B. (2011). Formación y desarrollo de competencias matemáticas: una perspectiva teórica en la didáctica de las matemáticas. Revista Educación y Pedagogía, 23(59), 159-176.

Crispín, M. y Esquivel M. (2011). Aprendizaje Autónomo, orientaciones para la docencia, Aprendizaje Autónomo (pp. 49-65). México D. F., México: Universidad Iberoamericana.

Cruz, O. y Velázquez, M. (2017) Metodología innovadora para la práctica de ejercicios físicos. Revista de Educación, Argentina, 7(9), 317-335. Recuperado de http://fh.mdp.edu.ar/revistas/index.php/r_educ/article/view/1915

De Zubiría, M. (2004). Enfoques pedagógicos y didácticas contemporáneas. Fundación Internacional de Pedagogía Conceptual Alberto Merani: Bogotá.

Dede, C. (2010). Comparing frameworks for 21 st century skills.

Delors, J. (1996). Los cuatro pilares de la educación. La educación encierra un tesoro, 91 103. Recuperado de www.uv.mx/dgdaie/files/2012/11/CPP-DC-Delors-Los-cuatropilares.pdf

Dewey, J. (1916). Democracia y educación. Madrid: Morata, 2001, 4t edición.

Díaz, F. y Hernández, G. (1998) Estrategias docentes para un aprendizaje significativo. México D. F.: Mc Graw Hill.

Díaz, F. y Hernández, G. (2010) Estrategias docentes para un aprendizaje significativo, 2a Edición. México: Mc Graw Hill.

Dijkstra E. (1991). Instructional design models and the representation of knowledge and skills. Educational Technology, pp. 19-26.

Durán M. (2018). La Euritmia en el proceso de formación docente de Educación Inicial del Instituto Pedagógico Euroamericano, San Juan de Lurigancho. (Tesis de maestría). Universidad Nacional de Educación Enrique Guzmán y Valle, Lima, Perú.

Elena B. M., Hernández R. I., Reinoso D. M. (2013), Fundamentos teóricos para el diseño de una estrategia metodológica para la preparación de los profesores de Historia en las universidades Theoretical basis to the design of a methodological strategy to the training of professors of History in the universities Rev. Ciencias Médicas. Marzo-abril, 2013; 17(2):118-129 
Escobar-Pérez, J. y Cuervo-Martínez, A. (2008). Validez de contenido y juicio de

expertos: una aproximación a su utilización. Avances en Medición, 6, 27-36. Recuperado de http://www.humanas.unal.edu.co/psicometria/files/7113/8574/5708/ Articulo 3_Juicio_de_expertos_27-36.pdf

Felmer, P., Perdomo, J., Cisternas, T., Cea, F., Randolph, V., \& Mede, L. (2014). La Resolución de Problemas en la Formación Inicial de Profesores de Matemática de Enseñanza Media. Fondo de Investigación y Desarrollo En Educación - FONIDE.

Fernández C. L. y Aguado M. I. (2016). Educación Química (2017) 28, 154---162. Chaco Argentina.

Flores J. (2011). Construyendo la tesis universitaria. Guía didáctica. Lima: Garden Graf.

Flores, R. (2013). Pedagogía del conocimiento. México D.F: McGraw Hill.

Flores y Gaita (2014). Situación actual de la educación matemática en el Perú. Revista de Matemática, Ensino e Cultura. 9. 82-95.

Freire P. (1997). La educación como práctica de la libertad. Lima: ICIRA

Galmés, M. (2012). Métodos de muestreo. Uruguay: Food and Agriculture Organization United Nations - FAO

García B., Loredo J., Luna E. y Rueda M. (2008). Modelo de evaluación de competencias docentes para la educación media y superior. Revista Iberoamericana de Evaluación Educativa,1 (3), 124-136

García, M. E. G. y Pérez, E. C. (2013). El problema científico: elementos que lo identifican y caracterizan como componente del diseño teórico de la investigación científica. Pedagogía Universitaria, 18(4), 30-39. Recuperado de https://goo.gl/f8bapg.

Gardner H., y Walters J. (1993). Inteligencias Múltiples La teoría en la práctica. PAIDÓS, 1-14. Recuperado a partir de http://ict.edu.ar/renovacion/wpcontent/uploads/2012/02/Gardner_inteligencias.pdf\%5Cnhttp://datateca.unad.edu. co/contenidos/401509/2014-1/unidad_I/Gardner_inteligencias.pdf

Gómez, Marcelo M. (2006): "Introducción a la Metodología de la Investigación Científica". Edit. Brujas. Córdoba, Argentina 
Gómez C., Sanjosé V., y Solaz J. (2016). Estudios sobre comprensión y control de la comprensión en resolución de problemas académicos. Revista de Enseñanza de la Física, 28(1), 21-35. Recuperado de https://goo.gl/YQrNG5

Gonczi, A., y Athanasou, J. (1996). Instrumentación de la educación basada en competencias: Perspectiva de la teoría y la práctica en Australia. Limusa.

González J. et. al (2007). Tuning - América Latina: Reflexiones y perspectivas de la Educación Superior en América Latina. Revista Iberoamericana de Educación.

González J. (2013). Alternativa metodológica mediante estrategias de aprendizaje.

Gravemeijer K. y Teruel J. (2000). Hans Freudenthal, un matemático en Didáctica y Teoría curricular (Trad. Saggesse N., Gallego F. y Bressan A.). J. Currículo Studies (32), №.6, $777-796$.

Guaña E., Quinatoa E., Pérez M. (2017). Tendencias del uso de las tecnologías y conducta del consumidor tecnológico. Ciencias Holguín, vol. 23, núm. 2, abril-junio, 2017, pp. 1-17 Centro de Información y Gestión Tecnológica de Holguín. Holguín, Cuba.

Guzman (1993): Tendencias innovadoras en Educación Matemática. Perú. Editorial Moshera SRL.

Hamdan, N. (2011). Métodos estadísticos en educación. Caracas: Universidad Central de Venezuela

Hernández, F. Repensar la función de la Escuela desde los proyectos de trabajo, Fernando Hernández. Artículo publicado en Patio. Revista Pedagógica, 6, 26-31 (1998).

Hernández, R., Fernández, C., Baptista, P. (2010) Metodología de la Investigación. 5ta Edición. México, México D.F.: Editorial McGraw Hill.

Hernàndez R., Fernández C., Baptista P. (2014) Metodología de la investigación. VI edición. Editorial Mc Graw Hill. México

Hernández S. (2002). Metodología de la investigación social. México. Ed. S A de Ciudad México.

Hodkinson, P. y Issitt, M. (1995). The challenge of competence, London: Cassell.

Icart, M., Pulpón, A., Garrido, E. y Delgado, P. (2012). Cómo elaborar y presentar un proyecto de investigación, una tesina y una tesis. Barcelona, España: Universitat de Barcelona. 
Inciarte G. A., Parra S. M., Bozo de C. A. (2011) "Reconceptualización de la Universidad. Una mirada desde América Latina". Maracaibo Venezuela. Vol. 20

Instituto de Estudios Sociales Avanzados-IESA. (2015). Introducción a los métodos de encuestación y muestreo estadístico. Caracas: IESA-CSCI.

J. Bellanca y R. Brandt (Ed.). 21st Century Skills (Competencias del siglo XXI), págs. 51-76. Bloomington, Indiana: Solution Tree Press.

Jensen, B., et al. (2012), The Experience of New Teachers: Results from TALIS 2008

Kanhime, M., González-Hernández, W. (2017). Estrategia metodológica para lograr la Evaluación desarrolladora de la matemática en la escuela de formación de profesores de Kuando Kubango, Angola. Góndo-la, Enseñ Aprend Cienc, 12(1), 7391.

Kilpatrick, W. H. (1918). the project method. teacher s collage record, 19, 319 - 335. Kirby, I. (1984). Cognitive strategies and educational performance. New York: Academic Press.

Kinnear, T. y Taylor, J. (1998). Investigación de mercados. Un enfoque aplicado. (5 $5^{\mathrm{a}}$ ed.). Colombia: McGraw-Hill

Klingberg, L. (1978). Introducción a la Didáctica General. La Habana: Pueblo y Educación.

Lanuez, M. y Férnandez, E. (2003) Material docente del curso básico de Metodología de la Investigación Educativa. Maestría en Educación. La Habana: Instituto Pedagógico Latinoamericano y caribeño. Cátedra UNESCO.

Leadbeater, C. y Wong, A. (2010). Learning from the Extremes: A White Paper. San José, Calif., Cisco Systems Inc.

López F. (2002) Revista de Educación: El análisis de contenido como método de investigación 167-179. Universidad de Huelva

López R., Molina M. y ZA E. (2017). Modelización en el aula de ingeniería: un estudio de caso en el marco de un experimento de enseñanza. PNA, 11(2), 75-96. Recuperado de https://goo.gl/w0Jg6N

Ludewig, C. (2014). Universo y Muestra. México: Colegio Mexicano de Ortopedia y 
Traumatología. Recuperado de http://www.smo.edu.mx/colegiados/apoyos/ muestreo.pdf

Malhotra, N. (2004). Investigación de mercados. Un enfoque práctico. (4aa ed.). México: Prentice-Hall.

Martínez M. (1998). La investigación cualitativa etnográfica en educación. México: Trillas; p. 65-68.

Martínez, M. (2004) Ciencia y arte en la metodología cualitativa. México: Trillas.

Martínez, G. J. (2010). El Espacio Europeo de Educación Superior (EEES) y nuevo rol del estudiante Universitario. Cuadernos de Educación y Desarrollo, 2(16). Recuperado de http://www.eumed.net/rev/ced/16/jamg.htm

Martin Mulder, Tanja Weigel, Kate Collins. (2007) The concept of competence in the development of vocational education and training in selected EU member states: a critical analysis. Journal of Vocational Education \& Training 59:1, pages 67-88.

Martínez, A. M., Cobos, J. C., y Torres, E. (2015). Matematización y modelización: experiencias y saberes. Una propuesta de aula. Espiral. Revista de Docencia e Investigación, 5(2), 9-22. DOI: http://doi.org/b959

McClelland, D. (1998). Identifying competencies with behavioural-event interviews, Psychological Science, 9, 5, 331-339.

Mayntz R, Holm K, Hubner P. Introducción a los métodos de la sociología empírica. Madrid: Alianza Editorial; 1975.

McGartland, D. Berg, M., Tebb, S. S., Lee, E. S. \& Rauch, S. (2003). Objectifying content validity: Conducting a content validity study in social work research. Social Work Research,27 (2), 94-104

McLoughlin, C. y Lee, M.J.W. 2008a. The three p's of pedagogy for the networked society: personalization, participation, and productivity. International Journal of Teaching and Learning in Higher Education, Vol. 20, No. 1, págs. 10 a 20

Mejías D. E. (2016), Relación entre estrategias didácticas y la enseñanza de la matemática en los estudiantes del primer ciclo de la unidad académica de estudios generales de la universidad de san Martín de Porres en el año 2014. Tesis para optar el grado de maestra en educación con mención en problemas de aprendizaje. 
Universidad Privada Antenor Orrego. Escuela de Postgrado. Trujillo, La Libertad, Perú.

Ministerio de Educación. (2005). Propuesta pedagógica Matemática para la Vida. Rutas de Aprendizaje. Lima

Ministerio de Educación (2014). Marco Curricular Nacional. Propuesta para el diálogo. Lima Ministerio de Educación. (2015). Rutas de Aprendizaje. Lima

Ministerio de Educación. (2016). Diseño Curricular Nacional. Lima

Ministerio de Educación. (2016). Programa Curricular Nacional. Lima

Ministerio de Educación. (2015).la competencia matemática en el marco de pisa 2015. Orientaciones didácticas. Lima.

McClelland D. (1973). Testing for competence rather than for intelligence. American Psychologist.

Monereo, C., Castelló, M., Clariana, M., Palma, M. y Pérez, M. (2000). Estrategias de enseñanza y aprendizaje. 8a Edición. Barcelona: Grao de IRIF.

Montes de Oca Recio, N., y Machado Ramírez, E. (2011). Estrategias docentes y métodos de enseñanza-aprendizaje en la Educación Superior. Humanidades Médicas, 11(3), 475-488. Recuperado de http://www.humanidadesmedicas.sld.cu/index.php/hm/article/view/127/81

Morín, E. (2016). Renacimiento latinoamericano pensamiento complejo y pensamiento meridional. Revista Cronos, 1(2), 141-146. Recuperado de https://goo.gl/IAYbCS.

Robles (2005). Los docentes en el proceso de gestión de un currículo por competencias: Estudio de casos en tres Centros Educativos de Barranco. Pontificia Universidad Católica del Perú.

Morillo (2007). Reformas Educativas en Perú en el Siglo XX. Revista Iberoamericana de educación, www. rieoei. org/deloslectores/233Morillo. PDF.

Morín, E. (2000a). Los siete saberes necesarios para la educación del futuro. Ministerio de Educación Nacional. Bogotá.

Morin E. (2011). Los Siete saberes necesarios para la educación del futuro. (Unesco). Francia. 
National Council of Teachers of Mathematics NCTM (2.000). Principles and standards for school mathematics. Reston, Virginia (USA): National Council of Teachers of Mathematics. (Trad. cast.: Sociedad Andaluza de Educación Matemática Thales (2.003). Principios y Estándares para la Educación Matemática. Granada. Sociedad Andaluza de Educación Matemática Thales).

Nicolescu, B. (1996). La Transdisciplinariedad: Manifiesto. Monaco: Ediciones: Du Rocher. Norabuena, M. (2015). Tesis Magistral. La enseñanza problemática y su influencia en el logro de habilidades matemáticas en la resolución de problemas de álgebra en los alumnos del segundo grado de educación secundaria en la Institución Educativa Nuestra Señora de la Asunción - Huaraz 2013. Unidad de Postgrado de UNMSM.

Norris, N. (1991). The trouble with competence, Cambridge Journal of Education, 21, 3, $331-341$.

Oropeza, A. (2015). El trabajo colaborativo en el aula: Una estrategia pedagógica para mejorar el aprendizaje de los alumnos (as) en la educación primaria en la delegación Gustavo a. Madero del Distrito Federal. México, D.F.: Universidad Pedagógica Nacional. Tesis de Maestría.

Ortiz, A. (2012). Didáctica problematizadora y aprendizaje basado en problemas. Cali, Colombia: Litoral.

Ortiz, E. (2012). La Interdisciplinariedad En Las Investigaciones Educativas. Didasc@. lia: Didáctica y Educación 3.1.

Parada E., Conde A. y Fiallo J. (2016). Mediación Digital e Interdisciplinariedad: una Aproximación al Estudio de la Variación/Digital Mediation and Interdisciplinarity: an Approach to the Study of Variation. Bolema, 30(56), 10-31. DOI: http://doi.org/b96c

Pavlov, I. (1986). Fisiología y psicología. Madrid: Alianza Editorial.

Peñaloza, W. (2004) Los propósitos de la educación. Lima, F. Editorial del Pedagógico San Marcos.

Piaget, J. (1978) La equilibración de las estructuras cognitivas. Madrid: Sigo XXI

Poggioli, Lisette (1999): "Estrategias de resolución de problemas". Serie Enseñando a Aprender 5. Caracas: Fundación Polar.

Pólya, G. (1981). ¿Cómo plantear y resolver problemas? México: Editorial Trillas. 
Schoenfeld, A. (1985). Sugerencias para la enseñanza de la Resolución de Problemas Matemáticos. Madrid. En Separata del libro "La enseñanza de la matemática a debate". Ministerio de Educación y Ciencia.

OECD Publishing. OCDE (2009). (C) Santillana Educación, S. L. 2009 para la edición española.

Ortiz, E. (2012). Los Niveles Teóricos y Metodológicos en la Investigación Educativa Cinta moebio 43: 14-23

Palella, S. y Martins, F. (2011). Metodología de la investigación cuantitativa. (3aa ed.). Caracas: Fedupel

Pansza, M y otros. 1987. Fundamentación de la Didáctica. Editorial Gernika S.A. México. 2a. Edición. Tomo I.

Pérez, S., Llantá, G. y González, D. (2017). La sistematización de los métodos de enseñanza aprendizaje. Una necesidad de superación de los docentes postgraduados. Revista Conrado, 13(58), 55- 59. Recuperado de http://conrado.ucf.edu.cu/index.php/conrado

Pimienta, J. (2012). Estrategias de enseñanza - aprendizaje. Docencia universitaria basada en competencias. Naucalpan de Juárez, México: Pearson Educación

Poggioli, Lisette. (2018). Estrategias de resolución de problemas / Lisette Poggioli. Serbiula (sistema librum 2.0)

Quijandria, T. (2019). Tesis magistral. Estrategia metodológica para desarrollar el emprendimiento social en los alumnos del vii ciclo de eduación básica regular de una institución educativa de san juan de Lurigancho. Postgrado. Usil.

Real Academia Española. (2015). Diccionario de la Lengua Española, (21 a ed.). Madrid, España

Real Institución educativa privada Española. (2001). Diccionario de la lengua española (23.a ed.). Madrid, España: Autor

Real Academia Española (2017a). Diccionario de la Real Academia Española (REA). Vigésima edición, .Recuperado de http://dle.rae.es/?id=GxPofZ8

Real Academia Española (2017b). Diccionario de la Lengua Española (REA). Recuperado de http://dle.rae.es/?id=GxPofZ8 
Real Decreto 1105/2014, de 26 de diciembre, por el que se establece el currículo básico de la Educación Secundaria Obligatoria y del Bachillerato en España.

Redecker, C. y Punie, Y. (2013). The future of learning 2025: developing a vision for change. Future Learning, Vol. 1, págs. 3 a 17

Reyes Piña, O., \& Bringas Linares, J. (2006). La Modelación Teórica como método de la investigación científica. VARONA, (42), 8-15.

Revilla D. y Sime L. (2002) La investigación en la maestría en educación y doctorado en ciencias de la educación

Rico, P. (2013). Procedimientos y tareas de aprendizaje. La Zona de Desarrollo Próximo 2da edición. La Habana. Editorial: Pueblo y Educación.

Rico P. Santos E. y Martín V. (2013) Proceso de enseñanza- aprendizaje desarrollador en la escuela Primaria. La Habana, Pueblo y Educación.

Robinson, K. (2006). How schools kill creativity (online video). TED Conference 2006. Monterrey, www.ted.com/talks/ken_robinson_says_scholos_kill_creativity

Rodríguez, A. y Pérez, A. O. (2017). Métodos científicos de indagación y de construcción del conocimiento. Revista https://doi.org/10.21158/01208160.n82.2017.1647

Romero A.; Gamarra R.; Miranda E. (2017) influencia etnomatemática en la resolución de problemas en estudiantes del primer grado de la institución educativa bilingüe san francisco distrito Yarinacocha. revista científica señor de Sipán, TZHOECOEN. vol. 10 núm. 1 (2018): vol. 10 n¹.

Rugeles, P., Mora, B. y Metaute, P. (2015). El rol del estudiante en los ambientes educativos mediados por las TIC. Revista Lasallista de Investigación. 12(2), 132138.

Rychen y L. H. Salganik (Eds.). Defining and selecting key competencies, Göttingen: Hogrefe.

Saavedra, A. y Opfer, V. (2012). Teaching and Learning 21st Century Skills: Lessons from the Learning Sciences. A Global Cities Education Network Report. Nueva York, Asia Society. 
Sabariego M. (2004). El proceso de investigación. En R. Bisquerra (Coord.) Metodología de la investigación educativa (capítulo 4, pp. 127-163). Madrid: La Muralla.

Salas-Pilco, S. Z. (2013). Evolution of the framework for 21 st century competencies. Knowledge Management y E-Learning: An International Journal. Vol. 5, No. 1, págs. 10-2

Salinas A. (2004) Tema 4: Métodos de Muestreo. Ciencia UANL, México. Enero-marzo, año - vol. VII, número 001. Universidad Autónoma de Nuevo León Monterrey, México. pp. 121-123

Sánchez. V. (2010). Pedagogía General. UTPL. Maestría: Pedagogía. Guía didáctica Loja. Ecuador

Sánchez, C. y Reyes, C. (2009). Metodología de la Investigación y Diseños en la Investigación Científica. Lima, Perú: Visión Universitaria

Sánchez C. y Reyes C. (2015). Metodología y diseños en la investigación científica, 5ta Edición. Lima. Peru. Editorial: Vision Universitaria

Schoenfeld (1985). Mathematical Problem Solving. California: Berkey

Scott, C.L. (2015). El futuro del aprendizaje (i) ¿Por qué deben cambiar el contenido y los métodos de aprendizaje en el siglo XXI? Investigación y Prospectiva en Educación UNESCO, Paris. [Documentos de Trabajo ERF, No. 13].

Sierra, V. y Álvarez, C. (s/a) Cómo se modela una investigación científica.

Sierra V., Álvarez C. (1996). Metodología de la Investigación Científica. Tacna. Perú, 1996

Sierra R. (2004). Modelo teórico para el diseño de una estrategia pedagógica en la Educación Primaria y Secundaria. Tesis para obtener el grado de Doctor en Educación. Universidad Enrique José Varona. La Habana.

Silva, A. (2011). Determinando la población y la muestra. Recuperado de https://allanucatse.files.wordpress.com/2011/01/tipo-de-muestreo.pdf

Silvestre, M. (2002). Exigencias didácticas para dirigir un proceso de enseñanza aprendizaje desarrollador y educativo. Ediciones CEIDE. México.

Skinner, B. (1974). About behaviorism. New York. Distributed by Random House. 
Skjong, R. y Wentworth, B. (2000). Expert Judgement and risk perception. Recuperado de http://research.dnv.com/skj/Papers/SkjWen.pdf

Sternberg, R.J. y Subotnik, R.F. (compiladores). 2006. Optimizing Student Success in School with the Other Three Rs: Reasoning, Resilience, and Responsibility. Research in Educational Productivity Series. Charlotte, Carolina del Norte

Tambychik, T., y Meerah, T. S. M. (2010). Students' difficulties in mathematics problemsolving: What do they say? In Procedia - Social and Behavioral Sciences (Vol. 8, pp. 142-151). DOI: 10.1016/j.sbspro.2010.12.020

Tobón, S. (2005). Formación basada en competencias (2a. ed.). Bogotá, Colombia: Ecoe. Ediciones.

Tobón, S. (2009a). Formación basada en competencias: pensamiento complejo, diseño curricular y didáctica. Bogotá: Ecoe.

Tobón, S, Pimienta J. y García J. (2010). Secuencias didácticas: Aprendizaje y evaluación de competencias. México: Pearson.

Tobón, S. (2013a). Trabajo colaborativo e inter-aprendizaje. México: CIFE. Recuperado de: https://issuu.com/cife/docs/e-book_aprendizaje_colaborativo_3.6

Tobón, S. (2013b). Formación integral y competencias. Pensamiento complejo, currículo, didáctica y evaluación (4ta. Ed.). Bogotá: ECOE.

Tobón, S. E., Calderón, C. E., Hernández, J. S., y Cardona, S. (2015). Sociedad del Conocimiento: Estudio documental desde una perspectiva humanista y compleja. Paradigma, 36(2), 7-36. Recuperado de https://goo.gl/hg5P6d

Tobón, S., González, L., Nambo, J. S., y Vázquez, J. M. (2015). La Socioformación: Un Estudio Conceptual. Paradigma, 1, 7-29. Recuperado de https://goo.gl/u6JhAj

Tobón, S. (2017). Conceptual analysis of the socioformation according to the knowledge society. Knowledge Society and Quality of Life (KSQL), 1(1), 9-35. https://goo.gl/aJeSvw

Valdez E., Tobón S. (2018). Diseño de situaciones de aprendizaje para la resolución de problemas con base en las matemáticas desde la socioformación. Revista Espacios Vol. 39. N. 59. Pág. 18 - 37. Recuperado de http://www.revistaespacios.com/cited2017/cited2017-18.pdf 
Vara A. (2010). ¿Cómo evaluar la rigurosidad científica de las tesis doctorales? Lima: Facultad de Ciencias Administrativas y Recursos Humanos de la Universidad San Martín de Porres.

Vargas V. (2013). Tesis de Maestría. Factores psicopedagógicos que inciden en el bajo rendimiento académico de la asignatura de español, en la labor docente con estudiantes de sétimo año del Liceo Edgar Cervantes Villalta, Hatillo centro.

Vasco, C.E. (2003). Objetivos específicos, indicadores de logros y competencias ¿y ahora estándares? Educación y Cultura, 62, 33-41.

Velázquez M. (2014). Propuesta metodológica dirigida a la competencia comunicativa en la construcción de textos escritos en los estudiantes de sexto grado en la educación primaria. Tesis para obtener el grado de Doctor en Educación. Pontificia Universidad Católica Americana de los Estados Unidos- Florida

Velásquez y Cruzata, A. (2018). Reflexiones para el debate sobre los conceptos claves en la producción científica del docente investigador contemporáneo: Estrategia Didáctica, Estrategia Metodológica y Alternativa Metodológica. Lima-Perú: USIL.Universidad San Ignacio de Loyola

Villa, A. y Poblete, M. (2004). Practicum y evaluación de competencias. Profesorado. Revista de currículo y formación del profesorado

Villalobos, X. (2008). Resolución de problemas matemáticos: un cambio epistemológico con resultados metodológicos. Revista Iberoamericana sobre Calidad, Eficacia y Cambio en Educación. 3 (1) 36 - 58.

Villarroel, I. (2008). Resolución de problemas en la educación matemática. Chile.

Vygotsky, L. (1979) El desarrollo de los procesos psicológicos superiores. Barcelona: Crítica

Vigotsky, L. S. (1987): Historia del desarrollo de las Funciones Psíquicas Superiores, Ed. Científico Técnica, Ciudad de la Habana, Cuba Habana Cuba.

Vygotski, L. S. (1989). El desarrollo de los procesos psicológicos superiores. Barcelona: Crítica-Grijalbo.

Wagner, T. (2010). Overcoming The Global Achievement Gap (en línea). Cambridge, Massachusetts: Universidad de Harvard.

Weinert, F. E. (2001). Concept of competence: a conceptual clarification, in: D. S. 
Wiggins H., Harding A. y Engelbrecht J. (2017) Student enrichment in mathematics: a case study with first year university students, International Journal of Mathematical Education in Science and Technology, 48:sup1, S16-S29, DOI: 10.1080/0020739X.2017.1352046

Zabalza, M. (2011). Metodología docente. REDU, 9, 75-98. Recuperado de file://C:Users/crowned/Downloads/6150-20380-1.PB.pdf

Zilberstein, J. y Silvestre M. (1997). Una didáctica para una enseñanza y un aprendizaje desarrollador. ICCP. Pueblo y Educación. La Habana. 


\section{Anexos}

\section{Índice de Anexos}

Anexo 1: Matriz de Categorización

Anexo 2: Matriz de consistencia lógica

Anexo 3: Guión de entrevista a los docentes

Anexo 4: Guía de observación de una sesión de aprendizaje del área de Matemática Anexo 5: Tablas del cuestionario a los estudiantes

Anexo 6: Prueba Pedagógica

Anexo 7: Ficha de validación interna

Anexo 8: Ficha de validación externa

Anexo 9: Validación de Instrumentos por criterio de expertos

Anexo 10: Validación de la Propuesta Metodológica por criterio de expertos 


\section{Anexo 1}

Matriz de Categorización

\begin{tabular}{|c|c|c|}
\hline Categoría apriorística & Subcategorías & Indicadores \\
\hline \multirow{7}{*}{$\begin{array}{l}\text { Competencia de Resolución de } \\
\text { Problemas: Es un proceso } \\
\text { complejo que incluye una } \\
\text { interacción de conocimientos y } \\
\text { procesos con el objetivo de guiar } \\
\text { la enseñanza - aprendizaje, } \\
\text { permitiendo al estudiante crear } \\
\text { relaciones entre experiencias, } \\
\text { conceptos, procedimientos e } \\
\text { interpretaciones matemáticas } \\
\text { frente a las situaciones de } \\
\text { contextos diferentes que } \\
\text { estimulen el desarrollo del } \\
\text { aprendizaje interpersonaly social. } \\
\text { (Minedu 2015). }\end{array}$} & Base Conceptual & $\begin{array}{l}\text { Conoce los principios, teorías, leyes y } \\
\text { postulados sobre la resolución de problemas } \\
\text { matemáticos } \\
\text { Maneja argumentos matemáticos para realizar } \\
\text { demostraciones. } \\
\text { Identifica y discrimina la información relevante } \\
\text { para la resolución del problema }\end{array}$ \\
\hline & \multirow{3}{*}{ Base Procedimental } & Realiza representaciones matemáticas \\
\hline & & $\begin{array}{l}\text { Elabora gráficos estadísticos } \\
\text { terminologías y reglas matemáticas. }\end{array}$ \\
\hline & & $\begin{array}{l}\text { Diseña una estrategia para afrontar una } \\
\text { situación problémica, empleando un amplio } \\
\text { repertorio de recursos o procedimientos. }\end{array}$ \\
\hline & \multirow{3}{*}{ Base Actitudinal } & $\begin{array}{l}\text { Muestra motivación al momento de resolver una } \\
\text { situación problémica. }\end{array}$ \\
\hline & & $\begin{array}{l}\text { Valora la actividad realizada, contrastándola con } \\
\text { su realidad }\end{array}$ \\
\hline & & $\begin{array}{l}\text { Respeta las opiniones de los demás al momento } \\
\text { de trabajar en equipo con el objetivo de resolver } \\
\text { una situación problémica }\end{array}$ \\
\hline \multirow{7}{*}{$\begin{array}{l}\text { Estrategia metodológica: } \\
\text { Según Díaz y Hernández (2010), } \\
\text { sostienen que la estrategia } \\
\text { metodológica, está formada por } \\
\text { un conjunto de procedimientos } \\
\text { que ayudan a dirigir la sesión de } \\
\text { clase, con el objetivo de fomentar } \\
\text { conciencia entre los estudiantes } \\
\text { mediante la aplicación de } \\
\text { diversos procedimientos, } \\
\text { aplicando el autoaprendizaje y la } \\
\text { autoevaluación respecto de lo } \\
\text { que están realizando, cómo lo } \\
\text { están realizando y porqué lo están } \\
\text { realizando contribuyendo al } \\
\text { desarrollo de las habilidades y de } \\
\text { la independencia cognoscitiva del } \\
\text { estudiante. }\end{array}$} & $\begin{array}{llr}\text { Exigencia } & \text { de } & \text { la } \\
\text { enseñanza } & & - \\
\text { aprendizaje } & & \end{array}$ & $\begin{array}{l}\text { Diagnostica la situación real para reconocer las } \\
\text { fortalezas y debilidades sobre la resolución de } \\
\text { Problemas. } \\
\text { Aplica las leyes, principios y teorías en la } \\
\text { Enseñanza Aprendizaje de resolución de } \\
\text { problemas. }\end{array}$ \\
\hline & \multirow[t]{2}{*}{$\begin{array}{l}\text { Sistematización del } \\
\text { método problémico }\end{array}$} & $\begin{array}{l}\text { Aplica diferentes sistemas de métodos } \\
\text { problémicos, heurísticos, investigativos y } \\
\text { argumentativos para el tratamiento de } \\
\text { contenidos. }\end{array}$ \\
\hline & & $\begin{array}{l}\text { Presenta contenido a partir de situaciones } \\
\text { problematizadoras, reflexivas y dialógicas. }\end{array}$ \\
\hline & \multirow{2}{*}{ Rol del docente } & $\begin{array}{l}\text { Evidencia ser un mediador asertivo y } \\
\text { competente, que atiende la diversidad del grupo. }\end{array}$ \\
\hline & & $\begin{array}{l}\text { Promueve una buena actitud de aprendizaje a } \\
\text { través del trabajo en grupo. }\end{array}$ \\
\hline & \multirow{2}{*}{ Rol del estudiante } & $\begin{array}{l}\text { Demuestra dominio del saber hacer y es } \\
\text { responsable de su propio aprendizaje. }\end{array}$ \\
\hline & & $\begin{array}{l}\text { Establece relaciones interpersonales asertivas } \\
\text { con sus compañeros. }\end{array}$ \\
\hline
\end{tabular}


Anexo 2

Matriz de consistencia lógica

\begin{tabular}{|c|c|c|c|c|}
\hline tas ci & bjetivos & ate & Subc & \\
\hline \multirow{9}{*}{$\begin{array}{l}\text { Pregunta General: ¿Cómo } \\
\text { desarrollar la competencia de } \\
\text { resolución de problemas } \\
\text { matemáticos en los estudiantes } \\
\text { de V grado de Secundaria } \\
\text { Básica de una institución } \\
\text { educativa privada de Lima? } \\
\text { Pregunta Específica: ¿Cuál es } \\
\text { el estado actual del desarrollo } \\
\text { de la competencia de resolución } \\
\text { de problemas matemáticos en } \\
\text { los estudiantes del V grado de } \\
\text { Secundaria Básica de una } \\
\text { institución educativa privada de } \\
\text { Lima? ¿Cuáles son los } \\
\text { fundamentos teóricos y } \\
\text { metodológicos del desarrollo de } \\
\text { la competencia de la resolución } \\
\text { de problemas matemáticos en } \\
\text { los estudiantes del V grado de } \\
\text { Secundaria Básica de una } \\
\text { institución educativa privada de } \\
\text { Lima? ¿Qué criterios teóricos y } \\
\text { didácticos sustentan (sirven de } \\
\text { base) a la modelación de la } \\
\text { estrategia metodológica para }\end{array}$} & \multirow{9}{*}{ 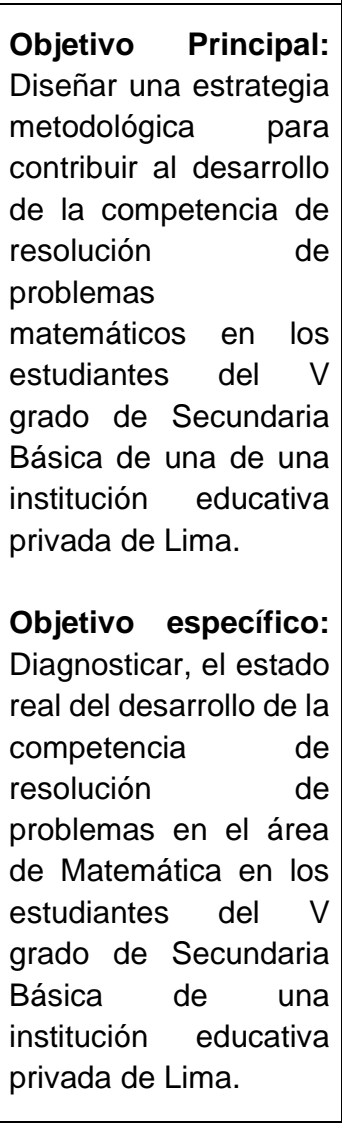 } & \multirow{9}{*}{ 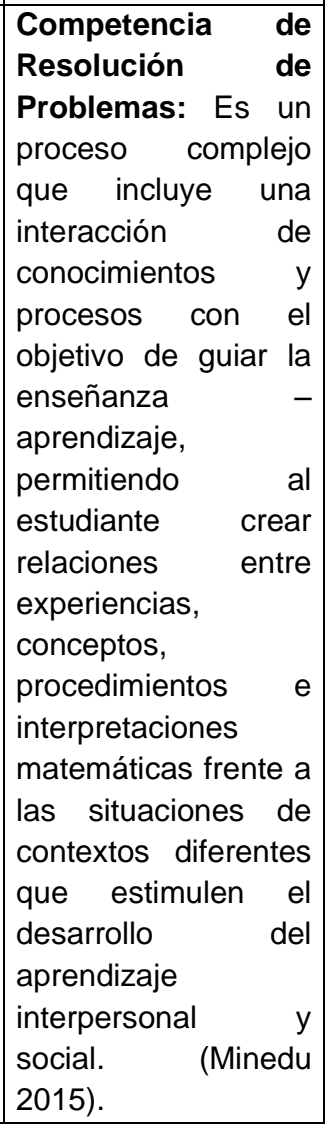 } & \multirow{3}{*}{$\begin{array}{l}\text { Base Conceptual: Según Tobón (2013), son los } \\
\text { conocimientos teóricos, principios o leyes que el estudiante } \\
\text { posee en relación a una actividad determinada y mediante la } \\
\text { cual el estudiante analiza, sistematiza, argumenta, plantea, } \\
\text { discrimina e interioriza la nueva información. }\end{array}$} & $\begin{array}{l}\text { Conoce los principios, teorí } \\
\text { postulados sobre la res } \\
\text { problemas matemáticos }\end{array}$ \\
\hline & & & & $\begin{array}{l}\text { Maneja argumentos matemáticos para } \\
\text { realizar demostraciones. }\end{array}$ \\
\hline & & & & $\begin{array}{l}\text { Identifica y dis } \\
\text { relevante para la } r\end{array}$ \\
\hline & & & \multirow{3}{*}{$\begin{array}{l}\text { Base Procedimental: Según Tobón (2013), es la forma en la } \\
\text { que el estudiante relaciona los nuevos conocimientos con la } \\
\text { experiencia que ya posee, es decir, es el desarrollo de las } \\
\text { habilidades, estrategias y técnicas que el estudiante utiliza al } \\
\text { representar el lenguaje verbal en lenguaje matemático, al } \\
\text { seleccionar y construir gráficos estadísticos según } \\
\text { necesidades del contexto, y al diseñar estrategias para } \\
\text { afrontar una situación problémica. }\end{array}$} & Realiza represent \\
\hline & & & & $\begin{array}{l}\text { Elabora gráfico } \\
\text { terminologías y } \mathrm{r}\end{array}$ \\
\hline & & & & $\begin{array}{l}\text { Diseña una estra } \\
\text { situación problémi } \\
\text { repertorio de recur }\end{array}$ \\
\hline & & & \multirow{3}{*}{$\begin{array}{l}\text { Base Actitudinal: Según Tobón (2013), son las } \\
\text { competencias que permiten relacionar de manera } \\
\text { satisfactoria al estudiante con su entorno, es decir es la } \\
\text { aplicación de la nueva información adquirida frente a las } \\
\text { diversas situaciones problémicas que el sujeto pueda afrontar } \\
\text { en la vida y que se reflejan en su personalidad, en su manejo } \\
\text { de actitudes y emociones. }\end{array}$} & una situación prob \\
\hline & & & & $\begin{array}{lll}\text { Valora la actividad realizada, } \\
\text { contrastándola con su realidad }\end{array}$ \\
\hline & & & & $\begin{array}{l}\text { Respeta las opiniones de los demás al } \\
\text { momento de trabajar en equipo con el } \\
\text { objetivo de resolver una situación } \\
\text { problémica }\end{array}$ \\
\hline
\end{tabular}




\begin{tabular}{|c|c|c|c|c|}
\hline \multirow{6}{*}{$\begin{array}{l}\text { contribuir al desarrollo de la } \\
\text { competencia de resolución de } \\
\text { problemas matemáticos en los } \\
\text { estudiantes del } V \text { grado de } \\
\text { Secundaria Básica de } \\
\text { institución educativa privada de } \\
\text { Lima? ¿Cómo validar la } \\
\text { efectividad de la estructura } \\
\text { metodológica modelada, para } \\
\text { contribuir al aprendizaje en el } \\
\text { desarrollo de la competencia de } \\
\text { resolución de problemas } \\
\text { matemáticos en los estudiantes } \\
\text { del V grado de Secundaria } \\
\text { Básica de institución educativa } \\
\text { privada de Lima? }\end{array}$} & \multirow{6}{*}{ 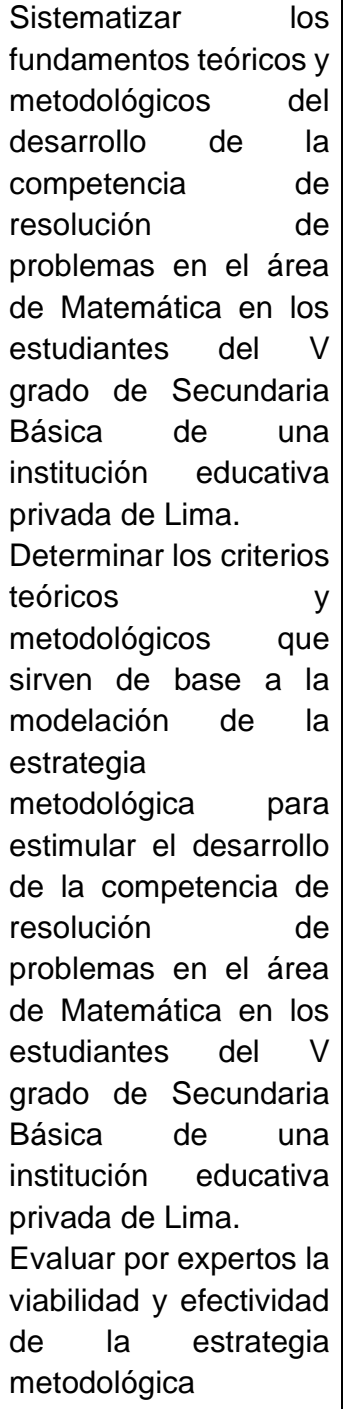 } & \multirow{6}{*}{$\begin{array}{l}\text { Estrategia } \\
\text { metodológica: } \\
\text { Según Díaz y } \\
\text { Hernández (2010), } \\
\text { sostienen que la } \\
\text { estrategia } \\
\text { metodológica, está } \\
\text { formada por un } \\
\text { conjunto de } \\
\text { procedimientos que } \\
\text { ayudan a dirigir la } \\
\text { sesión de clase, con } \\
\text { el objetivo de } \\
\text { fomentar conciencia } \\
\text { entre los estudiantes } \\
\text { mediante la la de } \\
\text { aplicación la } \\
\text { diversos des } \\
\text { procedimientos, } \\
\text { aplicando } \\
\text { autoaprendizaje y la } \\
\text { autoevaluación } \\
\text { respecto de lo que } \\
\text { están realizando, } \\
\text { cómo lo están } \\
\text { realizando y porqué } \\
\text { lo están realizando } \\
\text { contribuyendo a } \\
\text { desarrollo de las } \\
\text { habilidades y de la } \\
\text { independencia } \\
\text { cognoscitiva de } \\
\text { estudiante. }\end{array}$} & \multirow{2}{*}{$\begin{array}{l}\text { Exigencia de la enseñanza - aprendizaje: Según Monereo } \\
\text { (2000) y Velásquez (2018),, proponen que, para realizar un } \\
\text { proceso de aprendizaje óptimo, se debe realizar una } \\
\text { evaluación del contexto real, seleccionar una estrategia que } \\
\text { tenga como objetivo final que el estudiante se desarrolle de } \\
\text { manera integral con pensamiento crítico y toma decisiones } \\
\text { consientes mientras plantea las posibles soluciones a un } \\
\text { problema determinado en su contexto, tanto de manera } \\
\text { individual y conjunta. Esto involucra que el docente profundice } \\
\text { aún más en sus conocimientos relacionados a los contenidos } \\
\text { a enseñar, para poder realizar una eficiente sesión de clase, } \\
\text { donde se planifique, se aplique estrategias idóneas y se lleve } \\
\text { un control constante durante toda la clase. }\end{array}$} & $\begin{array}{l}\text { Diagnostica la situación real para reconocer } \\
\text { las fortalezas y debilidades sobre la } \\
\text { resolución de Problemas. }\end{array}$ \\
\hline & & & & $\begin{array}{l}\text { Aplica las leyes, principios y teorías en la } \\
\text { Enseñanza Aprendizaje de resolución de } \\
\text { problemas. }\end{array}$ \\
\hline & & & $\begin{array}{l}\text { Sistematización del método problémico: Según Ortiz } \\
(2012) \text { y Bravo (2014), la sistematización del método } \\
\text { problémico viene hacer un proceso que busca que el } \\
\text { estudiante como protagonista desarrolle una autogestión del } \\
\text { conocimiento mediante la aplicación de diferentes métodos en }\end{array}$ & $\begin{array}{l}\text { Aplica diferentes sistemas de métodos } \\
\text { problémicos, heurísticos, investigativos y } \\
\text { argumentativos para el tratamiento de } \\
\text { contenidos. }\end{array}$ \\
\hline & & & $\begin{array}{l}\text { donde pueda generarse nuevos conocimientos partiendo de } \\
\text { la reflexión de sus propias experiencias y en la que la nueva } \\
\text { información impartida, potencie, confronte y modifique al } \\
\text { conocimiento anterior para toda la vida. }\end{array}$ & \\
\hline & & & $\begin{array}{l}\text { Rol del docente: Para Díaz, Hernández (2010) y Velásquez } \\
\text { (2018), refiere que el docente tiene la responsabilidad y el } \\
\text { deber de utilizar métodos que motiven al estudiante a }\end{array}$ & $\begin{array}{l}\text { Evidencia ser un mediador asertivo y } \\
\text { competente, que atiende la diversidad del } \\
\text { grupo. }\end{array}$ \\
\hline & & & $\begin{array}{l}\text { desarrollar un pensamiento lógico, un proceso de información, } \\
\text { una construcción de conocimiento y aplicación al contexto } \\
\text { real, al momento de resolver un problema, mediante trabajos } \\
\text { colaborativos, como añade (Tobón 2013a). Esto se debe } \\
\text { reflejar en la secuencia metodológica al desarrollar la clase, } \\
\text { donde la relación entre categorías didácticas debe ser } \\
\text { armónica y dialéctica de manera integral a fin de desarrollar } \\
\text { en el estudiante las habilidades, destrezas y conocimientos } \\
\text { tanto aptitudinales como procedimentales para la vida. }\end{array}$ & a través del trabajo en \\
\hline
\end{tabular}




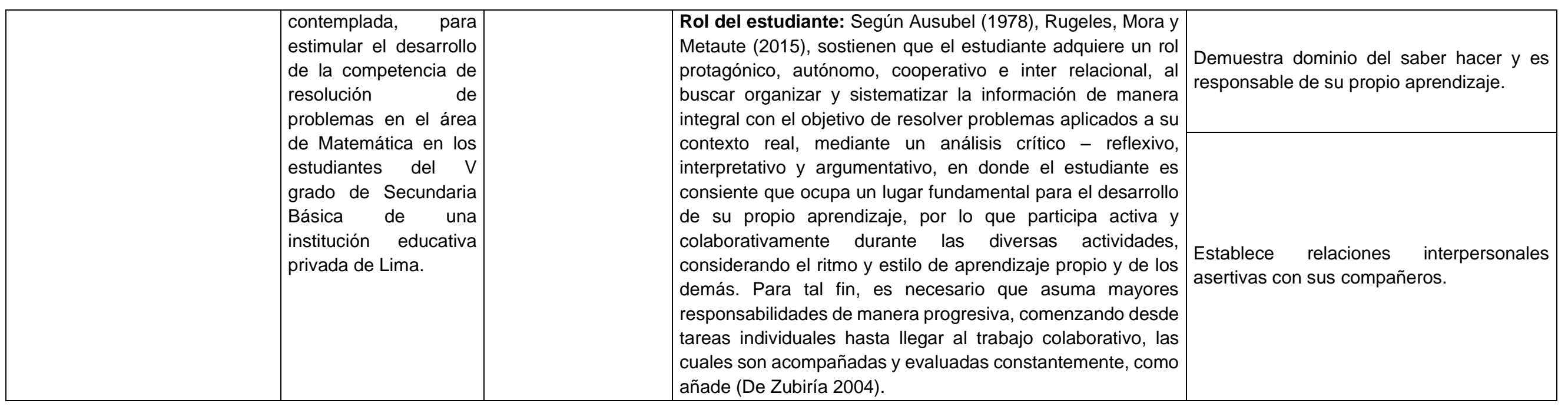




\section{Anexo 3}

\section{Guión de entrevista a los docentes}

\section{OBJETIVOS:}

Constatar el nivel de conocimientos teóricos, didácticos y metodológicos que tienen los docentes en el área de matemática de $\mathrm{V}$ grado de secundaria, considerando las categorías de competencia de resolución de problemas y estrategia metodológica.

\section{DATOS GENERALES:}

Institución:

Fecha:

Área:

Asignatura:

\section{PREGUNTAS:}

1. ¿Qué entiende usted por competencia de resolución de problemas en los estudiantes?

2. ¿Cómo diagnostica usted las fortalezas y debilidades de los estudiantes sobre la resolución de problemas?

3. Antes de realizar su clase, ¿planifica la estrategia didáctica a utilizar? Detalle en que forma.

4. ¿Qué estrategias didácticas de la resolución de problemas utilizas usted para el desarrollo de su clase?

5. ¿Qué métodos utiliza usted para presentar la situación problémica al estudiante, de modo que genere la reflexión y el diálogo?

6. ¿Qué actividades realiza usted para despertar el interés del estudiante respecto del tema a desarrollar en la sesión de clase?

7. ¿De qué manera logra usted que el estudiante reconozca y discrimine información necesaria para la resolución de problemas?

8. ¿Cómo utiliza usted los argumentos matemáticos para realizar demostraciones y contribuir al desarrollo de la competencia de resolución de problemas?

9. ¿Qué método problémico propone usted en donde el estudiante pueda reflexionar y establecer relaciones entre variables e incógnitas?

10. ¿Cómo utiliza usted los recursos educativos y pedagógicos para establecer una mejor comunicación entre el estudiante y profesor?

11. ¿De qué forma utiliza usted los proyectos interdisciplinarios donde el estudiante aplique y valore lo aprendido en clase, a la vida diaria?

12. ¿Qué actividades realiza usted para promover una buena actitud de aprendizaje y la participación activa del estudiante durante la clase?

13. ¿Qué actividades realiza usted, donde el estudiante demuestre lo aprendido en la clase?

14. ¿De qué forma promueve usted, los trabajos de campo donde el estudiante tenga que sustentar públicamente los resultados de su trabajo mediante gráficas estadísticas?

15. ¿Qué diferencia actitudinal encuentra usted en sus estudiantes cuando desarrolla trabajos colaborativos? 
Codificación de las entrevistas

\begin{tabular}{|c|c|c|c|c|}
\hline \multicolumn{5}{|c|}{ Entrevista $1 \quad$ Docente 1} \\
\hline Pregunta & Respuesta & Frase codificada & Microcategorías & \#Cod \\
\hline \multirow{6}{*}{$\begin{array}{l}\text { ¿Qué entiende } \\
\text { usted por } \\
\text { competencia de } \\
\text { resolución de } \\
\text { problemas en los } \\
\text { estudiantes? }\end{array}$} & \multirow{6}{*}{$\begin{array}{l}\text { Es el desenvolvimiento cuando } \\
\text { los chicos, eh digamos la } \\
\text { impresión ante un ejercicio o } \\
\text { problema que se le otorgue. } \\
\text { Usted cree que ¿hay alguna } \\
\text { diferencia entre competencia de } \\
\text { resolución de problemas y } \\
\text { resolución de problemas o es } \\
\text { hablar de lo mismo? } \\
\text { La competencia eh digamos } \\
\text { que, Son las capacidades, las } \\
\text { habilidades, que el alumno se } \\
\text { desenvuelva que busque la } \\
\text { forma no. } \\
\text { La resolución de problemas, } \\
\text { viene a ser, este... es cuando se } \\
\text { le da, se le presenta al alumno y } \\
\text { la competencia es lo que él va a } \\
\text { emplear. }\end{array}$} & $\begin{array}{l}\text { Desenvolvimiento de } \\
\text { los estudiantes }\end{array}$ & $\begin{array}{l}\text { Actitud de los estudiantes } \\
\text { frente a un problema }\end{array}$ & 34 \\
\hline & & $\begin{array}{l}\text { La competencia es } \ldots \\
\text { eh digamos la } \\
\text { impresión ante un } \\
\text { ejercicio }\end{array}$ & $\begin{array}{c}\text { Poco conocimiento acerca de } \\
\text { la competencia de resolución } \\
\text { de problemas }\end{array}$ & 5 \\
\hline & & $\begin{array}{l}\text { La competencia... son } \\
\text { las habilidades para } \\
\text { que el alumno se } \\
\text { desenvuelva }\end{array}$ & $\begin{array}{c}\text { Poco conocimiento acerca de } \\
\text { la competencia de resolución } \\
\text { de problemas }\end{array}$ & 5 \\
\hline & & $\begin{array}{l}\text { La forma de enfrentar } \\
\text { un problema }\end{array}$ & $\begin{array}{l}\text { Estrategia de resolución de } \\
\text { problemas }\end{array}$ & 35 \\
\hline & & $\begin{array}{l}\text { La resolución de } \\
\text { problema es cuando } \\
\text { se le presenta al } \\
\text { alumno }\end{array}$ & $\begin{array}{l}\text { Poco conocimiento acerca de } \\
\text { la resolución de problemas }\end{array}$ & 5 \\
\hline & & $\begin{array}{l}\text { La competencia es lo } \\
\text { que va a emplear para } \\
\text { dar solución al } \\
\text { problema }\end{array}$ & $\begin{array}{c}\text { Poco conocimiento acerca de } \\
\text { la competencia de resolución } \\
\text { de problemas }\end{array}$ & 5 \\
\hline \multirow{6}{*}{$\begin{array}{l}\text { ¿Cómo } \\
\text { diagnostica usted } \\
\text { las fortalezas y } \\
\text { debilidades de } \\
\text { los estudiantes } \\
\text { sobre ra } \\
\text { resolución de } \\
\text { problemas? }\end{array}$} & \multirow{6}{*}{$\begin{array}{l}\text { En primer lugar, comenzando } \\
\text { con nociones previas con los } \\
\text { alumnos, porque ellos tienen } \\
\text { conocimientos básicos, con } \\
\text { preguntas } \\
\text { ¿Alguna otra forma que utilice } \\
\text { para recoger saberes previos? } \\
\text { Bueno aparte de las Practicas } \\
\text { calificadas, intervenciones } \\
\text { orales en pizarra, eh algunos } \\
\text { chicos son valerosos para salir } \\
\text { a pizarra y piden resolverlo en } \\
\text { una hoja aparte antes. }\end{array}$} & $\begin{array}{l}\text { Comenzando con } \\
\text { nociones previas con } \\
\text { los alumnos }\end{array}$ & $\begin{array}{l}\text { Reconocimiento de saberes } \\
\text { previos }\end{array}$ & 2 \\
\hline & & $\begin{array}{l}\text { Porque ellos tienen } \\
\text { conocimientos } \\
\text { básicos }\end{array}$ & $\begin{array}{l}\text { Reconocimiento de saberes } \\
\text { previos }\end{array}$ & 2 \\
\hline & & Con preguntas & Estrategia didáctica & 38 \\
\hline & & Prácticas calificadas & Estrategias de evaluación & 11 \\
\hline & & $\begin{array}{l}\text { Intervenciones orales } \\
\text { en pizarra }\end{array}$ & Estrategia de evaluación & 11 \\
\hline & & $\begin{array}{l}\text { eh algunos chicos son } \\
\text { valerosos para salir a } \\
\text { pizarra }\end{array}$ & $\begin{array}{l}\text { Actitud de los estudiantes } \\
\text { frente a un problema }\end{array}$ & 34 \\
\hline \multirow{7}{*}{$\begin{array}{l}\text { Antes de realizar } \\
\text { su clase, } \\
\text { ¿planifica } \\
\text { estrategia } \\
\text { didáctica } \\
\text { utilizar? Detalle } \\
\text { en que forma. }\end{array}$} & \multirow{7}{*}{$\begin{array}{l}\text { Entrevistado: Si, bueno eh, } \\
\text { planificando en primer lugar } \\
\text { aparte de desarrollar las clases, } \\
\text { eh la motivación no. } \\
\text { Entrevistador: } \\
\text { planifica la motivación en clase? } \\
\text { Poniendo el título y preguntando } \\
\text { si tienen conocimiento del tema. } \\
\text { Colocando por ejemplo el tema: } \\
\text { ecuaciones o en trigonometría } \\
\text { el tema es un poquito más } \\
\text { complejo y se enseña a partir de } \\
\text { primer año no, más o menos ya } \\
\text { tienen una idea. } \\
\text { Entrevistador: ¿Alguna otra } \\
\text { forma que planifique o } \\
\text { demuestre que ha planificado } \\
\text { su estrategia? ¿o solo se da en } \\
\text { la clase y no hay otra forma? En } \\
\text { caso alguien le pidiera una } \\
\text { prueba para demostrar su } \\
\text { planificación. } \\
\text { Mmm, con fichas, con prácticas, } \\
\text { evaluaciones escritas }\end{array}$} & $\begin{array}{l}\text { Si, bueno eh, } \\
\text { planificando en primer } \\
\text { lugar... desarrollar las } \\
\text { clases }\end{array}$ & $\begin{array}{l}\text { Poco conocimiento de una } \\
\text { planificación de estrategia } \\
\text { didáctica }\end{array}$ & 35 \\
\hline & & La motivación & Motivación por el aprendizaje & 36 \\
\hline & & $\begin{array}{l}\text { Poniendo el título y } \\
\text { preguntando si tienen } \\
\text { conocimiento del } \\
\text { tema. }\end{array}$ & $\begin{array}{c}\text { Pobre planificación de la } \\
\text { estrategia didáctica }\end{array}$ & 36 \\
\hline & & 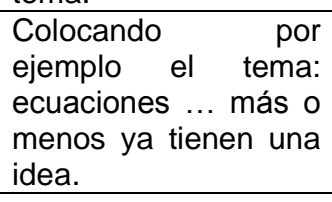 & $\begin{array}{c}\text { Poco conocimiento de una } \\
\text { planificación de estrategia } \\
\text { didáctica }\end{array}$ & 34 \\
\hline & & Fichas & Estrategias de evaluación & 11 \\
\hline & & Prácticas & Estrategias de evaluación & 11 \\
\hline & & Evaluaciones escritas & Estrategias de evaluación & 11 \\
\hline
\end{tabular}




\begin{tabular}{|c|c|c|c|c|}
\hline \multirow{3}{*}{$\begin{array}{l}\text { ¿Qué estrategias } \\
\text { didácticas de la } \\
\text { resolución de } \\
\text { problemas utiliza } \\
\text { usted para el } \\
\text { desarrollo de su } \\
\text { clase? }\end{array}$} & \multirow{3}{*}{$\begin{array}{l}\text { Entrevistado: Eh, formando } \\
\text { grupos heterogéneos, de } 3 \text { o } 4 \\
\text { dependiendo la cantidad. } \\
\text { Aunque en primaria son tan } \\
\text { numerosos que mucho } \\
\text { demoran y en secundaria } \\
\text { resulta más práctico. } \\
\text { Entrevistador: ¿Alguna otra } \\
\text { estrategia didáctica en } \\
\text { secundaria que le haya } \\
\text { funcionado? } \\
\text { Mmm, por el momento hasta allí } \\
\text { con los grupos, ahora con el } \\
\text { libro se da más facilidad } \\
\text { todavía. }\end{array}$} & $\begin{array}{l}\text { formando grupos } \\
\text { heterogéneos, de } 30 \\
4 \text { dependiendo la } \\
\text { cantidad. }\end{array}$ & Trabajo colaborativo & 10 \\
\hline & & $\begin{array}{l}\text { en secundaria resulta } \\
\text { más práctico }\end{array}$ & $\begin{array}{c}\text { Valoración de la estrategia } \\
\text { pedagógica }\end{array}$ & 37 \\
\hline & & $\begin{array}{l}\text { Desarrollo con los } \\
\text { libros }\end{array}$ & $\begin{array}{l}\text { Uso de recursos pedagógicos } \\
\text { tradicional }\end{array}$ & 20 \\
\hline \multirow{4}{*}{$\begin{array}{l}\text { ¿Qué métodos } \\
\text { utiliza usted para } \\
\text { presentar la } \\
\text { situación } \\
\text { problémica al } \\
\text { estudiante, de } \\
\text { modo que genere } \\
\text { la reflexión y el } \\
\text { diálogo? }\end{array}$} & \multirow{4}{*}{$\begin{array}{l}\text { Entrevistado: Mmm, } \ldots \\
\text { digamos le tendría que pedir al } \\
\text { estudiante una opinión sobre el } \\
\text { curso, sobre el tema, sobre lo } \\
\text { que ellos han observado } \\
\text { Entrevistador: ¿Cómo definiría } \\
\text { usted una situación } \\
\text { problémica? } \\
\text { Bueno digamos que para mí, } \\
\text { son las, yo lo observo como la } \\
\text { dificultad no, como una } \\
\text { dificultad que por lo menos } \\
\text { pueda tener el alumno y } \\
\text { también la dificultad mía de } \\
\text { como tenga que emplear las } \\
\text { estrategias }\end{array}$} & $\begin{array}{l}\text { Preguntas abiertas } \\
\text { sobre el tema }\end{array}$ & Estrategia didáctica & 38 \\
\hline & & $\begin{array}{l}\text { Preguntas } \\
\text { sobre lo quertas } \\
\text { observado }\end{array}$ & Estrategia didáctica & 38 \\
\hline & & $\begin{array}{l}\text { yo lo observo como la } \\
\text { dificultad... que .... } \\
\text { pueda tener el alumno }\end{array}$ & $\begin{array}{l}\text { Poco conocimiento acerca de } \\
\text { la situación problémica }\end{array}$ & 39 \\
\hline & & $\begin{array}{l}\text { también la dificultad } \\
\text { mía de como tenga } \\
\text { que emplear las } \\
\text { estrategias }\end{array}$ & $\begin{array}{l}\text { Poco conocimiento del empleo } \\
\text { de las estrategias didácticas }\end{array}$ & 34 \\
\hline \multirow{3}{*}{$\begin{array}{l}\text { ¿Qué actividades } \\
\text { realiza usted } \\
\text { para despertar el } \\
\text { interés del } \\
\text { estudiante } \\
\text { respecto del } \\
\text { tema a } \\
\text { desarrollar en la } \\
\text { sesión de clase? }\end{array}$} & \multirow{3}{*}{$\begin{array}{l}\text { Entrevistado: Bueno por el } \\
\text { momento re preguntas, pero } \\
\text { quisiera elaborar con ellos este } \\
\text { elaborar fichas, como paneles o } \\
\text { sea que ellos elaboren. } \\
\text { Actualmente solamente solo lo } \\
\text { hago con la pizarra. }\end{array}$} & re preguntas & Estrategias didácticas & 38 \\
\hline & & $\begin{array}{l}\text { pero quisiera elaborar } \\
\text { con ellos este elaborar } \\
\text { fichas, como paneles } \\
0 \text { sea que ellos } \\
\text { elaboren. }\end{array}$ & Estrategias motivacionales & 39 \\
\hline & & $\begin{array}{l}\text { Actualmente } \\
\text { solamente solo lo } \\
\text { hago con la pizarra. }\end{array}$ & $\begin{array}{l}\text { Uso de recursos pedagógicos } \\
\text { tradicional }\end{array}$ & 7 \\
\hline \multirow{5}{*}{$\begin{array}{l}\text { ¿De qué manera } \\
\text { logra usted que el } \\
\text { estudiante } \\
\text { reconozca y } \\
\text { discrimine } \\
\text { información } \\
\text { necesaria para la } \\
\text { resolución de } \\
\text { problemas? }\end{array}$} & \multirow{5}{*}{$\begin{array}{l}\text { Entrevistado: La única manera } \\
\text { es este, haciéndole y } \\
\text { elaborando preguntas } \\
\text { Entrevistador: ¿De qué } \\
\text { manera usted motiva a que el } \\
\text { estudiante reconozca la } \\
\text { información que necesita? } \\
\text { ¿Cómo se da cuenta que el } \\
\text { alumno está avanzando y que } \\
\text { acciones realiza? } \\
\text { Yo me doy cuenta, por la } \\
\text { manera en que algunos lo } \\
\text { resuelven con menor tiempo un } \\
\text { ejercicio } \\
\text { Entrevistador: ¿A través de } \\
\text { que se da cuenta de ello? } \\
\text { Por medio de una práctica, o } \\
\text { cuando salen a pizarra en un } \\
\text { paso oral. }\end{array}$} & $\begin{array}{l}\text { La única manera es } \\
\text { este ... }\end{array}$ & $\begin{array}{l}\text { Poco conocimiento acerca de } \\
\text { estrategias de resolución de } \\
\text { problemas }\end{array}$ & 35 \\
\hline & & $\begin{array}{l}\text { haciéndole y } \\
\text { elaborando preguntas }\end{array}$ & Estrategia didáctica & 38 \\
\hline & & $\begin{array}{l}\text { Yo me doy cuenta, por } \\
\text { la manera en que } \\
\text { algunos lo resuelven } \\
\text { con menor tiempo un } \\
\text { ejercicio }\end{array}$ & Estrategia de evaluación & 11 \\
\hline & & práctica & $\begin{array}{c}\text { Estrategia de evaluación } \\
\text { tradicional }\end{array}$ & 11 \\
\hline & & paso oral & $\begin{array}{l}\text { Estrategia de evaluación } \\
\text { tradicional }\end{array}$ & 11 \\
\hline $\begin{array}{lr}\text { ¿Cómo } & \text { utiliza } \\
\text { usted } & \text { los } \\
\text { argumentos } & \\
\end{array}$ & $\begin{array}{lcr}\text { Entrevistado: } & \text { Ah } & \text { algunas } \\
\text { propiedades. } & \text { En } & \text { realidad, } \\
\text { algunos alumnos } & \text { piden... } \\
\end{array}$ & $\begin{array}{l}\text { En realidad, algunos } \\
\text { alumnos piden }\end{array}$ & Motivación del estudiante & 3 \\
\hline
\end{tabular}




\begin{tabular}{|c|c|c|c|c|}
\hline \multirow{3}{*}{\begin{tabular}{ll}
\multicolumn{2}{l}{ matemáticos } \\
para realizar \\
demostraciones y \\
contribuir al \\
desarrollo de la \\
competencia de \\
resolución de \\
problemas?
\end{tabular}} & \multirow{3}{*}{$\begin{array}{l}\text { bueno lo que es productos } \\
\text { notables se hace mediante la } \\
\text { división de dos en un rectángulo } \\
\text { y se puede demostrar. } \\
\text { Entrevistador: ¿Entonces, } \\
\text { usted solo realiza } \\
\text { demostraciones cuando el } \\
\text { alumno lo pide? } \\
\text { Si, más o menos mayormente } \\
\text { cuando el alumno lo pide } \\
\text { Entrevistador: ¿Y en alguna } \\
\text { vez, en alguna prueba ha } \\
\text { tomado una pregunta para que } \\
\text { ellos argumenten? ¿Qué } \\
\text { observo? } \\
\text { No }\end{array}$} & \multirow{2}{*}{$\begin{array}{l}\text { bueno lo que es } \\
\text { productos notables se } \\
\text { hace mediante la } \\
\text { división de dos en un } \\
\text { rectángulo y se puede } \\
\text { demostrar } \\
\text { Si, más o menos } \\
\text { mayormente cuando } \\
\text { el alumno lo pide }\end{array}$} & \multirow{2}{*}{$\begin{array}{l}\text { Dominio teórico del tema } \\
\text { Motivación del estudiante }\end{array}$} & \multirow{2}{*}{$\begin{array}{l}5 \\
\\
\end{array}$} \\
\hline & & & & \\
\hline & & $\begin{array}{l}\text { No (utiliza preguntas } \\
\text { argumentativas en las } \\
\text { pruebas) }\end{array}$ & $\begin{array}{l}\text { Deficiente elaboración de una } \\
\text { prueba }\end{array}$ & 11 \\
\hline \multirow{4}{*}{$\begin{array}{lr}\text { ¿Qué método } \\
\text { problémico } \\
\text { propone usted en } \\
\text { donde } & \text { el } \\
\text { estudiante pueda } \\
\text { reflexionar } \\
\text { establecer } \\
\text { relaciones } & \text { entre } \\
\text { variables } & \text { e } \\
\text { incógnitas? }\end{array}$} & \multirow{4}{*}{$\begin{array}{l}\text { Entrevistado: En una situación } \\
\ldots \text { eh ... bueno aparte de una } \\
\text { ecuación ... eh ... la única } \\
\text { manera que lo puedo realizar, } \\
\text { es escribir en la pizarra, por } \\
\text { ejemplo, haber: con números } \\
\text { no, por ejemplo, } 2 x+1=x+6 \\
\text { Entrevistador: ¿Para usted } \\
\text { profesor eso sería presentar } \\
\text { una situación problémica? } \\
\text { Sí, eso es con número ahora } \\
\text { con letra se puede decir que, en } \\
\text { vez de } 2 \text {, por ejemplo ax }+b=c\end{array}$} & $\begin{array}{l}\text { En una situación ... eh } \\
\ldots \text { bueno aparte de } \\
\text { una ecuación }\end{array}$ & $\begin{array}{l}\text { Poco conocimiento sobre } \\
\text { métodos problémicos }\end{array}$ & 39 \\
\hline & & $\begin{array}{l}\text { la única manera que lo } \\
\text { puedo realizar, es } \\
\text { escribir en la pizarra }\end{array}$ & Estrategia didáctica tradicional & 20 \\
\hline & & $\begin{array}{l}\text { por ejemplo, haber: } \\
\text { con números... por } \\
\text { ejemplo, } 2 x+1=x+6\end{array}$ & $\begin{array}{l}\text { Poco conocimiento sobre } \\
\text { métodos problémicos }\end{array}$ & 39 \\
\hline & & $\begin{array}{l}\text { ahora con letra se } \\
\text { puede decir que, en } \\
\text { vez de } 2 \text {, por ejemplo } \\
a x+b=c\end{array}$ & $\begin{array}{l}\text { Poco conocimiento sobre } \\
\text { métodos problémicos }\end{array}$ & 39 \\
\hline \multirow{4}{*}{$\begin{array}{lr}\text { ¿Cómo utiliza } \\
\text { usted } & \text { los } \\
\text { recursos } & \\
\text { educativos } & \text { y } \\
\text { pedagógicos } & \\
\text { para establecer } \\
\text { una r mejor } \\
\text { comunicación } \\
\text { entre } & \text { el } \\
\text { estudiante } & \text { y } \\
\text { profesor? } & \end{array}$} & \multirow{4}{*}{$\begin{array}{l}\text { Entrevistado: A ya los } \\
\text { recursos, mmm el único recurso } \\
\text { que tengo en material es el libro, } \\
\text { me gustaría tener otros } \\
\text { recursos más, como imágenes } \\
\text { o gráficos, algo por ahí. } \\
\text { Entrevistador: ¿Profesor, hay } \\
\text { alguna diferencia entre recurso } \\
\text { pedagógico y recurso } \\
\text { educativo? } \\
\text { Los recursos pedagógicos son } \\
\text { las estrategias y la parte } \\
\text { educativa lo veo que tiene que } \\
\text { ver más con la formación. }\end{array}$} & $\begin{array}{l}\text { el único recurso que } \\
\text { tengo en material es el } \\
\text { libro }\end{array}$ & $\begin{array}{l}\text { Recursos pedagógicos } \\
\text { limitados }\end{array}$ & 40 \\
\hline & & $\begin{array}{l}\text { me gustaría tener } \\
\text { otros recursos más, } \\
\text { como imágenes o } \\
\text { gráficos, algo por ahí. }\end{array}$ & $\begin{array}{l}\text { Recursos pedagógicos } \\
\text { limitados }\end{array}$ & 40 \\
\hline & & $\begin{array}{l}\text { Los recursos } \\
\text { pedagógicos son las } \\
\text { estrategias }\end{array}$ & $\begin{array}{l}\text { Poco conocimiento acerca de } \\
\text { los recursos pedagógicos }\end{array}$ & 41 \\
\hline & & $\begin{array}{l}\text { la parte educativa lo } \\
\text { veo que tiene que ver } \\
\text { más con la formación. }\end{array}$ & $\begin{array}{l}\text { Poco conocimiento acerca de } \\
\text { los recursos educativos }\end{array}$ & 42 \\
\hline \multirow{5}{*}{$\begin{array}{l}\text { ¿De qué forma } \\
\text { utiliza usted los } \\
\text { proyectos } \\
\text { interdisciplinarios } \\
\text { donde el } \\
\text { estudiante } \\
\text { aplique y valore } \\
\text { lo aprendido en } \\
\text { clase, a la vida } \\
\text { diaria? }\end{array}$} & \multirow{5}{*}{$\begin{array}{l}\text { Entrevistado: Mmm, lo he } \\
\text { trabajado solo en power point. } \\
\text { Digamos que hago que ellos } \\
\text { mismos lo elaboren en el power } \\
\text { point, con el apoyo del docente, } \\
\text { esta sí, esto no y ya más o } \\
\text { menos le daba indicaciones. } \\
\text { Esto solo en mi área. } \\
\text { Entrevistador: ¿De qué } \\
\text { manera era evaluado, solo por } \\
\text { usted o había alguien más? } \\
\text { Era una presentación donde } \\
\text { claro tenía que estar presente el } \\
\text { profesor, el director en todo } \\
\text { caso. } \\
\text { Entrevistador: ¿Alguna otra } \\
\text { opción para manejar proyectos } \\
\text { o a utilizado otra forma? } \\
\text { No, solo power point }\end{array}$} & $\begin{array}{l}\text { lo he trabajado solo en } \\
\text { power point. }\end{array}$ & Limitado uso de las Tic's & 43 \\
\hline & & $\begin{array}{l}\text { Digamos que hago } \\
\text { que ellos mismos lo } \\
\text { elaboren en el power } \\
\text { point, con el apoyo del } \\
\text { docente, esta sí, esto } \\
\text { no y ya más o menos } \\
\text { le daba indicaciones. }\end{array}$ & Estrategia didáctica & 38 \\
\hline & & Esto solo en mi área. & $\begin{array}{l}\text { No utiliza proyectos } \\
\text { interdisciplinarios }\end{array}$ & 27 \\
\hline & & $\begin{array}{l}\text { Era una presentación } \\
\text { donde claro tenía que } \\
\text { estar presente el } \\
\text { profesor, el director en } \\
\text { todo caso }\end{array}$ & $\begin{array}{c}\text { Escasa estrategia de } \\
\text { evaluación }\end{array}$ & 44 \\
\hline & & No, solo power point & Limitado uso de las Tic's & 43 \\
\hline
\end{tabular}




\begin{tabular}{|c|c|c|c|c|}
\hline \multirow{4}{*}{$\begin{array}{l}\text { ¿Qué actividades } \\
\text { realiza usted } \\
\text { para promover } \\
\text { una buena } \\
\text { actitud de } \\
\text { aprendizaje y la } \\
\text { participación } \\
\text { activa del } \\
\text { estudiante } \\
\text { durante la clase? }\end{array}$} & \multirow{4}{*}{$\begin{array}{l}\text { Entrevistado: Me gustaría } \\
\text { utilizar una dinámica, pero } \\
\text { actualmente poco lo utilizo, } \\
\text { porque ya conozco a los } \\
\text { alumnos, bueno no con todos } \\
\text { ah, pero hay alumnos que no lo } \\
\text { toman muy enserio, hay } \\
\text { alumnos que son un poco } \\
\text { rebeldes en ese aspecto. Lo he } \\
\text { intentado pero no me funciono. }\end{array}$} & $\begin{array}{l}\text { Me gustaría utilizar } \\
\text { una dinámica, pero } \\
\text { actualmente poco lo } \\
\text { utilizo }\end{array}$ & $\begin{array}{c}\text { Uso limitado de estrategias } \\
\text { didácticas }\end{array}$ & 38 \\
\hline & & $\begin{array}{l}\text { porque ya conozco a } \\
\text { los alumnos }\end{array}$ & $\begin{array}{c}\text { Prejuicio del profesor con el } \\
\text { aula }\end{array}$ & 45 \\
\hline & & \begin{tabular}{l}
\multicolumn{3}{l}{ pero hay alumnos que } \\
no lo toman muy \\
enserio...
\end{tabular} & Falta de manejo en el aula & 31 \\
\hline & & $\begin{array}{l}\text { Lo he intentado pero } \\
\text { no me funciono } \\
\end{array}$ & $\begin{array}{l}\text { Pasivismo ante el fracaso del } \\
\text { uso de estrategias didácticas }\end{array}$ & 45 \\
\hline \multirow{5}{*}{$\begin{array}{lr}\text { ¿Qué actividades } \\
\text { realiza } & \text { usted, } \\
\text { donde } & \text { el } \\
\text { estudiante } & \\
\text { demuestre } & \text { lo } \\
\text { aprendido en la } \\
\text { clase? }\end{array}$} & \multirow{5}{*}{$\begin{array}{l}\text { Entrevistado: Bueno aparte de } \\
\text { las practicas, en la participación } \\
\text { en pizarra. } \\
\text { Entrevistador: ¿Alguna otra } \\
\text { que le gustaría trabajar? } \\
\text { Algo que a mí me gustaría como } \\
\text { docente es utilizar las Tics. } \\
\text { Entrevistador: ¿Siente algún } \\
\text { respaldo de la institución acerca } \\
\text { de este tema o lo ha comentado } \\
\text { con otro profesor? } \\
\text { Bueno se le mencionó, pero } \\
\text { será por la parte de inversión yo } \\
\text { supongo, pero sería bueno este } \\
\text { no, si es que se propone y se } \\
\text { acepta eh, con una capacitación } \\
\text { tener un día y una fecha, } \\
\text { capacitarnos a los docentes. }\end{array}$} & las practicas & Estrategias de evaluación & 11 \\
\hline & & $\begin{array}{l}\text { la participación en } \\
\text { pizarra }\end{array}$ & Estrategias de evaluación & 11 \\
\hline & & $\begin{array}{l}\text { me gustaría como } \\
\text { docente utilizar las } \\
\text { Tics } \\
\end{array}$ & $\begin{array}{c}\text { Motivación por el uso de las } \\
\text { Tic's }\end{array}$ & 46 \\
\hline & & $\begin{array}{l}\text { se le mencionó, pero } \\
\text { será por la parte de } \\
\text { inversión yo supongo }\end{array}$ & $\begin{array}{l}\text { Poco respaldo de la institución } \\
\text { hacia el uso de las Tic's }\end{array}$ & 43 \\
\hline & & $\begin{array}{l}\text { con una capacitación } \\
\text { tener un día y una } \\
\text { fecha, capacitarnos a } \\
\text { los docentes }\end{array}$ & $\begin{array}{c}\text { Motivación por el uso de las } \\
\text { Tic's }\end{array}$ & 47 \\
\hline \multirow{6}{*}{$\begin{array}{l}\text { ¿De qué forma } \\
\text { promueve usted, } \\
\text { los trabajos de } \\
\text { campo donde el } \\
\text { estudiante tenga } \\
\text { que sustentar } \\
\text { públicamente los } \\
\text { resultados de su } \\
\text { trabajo mediante } \\
\text { gráficas } \\
\text { estadísticas? }\end{array}$} & \multirow{6}{*}{$\begin{array}{l}\text { Entrevistado: No he utilizado } \\
\text { eso aún. } \\
\text { Entrevistador: ¿Cómo le haría } \\
\text { en caso pudiera hacerlo? } \\
\text { En la parte de trigonometría, lo } \\
\text { utilizaría como una medición, la } \\
\text { proyección de su sombra, por } \\
\text { ejemplo. En primer lugar, haría } \\
\text { grupos pares o grupos de } 3 \text {, y } \\
\text { dejaría que uno de ellos se } \\
\text { proyecte no, que proyecte su } \\
\text { sombra, y la idea es que ellos } \\
\text { midan no, de los pies hacía con } \\
\text { respecto a la sombra. Con eso } \\
\text { mazo menos podríamos ah, con } \\
\text { su altura del alumno, que midan } \\
\text { la altura del alumno eh, se } \\
\text { podría decir que forman, las } \\
\text { proyecciones de la sombra con } \\
\text { la altura del alumno forman un } \\
\text { Angulo de } 90 \text { no, bien entonces } \\
\text { ahora quiero ver la distancia de } \\
\text { la proyección hacia la parte más } \\
\text { alta, usando el teorema de } \\
\text { Pitágoras } \\
\text { Entrevistador: ¿En que parte } \\
\text { utilizaría el uso de graficas } \\
\text { estadísticas en esta actividad? } \\
\text { Bueno la verdad relación no } \\
\text { habría con mi curso, a menos } \\
\text { que saque un promedio de sus } \\
\text { datos no, de sus datos. }\end{array}$} & $\begin{array}{l}\text { No he utilizado eso } \\
\text { aún }\end{array}$ & $\begin{array}{l}\text { Falta de uso de trabajos de } \\
\text { campo }\end{array}$ & 48 \\
\hline & & \begin{tabular}{|l} 
lo utilizaría como una \\
medición, la \\
proyección de su \\
sombra, por ejemplo \\
\end{tabular} & $\begin{array}{l}\text { Poco conocimiento acerca del } \\
\text { uso de gráficos estadísticos } \\
\text { orientados a conseguir un } \\
\text { aprendizaje significativo }\end{array}$ & 49 \\
\hline & & $\begin{array}{l}\text { En primer lugar haría } \\
\text { grupos pares o grupos } \\
\text { de } 3\end{array}$ & Trabajo colaborativo & 10 \\
\hline & & $\begin{array}{l}\text { dejaría que uno de } \\
\text { ellos se proyecte no, } \\
\text { que proyecte su } \\
\text { sombra, y la idea es } \\
\text { que ellos midan no, de } \\
\text { los pies hacía con } \\
\text { respecto a la sombra } \\
\end{array}$ & Estrategia didáctica & 38 \\
\hline & & $\begin{array}{l}\text { entonces ahora quiero } \\
\text { ver la distancia de la } \\
\text { proyección hacia la } \\
\text { parte más alta, } \\
\text { usando el teorema de } \\
\text { Pitágoras } \\
\end{array}$ & $\begin{array}{l}\text { Poco conocimiento del empleo } \\
\text { de las estrategias didácticas }\end{array}$ & 34 \\
\hline & & $\begin{array}{l}\text { la verdad relación no } \\
\text { habría con mi curso, a } \\
\text { menos que saque un } \\
\text { promedio de sus } \\
\text { datos no, de sus } \\
\text { datos. }\end{array}$ & $\begin{array}{l}\text { Poco conocimiento acerca del } \\
\text { uso de gráficos estadísticos } \\
\text { orientados a conseguir un } \\
\text { aprendizaje significativo }\end{array}$ & 49 \\
\hline
\end{tabular}


¿Qué diferencia actitudinal encuentra usted en estudiantes cuando desarrolla trabajos colaborativos?
Entrevistado: Diferente no, sino que siempre que forman grupos, he notado que se juntan los que congenian mas no, he notado más con el salón de intermedio, entonces siempre le digo formen grupo de 3 , pero siempre se juntan. lo que pienso hacer formar grupos por sorteo, o sea sortear.

Entrevistador: ¿Hasta el momento cual ha sido su percepción acerca de la actitud de los estudiantes?

Bueno son parejos, todos trabajan bien, lo que pasa es que hay 4 alumnos del año pasado, entonces hay alumnos que se han acoplado y hay una diferencia en conocimientos.

Entrevistador: ¿Sus actitudes de esos alumnos muestran motivación?

A las chicas les falta motivación, los varoncitos tienen una actitud diferente. Osea la actitud es lo que marca el curso, lo toman seriamente no lo toman al juego. Las señoritas mayormente chacota.

Entrevistador: ¿Intento cambiar eso con alguna otra estrategia?

Si e utilizado, pero digamos que rebota otra vez, están buen tiempo así, pero otra vez quieren regresar a lo mismo.

\begin{tabular}{|l|c|c|}
\hline $\begin{array}{l}\text { siempre que forman } \\
\text { grupos, he notado que } \\
\text { se juntan los que } \\
\text { congenian mas }\end{array}$ & $\begin{array}{c}\text { Relaciones interpersonales de } \\
\text { los estudiantes de forma } \\
\text { selectiva }\end{array}$ & 50 \\
\hline $\begin{array}{l}\text { lo que pienso hacer } \\
\text { formar grupos por } \\
\text { sorteo, o sea sortear }\end{array}$ & $\begin{array}{c}\text { Poco conocimiento del empleo } \\
\text { de estrategias didácticas }\end{array}$ & 34 \\
\hline $\begin{array}{l}\text { Bueno son parejos, } \\
\text { todos trabajan bien }\end{array}$ & $\begin{array}{c}\text { Pobre criterio para evaluar la } \\
\text { actitud de los estudiantes }\end{array}$ & 51 \\
\hline $\begin{array}{l}\text { lo que pasa es que } \\
\text { hay } 4 \text { alumnos del año } \\
\text { pasado, entonces hay } \\
\text { alumnos que se han } \\
\text { acoplado y hay una } \\
\text { diferencia } \\
\text { conocimientos }\end{array}$ & Prejuicio con el aula & 55 \\
\hline $\begin{array}{l}\text { A las chicas les falta } \\
\text { motivación }\end{array}$ & Falta de compromiso de los \\
\hline $\begin{array}{l}\text { los varoncitos tienen } \\
\text { una actitud diferente. } \\
\text { Osea la actitud es lo } \\
\text { que marca el curso, lo } \\
\text { toman seriamente no } \\
\text { lo toman al juego }\end{array}$ & estudiantes por aprender & 56 \\
\hline $\begin{array}{l}\text { Si e utilizado, pero } \\
\text { digamos que rebota } \\
\text { otra vez, están buen } \\
\text { tiempo así, pero otra } \\
\text { vez quieren regresar a } \\
\text { lo mismo. }\end{array}$ & $\begin{array}{c}\text { Pasivismo ante el fracaso del } \\
\text { uso de estrategias didácticas }\end{array}$ & 45 \\
& & \\
\hline & & \\
\hline
\end{tabular}

\begin{tabular}{|c|c|c|c|c|}
\hline \multicolumn{5}{|c|}{ Entrevista 2 Docente 2} \\
\hline Pregunta & Respuesta & Frase codificada & Microcategorías & \#Cod \\
\hline \multirow[t]{2}{*}{$\begin{array}{l}\text { ¿Qué entiende } \\
\text { usted por } \\
\text { competencia de } \\
\text { resolución de } \\
\text { problemas en los } \\
\text { estudiantes? }\end{array}$} & \multirow{2}{*}{$\begin{array}{l}\text { La competencia de resolución } \\
\text { de problemas son las } \\
\text { habilidades y destrezas que } \\
\text { tiene una persona para } \\
\text { comprender, transformar y dar } \\
\text { solución a una situación } \\
\text { problemática. } \\
\text { ¿Usted cree que hay alguna } \\
\text { diferencia entre competencia de } \\
\text { resolución de problemas y } \\
\text { resolución de problemas o es } \\
\text { hablar de lo mismo? } \\
\text { La competencia es la habilidad } \\
\text { que tiene la persona y la } \\
\text { resolución de problemas es el } \\
\text { proceso desarrollado del } \\
\text { mismo. }\end{array}$} & $\begin{array}{lr}\begin{array}{l}\text { La competencia } \\
\text { resolución }\end{array} \\
\text { problemas son le } \\
\text { habilidades } \\
\text { destrezas que } \\
\begin{array}{l}\text { una persona } \\
\text { comprender, }\end{array} \\
\begin{array}{lr}\text { transformar y } \\
\text { solución a dar } \\
\text { situación a una } \\
\text { problemática }\end{array} \\
\end{array}$ & $\begin{array}{l}\text { Dominio teórico de las } \\
\text { competencias }\end{array}$ & 57 \\
\hline & & $\begin{array}{l}\text { La competencia es la } \\
\text { habilidad que tiene la } \\
\text { persona y la } \\
\text { resolución } \\
\text { problemas es el } \\
\text { proceso desarrollado } \\
\text { del mismo }\end{array}$ & $\begin{array}{c}\text { Falta de conocimiento acerca } \\
\text { de la competencia de } \\
\text { resolución de problemas }\end{array}$ & 5 \\
\hline $\begin{array}{l}\text { ¿Cómo } \\
\text { diagnostica usted } \\
\text { las fortalezas y } \\
\text { debilidades de }\end{array}$ & $\begin{array}{l}\text { Se realiza evaluaciones orales } \\
\text { acerca de problemas que se } \\
\text { dan en el día a día y practicas } \\
\text { calificadas donde se pueda }\end{array}$ & $\begin{array}{lr}\text { Se } & \text { realiza } \\
\text { evaluaciones } & \text { orales } \\
\text { acerca de } & \text { problemas }\end{array}$ & $\begin{array}{l}\text { Limitado uso de situaciones } \\
\text { problematizadoras }\end{array}$ & 58 \\
\hline
\end{tabular}




\begin{tabular}{|c|c|c|c|c|}
\hline \multirow[t]{2}{*}{$\begin{array}{lr}\text { los estudiantes } \\
\text { sobre } & \text { la } \\
\text { resolución } & \text { de } \\
\text { problemas? }\end{array}$} & \multirow[t]{2}{*}{$\begin{array}{lll}\text { observar paso } & \text { a } & \text { paso el } \\
\text { procedimiento } & \text { al } & \text { resolver } \\
\text { problemas. } & & \end{array}$} & $\begin{array}{l}\text { que se dan en el día a } \\
\text { día }\end{array}$ & & \\
\hline & & $\begin{array}{l}\text { practicas calificadas } \\
\text { donde se pueda } \\
\text { observar paso a paso } \\
\text { el procedimiento al } \\
\text { resolver problemas }\end{array}$ & $\begin{array}{l}\text { Uso de estrategias de } \\
\text { evaluación orientadas solo al } \\
\text { conocimiento }\end{array}$ & 11 \\
\hline \multirow{2}{*}{$\begin{array}{lr}\text { Antes de realizar } \\
\text { su } & \text { clase, } \\
\text { ¿planifica } & \text { la } \\
\text { estrategia } & \\
\text { didáctica } & \text { a } \\
\text { utilizar? } & \text { Detalle } \\
\text { en que forma. }\end{array}$} & \multirow{2}{*}{$\begin{array}{l}\text { Ahh, bueno... se revisa el } \\
\text { material propuesto y el nivel de } \\
\text { los problemas, de acuerdo al } \\
\text { tiempo a tener en la clase, } \\
\text { entonces se planifica la } \\
\text { motivación, estructura de la } \\
\text { clase y retroalimentación. }\end{array}$} & $\begin{array}{l}\text { se revisa el material } \\
\text { propuesto y el nivel de } \\
\text { los problemas }\end{array}$ & $\begin{array}{l}\text { Limitado uso de recursos } \\
\text { pedagógicos }\end{array}$ & 7 \\
\hline & & $\begin{array}{l}\text { de acuerdo al tiempo } \\
\text { a tener en la clase, } \\
\text { entonces se planifica } \\
\text { la motivación, } \\
\text { estructura de la clase } \\
\text { y retroalimentación }\end{array}$ & $\begin{array}{c}\text { Planificación centrada en el } \\
\text { conocimiento }\end{array}$ & 59 \\
\hline \multirow{3}{*}{$\begin{array}{l}\text { ¿Qué estrategias } \\
\text { didácticas de la } \\
\text { resolución de } \\
\text { problemas utiliza } \\
\text { usted para el } \\
\text { desarrollo de su } \\
\text { clase? }\end{array}$} & \multirow{3}{*}{$\begin{array}{l}\text { Ahh.. este... Se formula } \\
\text { ejemplos de situaciones } \\
\text { problemáticas no... de acuerdo } \\
\text { al tema y cada parte que tiene, } \\
\text { presentándola en la pizarra o } \\
\text { utilizando una ppt }\end{array}$} & $\begin{array}{l}\text { Se formula ejemplos } \\
\text { de situaciones } \\
\text { problemáticas no... de } \\
\text { acuerdo al temas }\end{array}$ & Situaciones problémicas & 59 \\
\hline & & $\begin{array}{l}\text { presentándola en la } \\
\text { pizarra }\end{array}$ & $\begin{array}{c}\text { Uso limitado de recursos } \\
\text { pedagógicos }\end{array}$ & 7 \\
\hline & & utilizando una ppt & Uso de Tic & 43 \\
\hline \multirow{2}{*}{$\begin{array}{l}\text { ¿Qué métodos } \\
\text { utiliza usted para } \\
\text { presentar la } \\
\text { situación } \\
\text { problémica al } \\
\text { estudiante, de } \\
\text { modo que genere } \\
\begin{array}{ll}\text { la reflexión y el } \\
\text { diálogo? }\end{array}\end{array}$} & \multirow{2}{*}{$\begin{array}{l}\text { Ehh, se plantean ejemplos de } \\
\text { situaciones reales o problemas } \\
\text { de aplicación donde el } \\
\text { estudiante tenga que analizar a } \\
\text { mayor detalle. } \\
\text { ¿Cómo definiría usted una } \\
\text { situación problémica? } \\
\text { Es un problema que se da de } \\
\text { acuerdo a una situación de la } \\
\text { vida diaria. }\end{array}$} & $\begin{array}{l}\text { se plantean ejemplos } \\
\text { de situaciones reales } \\
\text { o problemas de } \\
\text { aplicación donde el } \\
\text { estudiante tenga que } \\
\text { analizar a mayor } \\
\text { detalle }\end{array}$ & $\begin{array}{l}\text { Uso de situaciones } \\
\text { problémicas }\end{array}$ & 59 \\
\hline & & $\begin{array}{l}\text { Es un problema que } \\
\text { se da de acuerdo a } \\
\text { una situación de la } \\
\text { vida diaria }\end{array}$ & $\begin{array}{c}\text { Dominio teórico sobre } \\
\text { situaciones problematizadoras }\end{array}$ & 39 \\
\hline \multirow{2}{*}{$\begin{array}{l}\text { ¿Qué actividades } \\
\text { realiza usted } \\
\text { para despertar el } \\
\text { interés } \\
\text { estudiante } \\
\text { respecto del } \\
\text { tema del } \\
\text { desarrollar en la } \\
\text { sesión de clase? }\end{array}$} & \multirow[b]{2}{*}{$\begin{array}{l}\text { Bueno, yo utilizo lluvia de ideas } \\
\ldots \text { y también diversas } \\
\text { situaciones dadas en el día a } \\
\text { día para que el estudiante } \\
\text { pueda contrastar su realidad. }\end{array}$} & $\begin{array}{l}\text { yo utilizo lluvia de } \\
\text { ideas }\end{array}$ & Estrategias didácticas & 38 \\
\hline & & $\begin{array}{lr}\text { también } & \text { diversas } \\
\text { situaciones dadas en } \\
\text { el día a día para que el } \\
\text { estudianterreda } \\
\text { contrastar su realidad }\end{array}$ & $\begin{array}{l}\text { Uso de situaciones } \\
\text { problematizadoras }\end{array}$ & 59 \\
\hline \multirow{4}{*}{$\begin{array}{l}\text { ¿De qué manera } \\
\text { logra usted que el } \\
\text { estudiante } \\
\text { reconozca y } \\
\text { discrimine } \\
\text { información } \\
\text { necesaria para la } \\
\text { resolución de } \\
\text { problemas? }\end{array}$} & \multirow{4}{*}{$\begin{array}{l}\text { Bueno, cuando realizo mi clase, } \\
\text { trato de que el estudiante en } \\
\text { cada momento analice el } \\
\text { problema y determine el orden } \\
\text { de operación de resolución de } \\
\text { problemas. } \\
\text { ¿De qué manera usted motiva a } \\
\text { que el estudiante reconozca la } \\
\text { información que necesita? } \\
\text { Se realiza la lectura y análisis } \\
\text { en conjunto con el alumno y } \\
\text { luego se explica cada paso del } \\
\text { planteo y resolución, para } \\
\text { después proponerle una }\end{array}$} & $\begin{array}{l}\text { cuando realizo mi } \\
\text { clase, trato de que el } \\
\text { estudiante en cada } \\
\text { momento analice el } \\
\text { problema }\end{array}$ & Estrategia didáctica & 38 \\
\hline & & $\begin{array}{lr}\text { determine el orden de } \\
\text { operación } & \text { de } \\
\text { resolución } & \text { de } \\
\text { problemas } & \\
\end{array}$ & $\begin{array}{l}\text { Enseñanza centrada en la } \\
\text { operación del problema }\end{array}$ & 70 \\
\hline & & $\begin{array}{l}\text { Se realiza la lectura y } \\
\text { análisis en conjunto } \\
\text { con el alumno }\end{array}$ & Estrategia didáctica & 38 \\
\hline & & $\begin{array}{l}\text { luego se explica cada } \\
\text { paso del planteo y } \\
\text { resolución }\end{array}$ & $\begin{array}{c}\text { Dominio teórico y } \\
\text { metodológico de la resolución } \\
\text { de problemas }\end{array}$ & 5 \\
\hline
\end{tabular}




\begin{tabular}{|c|c|c|c|c|}
\hline & $\begin{array}{l}\text { situación similar al primer } \\
\text { problema. } \\
\text { ¿Cómo se da cuenta que el } \\
\text { alumno esta avanzando y que }\end{array}$ & $\begin{array}{l}\text { para después } \\
\text { proponerle } \\
\text { situación similar al } \\
\text { primer problema }\end{array}$ & Estrategia didáctica & 38 \\
\hline & $\begin{array}{l}\text { acciones realiza? } \\
\text { Haber, ehh.. lo que yo hago, es } \\
\text { observar su análisis y } \\
\text { procedimiento en el momento } \\
\text { que realiza su resolución en el } \\
\text { problema dado. }\end{array}$ & $\begin{array}{l}\text { observo su análisis y } \\
\text { procedimiento en el } \\
\text { momento que realiza } \\
\text { su resolución en el } \\
\text { problema dado }\end{array}$ & Estrategia de evaluación & 11 \\
\hline \multirow{4}{*}{$\begin{array}{lr}\text { ¿Cómo utiliza } \\
\text { usted los } \\
\text { argumentos } \\
\text { matemáticos } \\
\text { para realizar } \\
\text { demostraciones y } \\
\text { contribuir al } \\
\text { desarrollo de la } \\
\text { competencia de } \\
\text { resolución } & \text { de } \\
\text { problemas? }\end{array}$} & \multirow{4}{*}{$\begin{array}{l}\text { Se avanza en conjunto con el } \\
\text { alumno, explicando cada } \\
\text { propiedad y operación ... en el } \\
\text { momento que el alumno } \\
\text { resuelva de forma } \\
\text { independiente el problema que } \\
\text { se observa y reafirma o corrige } \\
\text { cada paso que se realiza. } \\
\text { ¿Y ah tomado preguntas } \\
\text { argumentativas? } \\
\text { observo? } \\
\text { Si eh tomado ese tipo de } \\
\text { preguntas, allí observo que la } \\
\text { mayoría logran entender el } \\
\text { procedimiento a seguir en la } \\
\text { resolución, pero muchas veces } \\
\text { no tienen la forma correcta de } \\
\text { expresar sus ideas. }\end{array}$} & $\begin{array}{l}\text { Se avanza en } \\
\text { conjunto con el } \\
\text { alumno, explicando } \\
\text { cada propiedad y } \\
\text { operación }\end{array}$ & $\begin{array}{l}\text { Estrategias de enseñanza } \\
\text { constructivista }\end{array}$ & 21 \\
\hline & & $\begin{array}{l}\text { en el momento que el } \\
\text { alumno resuelva de } \\
\text { forma independiente } \\
\text { el problema... eh... se } \\
\text { observa y reafirma o } \\
\text { corrige cada paso que } \\
\text { se realiza }\end{array}$ & Mediador asertivo & 4 \\
\hline & & $\begin{array}{lrr}\text { observo } & \text { que } & \text { la } \\
\text { mayoría } & \text { logran } \\
\text { entender } & \text { el } \\
\text { procedimiento } & \text { a } \\
\text { seguir en la resolución }\end{array}$ & Estrategia de evaluación & 11 \\
\hline & & $\begin{array}{l}\text { pero muchas veces no } \\
\text { tienen la forma } \\
\text { correcta de expresar } \\
\text { sus ideas }\end{array}$ & $\begin{array}{c}\text { Deficiente expresión de ideas } \\
\text { matemáticas }\end{array}$ & 60 \\
\hline \multirow{2}{*}{$\begin{array}{lr}\text { ¿Qué método } \\
\text { problémico } \\
\text { propone usted en } \\
\text { donde } & \text { el } \\
\text { estudiante pueda } \\
\text { reflexionar } \\
\text { establecer } \\
\text { relaciones } & \text { entre } \\
\text { variables } & \text { e } \\
\text { incógnitas? }\end{array}$} & \multirow{2}{*}{$\begin{array}{l}\text { Mmmm, propondría situaciones } \\
\text { problémicas para analizar cada } \\
\text { parte del problema y luego } \\
\text { plantear cada ecuación, según } \\
\text { corresponda cada datos o datos } \\
\text { con la o las incógnitas del } \\
\text { problema. }\end{array}$} & $\begin{array}{ll}\text { propondría } & \\
\text { situaciones } & \\
\text { problémicas } & \text { para } \\
\text { analizar cada } & \text { parte } \\
\text { del problema } & \\
\end{array}$ & Estrategia didáctica & 38 \\
\hline & & $\begin{array}{l}\text { y luego plantear cada } \\
\text { ecuación, según } \\
\text { corresponda cada } \\
\text { datos o datos con la o } \\
\text { las incógnitas del } \\
\text { problema. }\end{array}$ & Interpretación matemática & 61 \\
\hline \multirow{4}{*}{$\begin{array}{lr}\text { ¿Cómo utiliza } \\
\text { usted } & \text { los } \\
\text { recursos } & \\
\text { educativos } & \text { y } \\
\text { pedagógicos } & \\
\text { para establecer } \\
\text { una mejor } \\
\text { comunicación } \\
\text { entre } & \text { el } \\
\text { estudiante } & \text { y } \\
\text { profesor? } & \end{array}$} & \multirow{4}{*}{$\begin{array}{l}\text { Aquí en el colegio se trabaja con } \\
\text { el material proporcionado en el } \\
\text { aula, incluyendo una motivación } \\
\text { y reconocimiento de cada parte } \\
\text { del tema en la pizarra. En } \\
\text { algunos casos se apoya con el } \\
\text { papelógrafo prediseñado, como } \\
\text { una guía para comprender } \\
\text { mejor el tema. }\end{array}$} & $\begin{array}{l}\text { Aquí en el colegio se } \\
\text { trabaja con el material } \\
\text { proporcionado en el } \\
\text { aula }\end{array}$ & Uso de recursos pedagógicos & 62 \\
\hline & & $\begin{array}{l}\text { incluyendo una } \\
\text { motivación }\end{array}$ & Motivación & 3 \\
\hline & & $\begin{array}{l}\text { y reconocimiento de } \\
\text { cada parte del tema } \\
\text { en la pizarra }\end{array}$ & Estrategia didáctica & 38 \\
\hline & & $\begin{array}{l}\text { se apoya con el } \\
\text { papelógrafo } \\
\text { prediseñado, como } \\
\text { una guía para } \\
\text { comprender mejor el } \\
\text { tema }\end{array}$ & Uso de recursos pedagógicos & 62 \\
\hline
\end{tabular}




\begin{tabular}{|c|c|c|c|c|}
\hline & $\begin{array}{l}\text { Claro, pues un recurso } \\
\text { pedagógico son los materiales y } \\
\text { adquisiciones que ayudan a una } \\
\text { mejor comprensión del tema, y } \\
\text { un recurso educativo es } \\
\text { proporcionado por el organismo } \\
\text { educativo. }\end{array}$ & \begin{tabular}{|lr} 
un recurso \\
pedagógico son los \\
materiales r y \\
adquisiciones que \\
ayudan a una mejor \\
comprensión del tema \\
un recurso educativo \\
es proporcionado por \\
el organismo \\
educativo \\
\end{tabular} & $\begin{array}{l}\text { Deficiente manejo de } \\
\text { conceptos pedagógicos }\end{array}$ & 63 \\
\hline \multirow{3}{*}{$\begin{array}{l}\text { ¿De qué forma } \\
\text { utiliza usted los } \\
\text { proyectos } \\
\text { interdisciplinarios } \\
\text { donde el } \\
\text { estudiante } \\
\text { aplique y valore } \\
\text { lo aprendido en } \\
\text { clase, a la vida } \\
\text { diaria? }\end{array}$} & \multirow{3}{*}{$\begin{array}{l}\text { Este, ... mm.. se suponen } \\
\text { ejemplos de momentos en la } \\
\text { vida diaria donde se puede } \\
\text { aplicar el tema a desarrollar y en } \\
\text { la retroalimentación se deja } \\
\text { problemas donde pueden volver } \\
\text { a aplicar lo realizado en clase. }\end{array}$} & \multirow{2}{*}{$\begin{array}{l}\text { ejemplos de } \\
\text { momentos en la vida } \\
\text { diaria donde se puede } \\
\text { aplicar el tema a } \\
\text { desarrollar }\end{array}$} & Situaciones problémicas & 59 \\
\hline & & & $\begin{array}{c}\text { Ausencia de trabajo por } \\
\text { proyectos interdisciplinarios }\end{array}$ & 27 \\
\hline & & $\begin{array}{l}\text { en la } \\
\text { retroalimentación se } \\
\text { deja problemas donde } \\
\text { pueden volver a } \\
\text { aplicar lo realizado en } \\
\text { clase } \\
\end{array}$ & $\begin{array}{l}\text { Uso de estrategias de } \\
\text { retroalimentación }\end{array}$ & 64 \\
\hline \multirow{3}{*}{ 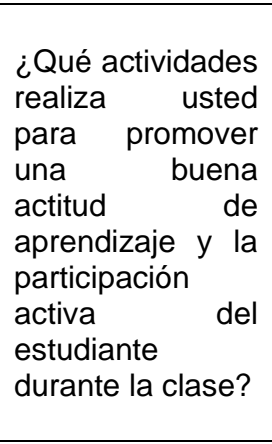 } & \multirow{3}{*}{$\begin{array}{l}\text { Con el fin de mejorar su actitud, } \\
\text { trato de realizar lluvia de ideas } \\
\text { al inicio de la clase, o trabajo en } \\
\text { grupo para que analicen y } \\
\text { desarrollen problemas al mismo } \\
\text { tiempo se busca que se apoyen } \\
\text { y coordinen para que el total del } \\
\text { grupo pueda aprender el tema } \\
\text { desarrollado. }\end{array}$} & $\begin{array}{l}\text { trato de realizar lluvia } \\
\text { de ideas al inicio de la } \\
\text { clase }\end{array}$ & Estrategias didáctica & 38 \\
\hline & & $\begin{array}{l}\text { trabajo en grupo para } \\
\text { que analicen y } \\
\text { desarrollen problemas } \\
\end{array}$ & Trabajos grupales & 10 \\
\hline & & $\begin{array}{l}\text { al mismo tiempo se } \\
\text { busca que se apoyen } \\
\text { y coordinen para que } \\
\text { el total del grupo } \\
\text { pueda aprender el } \\
\text { tema desarrollado } \\
\end{array}$ & $\begin{array}{c}\text { Fomento de buenas prácticas } \\
\text { grupales }\end{array}$ & 65 \\
\hline \begin{tabular}{lr}
\multicolumn{2}{l}{ ¿Qué actividades } \\
realiza & usted, \\
donde & el \\
estudiante & \\
demuestre & lo \\
$\begin{array}{l}\text { aprendido en } \\
\text { clase? }\end{array}$ & la \\
\end{tabular} & $\begin{array}{l}\text { Bueno, yo dejo problemas como } \\
\text { retroalimentación par que el } \\
\text { alumno refuerce lo aprendido en } \\
\text { clase. }\end{array}$ & $\begin{array}{l}\text { yo dejo problemas } \\
\text { como } \\
\text { retroalimentación par } \\
\text { que el alumno } \\
\text { refuerce lo aprendido } \\
\text { en clase }\end{array}$ & $\begin{array}{l}\text { Exceso de ejercicios solo } \\
\text { centrados en la operatividad }\end{array}$ & 66 \\
\hline \multirow{4}{*}{$\begin{array}{l}\text { ¿De qué forma } \\
\text { promueve usted, } \\
\text { los trabajos de } \\
\text { campo donde el } \\
\text { estudiante tenga } \\
\text { que sustentar } \\
\text { públicamente los } \\
\text { resultados de su } \\
\text { trabajo mediante } \\
\text { gráficas } \\
\text { estadísticas? }\end{array}$} & \multirow{4}{*}{$\begin{array}{l}\text { Mmm, ehhh... en la institución } \\
\text { manejamos ferias matemáticas, } \\
\text { como por ejemplo el día del } \\
\text { logro donde los estudiantes } \\
\text { tengan que aplicar sus } \\
\text { conocimientos mediante un } \\
\text { experimento o algún trabajo de } \\
\text { investigación. No utilizamos } \\
\text { gráficas estadísticas como } \\
\text { resultado del proyecto. }\end{array}$} & \begin{tabular}{|lr} 
en la institución \\
manejamos ferias \\
matemáticas
\end{tabular} & Trabajos colaborativos & 10 \\
\hline & & \multirow{2}{*}{ 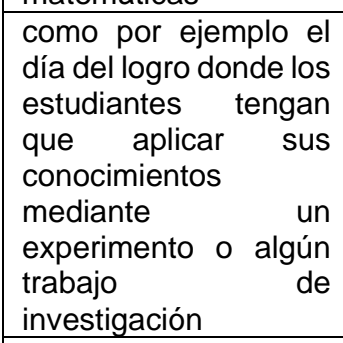 } & $\begin{array}{l}\text { Trabajos centrados en el } \\
\text { conocimiento }\end{array}$ & 66 \\
\hline & & & Trabajos investigativos & 67 \\
\hline & & $\begin{array}{l}\text { No utilizamos gráficas } \\
\text { estadísticas como } \\
\text { resultado del proyecto }\end{array}$ & $\begin{array}{l}\text { Ausencia del uso de } \\
\text { estadísticos }\end{array}$ & 68 \\
\hline \multirow{3}{*}{$\begin{array}{l}\text { ¿Qué diferencia } \\
\text { actitudinal } \\
\text { encuentra usted } \\
\text { en } \\
\text { estudiantes } \\
\text { cuando } \\
\text { desarrolla } \\
\text { trabajos } \\
\text { colaborativos? }\end{array}$} & \multirow{3}{*}{$\begin{array}{l}\text { Al realizar trabajos } \\
\text { colaborativos, muchos } \\
\text { entienden mejor la explicación y } \\
\text { la relación de algunos } \\
\text { problemas con cada situación } \\
\text { en la vida diaria además de } \\
\text { poder mejorar el liderazgo de } \\
\text { algunos al dirigir los grupos. }\end{array}$} & trabajos colaborativos & trabajos colaborativos & 10 \\
\hline & & $\begin{array}{l}\text { muchos entienden } \\
\text { mejor la explicación }\end{array}$ & $\begin{array}{l}\text { Fomento de un clima de } \\
\text { aprendizaje colaborativo }\end{array}$ & 69 \\
\hline & & $\begin{array}{l}\text { la relación de algunos } \\
\text { problemas con cada } \\
\text { situación en la vida } \\
\text { diaria }\end{array}$ & Aprendizaje significativo & 6 \\
\hline
\end{tabular}




\begin{tabular}{|l|l|l|l|l|}
\hline & $\begin{array}{l}\text { además de poder } \\
\text { mejorar el liderazgo } \\
\text { de algunos al dirigir } \\
\text { los grupos }\end{array}$ & $\begin{array}{c}\text { Fomento de buenas prácticas } \\
\text { grupales }\end{array}$ \\
\hline
\end{tabular}

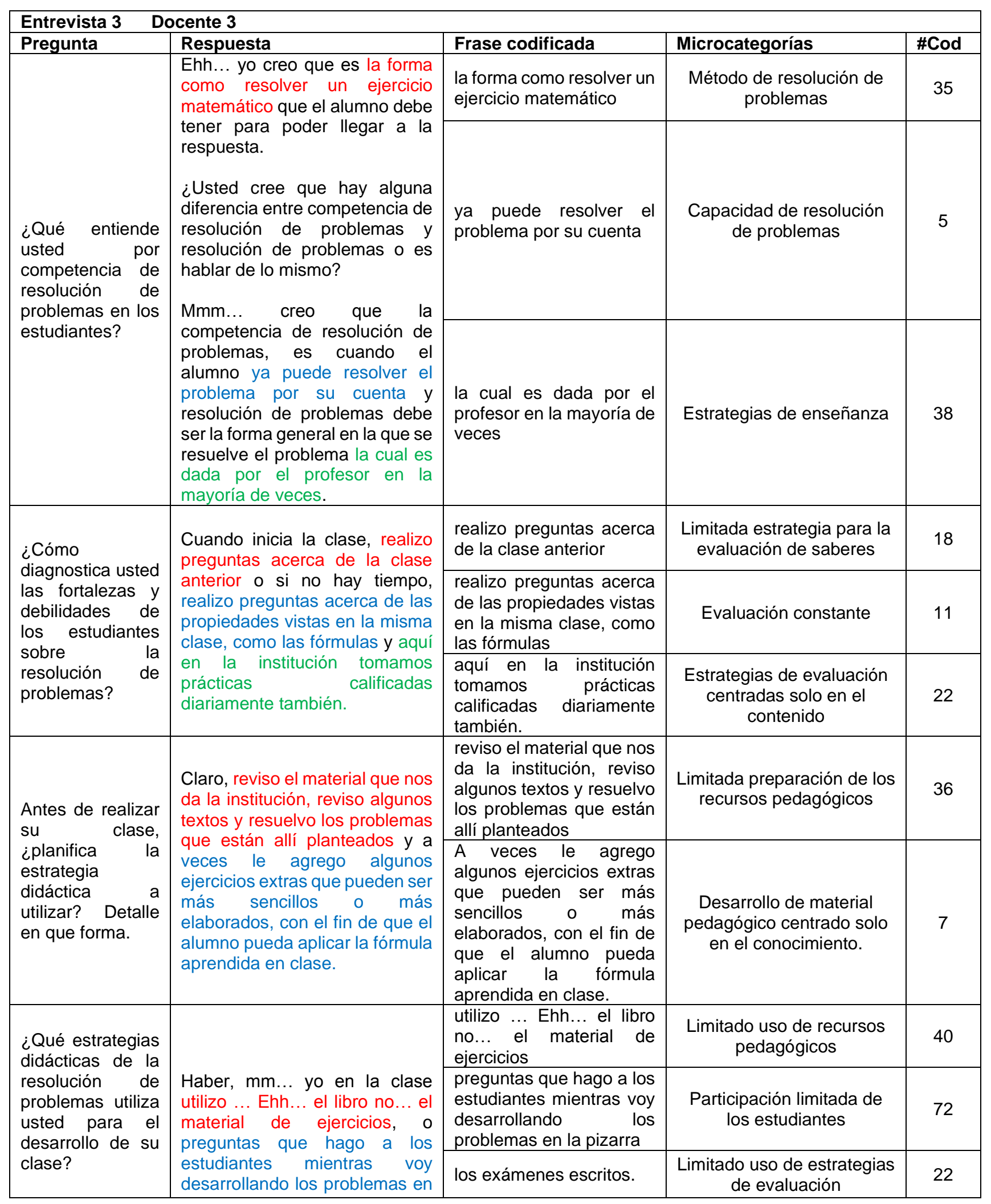




\begin{tabular}{|c|c|c|c|c|}
\hline & $\begin{array}{l}\text { la pizarra y los exámenes } \\
\text { escritos. De vez en cuando, } \\
\text { tomo pasos orales en pizarra } \\
\text { donde el estudiante tiene que } \\
\text { salir adelante a resolver un } \\
\text { ejercicio al azar. }\end{array}$ & $\begin{array}{l}\text { De vez en cuando, tomo } \\
\text { pasos orales en pizarra } \\
\text { donde el estudiante tiene } \\
\text { que salir adelante a } \\
\text { resolver un ejercicio al } \\
\text { azar. }\end{array}$ & $\begin{array}{l}\text { Limitado uso de estrategias } \\
\text { didácticas }\end{array}$ & 7 \\
\hline \multirow{4}{*}{$\begin{array}{l}\text { ¿Qué métodos } \\
\text { utiliza usted para } \\
\text { presentar la } \\
\text { situación } \\
\text { problémica al } \\
\text { estudiante, de } \\
\text { modo que genere } \\
\text { la reflexión y el } \\
\text { diálogo? }\end{array}$} & \multirow{4}{*}{$\begin{array}{l}\text { Amm, bueno... como los } \\
\text { problemas ya están en sus } \\
\text { materiales, lo que hago a veces, } \\
\text { es asociar una que otra palabra } \\
\text { a su realidad, con las que los } \\
\text { estudiantes asocian a su } \\
\text { entorno diario, y comparten } \\
\text { alguna anécdota asociada a } \\
\text { esta. } \\
\text { ¿Cómo definiría usted una } \\
\text { situación problémica? } \\
\text { La situación problémica son los } \\
\text { problemas que están en su } \\
\text { material y que el estudiante } \\
\text { tiene que resolver por sí mismo } \\
\text { (Osea las tareas domiciliarias } \\
\text { por ejemplo o en un examen } \\
\text { escrito). }\end{array}$} & $\begin{array}{l}\text { como los problemas ya } \\
\text { están en sus materiales }\end{array}$ & $\begin{array}{l}\text { Enseñanza limitada al } \\
\text { contenido }\end{array}$ & 70 \\
\hline & & $\begin{array}{l}\text { lo que hago a veces, es } \\
\text { asociar una que otra } \\
\text { palabra a su realidad }\end{array}$ & $\begin{array}{c}\text { Contextualización de los } \\
\text { problemas }\end{array}$ & 71 \\
\hline & & $\begin{array}{lr}\text { comparten alguna } \\
\text { anécdota asociada a esta }\end{array}$ & Mediador asertivo & 4 \\
\hline & & $\begin{array}{l}\text { que el estudiante tiene } \\
\text { que resolver por sí mismo } \\
\text { (Osea las tareas } \\
\text { domiciliarias por ejemplo } \\
\text { o en un examen escrito). }\end{array}$ & $\begin{array}{l}\text { Estrategia de enseñanza } \\
\text { tradicional }\end{array}$ & 7 \\
\hline \multirow{4}{*}{$\begin{array}{l}\text { ¿Qué actividades } \\
\text { realiza usted } \\
\text { para despertar el } \\
\text { interés del } \\
\text { estudiante } \\
\text { respecto del } \\
\text { tema a a } \\
\text { desarrollar en la } \\
\text { sesión de clase? }\end{array}$} & \multirow{4}{*}{$\begin{array}{l}\text { Bueno, en la clase trato de que } \\
\text { el estudiante constantemente } \\
\text { este participando, para ello } \\
\text { realizo preguntas en el proceso } \\
\text { de desarrollo de cada problema, } \\
\text { sobre todo cuando esta } \\
\text { distraído, para que pueda seguir } \\
\text { la secuencia de la clase en la } \\
\text { pizarra. } \\
\text { A veces también, Ehh... dejo un } \\
\text { ejercicio para que ellos } \\
\text { resuelvan y se ganen puntos } \\
\text { para su práctica calificada. }\end{array}$} & $\begin{array}{l}\text { trato de que el estudiante } \\
\text { constantemente este } \\
\text { participando, para ello } \\
\text { realizo prequntas }\end{array}$ & $\begin{array}{c}\text { Limitada estrategia de } \\
\text { participación del estudiante }\end{array}$ & 72 \\
\hline & & $\begin{array}{l}\text { en el proceso } \\
\text { desarrollo } \\
\text { problema }\end{array}$ & $\begin{array}{l}\text { Limitado uso de } \\
\text { Estrategias didácticas } \\
\text { constructivistas }\end{array}$ & 21 \\
\hline & & $\begin{array}{l}\text { sobre todo cuando esta } \\
\text { distraído }\end{array}$ & $\begin{array}{l}\text { Mal manejo de conducta en } \\
\text { el aula }\end{array}$ & 31 \\
\hline & & $\begin{array}{l}\text { dejo un ejercicio para que } \\
\text { ellos resuelvan y se } \\
\text { ganen puntos para su } \\
\text { práctica calificada }\end{array}$ & $\begin{array}{l}\text { Motivación por la } \\
\text { resolución de problemas }\end{array}$ & 73 \\
\hline \multirow{5}{*}{$\begin{array}{l}\text { ¿De qué manera } \\
\text { logra usted que el } \\
\text { estudiante } \\
\text { reconozca y } \\
\text { discrimine } \\
\text { información } \\
\text { necesaria para la } \\
\text { resolución de } \\
\text { problemas? }\end{array}$} & \multirow{5}{*}{$\begin{array}{l}\text { Tomando prácticas diarias, o } \\
\text { tomando pasos orales en la } \\
\text { pizarra. Así puedo saber cómo } \\
\text { el estudiante va resolviendo un } \\
\text { problema. } \\
\text { ¿De qué manera usted motiva a } \\
\text { que el estudiante reconozca la } \\
\text { información que necesita? } \\
\text { Realizo preguntas, o les pido } \\
\text { que lean el enunciado del } \\
\text { problema, varias veces hasta } \\
\text { que lo puedan comprender } \\
\text { realmente para su posterior } \\
\text { resolución. } \\
\text { ¿Cómo se da cuenta que el } \\
\text { alumno está avanzando y que } \\
\text { acciones realiza? } \\
\text { Cuando no puede resolver } \\
\text { ejercicios en el examen o } \\
\text { practica oral en pizarra. } \\
\text { Lo que realizo al observar estas } \\
\text { situaciones es hablar con el }\end{array}$} & $\begin{array}{l}\text { Tomando prácticas } \\
\text { diarias, o tomando pasos } \\
\text { orales en la pizarra }\end{array}$ & $\begin{array}{l}\text { Limitado uso de estrategias } \\
\text { de evaluación }\end{array}$ & 22 \\
\hline & & $\begin{array}{l}\text { Así puedo saber cómo el } \\
\text { estudiante va resolviendo } \\
\text { un problema }\end{array}$ & $\begin{array}{l}\text { Recojo de saberes } \\
\text { centrado en el contenido }\end{array}$ & 74 \\
\hline & & $\begin{array}{l}\text { Realizo preguntas, o les } \\
\text { pido que lean el } \\
\text { enunciado del problema, } \\
\text { varias veces hasta que lo } \\
\text { puedan comprender } \\
\text { realmente para su } \\
\text { posterior resolución }\end{array}$ & $\begin{array}{l}\text { Mal uso de estrategias } \\
\text { para la motivación }\end{array}$ & 39 \\
\hline & & $\begin{array}{l}\text { Cuando no puede } \\
\text { resolver ejercicios en el } \\
\text { examen o practica oral en } \\
\text { pizarra }\end{array}$ & $\begin{array}{l}\text { Evaluación centrada en el } \\
\text { contenido }\end{array}$ & 11 \\
\hline & & $\begin{array}{l}\text { es hablar con el alumno y } \\
\text { darle oportunidad a poder } \\
\text { repasar en casa y para la } \\
\text { siguiente clase tomarle } \\
\text { nuevamente }\end{array}$ & $\begin{array}{l}\text { Ineficiente manejo de } \\
\text { estudiantes con bajo } \\
\text { rendimiento }\end{array}$ & 75 \\
\hline
\end{tabular}




\begin{tabular}{|c|c|c|c|c|}
\hline & $\begin{array}{l}\text { alumno y darle oportunidad a } \\
\text { poder repasar en casa y para la } \\
\text { siguiente clase tomarle } \\
\text { nuevamente, pero de repetirse } \\
\text { a pesar de todo, cito al padre de } \\
\text { familia y le explico lo que pasa } \\
\text { para que puedan buscar ayuda } \\
\text { profesional aparte del que se le } \\
\text { brinda en la institución en las } \\
\text { asesorías. }\end{array}$ & $\begin{array}{l}\text { pero de repetirse a pesar } \\
\text { de todo, cito al padre de } \\
\text { familia y le explico lo que } \\
\text { pasa para que puedan } \\
\text { buscar ayuda profesional } \\
\text { aparte del que se le } \\
\text { brinda en la institución en } \\
\text { las asesorías. }\end{array}$ & Mediador asertivo & 4 \\
\hline \multirow{4}{*}{$\begin{array}{l}\text { ¿Cómo utiliza } \\
\text { usted los } \\
\text { argumentos } \\
\text { matemáticos } \\
\text { para realizar } \\
\text { demostraciones y } \\
\text { contribuir al } \\
\text { desarrollo de la } \\
\text { competencia de } \\
\text { resolución de } \\
\text { problemas? }\end{array}$} & \multirow{4}{*}{$\begin{array}{l}\text { Sobre todo, con los chicos de } \\
\text { último año, algunos preguntan } \\
\text { sobre un determinado tema y } \\
\text { piden realizar la demostración } \\
\text { de alguna propiedad, entonces } \\
\text { es allí que yo lo realizó en la } \\
\text { pizarra, para que todos también } \\
\text { puedan aprender. Esto } \\
\text { contribuye a la resolución de } \\
\text { problemas, pues le da la lógica } \\
\text { principal a la hora de plantear o } \\
\text { elegir el método para la } \\
\text { resolución de problemas. } \\
\text { ¿Y ha tomado preguntas } \\
\text { argumentativas? ¿Qué } \\
\text { observo? } \\
\text { No, aquí en este colegio no, } \\
\text { porque lo que se busca es que } \\
\text { el alumno llegue a una } \\
\text { respuesta numérica } \\
\text { mayormente. Y al plantearle } \\
\text { una pregunta argumentativa en } \\
\text { el examen, le tomaría más } \\
\text { tiempo al estudiante y además } \\
\text { porque no están } \\
\text { acostumbrados a ese tipo de } \\
\text { preguntas. Algunos de ellos } \\
\text { podrán hacerlo, pero los demás } \\
\text { no creo lo puedan hacer o se } \\
\text { demorarían mucho y por el } \\
\text { tiempo, dejarían de lado esa } \\
\text { pregunta. }\end{array}$} & $\begin{array}{l}\text { algunos preguntan sobre } \\
\text { un determinado tema y } \\
\text { piden realizar la } \\
\text { demostración de alguna } \\
\text { propiedad, entonces es } \\
\text { allí que yo lo realizó en la } \\
\text { pizarra }\end{array}$ & $\begin{array}{l}\text { Limitado uso de } \\
\text { argumentos para las } \\
\text { demostraciones } \\
\text { matemáticas }\end{array}$ & 12 \\
\hline & & $\begin{array}{l}\text { Esto contribuye a la } \\
\text { resolución de problemas, } \\
\text { pues le da la lógica } \\
\text { principal a la hora de } \\
\text { plantear o elegir el } \\
\text { método para la } \\
\text { resolución de problemas }\end{array}$ & $\begin{array}{c}\text { Razonamiento y análisis } \\
\text { para la resolución de } \\
\text { problemas }\end{array}$ & 76 \\
\hline & & $\begin{array}{l}\text { No, aquí en este colegio } \\
\text { no, porque lo que se } \\
\text { busca es que el alumno } \\
\text { llegue a una respuesta } \\
\text { numérica mayormente } \\
Y \text { al plantearle una } \\
\text { pregunta argumentativa } \\
\text { en el examen, le tomaría } \\
\text { más tiempo al estudiante } \\
\text { y además porque no } \\
\text { están acostumbrados a } \\
\text { ese tipo de preguntas. }\end{array}$ & $\begin{array}{l}\text { Ausencia de evaluación de } \\
\text { uso argumentos para } \\
\text { demostraciones } \\
\text { matemáticas }\end{array}$ & 12 \\
\hline & & $\begin{array}{l}\text { Algunos de ellos podrán } \\
\text { hacerlo, pero los demás } \\
\text { no creo lo puedan hacer } \\
\text { o se demorarían mucho y } \\
\text { por el tiempo, dejarían de } \\
\text { lado esa pregunta. }\end{array}$ & Prejuicios del docente & 45 \\
\hline \multirow{3}{*}{$\begin{array}{l}\text { ¿Qué método } \\
\text { problémico } \\
\text { propone usted en } \\
\text { donde } r \quad \text { el } \\
\text { estudiante pueda } \\
\text { reflexionar } \\
\text { establecer } \\
\text { relaciones } \\
\text { variables entre } \\
\text { incógnitas? }\end{array}$} & \multirow{3}{*}{$\begin{array}{l}\text { Ehh. mmm... bueno ... cuando } \\
\text { desarrollo ejercicios en la } \\
\text { pizarra, hago preguntas donde } \\
\text { el estudiante tiene que } \\
\text { interpretar, el enunciado del } \\
\text { problema de su material, para } \\
\text { que pueda ir analizando la } \\
\text { relación que hay entre las } \\
\text { palabras escritas y la } \\
\text { simbolización matemática, para } \\
\text { su posterior desarrollo. }\end{array}$} & $\begin{array}{l}\text { desarrollo ejercicios en la } \\
\text { pizarra, }\end{array}$ & $\begin{array}{l}\text { Limitado uso de estrategias } \\
\text { didácticas }\end{array}$ & 38 \\
\hline & & $\begin{array}{l}\text { hago preguntas donde el } \\
\text { estudiante tiene que } \\
\text { interpretar, el enunciado } \\
\text { del problema de su } \\
\text { material, }\end{array}$ & $\begin{array}{l}\text { Limitado uso de estrategias } \\
\text { de participación del } \\
\text { estudiante }\end{array}$ & 72 \\
\hline & & $\begin{array}{l}\text { para que pueda ir } \\
\text { analizando la relación } \\
\text { que hay entre las } \\
\text { palabras escritas y la } \\
\text { simbolización } \\
\text { matemática, para su } \\
\text { posterior desarrollo. }\end{array}$ & $\begin{array}{l}\text { Actividades de análisis e } \\
\text { interpretación matemática }\end{array}$ & 77 \\
\hline $\begin{array}{lr}\text { ¿Cómo } & \text { utiliza } \\
\text { usted } & \text { los } \\
\text { recursos } & \\
\text { educativos } & \text { y } \\
\text { pedagógicos } & \\
\text { para establecer } \\
\text { una r mejor }\end{array}$ & $\begin{array}{l}\text { Aquí en la institución utilizamos } \\
\text { los libros que proporciona la } \\
\text { institución y prácticas diarias } \\
\text { para poder llevar una revisión } \\
\text { del aprendizaje logrado en } \\
\text { clase. }\end{array}$ & $\begin{array}{l}\text { institución utilizamos los } \\
\text { libros que proporciona la } \\
\text { institución y prácticas } \\
\text { diarias para poder llevar } \\
\text { una revisión del } \\
\text { aprendizaje logrado en } \\
\text { clase. }\end{array}$ & $\begin{array}{l}\text { Enseñanza centrada en el } \\
\text { contenido }\end{array}$ & 70 \\
\hline
\end{tabular}




\begin{tabular}{|c|c|c|c|c|}
\hline \multirow[t]{4}{*}{$\begin{array}{ll}\text { comunicación } & \\
\text { entre } & \text { el } \\
\text { estudiante } & y \\
\text { profesor? } & \end{array}$} & \multirow{4}{*}{ 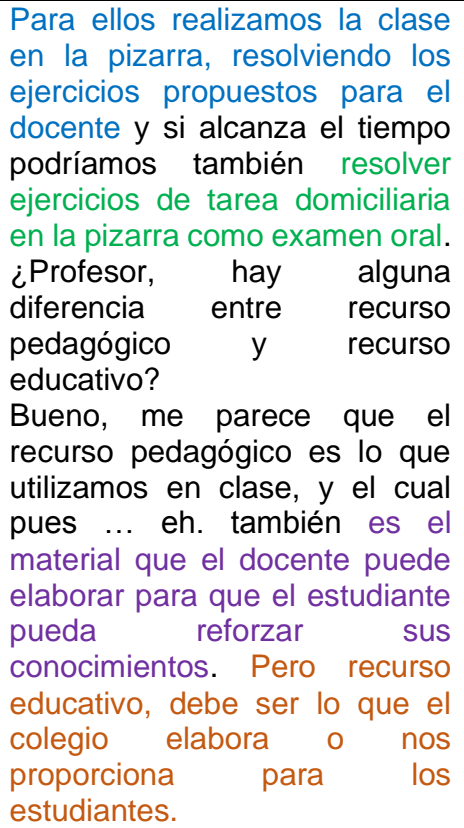 } & $\begin{array}{l}\text { Para ellos realizamos la } \\
\text { clase en la pizarra, } \\
\text { resolviendo los ejercicios } \\
\text { propuestos para el } \\
\text { docente }\end{array}$ & $\begin{array}{c}\text { Limitado uso de estrategias } \\
\text { didácticas }\end{array}$ & 7 \\
\hline & & $\begin{array}{l}\text { resolver ejercicios de } \\
\text { tarea domiciliaria en la } \\
\text { pizarra como examen } \\
\text { oral }\end{array}$ & $\begin{array}{c}\text { Limitado uso de estrategias } \\
\text { de evaluación del } \\
\text { aprendizaje }\end{array}$ & 11 \\
\hline & & $\begin{array}{l}\text { el material que el docente } \\
\text { puede elaborar para que } \\
\text { el estudianter pueda } \\
\text { reforzar } \\
\text { conocimientos }\end{array}$ & $\begin{array}{c}\text { Elaboración de materiales } \\
\text { pedagógicos }\end{array}$ & 20 \\
\hline & & 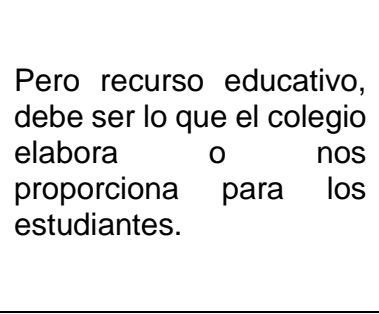 & $\begin{array}{l}\text { Deficiente manejo de } \\
\text { conceptos pedagógicos }\end{array}$ & 63 \\
\hline \multirow{3}{*}{$\begin{array}{l}\text { ¿De qué forma } \\
\text { utiliza usted los } \\
\text { proyectos } \\
\text { interdisciplinarios } \\
\text { donde el } \\
\text { estudiante } \\
\text { aplique y valore } \\
\text { lo aprendido en } \\
\text { clase, a la vida } \\
\text { diaria? }\end{array}$} & \multirow{3}{*}{$\begin{array}{l}\text { En mi área, realizamos } \\
\text { proyectos una vez al año, aquí } \\
\text { los estudiantes formaran grupos } \\
\text { que serán seleccionados por el } \\
\text { docente y se les dará un tema } \\
\text { bajo el cual tendrán que } \\
\text { investigar y elaborar una } \\
\text { presentación en power point } \\
\text { para su presentación ante los } \\
\text { padres de familia en una fecha } \\
\text { determinada por la institución. }\end{array}$} & $\begin{array}{l}\text { Aquí los estudiantes } \\
\text { formaran grupos que } \\
\text { serán seleccionados por } \\
\text { el docente }\end{array}$ & Trabajos grupales & 10 \\
\hline & & $\begin{array}{l}\text { se les dará un tema bajo } \\
\text { el cual tendrán que } \\
\text { investigar }\end{array}$ & Trabajos investigativos & 67 \\
\hline & & $\begin{array}{l}\text { elaborar } \\
\text { presentación en power } \\
\text { point }\end{array}$ & Uso de Tic & 46 \\
\hline \multirow{4}{*}{$\begin{array}{l}\text { ¿Qué actividades } \\
\text { realiza usted } \\
\text { para promover } \\
\text { una buena } \\
\text { actitud de } \\
\text { aprendizaje y la } \\
\text { participación } \\
\text { activa del } \\
\text { estudiante } \\
\text { durante la clase? }\end{array}$} & \multirow{4}{*}{$\begin{array}{l}\text { Realizo trabajos grupales en } \\
\text { clase, donde tienen que } \\
\text { resolver una lista de ejercicios } \\
\text { del tema visto en clase, o realizo } \\
\text { preguntas a medida que voy } \\
\text { desarrollando en pizarra para } \\
\text { también tener su atención y } \\
\text { saber que están siguiendo la } \\
\text { clase. } \\
\text { También converso con ellos, } \\
\text { acerca de los valores sociales } \\
\text { que deben tener para con sus } \\
\text { compañeros, según el valor } \\
\text { indicado por la institución. }\end{array}$} & $\begin{array}{l}\text { Realizo trabajos grupales } \\
\text { en clase }\end{array}$ & Trabajos grupales & 10 \\
\hline & & $\begin{array}{llr}\text { donde } & \text { tienen } & \text { que } \\
\text { resolver una lista de } & \\
\text { ejercicios del tema visto } \\
\text { en clase }\end{array}$ & $\begin{array}{l}\text { Enseñanza centrada en el } \\
\text { contenido }\end{array}$ & 7 \\
\hline & & $\begin{array}{l}\text { realizo preguntas a } \\
\text { medida que voy } \\
\text { desarrollando en pizarra } \\
\text { para también tener su } \\
\text { atención y saber que } \\
\text { están siguiendo la clase }\end{array}$ & $\begin{array}{l}\text { Limitado uso de estrategias } \\
\text { para la motivación }\end{array}$ & 39 \\
\hline & & $\begin{array}{l}\text { También converso con } \\
\text { ellos, acerca de los } \\
\text { valores sociales que } \\
\text { deben tener para con sus } \\
\text { compañeros, según el } \\
\text { valor indicado por la } \\
\text { institución. }\end{array}$ & $\begin{array}{c}\text { Falta de actividades que } \\
\text { promuevan el uso de los } \\
\text { valores sociales }\end{array}$ & 78 \\
\hline \multirow{2}{*}{$\begin{array}{l}\text { Entrevistador: } \\
\text { ¿Qué actividades } \\
\text { ¿ealiza usted, } \\
\begin{array}{lr}\text { donde } & \text { el } \\
\text { estudiante } & \\
\text { demuestre } & \text { lo } \\
\text { aprendido en } & \text { la } \\
\text { clase? }\end{array}\end{array}$} & \multirow[b]{2}{*}{$\begin{array}{l}\text { Tomo práctica escrita de } \\
\text { manera permanente, pasos } \\
\text { orales en la pizarra, y los } \\
\text { exámenes mensuales y } \\
\text { bimestrales principalmente. }\end{array}$} & \multirow[b]{2}{*}{$\begin{array}{l}\text { Tomo práctica escrita de } \\
\text { manera permanente, } \\
\text { pasos orales en la } \\
\text { pizarra, y los exámenes } \\
\text { mensuales y bimestrales } \\
\text { principalmente. }\end{array}$} & $\begin{array}{l}\text { Estrategias de evaluación } \\
\text { centradas en el contenido }\end{array}$ & 7 \\
\hline & & & $\begin{array}{l}\text { Limitado uso de estrategias } \\
\text { de evaluación }\end{array}$ & 11 \\
\hline
\end{tabular}




\begin{tabular}{|c|c|c|c|c|}
\hline \multirow{4}{*}{$\begin{array}{l}\text { ¿De qué forma } \\
\text { promueve usted, } \\
\text { los trabajos de } \\
\text { campo donde el } \\
\text { estudiante tenga } \\
\text { que sustentar } \\
\text { públicamente los } \\
\text { resultados de su } \\
\text { trabajo mediante } \\
\text { gráficas } \\
\text { estadísticas? }\end{array}$} & \multirow{4}{*}{$\begin{array}{l}\text { Eh, bueno. la verdad los únicos } \\
\text { trabajos que manejamos para } \\
\text { sustentación publica, son los } \\
\text { proyectos del curso, una vez al } \\
\text { año, pero que utilice gráficas } \\
\text { estadísticas... Ehh... mm... lo } \\
\text { dudo, pues implica mayor } \\
\text { tiempo para el procesamiento } \\
\text { de los datos y asesorías entre el } \\
\text { docente y alumno. Pero aquí en } \\
\text { la institución nos enfocamos } \\
\text { más en que los estudiantes, } \\
\text { puedan resolver ejercicios en } \\
\text { menor tiempo para asegurar su } \\
\text { ingreso en los próximos } \\
\text { exámenes de admisión. }\end{array}$} & $\begin{array}{l}\text { los únicos trabajos que } \\
\text { manejamos para } \\
\text { sustentación publica, son } \\
\text { los proyectos del curso, } \\
\text { una vez al año }\end{array}$ & $\begin{array}{l}\text { Poco uso de proyectos de } \\
\text { campo }\end{array}$ & 30 \\
\hline & & $\begin{array}{l}\text { que utilice } \text { gráficas } \\
\text { estadísticas... } \\
\text { mm... lo dudo, phh... } \\
\text { implica mayor tiempo } \\
\text { para el procesamiento de }\end{array}$ & $\begin{array}{l}\text { Ausencia de uso de } \\
\text { gráficas estadísticas. }\end{array}$ & 17 \\
\hline & & $\begin{array}{l}\text { los datos y asesorías } \\
\text { entre el docente y } \\
\text { alumno. }\end{array}$ & $\begin{array}{c}\text { Falta de compromiso } \\
\text { profesional }\end{array}$ & 79 \\
\hline & & $\begin{array}{l}\text { Pero aquí en la institución } \\
\text { nos enfocamos más en } \\
\text { que los estudiantes, } \\
\text { puedan resolver } \\
\text { ejercicios en menor } \\
\text { tiempo para asegurar su } \\
\text { ingreso en los próximos } \\
\text { exámenes de admisión. }\end{array}$ & $\begin{array}{l}\text { Objetivos de la institución } \\
\text { educativa sesgados }\end{array}$ & 80 \\
\hline \multirow{3}{*}{$\begin{array}{l}\text { ¿Qué diferencia } \\
\text { actitudinal } \\
\text { encuentra usted } \\
\text { en } \\
\text { estudiantes } \\
\text { cuando } \\
\text { desarrolla } \\
\text { trabajos } \\
\text { colaborativos? }\end{array}$} & \multirow{3}{*}{$\begin{array}{l}\text { Cada vez cuando se hace } \\
\text { trabajos grupales, eh visto que } \\
\text { al estudiante le gusta más pues } \\
\text { tiene la oportunidad de poder } \\
\text { trabajar en conjunto con sus } \\
\text { compañeros, pero el problema } \\
\text { es que muchas veces no todos } \\
\text { trabajan, sino más bien se } \\
\text { dedican a conversar de otras } \\
\text { cosas y pierden tiempo, o dejan } \\
\text { que uno o dos compañeros } \\
\text { resuelvan los problemas y los } \\
\text { demás solo copian. Además, } \\
\text { que demanda mucho tiempo } \\
\text { realizar este tipo de trabajos. } \\
\text { Por lo que creo que mejor es la } \\
\text { clase en pizarra, la práctica } \\
\text { escrita y/o paso oral. }\end{array}$} & $\begin{array}{l}\text { cuando se hace trabajos } \\
\text { grupales, eh visto que al } \\
\text { estudiante le gusta más }\end{array}$ & $\begin{array}{l}\text { Motivación por las } \\
\text { actividades grupales }\end{array}$ & 81 \\
\hline & & $\begin{array}{l}\text { muchas veces no todos } \\
\text { trabajan, sino más bien } \\
\text { se dedican a conversar } \\
\text { de otras cosas y pierden } \\
\text { tiempo, o dejan que uno o } \\
\text { dos compañeros } \\
\text { resuelvan los problemas } \\
\text { y los demás solo copian. }\end{array}$ & $\begin{array}{l}\text { Mal manejo del aula al } \\
\text { realizar trabajos } \\
\text { colaborativos }\end{array}$ & 45 \\
\hline & & $\begin{array}{l}\text { demanda mucho tiempo } \\
\text { realizar este tipo de } \\
\text { trabajos. Por lo que creo } \\
\text { que mejor es la clase en } \\
\text { pizarra, la práctica escrita } \\
\text { y/o paso oral. }\end{array}$ & $\begin{array}{c}\text { Indisposición por aplicar } \\
\text { otras formas de estrategias } \\
\text { didácticas }\end{array}$ & 82 \\
\hline
\end{tabular}




\section{Anexo 4}

\section{Guía de observación de una sesión de aprendizaje del área de Matemática}

\section{OBJETIVO:}

Constatar el tratamiento teórico y metodológico que ofrece el docente para dirigir el proceso de enseñanza - aprendizaje en el área de Matemática, en los estudiantes de $\mathrm{V}$ grado de Secundaria de una institución educativa de Lima.

\section{DATOS GENERALES:}

Observador:

Nivel:

Asignatura: Fecha:
Grado:

Tema :

Horario:

\begin{tabular}{|l|c|c|c|}
\hline \multicolumn{4}{|c|}{ Valoración DE LOS ÍTEMS } \\
\hline $\begin{array}{l}\text { Registre el puntaje obtenido de acuerdo a la } \\
\text { escala de la valoración siguiente. }\end{array}$ & \multicolumn{2}{|c|}{ ESCALA De VALORACIÓN } \\
\cline { 2 - 4 } & SI & NO & A VECES \\
\hline
\end{tabular}

\section{PREGUNTAS:}

\begin{tabular}{|c|c|c|}
\hline \multicolumn{2}{|c|}{ II. ITEMS } & \multirow[t]{2}{*}{ Observación } \\
\hline $\mathbf{N}^{\circ}$ & Inicio & \\
\hline 1 & Prepara las condiciones físicas necesarias para el desarrollo de la clase. & \\
\hline 2 & $\begin{array}{l}\text { El docente realiza actividades para reconocer las fortalezas y debilidades de los } \\
\text { estudiantes sobre la resolución de problemas. }\end{array}$ & \\
\hline \multirow[t]{2}{*}{3} & $\begin{array}{l}\text { Utiliza diversos métodos problémicos para generar el interés de la clase y } \\
\text { desarrollar su contenido. }\end{array}$ & \\
\hline & Desarrollo & \\
\hline 4 & Se expresa de forma clara durante el desarrollo de actividades. & \\
\hline 5 & $\begin{array}{l}\text { Muestra un amplio dominio teórico y metodológico acerca de la competencia de } \\
\text { resolución de problemas matemáticos. }\end{array}$ & \\
\hline 6 & $\begin{array}{l}\text { Utiliza diversas estrategias didácticas de resolución de problemas durante el } \\
\text { proceso de enseñanza aprendizaje. }\end{array}$ & \\
\hline 7 & $\begin{array}{l}\text { Emplea diversos métodos de representación situaciones problémicas donde el } \\
\text { estudiante reflexiona y dialoga. }\end{array}$ & \\
\hline 8 & $\begin{array}{l}\text { El profesor realiza actividades donde promueve una buena actitud de aprendizaje } \\
\text { mediante trabajos grupales. }\end{array}$ & \\
\hline 9 & $\begin{array}{l}\text { Utiliza argumentos matemáticos para realizar demostraciones al desarrollar la } \\
\text { competencia de resolución de problemas }\end{array}$ & \\
\hline \multirow[t]{2}{*}{10} & $\begin{array}{l}\text { Logra que el estudiante reconozca y discrimine información necesaria para la } \\
\text { resolución de problemas }\end{array}$ & \\
\hline & Salida & \\
\hline 11 & Escucha y resuelve dudas de los estudiantes & \\
\hline 12 & Promueve actividades donde el estudiante demuestre lo aprendido en la clase. & \\
\hline 13 & $\begin{array}{l}\text { Utiliza proyectos interdisciplinarios donde el estudiante valora lo aprendido, } \\
\text { aplicándolo a la vida diaria }\end{array}$ & \\
\hline 14 & $\begin{array}{l}\text { El docente promueve relaciones interpersonales asertivas entre los estudiantes, } \\
\text { mediante trabajos colaborativos. }\end{array}$ & \\
\hline 15 & Los estudiantes realizan valoración del proceso enseñanza aprendizaje & \\
\hline \multirow[t]{2}{*}{16} & $\begin{array}{l}\text { Promueve los trabajos de campo donde el estudiante sustenta públicamente los } \\
\text { resultados de su trabajo utilizando gráficas estadísticas }\end{array}$ & \\
\hline & Puntaje & \\
\hline
\end{tabular}




\section{Codificación de la guía de observación a clases}

\section{Observador: Joseph Hatson Mendoza Gonzales}

Nivel: Secundaria Grado: V

Asignatura: Trigonometría

Tema de la sesión de clase: Funciones Trigonométricas

Fecha: 12 Marzo 2019 Horario: 11:00 - 12:30pm

\begin{tabular}{|c|c|c|}
\hline Respuesta & Micro categoría & \# COD \\
\hline \multicolumn{3}{|l|}{ Inicio } \\
\hline $\begin{array}{l}\text { EL profesor ingresa al salón de clases, saluda a los alumnos y ordena el salón un } \\
\text { poco, mientras prepara sus plumones y separatas para el desarrollo de la clase. }\end{array}$ & $\begin{array}{l}\text { Preparación de los recursos } \\
\text { pedagógicos limitada }\end{array}$ & 1 \\
\hline $\begin{array}{l}\text { El docente toma una práctica calificada de cuatro preguntas, con cuaderno abierto, } \\
\text { acerca de la clase anterior. Dichas preguntas son idénticas a las resueltas en el } \\
\text { cuaderno. }\end{array}$ & Recojo de saberes previos & 2 \\
\hline $\begin{array}{l}\text { El profesor directamente se centra en presentar y desarrollar el contenido, sin } \\
\text { ninguna motivación para el estudiante. }\end{array}$ & Falta de Motivación & 3 \\
\hline \multicolumn{3}{|l|}{ Desarrollo } \\
\hline $\begin{array}{l}\text { El profesor se expresa de forma clara durante el desarrollo de actividades, utilizando } \\
\text { lenguaje sencillo en su clase. }\end{array}$ & Mediador asertivo & 4 \\
\hline $\begin{array}{l}\text { Mientras desarrolla los problemas de la separata, el profesor muestra su amplio } \\
\text { conocimiento del tema a tratar, pues enseña diversas formas de resolución de } \\
\text { problemas, pero no lo contrasta con la vida real. }\end{array}$ & $\begin{array}{l}\text { Dominio teórico y metodológico } \\
\text { Ausencia del aprendizaje } \\
\text { significativo }\end{array}$ & 5 \\
\hline $\begin{array}{l}\text { El profesor no utiliza diversas estrategias didácticas de resolución de problemas } \\
\text { durante el proceso de enseñanza aprendizaje, pues solo se limita a resolver ejercicios } \\
\text { y problemas en la pizarra. }\end{array}$ & $\begin{array}{l}\text { Estrategias Didácticas } \\
\text { tradicionales }\end{array}$ & 7 \\
\hline $\begin{array}{l}\text { El docente solo emplea la gráfica en pizarra de los ejercicios que lo ameriten, } \\
\text { ciñéndose a lo escrito en la separata y en la propuesta de la solución, para lo cual } \\
\text { realiza preguntas a los estudiantes y ellos responden. }\end{array}$ & $\begin{array}{l}\text { Escaso uso de gráficas para } \\
\text { resolver problemas matemáticos } \\
\text { Limitada participación del } \\
\text { estudiante }\end{array}$ & $\begin{array}{l}8 \\
9\end{array}$ \\
\hline $\begin{array}{l}\text { El profesor no realiza actividades grupales, solo resuelve los ejercicios en pizarra, } \\
\text { toma una práctica calificada y se retira. }\end{array}$ & $\begin{array}{c}\text { Ausencia de trabajos colaborativos } \\
\text { Estrategias didácticas } \\
\text { tradicionales } \\
\text { Evaluación del aprendizaje } \\
\text { limitado }\end{array}$ & $\begin{array}{l}10 \\
7 \\
11\end{array}$ \\
\hline $\begin{array}{l}\text { El profesor no utiliza argumentos matemáticos para realizar demostraciones, sino } \\
\text { solo presenta algunas propiedades a utilizar en los ejercicios y problemas y luego } \\
\text { plantea su solución de los mismos. }\end{array}$ & \begin{tabular}{|c|} 
No utiliza argumentos \\
matemáticos para demostraciones \\
Estrategia de resolución de \\
problemas \\
\end{tabular} & 12 \\
\hline $\begin{array}{l}\text { El profesor le da a los estudiantes las fórmulas necesarias para afrontar los ejercicios } \\
\text { y problemas presentes en su separata, pero no lo contrasta con los problemas de la } \\
\text { vida diaria. }\end{array}$ & $\begin{array}{l}\text { Dominio teórico y metodológico } \\
\text { Ausencia del aprendizaje } \\
\text { significativo }\end{array}$ & 5 \\
\hline \multicolumn{3}{|l|}{ Salida } \\
\hline $\begin{array}{l}\text { En cada momento de manera transversal, el docente pregunta si hay alguna duda } \\
\text { por parte de los estudiantes y se muestra predispuesto para resolver las consultas de } \\
\text { ellos. }\end{array}$ & Mediador asertivo & 4 \\
\hline $\begin{array}{l}\text { Así como al inicio de la sesión, el profesor toma como práctica una pregunta para que } \\
\text { los estudiantes resuelvan en su cuaderno y lo presenten como su producto de dicha } \\
\text { clase. }\end{array}$ & $\begin{array}{l}\text { Evaluación del aprendizaje } \\
\text { limitado }\end{array}$ & 11 \\
\hline $\begin{array}{l}\text { El docente no realiza, ni propone proyectos interdisciplinarios, solo deja las tareas de } \\
\text { las separatas que comprenden entre } 5 \text { a } 10 \text { ejercicios y problemas tipo examen de } \\
\text { admisión, que presentarán resueltas para la próxima clase. }\end{array}$ & $\begin{array}{l}\text { Ausencia de trabajos colaborativos } \\
\text { Responsabilidades del estudiante }\end{array}$ & 10 \\
\hline $\begin{array}{l}\text { El docente ante cualquier eventualidad entre los estudiantes, conversa con ellos, } \\
\text { llevándolos a la reflexión y en caso de reincidencia aplica las sanciones impuestas } \\
\text { por la institución, pero ninguna mediante trabajos colaborativos. }\end{array}$ & $\begin{array}{c}\text { Resolución de conflictos de } \\
\text { manera asertiva } \\
\text { Ausencia de trabajos colaborativos }\end{array}$ & $\begin{array}{l}15 \\
10\end{array}$ \\
\hline $\begin{array}{l}\text { Los estudiantes toman el curso como algo que tiene que aprender porque es } \\
\text { necesario para aprobar el examen de admisión. No hay una significatividad, ni } \\
\text { valoración óptima del proceso enseñanza aprendizaje en este curso. }\end{array}$ & $\begin{array}{l}\text { Ausencia del aprendizaje } \\
\text { significativo } \\
\text { Desvaloración del proceso } \\
\text { enseñanza aprendizaje }\end{array}$ & 6 \\
\hline
\end{tabular}




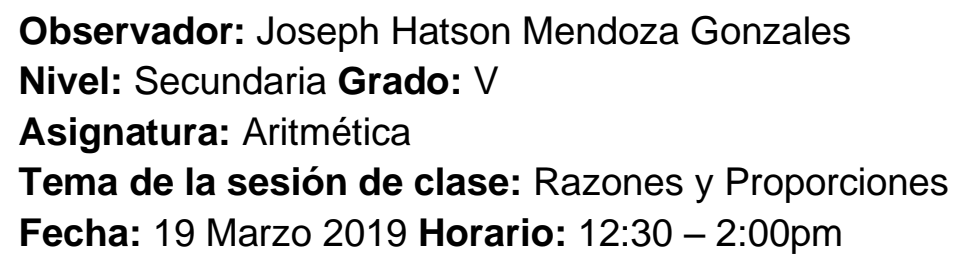

\begin{tabular}{|c|}
\hline Respuesta \\
\hline Inicio \\
\hline $\begin{array}{l}\text { El docente ingresa al aula, saluda a los alumnos cordialmente, los alumnos saludan } \\
\text { de la misma forma, el docente ingresa y todo los alumnos se ponen de pie y guardan } \\
\text { el silencio absolutamente en todo el salón, mientras el docente se prepara para dar } \\
\text { la clase, en la pizarra, acomodando sus plumones, regla y libro de problemas. }\end{array}$ \\
\hline $\begin{array}{l}\text { El docente inicia la clase, realizando preguntas, acerca de lo visto la clase anterior, } \\
\text { de manera personal. Registrando con una nota en el registro del docente si el alumno }\end{array}$ \\
\hline
\end{tabular}

A continuación, presenta el tema directamente con sus propiedades matemáticas y fórmulas a utilizar en el desarrollo de los ejercicios.

\begin{tabular}{|c|c|}
\hline Micro Categoría & \# COD \\
\hline $\begin{array}{l}\text { Preparación limitada de los } \\
\text { recursos pedagógicos }\end{array}$ & 1 \\
\hline Evaluación del tema anterior & 18 \\
\hline $\begin{array}{l}\text { Deficiente forma de evaluación } \\
\text { cuantitativa }\end{array}$ & 11 \\
\hline $\begin{array}{c}\text { Deficiente forma de presentar el } \\
\text { tema }\end{array}$ & 19 \\
\hline
\end{tabular}

\section{Desarrollo}

Durante la exposición de la clase, lo realiza con buen tono de voz, es empático con los estudiantes, aunque paradójicamente mantiene un perfil siempre distante de los estudiantes y una voz enérgica.

Cuando da la explicación del marco teórico acerca del tema tratado, el docente demuestra conocer a profundidad los tópicos y sub tópicos dando alcances a los alumnos de propiedades y sobretodo de fórmulas que no son muy usuales, las cuales utilizará para desarrollar los problemas del libro.

Durante la clase, el docente expuso en pizarra la parte teórica y la resolución de problemas, con la diferencia que en esta última pregunta constantemente y pide la participación de los estudiantes para ir armando la construcción de la solución de los problemas. Estas preguntas lo realiza de manera individual, escogiendo de preferencia a los alumnos que están distraídos.

En el desarrollo de los problemas del libro, en pizarra el docente realiza preguntas y respuestas, en base al planteamiento y aplicación de las propiedades o fórmulas presentadas al inicio de la clase, con el objetivo de que el estudiante lleve la secuencialidad de la clase, de forma mecánica, pues le servirán para el desarrollo de los ejercicios tipo admisión.

El docente, al final de la etapa del desarrollo de ejercicios y problemas del libro, a veces forma grupos de 5 estudiantes, donde tienen que resolver ejercicios o problemas que son proveídos por el docente, como trabajo práctico.

El docente al presentar las propiedades del tema a desarrollar, realiza demostraciones de algunas fórmulas, contrastando su importancia de saber esto porque forma parte del examen de admisión en algunas universidades nacionales. Así mismo, les plantea un problema reto, donde ellos tengan que realizar la demostración en pizarra, dando para esto un par de minutos y sino el profesor lo resuelve para el aprendizaje de los estudiantes.

El docente después de haber terminado de desarrollar los problemas en pizarra, usualmente deja unos minutos para que los estudiantes copien en clase, y realiza algunas preguntas a los estudiantes de manera puntual, acerca de lo visto en clase.

\section{Salida}

Durante los últimos 20 minutos, el docente recorre los pasillos del salón, preguntando si todos han entendido. Los estudiantes levantan la mano, consultan sus dudas, y el docente de manera individual va resolviendo las dudas de cada uno de ellos. Cuando la duda es común a todas, lo aclara en general para toda el aula.

\begin{tabular}{|c|c|}
\hline $\begin{array}{c}\text { Comunicación asertiva del } \\
\text { docente }\end{array}$ & 4 \\
\hline $\begin{array}{c}\text { Dominio teórico y metodológico } \\
\text { del tema }\end{array}$ & 5 \\
\hline Enseñanza limitada al contenido & 20 \\
\hline $\begin{array}{l}\text { Participación activa de los } \\
\text { estudiantes }\end{array}$ & 9 \\
\hline $\begin{array}{l}\text { Estrategia de enseñanza } \\
\text { constructivista }\end{array}$ & 21 \\
\hline Deficiente forma de motivación & 3 \\
\hline $\begin{array}{c}\text { Evaluación constante del } \\
\text { aprendizaje }\end{array}$ & 22 \\
\hline Enseñanza tradicional & 70 \\
\hline $\begin{array}{l}\text { Ausencia de situaciones } \\
\text { problematizadoras }\end{array}$ & 23 \\
\hline Trabajo colaborativo & 10 \\
\hline Dominio teórico del tema & 5 \\
\hline Ineficiente orientación pedagógica & 24 \\
\hline Actividades argumentativas & 25 \\
\hline $\begin{array}{l}\text { Limitado método de Evaluación } \\
\text { del aprendizaje }\end{array}$ & 11 \\
\hline Manejo de lugar, espacio & 26 \\
\hline Mediador asertivo & 4 \\
\hline
\end{tabular}


Faltando 10minutos para a terminar la clase, el docente reparte fichas de práctica calificada, con 4 a 5 ejercicios o problemas espejo de los visto en clase, para que puedan aplicar lo aprendido en clase, y de esta manera el docente pueda medir también el grado de recepción del conocimiento por parte de los estudiantes.

Por la misma exigencia de la institución, no se realizan proyectos interdisciplinarios, pues se enfoca más en la resolución de problemas tipo admisión.

Mediante el trabajo grupal, que realizan los estudiantes en algunas clases, el docente da las pautas bajo las cuales los estudiantes tendrán que realizarlo. Para esto, se apoya de la coordinación y auxiliar del nivel, para controlar la conducta de los estudiantes, y bajo las cuales ya está establecido que el estudiante que no respete las normas de conducta, recibirán una sanción inmediata las cuales son muy severas y por lo cual cada estudiante esta con miedo de poder ser suspendido.

La coordinación de manera periódica realiza una encuesta donde se evalúa el proceso de enseñanza aprendizaje impartida por el docente, y en donde el docente evaluado en esta clase, ha tenido un promedio de aceptación alto, en relación a su forma de enseñanza, talvez porque ya la mayoría ha llevado el curso con el profesor desde hace ya 5 años.

El docente no realiza trabajos de campo, pues la institución le exige notas en cada calce, tanto en paso oral, practica calificada, revisión de cuaderno de manera diaria. Por lo que satura al docente de manera que solo se limita a realizar una feria matemática una vez al año (día del logro). En la que el estudiante aplica los conocimientos aprendidos mediante un experimento o algún trabajo conceptual de investigación, sin considerar ningún tipo de aplicación a la vida diaria o problema real. Es decir se limitan a revisar las teorías y a solo exponerlas.

\begin{tabular}{|c|c|}
\hline $\begin{array}{l}\text { Limitado método de evaluación de } \\
\text { aprendizaje }\end{array}$ & 11 \\
\hline Estilo de enseñanza tradicional & 70 \\
\hline $\begin{array}{c}\text { Ausencia de proyectos } \\
\text { interdisciplinarios }\end{array}$ & 27 \\
\hline Estilo de enseñanza tradicional & 70 \\
\hline Trabajo colaborativo & 10 \\
\hline Control actitudinal tradicional & 28 \\
\hline $\begin{array}{c}\text { Evaluación del proceso enseñanza } \\
\text { aprendizaje. }\end{array}$ & 11 \\
\hline $\begin{array}{c}\text { Valoración del proceso enseñanza } \\
\text { aprendizaje sesgada }\end{array}$ & 29 \\
\hline $\begin{array}{l}\text { Ausencia de proyectos } \\
\text { interdisciplinarios }\end{array}$ & 27 \\
\hline Sobrecarga de labor docente & 28 \\
\hline $\begin{array}{l}\text { Limitadas actividades de } \\
\text { proyectos de investigación }\end{array}$ & 29 \\
\hline $\begin{array}{l}\text { Deficiente manejo de proyectos de } \\
\text { campo }\end{array}$ & 30 \\
\hline
\end{tabular}

\section{Observador: Joseph Hatson Mendoza Gonzales \\ Nivel: Secundaria Grado: V \\ Asignatura: Razonamiento Matemático \\ Tema de la sesión de clase: Probabilidades \\ Fecha: 14 Marzo 2019 Horario: 09:30 - 11:00am}

\begin{tabular}{|l|}
\hline \multicolumn{1}{|c|}{ Respuesta } \\
\hline \multicolumn{1}{|c|}{ Inicio } \\
\hline $\begin{array}{l}\text { EL profesor ingresa al salón de clases, saluda a los estudiantes y luego da unos } \\
\text { minutos mienras los estudiantes acomodan sus materiales y prepara la pizarra, para } \\
\text { el desarrollo del tema. }\end{array}$ \\
\hline $\begin{array}{l}\text { Cuando presenta la teoría, el docente va realizando preguntas acerca de las mismas } \\
\text { y si alguno no sabe, el profesor repite la propiedad para que los estudiantes recuerden } \\
\text { y luego contrastarlo en el desarrollo de los problemas. Por otro lado, no profundiza, } \\
\text { en el recojo de los saberes previos. }\end{array}$
\end{tabular}

No utiliza métodos problémicos para generar el interés, sino más bien directamente va hacia los problemas del libro, y se preocupa solamente en terminar el contenido.

\begin{tabular}{|c|c|}
\hline Micro categoría & \# COD \\
\hline $\begin{array}{l}\text { Limitada preparación de los } \\
\text { recursos pedagógicos }\end{array}$ & 1 \\
\hline participación activa del estudiante & 9 \\
\hline Mediador asertivo & 4 \\
\hline $\begin{array}{l}\text { Ausencia de recojo de saberes } \\
\text { previos }\end{array}$ & 2 \\
\hline Ausencia de métodos problémicos & 23 \\
\hline $\begin{array}{c}\text { Deficiente forma para presentar el } \\
\text { tema }\end{array}$ & 19 \\
\hline Enseñanza limitada al contenido & 20 \\
\hline Mediador asertivo & 4 \\
\hline $\begin{array}{l}\text { Dominio teórico y metodológico } \\
\text { limitado }\end{array}$ & 5 \\
\hline Enseñanza limitada al contenido & 20 \\
\hline
\end{tabular}




\begin{tabular}{|c|c|c|}
\hline $\begin{array}{l}\text { Durante el proceso de enseñanza aprendizaje realiza básicamente el desarrollo de } \\
\text { los ejercicios y problemas planteados del libro del estudiante en la pizarra. }\end{array}$ & Enseñanza limitada al contenido & 20 \\
\hline \multirow{2}{*}{$\begin{array}{l}\text { El docente solo se limita a presentar y desarrollar los problemas del libro, mediante } \\
\text { la cual realiza preguntas a los estudiantes para ir armando el desarrollo de los } \\
\text { problemas. }\end{array}$} & Enseñanza limitada al contenido & 20 \\
\hline & $\begin{array}{l}\text { Limitado uso de estrategia de } \\
\text { enseñanza constructivista }\end{array}$ & 21 \\
\hline $\begin{array}{l}\text { EL profesor realiza trabajos grupales, donde los estudiantes en grupos de } 4 \text { tienen } \\
\text { que resolver problemas seleccionados previamente del libro, según indican los } \\
\text { estudiantes este tipo de trabajos se realizan de vez en cuando. }\end{array}$ & Limitado uso de trabajos grupales & 10 \\
\hline \multirow{2}{*}{$\begin{array}{l}\text { Durante la calce observada, el docente no realizó ninguna demostración de las } \\
\text { propiedades o fórmulas presentadas al estudiante, sino que más bien se centró en } \\
\text { su aplicación directa de los ejercicios del libro. }\end{array}$} & $\begin{array}{l}\text { Ausencia de argumentos para } \\
\text { realizar demostraciones } \\
\text { matemáticas }\end{array}$ & 12 \\
\hline & Enseñanza limitada al contenido & 20 \\
\hline \multirow{2}{*}{$\begin{array}{l}\text { El docente toma práctica escrita al final de cada clase, dando las indicaciones } \\
\text { previamente para su desarrollo, pero se observó que en el cuidado de la práctica } \\
\text { calificada varios estudiantes estaban copiando y revisando incluso su cuaderno pero } \\
\text { el docente solo se sentó en su escritorio y no verificó el comportamiento de dichos } \\
\text { estudiantes. }\end{array}$} & $\begin{array}{l}\text { Limitado método de evaluación del } \\
\text { aprendizaje }\end{array}$ & 22 \\
\hline & $\begin{array}{l}\text { Deficiente control actitudinal del } \\
\text { aula } \\
\end{array}$ & 31 \\
\hline \multicolumn{3}{|l|}{ Salida } \\
\hline $\begin{array}{l}\text { Una vez que el docente termina de llenar la pizarra, deja minutos para que los } \\
\text { estudiantes tomen nota. Es aquí que el docente consulta si hay alguna duda por parte } \\
\text { de los estudiantes para ir explicándolo de manera grupal o personal. }\end{array}$ & Mediador asertivo & 4 \\
\hline $\begin{array}{l}\text { Para terminar la clase, faltando } 10 \text { minutos, el docente toma examen escrito como } \\
\text { única forma de medir lo aprendido y no utiliza otra forma. }\end{array}$ & $\begin{array}{l}\text { Limitado método de evaluación del } \\
\text { aprendizaje }\end{array}$ & 22 \\
\hline \multirow{2}{*}{$\begin{array}{l}\text { El docente no realiza proyectos interdisciplinarios, sino toma como único proyecto } \\
\text { aplicativo al impuesto por la institución. Lo toma más como una obligación, que por } \\
\text { iniciativa para desarrollar un aprendizaje más consiente en el estudiante. }\end{array}$} & $\begin{array}{c}\text { Ausencia de proyectos } \\
\text { interdisciplinarios }\end{array}$ & 27 \\
\hline & Falta de compromiso profesional & 32 \\
\hline \multirow{3}{*}{$\begin{array}{l}\text { Los estudiantes llevan el curso porque tienen que aprobar y no disfrutan el } \\
\text { aprendizaje. Hay un pequeño grupo que si muestra motivación para desarrollar los } \\
\text { ejercicios pero la gran mayoría no atiende a la clase y solo realizan los ejercicios de } \\
\text { forma mecánica. }\end{array}$} & Desvalorización del aprendizaje & 16 \\
\hline & $\begin{array}{l}\text { Motivación por resolver problemas } \\
\text { matemáticos }\end{array}$ & 23 \\
\hline & Enseñanza tradicional & 70 \\
\hline \multirow{3}{*}{$\begin{array}{l}\text { El docente no promueve trabajos de aplicación real ni de procesamiento, sino solo se } \\
\text { centra en transmitir conocimiento porque el perfil de la institución apunta a formar } \\
\text { estudiantes preparados para un examen de admisión tradicional y esto genera mayor } \\
\text { comodidad y pasividad en el docente que a su vez, tampoco sugiere nuevas formas } \\
\text { de enseñanza. }\end{array}$} & $\begin{array}{l}\text { Ausencia de proyectos } \\
\text { interdisciplinarios }\end{array}$ & 27 \\
\hline & $\begin{array}{l}\text { Objetivos de la institución } \\
\text { educativa sesgados }\end{array}$ & 33 \\
\hline & Enseñanza tradicional & 7 \\
\hline
\end{tabular}




\section{Anexo 5 \\ Tablas del cuestionario a los estudiantes}

Tabla 1:

¿Te sientes lo suficientemente satisfecho con los conocimientos adquinidos en clase de Matemática?

\begin{tabular}{ccc}
\hline \hline & Frecuencia & Porcentaje \\
\hline A veces & 5 & 41,7 \\
Siempre & 6 & 50,0 \\
Total & 12 & 100,0 \\
\hline \hline
\end{tabular}

En la tabla 1 y figura 1, se evidencia que el $8.33 \%$ de los sujettos encuestados, manifiestan que nunca se sienten lo suficientemente satiffecho con los conocimientos adquiridos en clase de matemática; El $41.67 \%$ de los mismos encuestados opinan que a veces se sienten lo suficientemente satiffecho con los conocimientos adquiridos en clase de matemática y el $50 \%$ de los mismos opinan que siempre se sienten lo suficientemente satisfecho con los conocimientos adquiridos en clase de matemática.

Tabla 3

¿Logras reconocer en un problema matemático, cual es la información relevante para tu solución?

\begin{tabular}{ccc}
\hline \hline & Frecuencia & Porcentaje \\
\hline A veces & 9 & 75,0 \\
Siempre & 3 & 25,0 \\
Total & 12 & 100,0 \\
\hline \hline
\end{tabular}

En la tabla 3 y figura 3, se puede visualizar que el $75 \%$ de los encuestados, muestran que a veces Logran reconocer en un problema matemático, cual es la información relevante para su solución, mientras que el $25 \%$ siempre logra reconocer en un problema matemático, cual es la información relevante para su solución.

Tatla 8:

jE occente promueve la refiexion del tema desanollado en clase de matemática, con su apilcacion a la vió diarla?

\begin{tabular}{ccc}
\hline \hline & Frecuencia & Porcentaje \\
\hline Nunca & 2 & 16,7 \\
A veces & 8 & 66,7 \\
Siempre & 2 & 16,7 \\
Total & 12 & 100,0 \\
\hline \hline
\end{tabular}

En la tabla 8 y figura 8 , se puede observar que el $16.67 \%$ ce las persaras enauestados expresan que el dacente

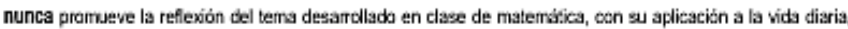
mierritas que el $66.67 \%$ expresa que el docente a veces prơnueve la rellexión del tema desarrellaco en clase de masemática, con su aplicación a la vida diaria y el $16.67 \%$ expresa que el docente runca promueve la reflexión det tema desarrollado en clase de matematica, con su aplicación a la vida dória.

Tatla 13:

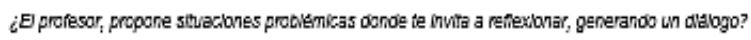

\begin{tabular}{ccc}
\hline \hline & Frecuencia & Porcentije \\
\hline Nunca & 1 & 8,3 \\
A veces & 8 & 66,7 \\
Siempre & 3 & 25,0 \\
Total & 12 & 100,0 \\
\hline \hline
\end{tabular}

En la tatla 13 y figura 13 , se otserva que el $8.33 \%$ de las encuestados expresa que el protesar, nurca propone situacianes problemicas donde le invita a reflexicnar, generando un diálogo, mientras que el $63.67 \%$ expresa que el prefesor, a veces propare sìusciones problemricas dende le invita a reflexionar, generando un áálogo y el $25 \%$ expresa que el prefesar, siempre propone situaciones probleimicas donde le imsita a reflexicnar, generando un diákgo.
Tabla 2:

¿Eres capaz de realizar ejercicios de demostración matemática, según el tema tratado?

\begin{tabular}{ccc}
\hline \hline & Frecuencia & Porcentaje \\
\hline A veces & 11 & 91,7 \\
Siempre & 1 & 8,3 \\
Total & 12 & 100,0 \\
\hline \hline
\end{tabular}

En la tabla 2 y figura 2 , se observa que el $81.67 \%$ de los sujetos encuestados, expresan que a veces son capaces de realizar ejercicios de demostración matemática, según el tema tratado y el $8.33 \%$ de los mismos opinan que siempre son capaces de realizar ejercicios de demostración matemática, según el tema tratado.

Tabla 4:

¿Utilizas alguna representación gráfica al resalver problemes matemáticas?

\begin{tabular}{ccc}
\hline \hline & Frecuencia & Porcentaje \\
\hline Nunca & 2 & 16,7 \\
A veoses & 7 & 58,3 \\
Siempre & 3 & 25,0 \\
Total & 12 & 100,0 \\
\hline \hline
\end{tabular}

En la tabla 4 y figura 4, se puede observar que el $18.67 \%$ de los encuestados nunca utilizan alguna representación gráfica al resolver problemas matemáticos, a su vez el $58.33 \%$ expresa que a veces utilizan alguna representación gráica al resolver problemas matemáticos y el $25 \%$ siempre utilza alguna representación gráfica al resolver problemas matemáticos.

Tatla 10:

¿E obcente de matematica, hace acdidades para reconocer las fontalezas y debilbades del aula score ia resoivicion de problemes?

\begin{tabular}{ccc}
\hline \hline & Frecuencia & Portentaje \\
\hline Nunca & 4 & 33,3 \\
A veces & 7 & 58,3 \\
Siempre & 1 & 8,3 \\
Total & 12 & 100,0 \\
\hline \hline
\end{tabular}

En la tabla 10 y figura 10 , se visualiza que el $33.33 \%$ de las sijelos encuestadas pertiben que, El docente de masennitica, nunca hace actividades para reconocer las fortalezas y debiidades del aula sabre la rescluxión de problemas, a su vez el $58.33 \%$ perciben que, el dacente de matemáica, a veces toce activitades para reconocer las fertialezas y deblitades del auja satre la resolución de problemss y el 8.33\% perciben que, el docente de masemática siempre hace actividades para reccoccer lix fortajezas y deblitades del alda sotre la resolucián de protiemas.

Tatla 17:

¿E docente reconoce las logros y procesos alcanzäoss par parte de las estudiantes en las alerentes activitades grupales desamolladas en ciase de matemattca?

\begin{tabular}{ccc}
\hline \hline & Frecuencia & Porcentaje \\
\hline Nunca & 1 & 8,3 \\
A veces & 6 & 50,0 \\
Siempre & 5 & 41,7 \\
Total & 12 & 100,0 \\
\hline \hline
\end{tabular}

En la tabla 17 y fgura 17, se muestra que el $8.33 \%$ de las personas encuestadas manifiestan que, el dacente nunea recanoce los logros y procescs akarzados par parte de las estudiantes en las diferentes actividades grupales desarnclladas en clase de matemśtica, miertras que el $50 \%$ marifiesta que, el dacerre a veces reconoce los logros y procesos akanzados por parte de los estudiantes en las diferentes actividades grupales desarroladas en clase de matemśtica y el $41.67 \%$ manifiesta que, el cocente sierpre reconoce los bogos y procesos akanzados por pare de los estudiantes en las diferentes actividades grupales desarroladas en clase de matemática. 


\section{Anexo 6 \\ Prueba Pedagógica}

\section{OBJETIVO:}

Constatar el nivel de conocimientos y habilidades que poseen los estudiantes del $\mathrm{V}$ grado de Secundaria de una Institución Educativa privada de Lima, acerca de la resolución de problemas en el área de Matemática.

\section{INSTRUCCIONES:}

Estimado (a) estudiante a continuación hay una serie de preguntas relacionadas al conocimiento que posees en el área de Matemática, en tal sentido, responde conscientemente las preguntas propuestas. La información obtenida será muy valiosa para la presente investigación.

\section{DATOS GENERALES:}

Área:

Grado:

Edad: Sexo: Masculino ( ) Femenino ( ) Fecha:

\section{PREGUNTAS:}

1. Analiza y completa la siguiente tabla, si:

De un tanque que estaba totalmente lleno, se han extraído esta mañana 48 litros y por la noche 7/12 de su capacidad total quedándose con solo 12 litros.

\begin{tabular}{|l|l|l|l|}
\hline & Ext. Mañana & \multicolumn{1}{|c|}{ Ext. Noche } & Queda \\
\hline Fracción & & $7 / 12$ & \\
\hline Litros & 48 & & 12 \\
\hline
\end{tabular}
a) $1 / 3-28-1 / 2$
b) $1 / 2-18-1 / 4$
c) $1 / 3-18-1 / 3$
d) $1 / 2-20-1 / 4$
e) $1 / 4-28-1 / 3$

2. ¿Con qué propiedad o tema matemático, demostrarías el teorema de Pitágoras?

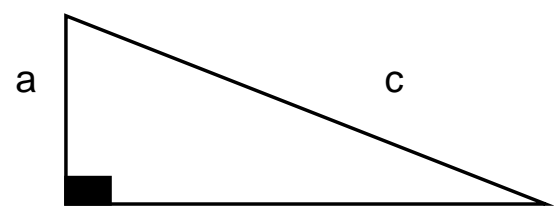

b
a) Teorema de Tales
b) Teorema de Bisectrices
c) Semejanza de Triángulos
d) Sector circular
e) Ángulo trigonométrico 
3. Evalúa la suficiencia de información y marca la alternativa correcta:

En una bolsa están contenidas bolas verdes, amarillas y blancas. Si en total existen nueve bolas, se desea saber de cuántas maneras distintas se pueden ordenar dichas bolas.

* Información brindada:

I) Existen 3 bolas verdes y 4 blancas.

II) Dentro de la bolsa existen además 2 bolas amarillas.

La pregunta se puede resolver, considerando:

a) Sólo la información I.

b) Sólo la información II.

c) Ambas informaciones a la vez.

d) Cada una de las informaciones por separada.

e) La información brindada es insuficiente.

4. Representar gráficamente mediante una función:

Durante las 5 primeras semanas de cultivo de una planta $P$, que media $1 \mathrm{~cm}$, se observó que su crecimiento era directamente proporcional al tiempo. Si en su primera semana ha pasado a medir $2,5 \mathrm{~cm}$.

a)<smiles>C1CC1</smiles>

b)

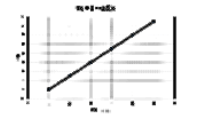

c)

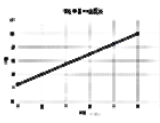

d)

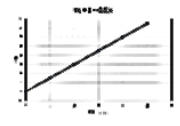

e)

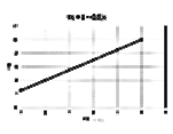

5. Representar mediante un gráfico de barras, si:

En una encuesta realizada en el restaurante "MI COMIDA FAVORITA", para saber cuáles son las comidas preferidas por sus clientes, se obtuvo la siguiente información:

\begin{tabular}{|l|l|}
\hline COMIDA PREFERIDA & $\begin{array}{l}\text { NUMERO DE PERSONAS QUE LO } \\
\text { PREFIEREN }\end{array}$ \\
\hline Arroz con Pollo & 18 \\
\hline Escabeche & 25 \\
\hline Espagueti & 5 \\
\hline Pollo a la Brasa & 30 \\
\hline Arroz Chaufa & 22 \\
\hline
\end{tabular}

a)

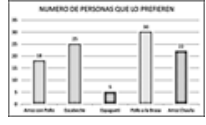

b)

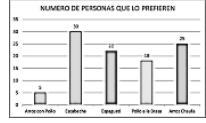

c)

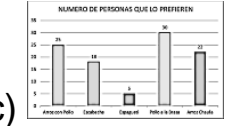

d)

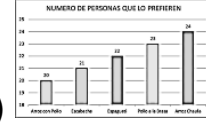

e)

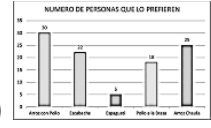

6. Plantea y resuelve el siguiente problema:

En un corral hay 92 patas y 31 cabezas; si lo único que hay son gallinas y conejos ¿Cuál es la diferencia entre el número de gallinas y conejos existentes?
a) 1
b) 2
c) 3
d) 4
e) 5 
7. Resuelve uno de los casos a continuación y marca la sensación que produce esto en usted:

\section{Caso 1:}

En una tienda de ropa el precio de todas las prendas es el mismo, pero a cada prenda se le aplica después un porcentaje de descuento. Nos han aplicado un $30 \%$ de descuento en una camiseta y un $10 \%$ en unos pantalones. ¿Cuál es el precio inicial de las prendas si hemos pagado en total S/.16? ¿Cuánto hemos pagado por cada prenda?

\section{Caso 2:}

Una cuerda de $180 \mathrm{~m}$ se corta en 3 trozos: trozo $A$, trozo $B$ y trozo $C$. Calcular cuánto miden los trozos sabiendo que el trozo $B$ y el trozo $C$ miden el doble y el triple que el trozo A, respectivamente.
a) Satisfacción
b) Nostalgia
c) Frustración
d) Motivación
e) Molestia

8. ¿Cuál es la emoción que produce una clase donde los estudiantes colaboran y construyen su propio aprendizaje desde su contexto?
a) Alegría
b) Tristeza
c) Aburrimiento
d) Motivación
e) Compasión

9. Si el docente realiza una clase donde se forman grupos para desarrollar diversos ejercicios y exponerlos, ¿Cuál es el valor más importante que se debe promover?
a) Rencor
b) Amistad
c) Respeto
d) Honestidad
e) Responsabilidad 


\section{Tablas de la prueba Pedagógica}

Tabla 1:

Conocen principios, feorlas, leyes y postulados necesarios para ia resolución de problemas

\begin{tabular}{lcc}
\hline \hline & Frecuencia & Porcentaje \\
\hline NO & 10 & 83,33 \\
SI & 2 & 16,67 \\
Total & 12 & 100,0 \\
\hline \hline
\end{tabular}

En la tabla 1 y figura 1, se observa que el 83.33\% de bs sujetos a quieres se le torno la prueta pedagógica, marifestan que no conocen las principies, tecrias, leyes y postulados necesarios para la resolución de problemas y el $16.67 \%$ de los mismos muestra que si conoce las principios, tescias, leyes y postulados necesarios para ta resolución de protlemas

Tabla 3:

Identifican la informacion relevante para la resoincion de probiemas

\begin{tabular}{lcc}
\hline \hline & Frecuencia & Porcen:aje \\
\hline NO & 10 & 83,33 \\
SI & 2 & 16,67 \\
Total & 12 & 100,0 \\
\hline \hline
\end{tabular}

En la tatla 3 y figura 3 , se visualiza que el $83.33 \%$ de las persconas a quienes se les tomó la prueba pedagógica, muestran que no san capaces de identificar la información relevante para la resolución de problemas, mientras que el $16.67 \%$ si son capaces de ifen:ficicar la información relevante para la resolución de prablemas.

Tabla 6:

Consiósan diversos metiodos al momento de resover problemas

\begin{tabular}{lcc}
\hline \hline & Frecuencia & Porcentaje \\
\hline NO & 10 & 83,33 \\
SI & 2 & 16,67 \\
Total & 12 & 100,0 \\
\hline \hline
\end{tabular}

En la tabla 6 y figura 6, se evidencia que el $83.33 \%$ de las individuas a quienes se les tomó la prueta pedagó no consideran diversos métodos de resolución de problemas y el $16.67 \%$ de las mismos si considera dive métodos de resolución de prablemas.

Tabla 8:

Muestra preferencia par realzar actividaoses donde pueden construr su propilo aprendizaje

\begin{tabular}{lcc}
\hline \hline & Frecuencia & Porcentaje \\
\hline NO & 1 & 8.33 \\
SI & 11 & 91.67 \\
Total & 12 & 100,0 \\
\hline \hline
\end{tabular}

En la tatla 8 y figura 8, se visualiza que el $8.33 \%$ de los sujetos evidencian que son irdiferentes ante las attividades realizadas por el docente en clase, y el $91.67 \%$ muestra su prelerencia poc realizar actividades donde los mismos puedan construir su propio aprendizaje.
Tabla 2

Mangjan angumentos matemattcos para resizar demostraciones

\begin{tabular}{lcc}
\hline \hline & Frecuencis & Porcentaje \\
\hline NO & 10 & 83,33 \\
SI & 2 & 16,67 \\
Total & 12 & 100,0 \\
\hline
\end{tabular}

En la tabla 2 y figura 2, se evidencia que el $83.33 \%$ de las individuos a quienes se les tomó la prueba pedagógita evidencian que no son capaces de manejar argumentos matemáticos para realizar demostraciones, mientras que el $16.67 \%$ de las mismos muestra que si scon capaces de manejar argumentos masemáticos.

Tabla 4:

Realzan representaciones matemattcas a/ momento de resolver problemas matematicos.

\begin{tabular}{lcc}
\hline \hline & Frecuencis & Portentaje \\
\hline NO & 10 & 83,33 \\
SI & 2 & 16,67 \\
Total & 12 & 100,0 \\
\hline \hline
\end{tabular}

En la tabla 4 y figura 4, se muestra que el 83.33\% de las sujetos a quienes se les tomó la prueba pedagógica evidencian que no realizan representaciones matemśticas al momento de resolver problemas masemáticos y el $16.67 \%$ de los mismos si realizan representaciones matemáticas al momento de resolver preblemas matemáticos.

Tabls 7

LNotivacion al momento de resoiver una situacion probiemica

\begin{tabular}{lcc}
\hline \hline & Frecuencis & Porcentaje \\
\hline NO & 6 & 50 \\
SI & 6 & 50 \\
Total & 12 & 100,0 \\
\hline \hline
\end{tabular}

En la tatla 7 y figura 7 , se otserva que el $50.00 \%$ de las personas se sienten motivadas al momento de resolver una situación problémica, y asi mismo el otro $50.00 \%$ de los individuos, no ve sienten motivados al momento de resolver una situación prablémica.

Tabla 9:

Respetia las opiniones de los demás al momento de trabąar en equipo al resolver una siluacion problemica

\begin{tabular}{lcc}
\hline \hline & Frecuencia & Porrentaje \\
\hline NO & 3 & 15 \\
SI & 9 & 75 \\
Total & 12 & 100,0 \\
\hline
\end{tabular}

En la tabla 9 y figura 9 , se muestra que el 15\% de los individuos a quienes se les tomó la prueba pedagógica, evidencian que no respetan las opinianes de los demás al momento de trabajar en equipo al resolver una situación problémica, y el 75\% de los mismos si respeta las opinianes de los denás al momento de trabajar en equipo para resolver una situación prablèmica. 
Anexo 7

Fichas de Validación Interna

Validación interna

\begin{tabular}{|c|c|c|c|c|c|c|c|}
\hline \multirow[t]{3}{*}{ indicadores } & \multicolumn{4}{|c|}{$\begin{array}{l}\text { Escabde } \\
\text { valoración }\end{array}$} & \multicolumn{3}{|l|}{ Aspectos } \\
\hline & & & & & \multirow{2}{*}{ Positivas } & \multirow{2}{*}{ Negatimos } & \multirow{2}{*}{ Sugerencies } \\
\hline & \begin{tabular}{l|l|l}
1 & 2 & \\
\end{tabular} & 3 & 4 & 5 & & & \\
\hline \multicolumn{8}{|l|}{ Factibilidad de aplicación del resultado que se presenta. } \\
\hline \multicolumn{8}{|l|}{ Claridad de la propuesta para ser aplicado por otros } \\
\hline \multicolumn{8}{|l|}{$\begin{array}{l}\text { Posibilidad de la propuesta de extensióna otros } \\
\text { contextos semejantes }\end{array}$} \\
\hline \multicolumn{8}{|l|}{$\begin{array}{l}\text { Correspondencia con las necesidades sociales e } \\
\text { individuales actuales }\end{array}$} \\
\hline \multicolumn{8}{|l|}{$\begin{array}{l}\text { Congruencia entre el resultado propuestoy el objetivo } \\
\text { fijado. }\end{array}$} \\
\hline \multicolumn{8}{|l|}{$\begin{array}{l}\text { Novedad en el uso de conceptosy procedimientos de la } \\
\text { propuesta. }\end{array}$} \\
\hline \multicolumn{8}{|l|}{$\begin{array}{l}\text { La modelación contiene propósitos basados en los } \\
\text { fundamentos educativos, curricularesy pedagógicos, } \\
\text { detallado. precisoy efectivo }\end{array}$} \\
\hline \multicolumn{8}{|l|}{$\begin{array}{l}\text { La propuesta está contextualizada a la realidad en } \\
\text { estudio. }\end{array}$} \\
\hline \multicolumn{8}{|l|}{$\begin{array}{l}\text { Presenta objetivos claros, coherentes y posibles de } \\
\text { alcanzar. }\end{array}$} \\
\hline Contiene un plan de acción de lo general a lo particular. & & & & & & & \\
\hline
\end{tabular}

Anexo 8

Fichas de Validación Externa

Ficha de validación externa (forma)

\begin{tabular}{|c|c|c|c|c|c|c|c|c|c|}
\hline \multicolumn{2}{|l|}{ Indicadores } & \multirow{2}{*}{\multicolumn{5}{|c|}{$\begin{array}{l}\text { Escabde } \\
\text { valoracóón }\end{array}$}} & \multicolumn{3}{|l|}{ Aspectos } \\
\hline & & & & & & & \multirow{2}{*}{ Positivas } & \multirow{2}{*}{ Negatiros } & \multirow{2}{*}{ Sugerenciess } \\
\hline & & 1 & 2 & 3 & 4 & 5 & & & \\
\hline Claridad & $\begin{array}{l}\text { Es formulado con lenguaje } \\
\text { apropiado }\end{array}$ & & & & & & & & \\
\hline Objetivitad & $\begin{array}{l}\text { Está expresado en conductas } \\
\text { observables }\end{array}$ & & & & & & & & \\
\hline Actualidad & $\begin{array}{l}\text { Adecuado al avance de la } \\
\text { ciencia pedagógica }\end{array}$ & & & & & & & & \\
\hline Orgarizaciōn & Existe una organización lógica & & & & & & & & \\
\hline Suficiencia & $\begin{array}{l}\text { Comprende los aspectos de } \\
\text { cantidady calidad }\end{array}$ & & & & & & & & \\
\hline Intencionalidad & $\begin{array}{l}\text { Adecuado para valorar los } \\
\text { aspectos de las categorías }\end{array}$ & & & & & & & & \\
\hline Consistencia & $\begin{array}{l}\text { Basado en aspectos teóricos } \\
\text { científicos de la educación }\end{array}$ & & & & & & & & \\
\hline Coherencia & $\begin{array}{l}\text { Entre el propósito, diseñoy la } \\
\text { implementación de la propuesta }\end{array}$ & & & & & & & & \\
\hline Metodblogia & $\begin{array}{l}\text { La estrategia responde al } \\
\text { propósito de la investigación }\end{array}$ & & & & & & & & \\
\hline Pertirencia & $\begin{array}{l}\text { Es útil y adecuado para la } \\
\text { investigación }\end{array}$ & & & & & & & & \\
\hline
\end{tabular}




\section{Anexo 9}

\section{Validación de Instrumentos por criterio de expertos}

\section{Dr. Ronal Garnelo Escobar}
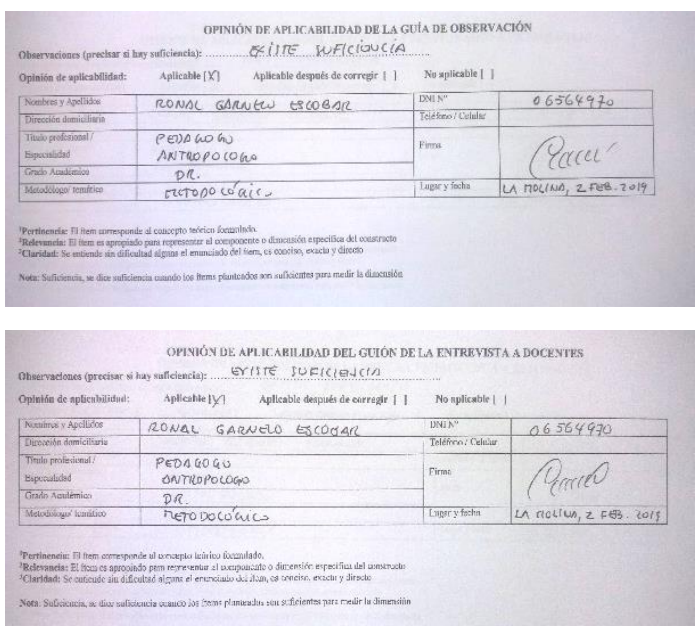

\section{Dr. Fernando Goñi Cruz}

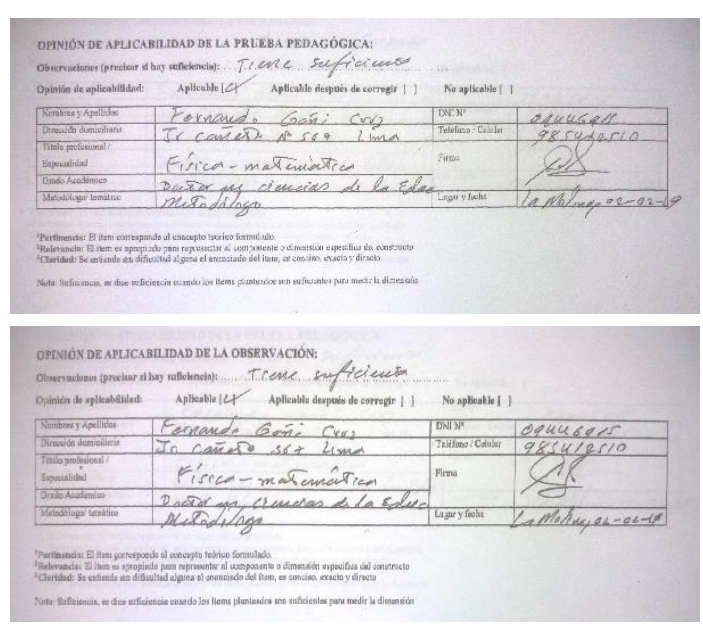

Mg. María Teresa Herrera Montoya

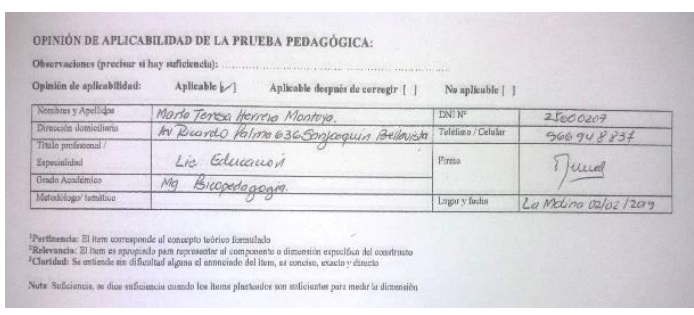

OPINÓN DE APLCABLIDA DEL ENTREVISTA

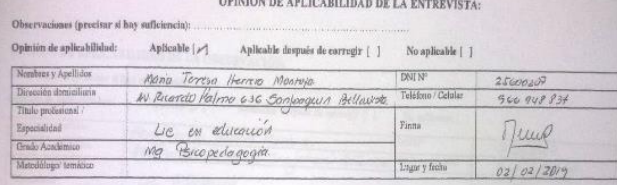

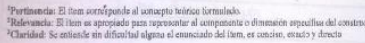
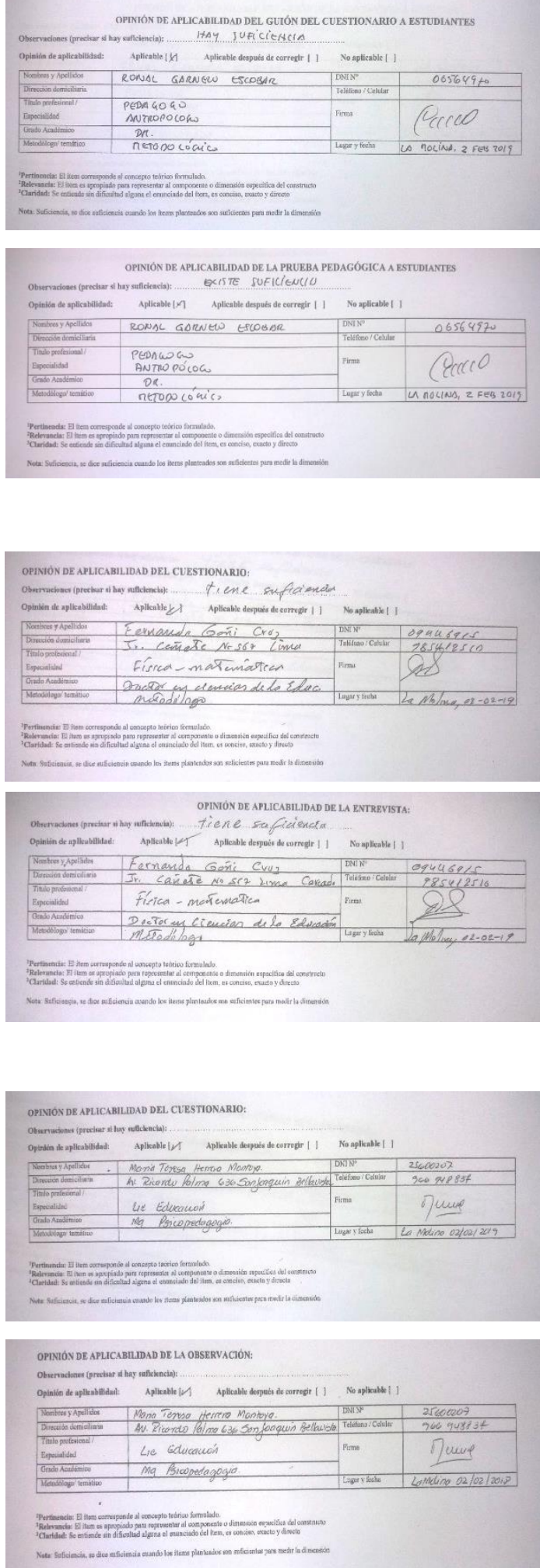
Anexo 10

\section{Validación de la Propuesta Metodológica por criterio de expertos}

\section{Dr. Fernando Goñi Cruz}

Opinión de aplicabilidad:
a) Deficiente ( )
b) Baja ( )
c) Regular ( )
d) Buena ( )
e) Muy Buena $\alpha$ )

\begin{tabular}{|c|c|c|c|}
\hline Nombres y Apellidos & Fernoncto & DNI No & $09446 \mathrm{~g} / 5$ \\
\hline Dirección domiciliaria & Ir cañete 567 Lima & Teléfono / Celular & 985412510 \\
\hline $\begin{array}{l}\text { Titulo profesional / } \\
\text { Especialidad }\end{array}$ & \multicolumn{3}{|l|}{ Fisica - Matrematice } \\
\hline Grado Académico & \multicolumn{3}{|l|}{ Dor en Educación } \\
\hline $\begin{array}{l}\text { Ocupación y año de } \\
\text { experiencia }\end{array}$ & \multirow{2}{*}{\multicolumn{3}{|c|}{ Durente $/ 20$ años }} \\
\hline Metodólogo/temático & & & \\
\hline
\end{tabular}

Metodólogo/temático

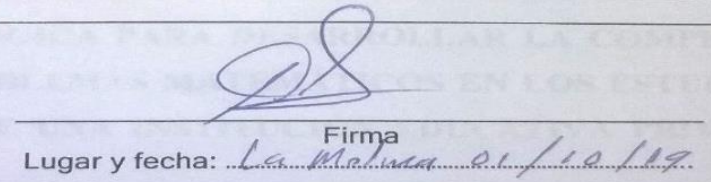

\section{Dr. Alejandro Cruzata Martinez}

Opinión de aplicabilidad:
a) Deficiente ( )
b) Baja ( )
c) Regular ( )
d) Buena ( )
e) Muy Buena ( )

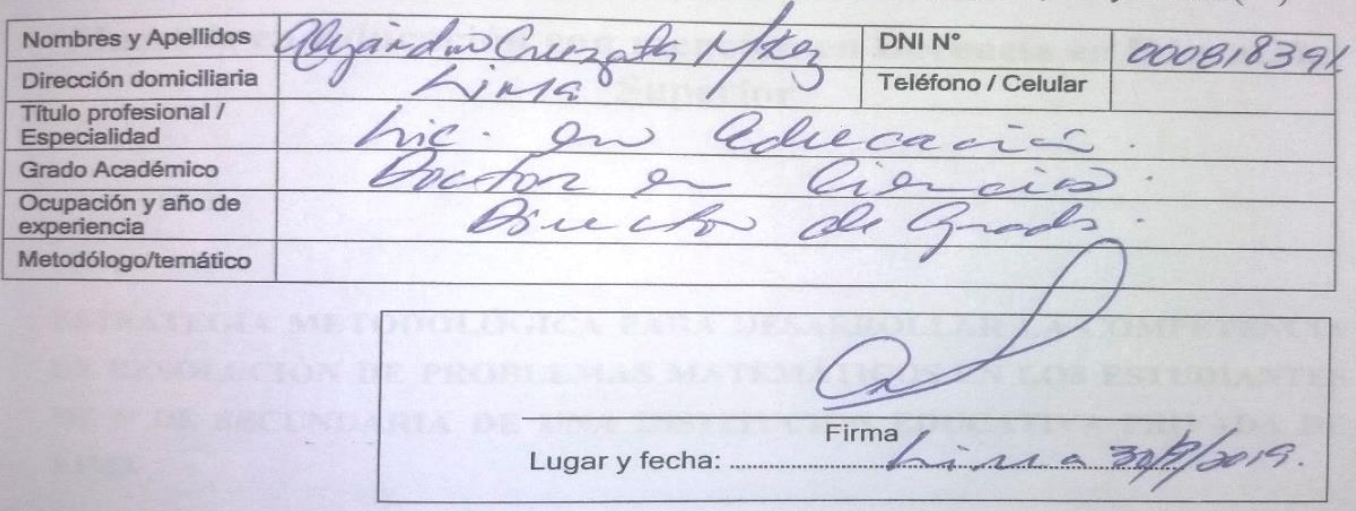

\section{Dr. Hernán Flores Valdiviezo}

Opinión de aplicabilidad:
a) Deficiente ( )
b) Baja ( ) c) Regular ( )
d) Buena ( )
e) Muy Buena ( )

\begin{tabular}{|c|c|c|c|}
\hline Nombres y Apellidos & HzRnAK Flones VAZU)/ULEZ & DNI N ${ }^{\circ}$ & 0605510 \\
\hline Dirección domiciliaria & $159(201)$ & Teléfono / Celular & 994461104 \\
\hline $\begin{array}{l}\text { Titulo profesional / } \\
\text { Especialidad }\end{array}$ & 10 & & \\
\hline Grado Académico & & & \\
\hline $\begin{array}{l}\text { Ocupación y año de } \\
\text { experiencia }\end{array}$ & 0 & & \\
\hline Metodólogo/temático & 20 & & \\
\hline
\end{tabular}

